\title{
Diseño de un proceso térmico de fluidización para la producción de soja crocante
}

Tesis doctoral presentada por

\section{Ricardo Martín Torrez Irigoyen}

Presentada ante la Facultad de Ingeniería de la

Universidad Nacional de La Plata

como requisito para la obtención del grado académico de

\section{DOCTOR EN INGENIERÍA}

Dirección de tesis: Dr. Ing. Sergio Adrián Giner

Jurado de tesis: Dra. María Luisa Genta

Dra. Laura Ana Ramallo

Fecha de defensa: 12 de Marzo de 2013

Área de referencia: Departamento de Ingeniería Química 


\section{AGRADECIMIENTOS}

Agradecer genuinamente es un acto muy poderoso. Decir gracias es reconocer que hemos recibido algo: una sonrisa, un abrazo, un favor, tiempo, una palabra de aliento.

Al Dr. Sergio Giner mis más sincero agradecimiento por su inmenso apoyo y la confianza que deposito en mí permitiéndome crecer como persona y como profesional. Por los gratos momentos compartidos, por las charlas laborales, los mates y las reflexiones futboleras que hicieron más ameno nuestro trabajo cotidiano, simplemente gracias.

A mis amigos y compañeros del CIDCA por haberme permitido ser parte de sus vidas, por todos esos momentos agradables que compartimos, por haberme brindado su ayuda cuando la necesite, por sus palabras de aliento y sus consejos, a todos ellos gracias por su amistad.

Al personal directivo y administrativo del CIDCA, al CONICET y a la Facultad de Ingeniería de la Universidad Nacional de La Plata por financiar y contribuir al desarrollo de este trabajo. 
A mis papás, Hugo y Cristina por todo su amor, por todo su afecto y comprensión por que gracias a ellos llegue a ser la persona que soy, este trabajo está dedicado a ellos 
La soja (Glycine max) es una planta leguminosa de alto valor nutritivo que posee alrededor de 40\% (p/p) de proteínas con un buen balance de aminoácidos. A pesar de que la Argentina es el tercer productor mundial de soja luego de Estados Unidos y Brasil, el consumo local es escaso. El presente trabajo de tesis se realizó con el objetivo de diseñar un proceso para la obtención de un snack listo para consumir a base de grano entero de soja, pre-cocido y secado-tostado en lecho fluidizado. Se realizó una caracterización geométrica de los granos, y se determinaron el volumen y la densidad de las partículas en muestras de grano entero de soja resultantes de tres etapas del desarrollo del snack: remojado, cocido y secado-tostado a $140^{\circ} \mathrm{C}$ (RCST), así como también, un método en dos etapas: remojado y secado-tostado a $140^{\circ} \mathrm{C}$ (RST). Adicionalmente se estudiaron dos tratamientos alternativos, como remojado y secado a $60^{\circ} \mathrm{C}$ (RS), y humectación y secado a $60^{\circ} \mathrm{C}$ (HS). Estos dos últimos no conducen a un producto snack pero establecen una referencia para compararla variación del volumen y densidad de los granos de soja en función del contenido de humedad. Para interpretar la expansión del grano de soja durante el remojado y la contracción volumétrica durante el secado o secado-tostado en lecho fluidizado, se dedujeron los modelos correspondientes, dotados de sentido físico. Se encontró que la expansión de volumen observada en el remojado fue mayor a la contracción encontrada durante el secado o secado-tostado, lo cual genera mayor porosidad y, en consecuencia, productos menos densos. Se determinaron coeficientes de contracción volumétrica (un valor de 0 indica ausencia de contracción o volumen constante, mientras que un coeficiente unitario indica una reducción de volumen igual a la cantidad de agua removida, sugiriendo un colapso máximo de la estructura) que revelaron un mayor grado de encogimiento conforme aumentaba la intensidad del tratamiento térmico: 0.248 (HS) $<0.389$ (RS)< 
0.567 (RST) 0.745 (RCST). Dado que las características físicas y geométricas de los granos se modificaron durante el tratamiento en lecho fluidizado, se consideró que ellas también podrían afectar los parámetros de la fluidización. Por ello, se realizó un estudio de la fluidodinámica del lecho en estado fijo y fluidizado, determinándose la velocidad de mínima fluidización $\left(\mathrm{V}_{\mathrm{mf}}\right)$ durante el tratamiento térmico. Por su parte, la velocidad que asegura la correcta fluidización del lecho de partículas, o velocidad operativa de fludización, se determinó como $\mathrm{V}_{\mathrm{f}}=1.5 \mathrm{~V}_{\mathrm{mf}}$. Los resultados revelaron que la $\mathrm{V}_{\mathrm{f}}$ requerida, disminuía conforme el producto se deshidrataba, porque el lecho pierde peso, y la pérdida de carga necesaria para sustentarlo disminuye en forma concomitante. Por tanto, a los fines de mantener un consumo adecuado de energía y evitar la pérdida de material por arrastre neumático, debería considerarse la reducción de la velocidad de fluidización durante el proceso.

Con respecto al equilibrio sorcional de granos remojados y luego parcial y totalmente secados-tostados a $140^{\circ} \mathrm{C}$, la isoterma de equilibrio fue de tipo exponencial (aproximadamente tipo III), sin un efecto significativo de la temperatura. El modelo de Halsey fue el que presentó mejor ajuste a los datos, de acuerdo al método de los cuadrados mínimos para modelos no lineales. La ausencia de un un efecto significativo de la temperatura sobre la actividad de agua implicó que, al usar la ecuación de Clapeyron, el calor de desorción del agua en el grano resultara igual al del agua pura.

La transferencia de materia y energía durante el secado-tostado de soja previamente remojada se estudió primeramente a través de experiencias de cinética de secado en capa delgada, midiéndose el contenido de humedad de los granos y su temperatura en función del tiempo, en un rango de temperaturas de aire de 100 a $160^{\circ} \mathrm{C}$. Para interpretar los resultados, se planteó en primer lugar un modelo difusivo, aplicándose la solución analítica de la ecuación de difusión considerando el tamaño 
inicial (radio $R$ ) y el coeficiente de difusión de agua constantes $\left(D_{\text {eff }}\right)$. Los valores del parámetro de transporte para cada temperatura resultaron, $1.460 \times 10^{-9} \mathrm{~m}^{2} / \mathrm{s}$ a $100^{\circ} \mathrm{C}$, $2.147 \times 10^{-9} \mathrm{~m}^{2} / \mathrm{s}$ a $120^{\circ} \mathrm{C}, 3.703 \times 10^{-9} \mathrm{~m}^{2} / \mathrm{s}$ a $140^{\circ} \mathrm{C}$ y $5.815 \times 10^{-9} \mathrm{~m}^{2} / \mathrm{s}$ a $160^{\circ} \mathrm{C}$. La correlación de estos valores con la temperatura del aire mediante una ecuación tipo Arrhenius, permitió hallar una energía de activación $\left(E_{a}\right)$ de $31.4 \mathrm{~kJ} / \mathrm{mol}$. Los resultados de la predicción del secado fueron excelentes a pesar de que el grano experimentaba contracción volumétrica durante el secado-tostado. Esto fue atribuido a que era la relación $D_{\text {eff }} / \mathrm{R}^{2}$ presente en la solución analítica difusiva la que se mantuvo constante (esto es ni el numerador, ni el denominador, como postula la solución analítica). La constancia de dicha relación ofreció una oportunidad interesante para evaluar de manera indirecta la funcionalidad del coeficiente de difusión con el contenido de humedad. Así, para realizar un análisis más riguroso del secado-tostado en capa delgada se utilizó el modelo de la relación volumen-humedad de grano desarrollada previamente, dentro del modelo difusivo que, a su vez, es una forma específica de balance microscópico de materia que contempla ahora la contracción volumétrica del grano y la variación del coeficiente de difusión con la humedad. Se obtuvo así una ecuación diferencial parcial no lineal que requirió, por tanto, una solución numérica. Mediante ésta, los valores de la humedad local en el grano se predijeron en función de la posición radial, a distintos tiempos, con un dominio que resulta variable también. Se utilizó el método de las diferencias finitas con un esquema implícito para la resolución del sistema. En forma acoplada se predijo el calentamiento del grano con un balance macroscópico de energía no estacionario, en el grano. Las predicciones de las curvas de secado y de las historias térmicas mostraron una satisfactoria concordancia con los datos experimentales. 
Tomando como base el estudio de la cinética de secado, se planteó un modelo para predecir el comportamiento del lecho fluidizado, combinando los modelos ya realizados de transferencia de calor y materia en los granos individuales, que en un sistema con mezclado perfecto son válidos para la masa de granos en el lecho, con los balances de materia y energía macroscópicos del aire de secado que atraviesa el lecho, a efectos de evaluar los cambios de la humedad absoluta de salida y la temperatura de salida del aire con el tiempo. Las curvas predichas de secado e historias térmicas calculadas del lecho se convalidaron satisfactoriamente con los datos medidos. Por su parte, se calcularon bajas humedades relativas de aire de salida y temperaturas elevadas, que tienden a la condición de entrada luego de aproximadamente 15 minutos de proceso (tiempo total = $60 \mathrm{~min}$ ). Se simuló entonces un sistema considerando la recirculación de una fracción importante del aire de salida para encontrar un aumento de la eficiencia térmica del 7\% (sin recirculación) a un 42\% (con recirculación), lo que revela el alto potencial de aplicación del proceso.

Finalmente, se evaluó la calidad de los productos RST y RCST a $140^{\circ} \mathrm{C}$. Los resultados indicaron que el tratamiento RCST, que incluía una etapa de cocción en agua luego del remojado, fue más severo para las proteínas, de acuerdo a los excesivamente bajos valores de solubilidad proteica encontrados. Más aún, la electroforesis sugirió la formación de agregados insolubles que dificultarían el aporte nutricional de las muestras RCST. De acuerdo a los resultados de los ensayos de inactivación de los factores antinutricionales, las muestras remojadas y secadas-tostadas (RST) presentaron valores aceptables para el consumo. Así, la etapa de cocción no resultaría necesaria dado que se realiza in situ durante la fluidización de las muestras remojadas, que tiene lugar en aire a temperatura elevada. Por otra parte, de acuerdo al ensayo con el radical DPPH, la muestra RST presentó mayor capacidad antioxidante que las muestras cruda y RCST. 
Este aumento puede deberse a dos mecanismos: el primero de ellos es la liberación de compuestos fenólicos solubles que permanecían en el interior de la matriz celular. El tratamiento térmico altera las membranas y paredes celulares permitiendo la salida de estas sustancias al medio extracelular. El segundo mecanismo correspondería a subproductos originados durante la reacción de Maillard que manifiestan propiedades antioxidantes. Por tanto, se plantea la posibilidad de continuar profundizando al respecto e identificar las sustancias que introducen aumentos del poder antioxidante mediante metodologías avanzadas. Con respecto a los ensayos de evaluación sensorial, ambas muestras de soja crocante, RST y RCST presentaron un alto grado de aceptabilidad general. Al comparar los resultados de ambas se observó una preferencia hacia la muestra remojada y secada-tostada, posiblemente porque, al presentar menor densidad, que la muestra RCST, su estructura fue más porosa, proveyendo un balance entre masticabilidad y crocancia que resultó más atractivo para los consumidores.

Se propone entonces el proceso de remojado y secado-tostado a $140^{\circ} \mathrm{C}$ en lecho fluidizado como una manera apropiada de desarrollar el snack de soja. Se considera que el proceso propuesto, utilizado con velocidad de fluidización decreciente y recirculación del aire de salida, podría ser económicamente viable para la transferencia de tecnología al sector industrial. 
ÍNDICE 


\section{ÍNDICE}

\section{Capítulo 1 Introducción y objetivos generales}

1 Introducción 1

$\begin{array}{lr}\text { 1.1 Características generales } & 1\end{array}$

1.2 Siembra y producción 2

$\begin{array}{ll}1.3 \text { Marco actual } & 4\end{array}$

\section{Capítulo 2 Caracterización Física y geométrica}

2 Introducción 11

2.1 Consideraciones teóricas 12

2.2.1 Modelo matemático para las relaciones entre el volumen y densidad de soja y el $\begin{array}{ll}\text { contenido de humedad } & 12\end{array}$

$\begin{array}{lr}\text { 2.2.2 Contenido de humedad creciente } & 12\end{array}$

2.2.3 Contenido de humedad decreciente 14

2.2.3.1 Relación volumen humedad 14

2.2.3.2 Relación densidad contenido de humedad 16

$\begin{array}{ll}2.3 \text { Materiales y Métodos } & 16\end{array}$

2.3.1 Material 16

$\begin{array}{lr}\text { 2.3.2 Plan experimental } & 17\end{array}$

$\begin{array}{ll}\text { 2.3.3 Determinación del contenido de humedad } & 18\end{array}$

$\begin{array}{ll}\text { 2.3.4 Humectación } & 19\end{array}$

$\begin{array}{ll}2.3 .5 \text { Remojado } & 19\end{array}$

$\begin{array}{ll}\text { 2.3.6 Cocción } & 20\end{array}$ 
2.3.7 Pre-secado superficial

2.3.8 Equipo de lecho fluidizado

2.3.9 Secado y secado-tostado en lecho fluidizado

2.3.10 Determinación de la densidad y volumen de partícula 22

2.3.11 Análisis estadístico 23

2.4 Resultados y Discusión 23

2.4.1 Descripción de los cambios observados durante el remojado y cocción 23

2.4.2 Descripción de los cambios observados durante la fluidización 24

2.4.3 Determinación del factor de encogimiento $a$ en equilibrio durante los tratamientos en lecho fluidizado

2.4.4 Predicción de la densidad de partícula como función del contenido de humedad

2.5 Extensión del análisis previo en condiciones de temperaturas elevadas

2.5.1 Determinación del factor de encogimiento $a$ en equilibrio durante los tratamientos en lecho fluidizado a temperaturas elevadas

2.5.2 Predicción de la densidad de partícula como función del contenido

de humedad a temperaturas elevadas

\section{Capítulo 3 Fluidodinámica de grano entero de soja durante el tratamiento térmico}

3 Introducción

3.1 Materiales y Métodos 53

3.1.1 Plan experimental

3.1.2 Determinación de la densidad de lecho fijo y porosidad 54

3.1.3 Preparación de las muestras por secado-tostado en lecho fluidizado 54 
3.1.4 Caracterización geométrica mediante análisis de imagen

3.1.5 Análisis estadístico

3.1.6 Estudio de la fluidodinamica en condiciones de lecho fijo y fluidizado

3.1.7 Determinación de los parámetros de la ecuación de Ergun

3.1.8 Determinación de la velocidad de mínima fluidización

3.2 Resultados y Discusión

3.2.1 Caracterización geométrica del grano de soja

3.2.2 Estudio de la fluidodinamica del lecho fijo y fluidizado

3.2.2.1 Determinación de los parámetros de Ergun

3.2.3 Determinación de la velocidad operativa de fluidización

3.2.4 Efecto de la temperatura del aire sobre la velocidad de mínima fluidización

\section{Capítulo 4 Equilibrio sorcional}

4 Introducción

4.1 Consideraciones teóricas

4.1.3 Cambios producidos en los alimentos por la $\mathrm{a}_{\mathrm{w}}$

4.1.4 Análisis de modelos matemáticos para la predicción de las isotermas de sorción 84 
4.3 Resultados y Discusión 90

4.3.1 Isoterma de equilibrio experimental 90

4.3.2 Ajuste de las ecuaciones matemáticas a los datos experimentales 93

4.3.3 Ajuste del modelo teórico de G.A.B. 100

4.3.4 Determinación del calor de sorción 102

4.3.4.1 Método de Clapeyron isoterma de sorción 103

$\begin{array}{ll}\text { 4.4 Conclusiones } & 104\end{array}$

\section{Capítulo 5 Cinética de secado-tostado en lecho fluidizado}

$\begin{array}{ll}5 \text { Introducción } & 107\end{array}$

5.1 Materiales y Métodos 109

$\begin{array}{ll}\text { 5.1.1 Plan experimental } & 109\end{array}$

5.1.2 Secado-tostado en capa delgada en condiciones de fluidización 109

$\begin{array}{ll}5.2 \text { Resultados y Discusión } & 110\end{array}$

$\begin{array}{ll}\text { 5.2.1 Curvas de secado experimental } & 110\end{array}$

5.2.2 Modelado matemático 113

5.2.2.1 Balance microscópico de materia con transporte difusivo 113

5.2.2.1.1 Condiciones iniciales y de contorno de transferencia de materia 114

5.2.2.1.2 Solución analítica de la ecuación de difusión 116

5.2.2.1.3 Ajuste de la solución analítica aproximada. Ecuación de Becker $\quad 118$

$\begin{array}{ll}\text { 5.2.2.1.4 Ajuste mediante la serie infinita } & 121\end{array}$

5.2.2.1.5 Ecuaciones de contracción volumétrica 124

5.2.2.1.6 Correlación de los coeficientes de difusión efectivos con la temperatura $\quad 126$

5.2.2.1.7 Resolución numérica mediante diferencias finitas 129 
5.2.2.1.8 Estudio de la correlación entre el coeficiente de difusión y el contenido de humedad

5.2.2.2 Balance microscópico de energía

5.2.2.2.1 Condiciones iniciales y de contorno en transferencia de calor con evaporación superficial

5.2.2.2.2 Curvas de evolución de temperatura experimental en el grano

5.2.2.2.3 Determinación del coeficiente de transferencia de calor efectivo aire-grano durante el secado-tostado

5.2.3 Resolución del modelo

\section{Capítulo 6 Modelado de secado-tostado en lecho fluidizado}

6 Introducción

6.1 Consideraciones teóricas

6.1.1 Modelo matemático para el secado en lecho fluidizado

6.1.2 Ecuaciones del modelo de secado en lecho fluidizado

6.1.2.1 Balances en los granos del lecho

6.1.2.2 Balances en el aire de secado

6.1.3 Resolución numérica del modelo de secado en lecho fluidizado

6.1.3.2 Parámetros del modelo (propiedades geométricas, físicas, térmicas y de transporte)

6.1.3.3 Propiedades del agua y del aire 
6.2 Materiales y Métodos 164

6.2.1 Secado-tostado en lecho fluidizado 164

6.3 Resultados y Discusión 164

6.3.1 Validación del modelo de predicción de humedad y temperatura en lecho

$\begin{array}{ll}\text { fluidizado } & 164\end{array}$

6.3.2 Evolución de la humedad absoluta y relativa durante el secado-tostado $\quad 167$

6.4 diseño del proceso con recirculación de aire 171

6.5 Conclusiones 174

\section{Capítulo 7 Evaluación de la calidad del grano entero de soja secado-tostado}

7 Introducción 177

$\begin{array}{ll}\text { 7.1 Materiales y Métodos } & 179\end{array}$

$\begin{array}{ll}\text { 7.1.1 Plan experimental } & 179\end{array}$

$\begin{array}{ll}\text { 7.1.2 Caracterización química del grano de soja } & 180\end{array}$

7.1.2.1 Método de Kjeldahl o nitrógeno total para determinar el porcentaje de

$\begin{array}{ll}\text { Proteínas } & 181\end{array}$

7.1.2.2 Método de Soxhlet para el cálculo de la materia grasa 182

7.1.2.3 Cenizas totales por el método directo 183

7.1.3 Acondicionamiento de las muestras 184

7.1.4 Determinación de la solubilidad proteica en KOH 0.2\% 184

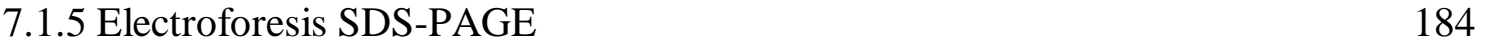

7.1.6 Determinación de la actividad antitríptica. Método de Gonzalez y Carrillo 188

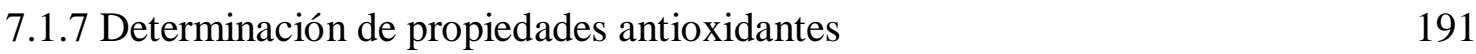

7.1.8 Evaluación sensorial 192

7.1.9 Análisis estadístico 194 
7.2 Resultados y Discusión 195

7.2.1. Caracterización química del grano de soja crudo 195

7.2.2 Solubilidad proteica en $\mathrm{KOH} 0.2 \%$ 195

7.2.3 Electroforesis SDS-PAGE 197

7.2.4 Determinación de la actividad antitríptica 200

7.2.5 Ensayo del radical DPPH 203

7.2.6 Evaluación sensorial 205

7.3 Conclusiones

\section{Conclusión general}

Conclusiones generales

\section{Notación}

Notación

\section{Bibliografía}

Bibliografía 
CAPÍTULO I

INTRODUCCIÓN 


\section{Introducción.}

\subsection{Características Generales.}

La soja (Glycine max) es una planta leguminosa que en su estado de madurez adopta una geometría esferoidal, aunque como sucede con la mayoría de los alimentos provenientes del campo, no solo su forma sino también su composición química depende de muchos factores, tales como el cultivar y las condiciones de siembra y cultivo. Un grano de soja típico, está compuesto por tres partes principales: la cubierta de semilla o tegumento que representa un $8 \%$ del grano entero, los cotiledones que alcanzan un 90\% del total, y el germen o hipocótilo que representa sólo un 2\%.

Desde el punto de vista nutricional, se destaca por su alto contenido proteico, (38-44\% p/p) superior al de otras leguminosas y mucho mayor al de los cereales, y un mejor perfil de aminoácidos (Kashaninejad y col., 2008). Su contenido en materia grasa, alrededor del 20\% p/p, es menor que el de otras oleaginosas (Deshpande y col., 1993).

Al igual que en otros tejidos vegetales, la soja contiene en su estado natural diversos factores antinutricionales, como son los inhibidores de tripsina. Estas sustancias interfieren con la digestibilidad proteica, por lo que es indispensable aplicar un tratamiento térmico para inactivarlas (Dergal, 1990).

La Tabla 1.1 presenta la composición porcentual del grano de soja y las diferentes partes que lo componen. 
Tabla 1.1 Composición química del grano de soja y sus componentes. Expresados en base seca (Erickson, 1995).

\begin{tabular}{lcccc}
\hline \multicolumn{5}{c}{ Composición de Soja } \\
\hline Componente & $\begin{array}{l}\text { Proteína } \\
\% \text { (b.s.) }\end{array}$ & $\begin{array}{c}\text { Lípidos } \\
\% \text { (b.s.) }\end{array}$ & $\begin{array}{c}\text { Hidratos de Carbono } \\
\% \text { (b.s.) }\end{array}$ & $\begin{array}{c}\text { Cenizas } \\
\% \text { (b.s.) }\end{array}$ \\
\hline Grano entero & 40.3 & 21 & 33.9 & 4.9 \\
Cotiledón & 42.8 & 22.8 & 29.4 & 5 \\
Cáscara & 8.8 & 1 & 85.9 & 4.3 \\
Hipocotiledon & 40.8 & 11.4 & 43.4 & 4.4 \\
\hline
\end{tabular}

\subsection{Siembra y producción.}

El cultivo de soja es uno de los más antiguos de la humanidad. Por miles de años ha sido utilizada como una de las principales fuentes de proteína en la dieta de las culturas orientales. Se encontraron registros de su cultivo en el noroeste de China (siglo XI a.C.). En la actualidad puede estar presente en una amplia variedad de productos tradicionales tales como la leche de soja, el tofu, la harina tostada y el tempeh, entre otros, mientras que en Europa, América y África su historia data de apenas 100 años a la fecha.

En nuestro país su cultivo comenzó a adquirir importancia en la década de 1970, pero fue durante los últimos 25 años que se desarrolló en forma creciente y sostenida. En la década de 1970 la superficie de siembra evolucionó de 37.700 a 2.100.000 ha mientras que a fines de la década del 90 alcanzó las 8.790.000 ha.

A continuación podemos observar en la Figura 1.1 la distribución de la superficie sembrada de soja en nuestro país. 


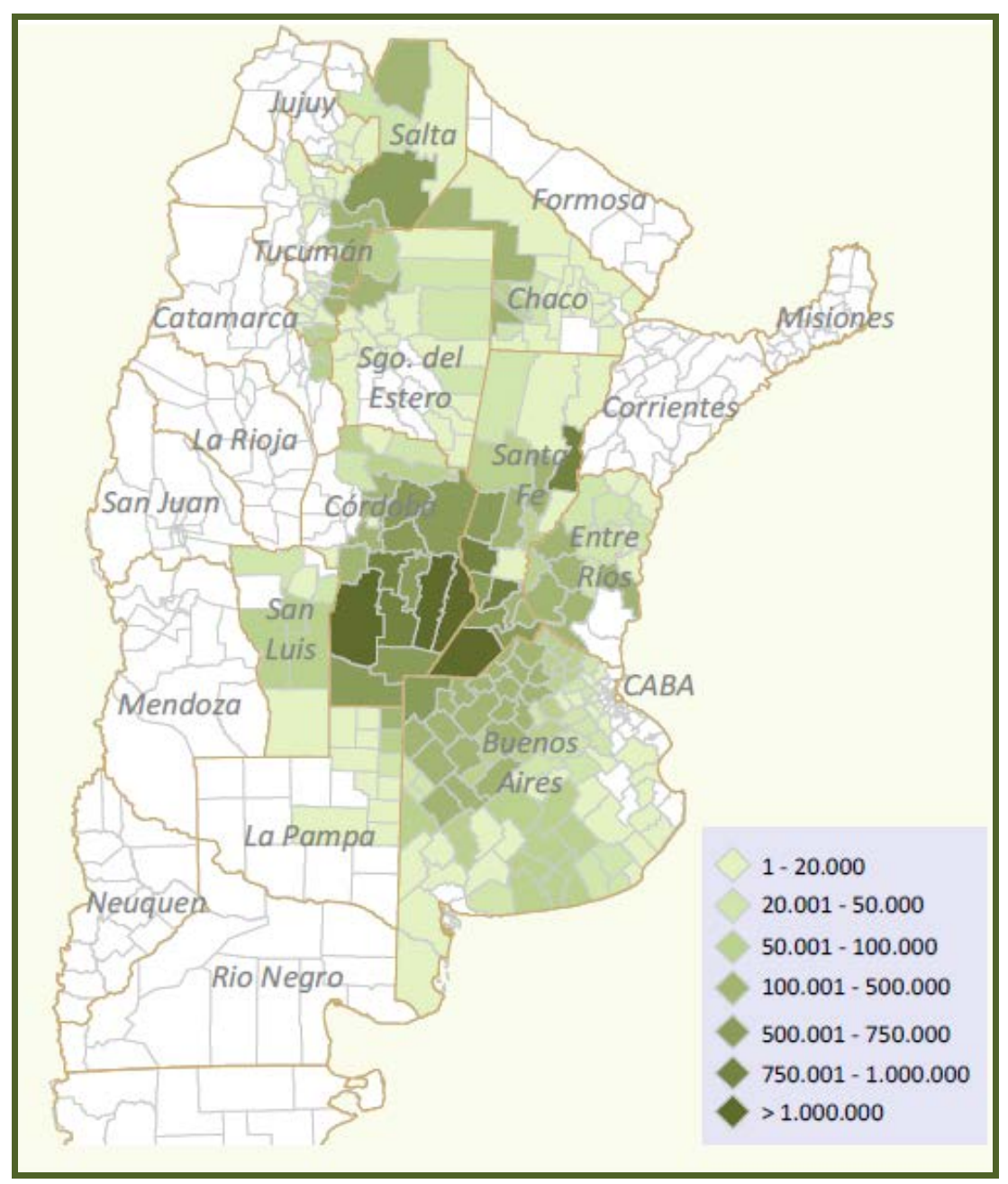

Figura 1.1 Distribución territorial de soja en hectáreas en Argentina. (Fuente Ministerio de Economía y Finanzas Públicas, 2011)

De acuerdo a estos datos, el $84 \%$ de la superficie sembrada se encuentra en las provincias de Buenos Aires (29\%), Córdoba (28\%), Santa Fe (19\%) y Entre Ríos (8\%). El 16\% restante se distribuye entre provincias del noroeste y noreste argentino.

La producción, se incrementó en la década del 70 de 59.000 a 3.5 millones de toneladas, y a fines de los 90 llegó a los 20.2 millones de toneladas (Baigorri y Pereyra, 2002; Cuniberti y col., 2002). En relación a la campaña 2011/12, el Departamento de Agricultura de Estados Unidos (USDA) estimó la producción en Argentina en alrededor de 42.5 millones de toneladas. 
La soja y sus derivados representan actualmente el principal producto de exportación y ubican a la Argentina como el primer exportador mundial de aceite y harina desgrasada de soja, y como tercer productor mundial de soja luego de EEUU y Brasil.

Bocchetto (2005), en un informe realizado para el INTA, destacó la importancia del bloque formado por Argentina, Brasil, Paraguay, Uruguay y Bolivia, considerándolo como la principal zona de producción de soja en el mundo. El área sembrada en estos países alcanza los 40 millones de hectáreas donde se producen 94 millones de toneladas, superando en bloque a la producción de Estados Unidos que es de 83 millones de toneladas.

\subsection{Marco actual.}

En los países occidentales productores de soja como Estados Unidos, Brasil y Argentina, los granos son empleados a nivel industrial para la extracción de aceite quedando una harina desgrasada, rica en proteínas, la que, tanto a nivel local como en destino de exportación se usa en su mayoría para alimentación animal. Durante el desgrasado, el ya elevado valor biológico de las proteínas de soja aumenta aún más asemejándose a proteínas cárnicas. La soja es un excelente recurso para complementar la alimentación, no como un alimento único, sino considerándolo como un alimento más, dentro de los disponibles y accesibles, para lograr una alimentación variada, completa y nutricionalmente adecuada.

Según el Código Alimentario Argentino, los productos alimenticios básicos derivados de la soja se encuadran en los siguientes grupos, dependiendo de su contenido de grasa y proteína; harinas y sémolas de soja (proteína, 35-50\%), concentrados de soja 
(proteína 70\%) y aislado de soja (proteína 90-95\%) (CAA, Capítulo XIX). De todos ellos, los concentrados y aislados proteicos han encontrado aplicación como ingredientes nutricionales y funcionales en casi todos los tipos de alimentos.

Mientras que en los países asiáticos el grano de soja es considerado como un integrante esencial de la dieta, pese a su abundancia no ocurre lo mismo en occidente. En el caso de Argentina, siendo el mayor productor de soja per cápita del mundo, el consumo de soja a nivel interno resulta ser muy bajo debido a una cultura desarrollada durante largos años en el consumo de proteínas de origen animal (Cuniberti y col., 2002). Al mismo tiempo, los estilos de vida actuales, especialmente en áreas urbanas no son compatibles con el largo periodo de preparación requerido para cocinar e inactivar los factores antinutricionales presentes en la soja (Soponronnarit y col., 2001), y la preparación de soja entera cocida y enlatada no parece desarrollar la suficiente aceptabilidad como hacer rentable su producción.

La evidente tendencia hacia el consumo de productos deshidratados, crocantes, listos para consumir tipo snack (Aguilera y col., 2003) justifica el desarrollo de un proceso mediante el cual la soja pueda ser pre-cocida, inactivada y secada-tostada para producir un producto poroso de bajo contenido de humedad.

La mayor parte de las investigaciones ingenieriles llevadas a cabo con soja se han dedicado a las operaciones de conservación post-cosecha en particular al tratamiento térmico con aire caliente (Mensah y col., 1985; Zeng y col., 1996, Sobral y Wagner, 2007), o el análisis de la harina de soja desgrasada, o el aceite comestible como principales productos (Erickson, 1995). En el ámbito de la calidad y mejora del perfil nutricional de diversos productos, recientemente se llevaron adelante estudios relacionados con el agregado de concentrado proteico de soja en fórmulas comerciales 
de alimento infantil como así también en el desarrollo de películas o recubrimientos comestibles (Ou y col., 2004).

En menor medida se prestó atención a las etapas necesarias para el desarrollo de un snack a base de soja, donde la integridad del grano sea considerada esencial. Por lo tanto, para tal fin, los granos de soja cosechados recientemente deben ser secados con aire a temperatura ambiente empleando flujos lentos de aire para prevenir la fractura de los granos en el almacenamiento o durante etapas posteriores de procesamiento (Hansen y col., 1996).

Por su parte, la fluidización es una técnica que ha mostrado debido a su aptitud a para aplicar un tratamiento térmico uniforme al grano, como lo demostraron Giner y Calvelo (1987) en el secado de trigo, y Kitic y Viollaz (1984) al estudiar el secado de soja post-cosecha. Las altas velocidades de aire requeridas para la fluidización, producen un alto grado de mezclado, característica en partículas grandes y hacen de esta técnica una alternativa adecuada para procesos que tienen como fin añadir valor agregado a los alimentos (Yang, 2003; Senadeera y col., 2006). Desde el punto de vista energético, Giner y De Michelis (1988) encontraron un alto potencial para la recuperación de energía durante el proceso de fluidización, dado que en su paso por el lecho, el aire sale con elevada temperatura y baja humedad.

Desde el punto de vista de calidad, Osella y col., (1997) y Soponronnarit y col., (2001) propusieron la fluidización con aire caliente como una técnica de secado conveniente para la inactivación de los factores antinutricionales, aun manteniendo niveles aceptables de lisina y evaluando la intensidad del tratamiento térmico a través de diferentes indicadores. Para tal fin recomendaron temperaturas de aire a la entrada, de alrededor de $140^{\circ} \mathrm{C}$. 
Para este trabajo de tesis, que estudiará un proceso, donde la soja se remoja para luego ser secada-tostada en lecho fluidizado, no se encontró en la bibliografía estudios de fluidización con aire caliente en granos de soja previamente remojados o cocidos. Por tanto, el diseño y desarrollo de un proceso que permita transformar el grano entero de soja, en un producto inactivado deshidratado, crocante y listo para consumir tipo snack se presenta como una alternativa novedosa. En vista de esto y lo planteado en párrafos previos, los objetivos de este trabajo son:

(1) Determinar las propiedades físicas y geométricas de grano de soja entero en diferentes condiciones: crudo, remojado, cocido y secado-tostado a diferentes temperaturas e intervalos de tiempo.

(2) Desarrollar modelos matemáticos con fundamento físico que permita predecir el comportamiento del grano durante el tratamiento térmico en lecho fluidizado.

(3) Determinar los parámetros fluidodinámicos de la soja, de manera tal que sea posible encontrar las condiciones adecuadas de secado-tostado en lecho fluido.

(4) Determinar el comportamiento sorcional del grano de soja parcial y totalmente secado-tostado. Establecer mediante el modelo matemático más conveniente la relación entre el contenido de humedad y temperatura.

(5) Determinar la cinética de secado-tostado en lecho fluidizado de una capa delgada de soja remojada, a temperaturas entre 100 y $160^{\circ} \mathrm{C}$. Seleccionar un modelo matemático 
conveniente para describir el proceso de la forma más realista posible, que pueda ser aplicado en un algoritmo de diseño de lecho fluidizado.

(6) Aplicar un modelo matemático para interpretar la transferencia de calor y materia experimental.

(7) Desarrollar un modelo matemático para lecho fluidizado a partir de los resultados obtenidos en capítulos previos. Dicho modelo permitirá predecir el comportamiento de un lecho de granos durante el secado-tostado y seleccionar las condiciones más adecuadas para su diseño y optimización.

(8) Evaluar la calidad del producto secado-tostado, mediante técnicas analíticas, y realizando una prueba de aceptabilidad general en el producto final. 


\section{CAPÍTULO II}

CARACTERIZACIÓN FÍSICA Y GEOMÉTRICA 


\section{Introducción.}

Cuando las propiedades físicas de granos, semillas, frutas y vegetales se estudian, como conjunto o de manera individual, resulta importante estimar con la mayor precisión posible la forma, tamaño, volumen, densidad, área superficial entre otras características (Mohsenin, 1970). La determinación de estos parámetros es esencial para el diseño de equipos destinados al manejo, cosecha, secado y almacenamiento de estos productos. Las propiedades físicas de diversos granos y semillas fueron el objeto de estudio de varios autores como Baryeh (2002) en semillas de mijo, Vilche y col. (2003) en quinoa y Kashaninejad y col. (2008) en soja, entre otros.

A pesar de la extensa bibliografía encontrada sobre el tema, no se encontraron trabajos en relación a la determinación de las propiedades físicas de grano entero de soja remojado, cocido y secado-tostado en lecho fluidizado.

Con este fin, el objetivo principal de este capítulo es estudiar muestras de tres etapas de un proceso propuesto para producir un snack de grano entero de soja: remojado, cocido y secado-tostado a $140^{\circ} \mathrm{C}$. El objetivo específico es determinar las propiedades físicas y geométricas de grano de soja entero en diferentes condiciones: crudo, remojado, cocido y secado-tostado a diferentes temperaturas en intervalos de tiempo. Desarrollar modelos matemáticos con fundamento físico que permita predecir el comportamiento del grano durante el tratamiento térmico en lecho fluidizado. Para analizar los cambios estructurales, los volúmenes y densidades medidas se compararon con aquellas generadas en tratamientos alternativos como: humectado y secado a $60^{\circ} \mathrm{C}$, remojado y secado a $60^{\circ} \mathrm{C}$, y un remojado y secado-tostado a $140^{\circ} \mathrm{C}$. 


\subsection{Consideraciones teóricas.}

2.2.1. Modelo matemático para las relaciones entre el volumen y densidad de soja y el contenido de humedad.

\subsubsection{Contenido de humedad creciente.}

Un producto de bajo contenido de humedad de volumen $V_{O}$ y contenido de humedad $W_{0}$ puede ser humectado, remojado o cocido en agua produciendo su hinchamiento.

$\mathrm{V}=\mathrm{V}_{0}+a_{\mathrm{s}} \mathrm{V}_{\mathrm{w} a}$

donde $V_{w a}$ es el volumen del agua absorbida y $a_{\mathrm{s}}$ un coeficiente promedio de hinchamiento, el cual puede representar la fracción del volumen completo de expansión, durante la absorción de agua en la muestra. De este modo, un factor igual a la unidad indicaría que la muestra se expandió $1 \mathrm{~mm}^{3}$ por cada $\mathrm{mm}^{3}$ de agua absorbida, luego de alcanzar el equilibrio. Si reemplazamos en la Ecuación (2.1) el valor de $V_{w a}$ por la relación entre la masa de agua absorbida $\left(m_{w a}\right)$ y su densidad $\left(\rho_{w}\right)$, se obtiene la expresión siguiente

$V=V_{0}+a_{s} \frac{m_{w a}}{\rho_{w}}$

entonces, $m_{w a}$ puede ser expresado como el producto de la materia seca y la diferencia en el contenido de humedad entre el estado actual y el inicial $m_{d}\left(W-W_{0}\right)$ 
$V=V_{0}+a_{s} \frac{m_{d}\left(W-W_{0}\right)}{\rho_{w}}$

considerando que la materia seca se calcula usando la masa del producto con un contenido de humedad dado, $m_{d}=m_{0} /\left(1+W_{0}\right)$

$V=V_{0}+a_{s} \frac{m_{0}\left(W-W_{0}\right)}{\left(1+W_{0}\right) \rho_{w}}$

al expresar $m_{0}=\rho_{0} V_{0}$ y reordenando, la relación entre el volumen y el contenido de humedad en la ecuación anterior se expresa de siguiente manera

$\frac{V}{V_{0}}=\left[1+a_{s} \frac{\rho_{0}\left(W-W_{0}\right)}{\left(1+W_{0}\right) \rho_{w}}\right]$

El modelo de densidad correspondiente $\rho=m / V$ requiere desarrollos matemáticos previos en su numerador. La masa del producto se expresa primero en términos de su masa seca y contenido de humedad. Entonces, la masa seca es reemplazada por una relación que involucra la masa inicial y el contenido de humedad, finalmente, la masa inicial se reescribe como el producto de la densidad y el volumen inicial

$$
\rho=\frac{m}{V}=\frac{m_{d}(1+W)}{V}=\frac{\frac{m_{0}(1+W)}{\left(1+W_{0}\right)}}{V}=\frac{m_{0}(1+W)}{\left(1+W_{0}\right) V}=\frac{\rho_{0} V_{0}(1+W)}{\left(1+W_{0}\right) V}
$$


reemplazando $V$ en la Ecuación (2.6) por su expresión en la Ecuación (2.4), encontramos la forma final del modelo de densidad para contenidos de humedad crecientes

$$
\rho=\rho_{0} \frac{(1+W)}{\left[1+W_{0}+a_{s} \frac{\rho_{0}\left(W-W_{0}\right)}{\rho_{w}}\right]}
$$

\subsubsection{Contenido de humedad decreciente.}

\subsubsection{Relación volumen-humedad.}

Si el agua se remueve por evaporación en un grano húmedo de soja, el volumen del grano puede describirse como

$V=V_{0}-a V_{w e v}$

donde $V_{0}$ es el volumen inicial en $\mathrm{m}^{3}$, volumen de grano a un contenido de humedad $W_{0}$, en $\mathrm{kg}$ de agua $/ \mathrm{kg}$ de materia seca, $V_{\text {wev }}$ es el volumen de agua evaporada y $a$ un factor promedio de contracción volumétrica que puede variar de 0 (volumen constante) a 1 (contracción equivalente al volumen de agua evaporada). Este es un factor en equilibrio porque su determinación se realiza cuando el gradiente de humedad se relaja. Un comportamiento con $a=1$ (colapso completo) se observa usualmente en productos en estado gomoso (Mayor y Sereno, 2004) y, siempre y cuando la densidad de la materia seca sea mayor que la del agua, implica un incremento en la densidad del alimento para contenidos de humedad decrecientes. En cambio, si $a=0$, el producto 
presenta un comportamiento correspondiente al estado vítreo, como por ejemplo durante una liofilización (Bhandari y Adhikari, 2009), manifestándose una disminución en la densidad para contenidos de humedad decrecientes al reducirse la masa y no el volumen.

A partir de la expresión del volumen de agua evaporada en términos de la masa y densidad correspondiente, se halló la siguiente ecuación

$$
V=V_{0}-a \frac{m_{w e v}}{\rho_{w}}
$$

la masa de agua evaporada puede representarse en términos del agua perdida por el grano, $m_{d}\left(W_{0^{-}} W\right)$, donde $m_{d}$ es la materia sólida seca y $W$ el contenido de humedad en un determinado momento. Por tanto, la relación del volumen se convierte en

$$
V=V_{0}-a \frac{m_{d}\left(W_{0}-W\right)}{\rho_{w}}
$$

La masa seca $m_{d}$ puede reescribirse como $m /(1+W)$, y en nuestro caso particular, en términos de las condiciones iniciales $m_{0} /\left(1+W_{0}\right)$. Además, reemplazando $m_{0}$ por $\rho_{0} V_{0}$, la relación volumen-humedad puede reescribirse como

$$
\frac{V}{V_{0}}=1-a \frac{\rho_{0}\left(W_{0}-W\right)}{\rho_{w}\left(1+W_{0}\right)}
$$


esta expresión puede ajustarse a los datos experimentales del volumen del producto en función del contenido de humedad para poder determinar el factor de contracción volumétrica $a$.

\subsubsection{Relación densidad contenido de humedad.}

El modelo de densidad del producto $\rho=m / V$ se alcanzó a partir de la expresión de la masa del producto, $m=m_{d}(1+W)$. Así en la Ecuación (2.10) $m_{d}$ se reemplazó por $\rho_{0} \mathrm{~V}_{0} /\left(1+W_{0}\right)$. El volumen $V$ fue reemplazado por la Ecuación (2.11). Cancelando factores y reordenando, la expresión resultante queda de la siguiente manera

$$
\rho=\rho_{0} \frac{(1+W)}{\left[1+W_{0}-a \frac{\rho_{0}\left(W_{0}-W\right)}{\rho_{w}}\right]}
$$

\subsection{Materiales y Métodos.}

\subsubsection{Material.}

Se trabajó con granos de soja variedad 5.5i, las cuales fueron provistas gentilmente por la empresa Don Mario Semillas, Chacabuco, Provincia de Buenos Aires, Argentina. 


\subsubsection{Plan experimental.}

Con el objeto de diseñar un proceso para generar un producto inactivado, listo para consumir a base de grano entero de soja, se plantearon dos caminos diferentes, remojado y secado-tostado a $140^{\circ} \mathrm{C}$ (RST), y remojado, cocido y secado-tostado a $140^{\circ} \mathrm{C}$ (RCST). A pesar de ello, solo con el fin de comparar los cambios en la estructura debidos a la variación de la densidad y volumen con el contenido de agua, se llevaron adelante tratamientos adicionales, remojado y secado a $60^{\circ} \mathrm{C}$ (RS), y humectada (un incremento de la humedad dentro del rango post-cosecha) y secado a $60^{\circ} \mathrm{C}$ (HS). El diagrama de flujo del plan experimental realizado se presenta en la Figura 2.1 


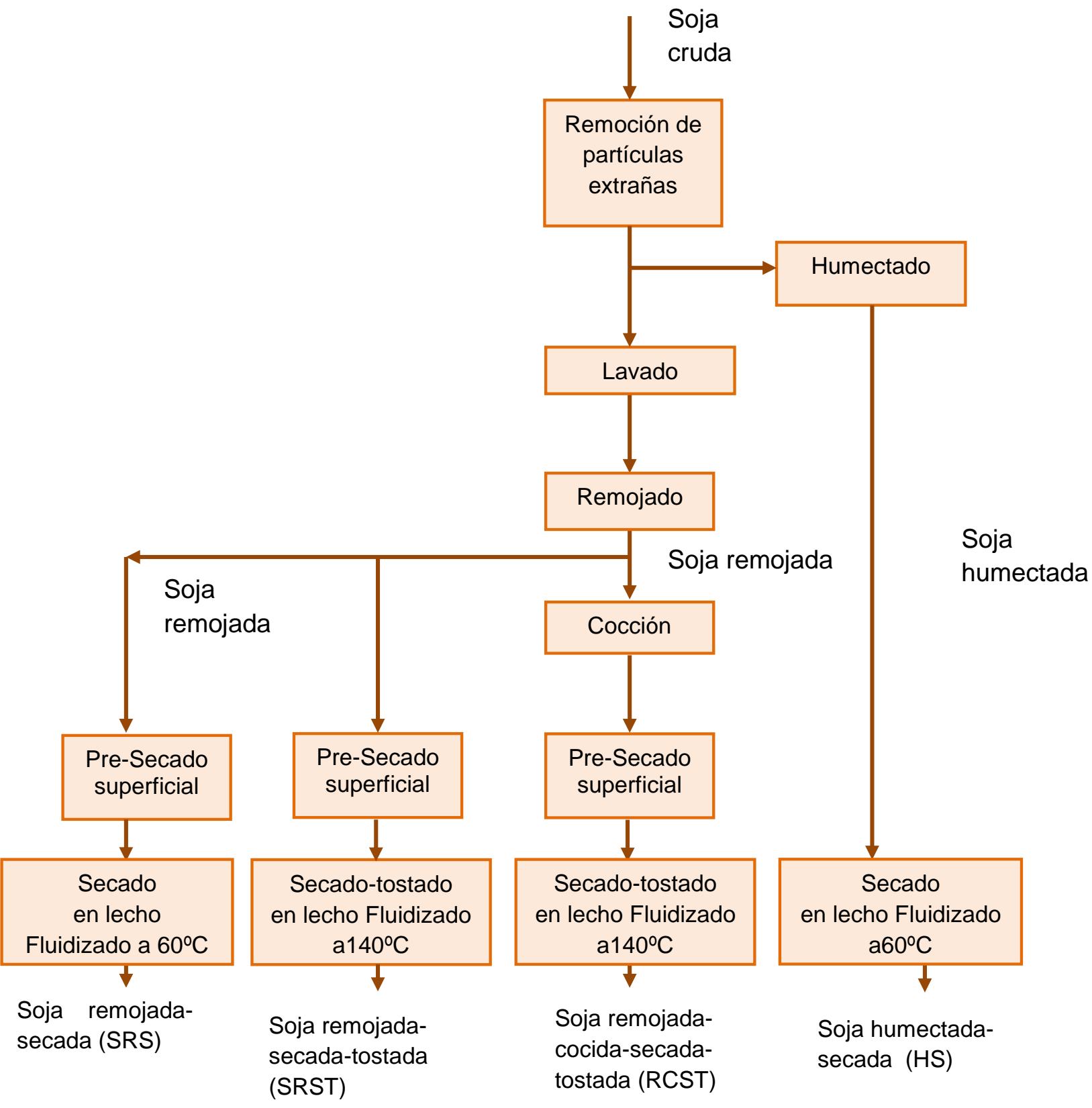

Figura 2.1. Diagrama de flujo de las experiencias llevadas a cabo en este trabajo.

\subsubsection{Determinación del contenido de humedad.}

El contenido de humedad se determinó por triplicado, utilizando un método específico para semillas oleaginosas a presión atmosférica (AOCS Ac $2-41,130^{\circ} \mathrm{C}$ por 3 
h). Con este propósito se empleó una estufa de convección forzada (velocidad de aire, $0.25 \mathrm{~m} / \mathrm{s}$ ). El contenido de humedad se expresó en $\mathrm{kg}$ de agua $/ \mathrm{kg}$ de materia seca, unidad habitualmente denominada "decimal base seca" o "dec., b.s.".

\subsubsection{Humectación.}

Este tipo de muestras se produjeron para el estudio del comportamiento del volumen y densidad de grano durante la fluidización, en un rango de humedad correspondiente a las condiciones de manejo post-cosecha durante el secado y aireación, y comparar su coeficiente de contracción con aquellos obtenidos para las muestras remojadas y, remojadas y cocidas. Para humectar los granos de soja, se calculó previamente la cantidad de agua agregada mediante un balance de masa. El contenido de humedad se incrementó desde un valor inicial de 0.113 hasta 0.210 dec., b.s. A continuación, estas muestras se secaron en lecho fluidizado a $60^{\circ} \mathrm{C}$ como se describirá posteriormente en la sección 2.3.9.

\subsubsection{Remojado.}

Los granos se inspeccionaron visualmente para remover materiales extraños, posteriormente se lavaron dos veces por inmersión en agua caliente $\left(90^{\circ} \mathrm{C}\right)$ por un minuto. A continuación se sumergieron en agua, usando para ello una relación agua: masa de soja de 2:1, manteniéndolas durante $24 \mathrm{~h}$ a $10^{\circ} \mathrm{C}$. Este procedimiento fue recomendado por el gobierno argentino para el manejo de la soja (Coordinación de Políticas Sociales, 2002). 


\subsubsection{Cocción.}

Los granos de soja remojados, se sumergieron en agua hirviendo durante 45 minutos, luego de lo cual se dejaron escurrir para eliminar el agua en exceso. (Coordinación de Políticas Sociales, 2002).

\subsubsection{Pre-secado superficial.}

Para facilitar la fluidización de las partículas durante el secado o secado-tostado, las muestras de soja remojadas o remojadas y cocidas se sometieron a un pre-secado superficial en capa delgada, en estufa de convección forzada a $50^{\circ} \mathrm{C}$ por $10 \mathrm{~min}$.

\subsubsection{Equipo de lecho fluidizado.}

La Figura 2.2 muestra un esquema del secador experimental de lecho fluidizado construido para esté trabajo. Consiste de 5 componentes principales: la cámara de secado aislada térmicamente, de $0.10 \mathrm{~m}$ de diámetro interno y $0.30 \mathrm{~m}$ de altura, un micromanometro Testo 525 (rango: 0-25 hPa, error a fondo de escala $0.2 \%$ ) para medir las diferencias en la presión de aire a través del lecho y asegurar un adecuada fluidización, un anemómetro de hilo caliente TSI Mod. 1650 para medir la velocidad del flujo de aire a través del lecho, un controlador de temperatura, Novus Brand Mod. $\mathrm{N} 321-\mathrm{J} / \mathrm{Kit}$ y un sistema conversor de frecuencia que controla y varía la frecuencia de la corriente alterna que alimenta a un motor eléctrico Siemens (máxima velocidad angular, $2800 \mathrm{rev} / \mathrm{min}$ ) directamente conectado a un ventilador centrífugo. 


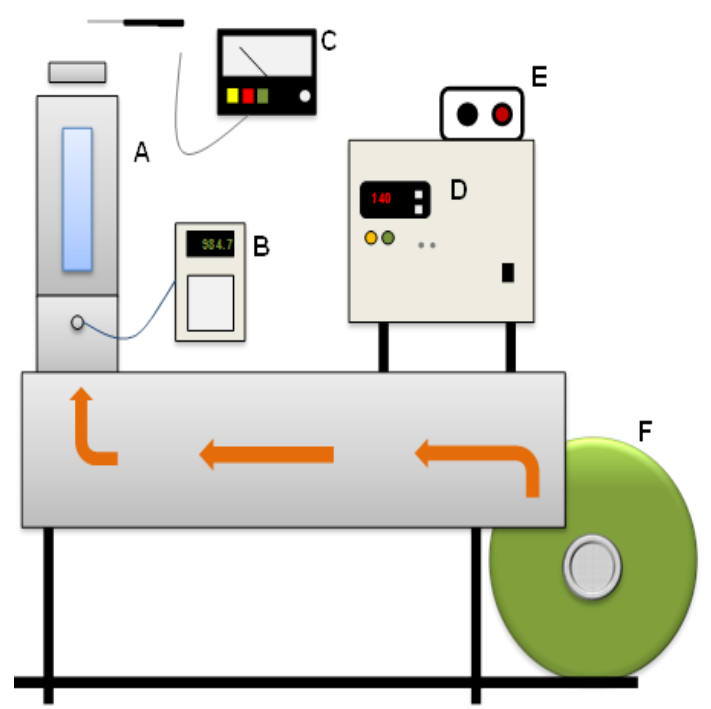

(a)

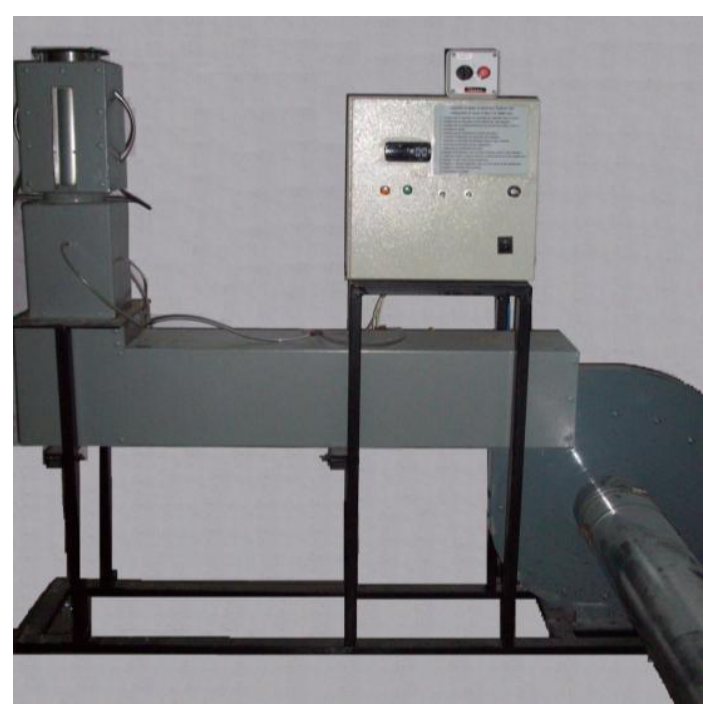

(b)

Figura 2.2 (A) Cámara de secado, (B) Micromanometro TESTO 525, (C) anemómetro de hilo caliente TSI Mod. 1650, (D) Controlador de Temperatura, (E) Conversor de Frecuencia, (F) Ventilador. (Las flechas indican la dirección del aire caliente).

\subsubsection{Secado y secado-tostado en lecho fluidizado.}

El proceso de secado y el de secado-tostado fue llevado a cabo con temperaturas de aire a la entrada de 60 y $140^{\circ} \mathrm{C}$, respectivamente, con una velocidad de aire promedio de $2.5 \mathrm{~m} / \mathrm{s}$ para alcanzar un alto grado de mezclado, y por consiguiente un tratamiento más uniforme en el lecho. La altura de lecho fijo del producto fue de $0.10 \mathrm{~m}$. Para el secado a $60^{\circ} \mathrm{C}$ se extrajeron muestras de soja a $5,10,15,20,60,80,120$ y $180 \mathrm{~min}$, mientras, en el secado-tostado a $140^{\circ} \mathrm{C}$, los tiempos de muestreo fueron a $3,7,10,20$, 30, 40 y 60 min. Una vez extraídas, las muestras fueron depositadas en frascos herméticos por $24 \mathrm{~h} \mathrm{a} 10^{\circ} \mathrm{C}$ para permitir la uniformización del contenido humedad en el grano. Si bien este periodo no se requiere para la determinación del contenido de humedad, sí resulta necesario para la medida del volumen y densidad de los granos de 
soja tratados. Todas las experiencias se realizaron por triplicado. La temperatura del secado-tostado a $140^{\circ} \mathrm{C}$ está por debajo del límite de pérdida de proteínas sugerido por Hsu y Satter (1995).

\subsubsection{Determinación de la densidad y volumen de partícula.}

La densidad $(\rho)$ y volumen $(V)$ del grano entero de soja en equilibrio se determinaron por picnometría usando agua destilada. Con este propósito se diseñó un picnómetro de vidrio de $100 \mathrm{ml}$ (los convencionales tiene $25 \mathrm{ml}$ ), al cual se le agregaron $20 \mathrm{~g}$ de muestra. La densidad se calculó de la siguiente manera

$\rho=\frac{m_{T P}}{V_{T P}}$

donde $m_{T P}$ es la masa total de grano entero de soja, previamente pesado en una balanza digital de precisión $( \pm 0.01 \mathrm{~g})$ y $V_{T P}$ es el volumen total de partículas en $\mathrm{m}^{3}$, determinado por desplazamiento del volumen en un picnómetro. El volumen promedio de partícula, se determinó de la siguiente forma

$V=\frac{V_{T P}}{N_{T P}}$

donde $N_{T P}$ es el número total de granos de soja contenidos en la muestra. El diámetro equivalente $D_{e}$, definido como el diámetro de una esfera con el mismo volumen que el grano de soja, fue calculado a partir del volumen de grano: 


$$
D_{e}=\left(\frac{6 V}{\pi}\right)^{1 / 3}
$$

\subsubsection{Análisis estadístico.}

Las experiencias se llevaron adelante por triplicado para cada condición de lecho fluidizado, midiendo la densidad y volumen de partícula como función del contenido de humedad. Los diferentes tratamientos se compararon mediante el test de Tukey (Montgomery, 1991), con un nivel de confianza de $95 \%$.

\subsection{Resultados y Discusión.}

\subsubsection{Descripción de los cambios observados durante el remojado y cocción.}

La Tabla 2.1 muestra el volumen y densidad de la soja cruda, remojada, y cocida (en este trabajo nos referimos como cocida a la soja remojada y luego cocida), junto con sus diámetros equivalentes. La densidad de los granos de soja remojados es menor que la de la soja cruda porque los granos hinchados se comportan como una mezcla de materia seca con alta densidad, y agua con baja densidad. Por tanto, a medida que el contenido de humedad aumentó en los granos remojados, su densidad disminuyó. 
Tabla 2.1. Parámetros físicos de grano entero de soja cruda, remojada y cocida.

\begin{tabular}{lcccc}
\hline \multicolumn{1}{c}{ Grano entero de soja } & $W($ dec., b.s. $)$ & $\rho\left(\mathrm{kg} / \mathrm{m}^{3}\right)$ & $V\left(\mathrm{x} 10^{7} \mathrm{~m}^{3}\right)$ & $D_{e}\left(\mathrm{x} 10^{3} \mathrm{~m}\right)$ \\
\hline Soja cruda de baja humedad & 0.071 & 1186 & 1.285 & 6.26 \\
Cruda & 0.113 & 1190 & 1.348 & 6.36 \\
Humectada & 0.213 & 1181 & 1.475 & 6.56 \\
Remojada & 1.450 & 1082 & 3.079 & 8.38 \\
Cocida & 1.494 & 1069 & 2.982 & 8.29 \\
\hline
\end{tabular}

Por el ajuste del modelo de volumen (Ec.(2.5)) a los datos experimentales de la Tabla 2.1 en función del contenido de humedad, se determinó un coeficiente promedio de hinchamiento por el método de mínimos cuadrados a partir de los triplicados de los datos, en primer lugar entre la muestra cruda y la humectada igual a 0.831 y a continuación entre la muestra cruda y la remojada el cual resultó igual a 0.895, en ambos casos el coeficiente de determinación, $r^{2}$ fue de 0.987 .

\subsubsection{Descripción de los cambios observados durante la fluidización.}

La Tabla 2.2 detalla el volumen y diámetro de partícula equivalente como función del contenido de humedad para los tratamientos en lecho fluidizado (secado a $60^{\circ} \mathrm{C}$ y secado-tostado a $140^{\circ} \mathrm{C}$ ) aplicados a las muestras de soja humectadas, remojadas y cocidas.

El volumen de la muestra humectada disminuyó sólo un $3.05 \%$ durante el tratamiento en lecho fluidizado a $60^{\circ} \mathrm{C}$ para una reducción del contenido de humedad de $48.8 \%$ (de 0.213 a 0.109 dec., b.s.) mostrando una relación de contracción volumétrica de 0.0625 entre ambas estados (muestra HS), dicha "relación de contracción volumétrica" mencionada en esta sección se estima a partir de la relación entre el porcentaje de disminución del volumen y el porcentaje de pérdida de humedad. En 
cambio, el volumen de las muestras de soja remojadas disminuyó durante el tratamiento en el lecho fluidizado a $60^{\circ} \mathrm{C}$ en un $17.6 \%$ para una reducción en el contenido acuoso del $87.5 \%$ (de 1.45 a 0.182 dec., b.s.), exhibiendo de este modo una mayor relación, 0.201. Con respecto a la muestra remojada y luego secada-tostada a $140^{\circ} \mathrm{C}$ en lecho fluido (RST), el volumen se redujo en alrededor de un $28.6 \%$ como consecuencia de una reducción considerable de humedad, $97.6 \%$ (de 1.45 a 0.034 dec., b.s.). Esto lleva a una alta relación de contracción volumétrica, 0.293. Finalmente, la muestra remojada y cocida experimentó una reducción en su volumen de $43.7 \%$, y un alto valor para la relación de contracción volumétrica, 0.445 (RCST).

A continuación se presentan las imágenes de los cuatro productos analizados 


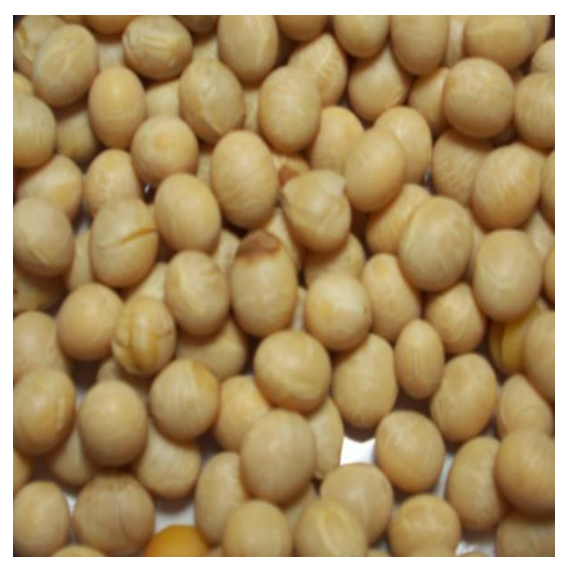

(a)

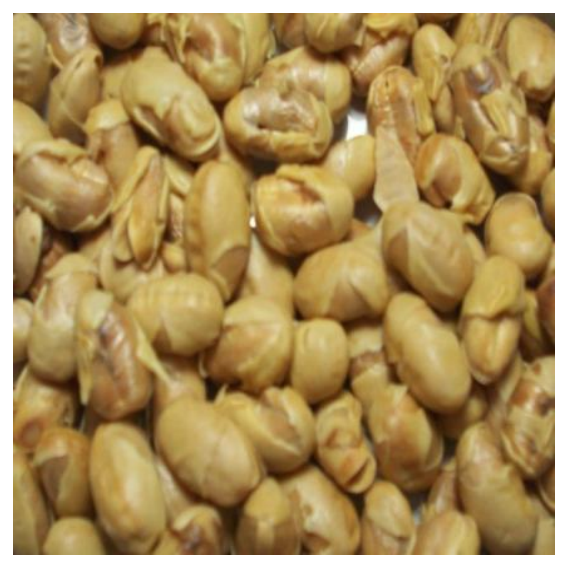

(c)

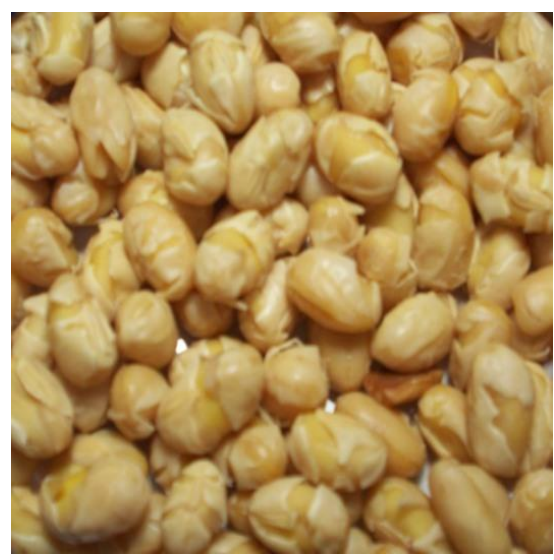

(b)

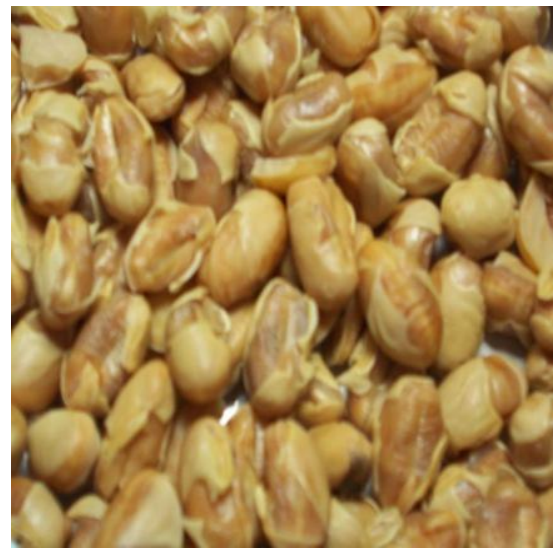

(d)

Figura 2.3 Imágenes de los cuatro productos bajo estudio: (a) humectado y secado a $60^{\circ} \mathrm{C}$, (b) remojado y secado a $60^{\circ} \mathrm{C}$, (c) remojado y secado-tostado a $140^{\circ} \mathrm{C}$ y (d) remojado, cocido y secado-tostado a $140^{\circ} \mathrm{C}$. 
Tabla 2.2. Volumen y diámetro equivalente de productos de grano entero de soja determinados durante el secado o secado-tostado en lecho fluidizado llevado a cabo luego del humectado, el remojado o la cocción, mediante picnometría.

\begin{tabular}{|c|c|c|c|}
\hline Muestra & $W($ dec., b.s. $)$ & $V\left(\mathrm{x} 10^{7} \mathrm{~m}^{3}\right)$ & $D_{e}\left(\mathrm{x} 10^{3} \mathrm{~m}\right)$ \\
\hline \multirow{7}{*}{$\begin{array}{l}\text { Humectada y secada a } 60^{\circ} \mathrm{C} \\
\text { (HS) }\end{array}$} & 0.213 & 1.475 & 6.556 \\
\hline & 0.186 & 1.507 & 6.603 \\
\hline & 0.181 & 1.510 & 6.608 \\
\hline & 0.165 & 1.502 & 6.597 \\
\hline & 0.142 & 1.410 & 6.450 \\
\hline & 0.119 & 1.440 & 6.510 \\
\hline & 0.109 & 1.430 & 6.480 \\
\hline \multirow{9}{*}{$\begin{array}{l}\text { Remojada y secada a } 60^{\circ} \mathrm{C} \\
\text { (RS) }\end{array}$} & 1.450 & 3.079 & 8.380 \\
\hline & 1.065 & 2.786 & 8.103 \\
\hline & 0.88 & 2.579 & 7.898 \\
\hline & 0.862 & 2.558 & 7.875 \\
\hline & 0.824 & 2.507 & 7.823 \\
\hline & 0.516 & 2.610 & 7.929 \\
\hline & 0.388 & 2.608 & 7.927 \\
\hline & 0.241 & 2.570 & 7.888 \\
\hline & 0.182 & 2.536 & 7.853 \\
\hline \multirow{9}{*}{$\begin{array}{l}\text { Remojada y secada-tostada a } \\
140^{\circ} \mathrm{C} \text { (RST) }\end{array}$} & & & \\
\hline & 1.450 & 3.079 & 8.380 \\
\hline & 0.867 & 2.619 & 7.939 \\
\hline & 0.613 & 2.199 & 7.489 \\
\hline & 0.304 & 2.049 & 7.314 \\
\hline & 0.115 & 2.108 & 7.384 \\
\hline & 0.061 & 2.013 & 7.271 \\
\hline & 0.043 & 1.967 & 7.216 \\
\hline & 0.034 & 2.198 & 7.488 \\
\hline \multirow{8}{*}{$\begin{array}{l}\text { Remojada-cocida y secada- } \\
\text { tostada a } 140^{\circ} \mathrm{C}(\mathrm{RCST})\end{array}$} & 1.494 & 2.896 & 8.288 \\
\hline & 0.832 & 2.385 & 7.315 \\
\hline & 0.792 & 2.192 & 7.423 \\
\hline & 0.711 & 1.906 & 7.140 \\
\hline & 0.273 & 1.895 & 7.127 \\
\hline & 0.102 & 1.781 & 6.982 \\
\hline & 0.056 & 1.749 & 6.906 \\
\hline & 0.026 & 1.630 & 6.778 \\
\hline
\end{tabular}

Por tanto, la relación de contracción volumétrica durante el tratamiento en el lecho fluidizado se incrementó con mayores valores de humedad inicial y temperaturas crecientes de aire. Se consideró de esta manera a este parámetro (relación de 
contracción volumétrica) como un indicador experimental interesante, el cual resultó superior en condiciones que involucran la formación de productos más blandos.

Con respecto a la forma del grano entero de soja, se observó que las muestras se hinchaban y deformaban durante el remojado o la cocción adoptando la forma típica de un poroto. Estas muestras luego se encogieron durante el secado o secado-tostado, adoptando una geometría más irregular debida a la combinación de los gradientes de humedad, altas temperaturas, ruptura de cáscara y, en el secado-tostado pérdida parcial del tegumento. En relación a la muestra que fue humectada y luego secada a $60^{\circ} \mathrm{C}$ en lecho fluidizado, dentro del rango post-cosecha de 0.21 a 0.103 dec., b.s. podemos decir que mantuvo su forma redondeada inalterada. Algunos cambios en la estructura de los alimentos procesados fueron investigados previamente por Aguilera y col. (2003) y Lewicki (2006). El encogimiento se representó mediante la relación de $\mathrm{V} / \mathrm{V}_{0}$, como función del contenido de humedad W, en lugar de la versión normalizada W/W $\mathrm{W}_{0}($ Ratti, 1994).

\subsubsection{Determinación del factor de encogimiento $a$ en equilibrio durante los tratamientos en lecho fluidizado.}

La Tabla 2.3 muestra los resultados del ajuste de uno de los parámetros de la ecuación de volumen (Ec. (2.11)) a los datos experimentales de $\mathrm{V} / \mathrm{V}_{0}$ como función de W. El coeficiente de contracción a se determinó para cada tratamiento por el procedimiento de cuadrados mínimos. Este modelo provee una predicción adecuada para el secado de la muestra humectada (HS) (Fig. 2.4a) donde el factor de encogimiento fue de 0.248 (Tabla 2.3). Esto significa que la partícula se encogió aproximadamente $0.25 \mathrm{~mm}^{3}$ por cada $\mathrm{mm}^{3}$ de agua removida. Con respecto a la muestra 
remojada y secada (RS) (Fig. 2.4b) su coeficiente de encogimiento fue de 0.389, más alto que el de la muestra HS posiblemente debido a la estructura más blanda de los granos remojados. El tratamiento RST (Fig. 2.4c) provee un coeficiente de encogimiento de 0.567 , el cual denota un colapso más importante debido a la alta temperatura de fluidización. Con relación al proceso RCST (Fig. 2.4d), el factor promedio de encogimiento fue de 0.745 . Esto pudo haber sido causado por el efecto combinado del ablandamiento generado durante la cocción y las altas temperaturas de secado-tostado. Por tanto, la determinación cuantitativa de un coeficiente de contracción como una fracción del colapso máximo durante los tratamientos en lecho fluidizado es congruente con el cálculo experimental de la relación de contracción volumétrica descrita previamente en la sección 2.4.2. Roos (1995) y Aguilera (2003), observaron modificaciones estructurales en varios productos secados a contenidos bajos de humedad.

Tabla 2.3. Ajuste del modelo de volumen de grano de soja como función del contenido de humedad (Ec. (2.11)) durante el tratamiento en lecho fluidizado para determinar el coeficiente promedio de encogimiento a. El error estándar de los parámetros ajustados se da entre paréntesis.

\begin{tabular}{lccc}
\hline Tratamiento & & coeficiente de encogimiento $a$ & $r^{2}$ \\
\hline Humectado-secado a $60^{\circ} \mathrm{C}$ & $(\mathrm{HS})$ & $0.248(0.152)$ & 0.999 \\
Remojado-secado a $60^{\circ} \mathrm{C}$ & $(\mathrm{RS})$ & $0.389(0.048)$ & 0.997 \\
Remojado, secado-tostado a $140^{\circ} \mathrm{C}$ & $(\mathrm{RST})$ & $0.567(0.031)$ & 0.997 \\
Remojado, cocción, secado-tostado a $140^{\circ} \mathrm{C}(\mathrm{RCST})$ & $0.745(0.050)$ & 0.994 \\
\hline
\end{tabular}




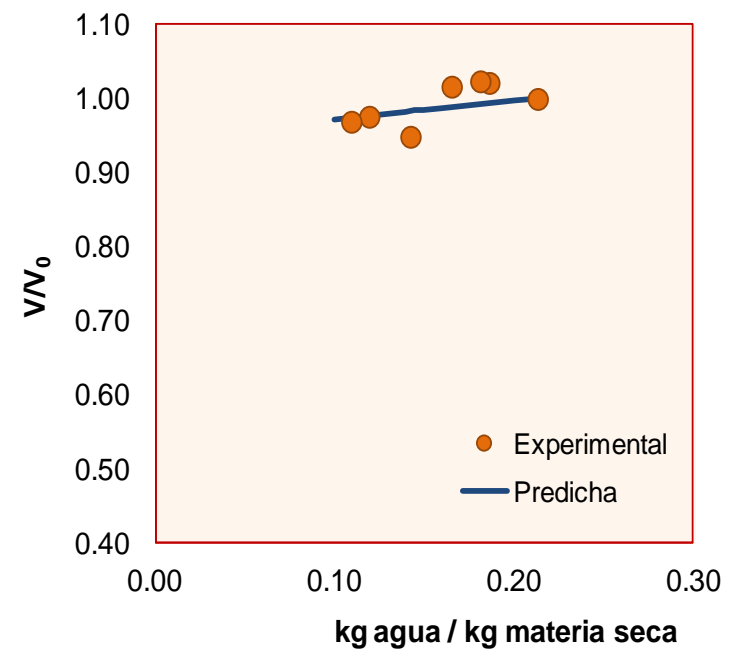

(a)

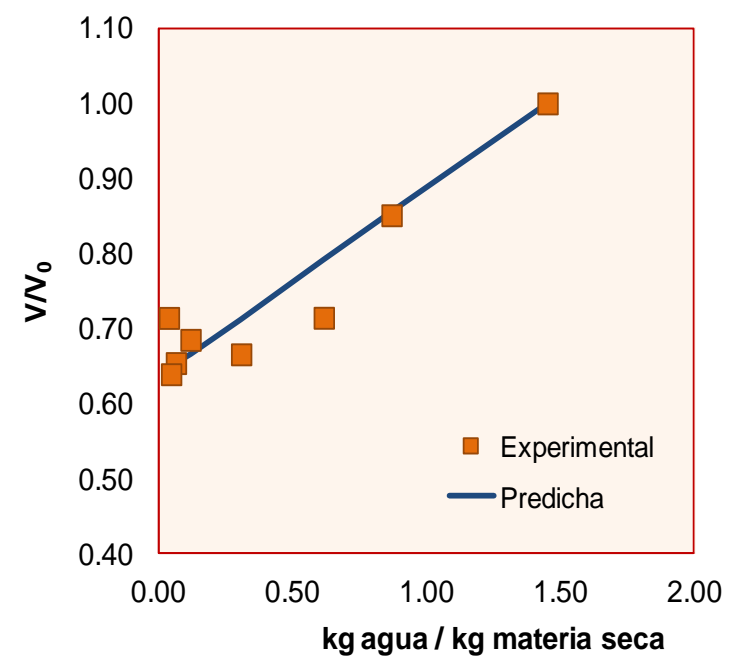

(c)

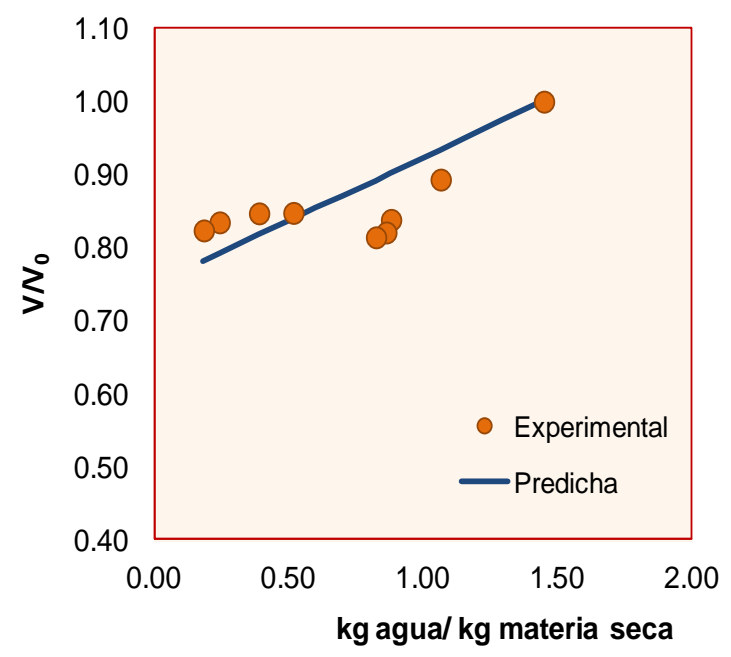

(b)

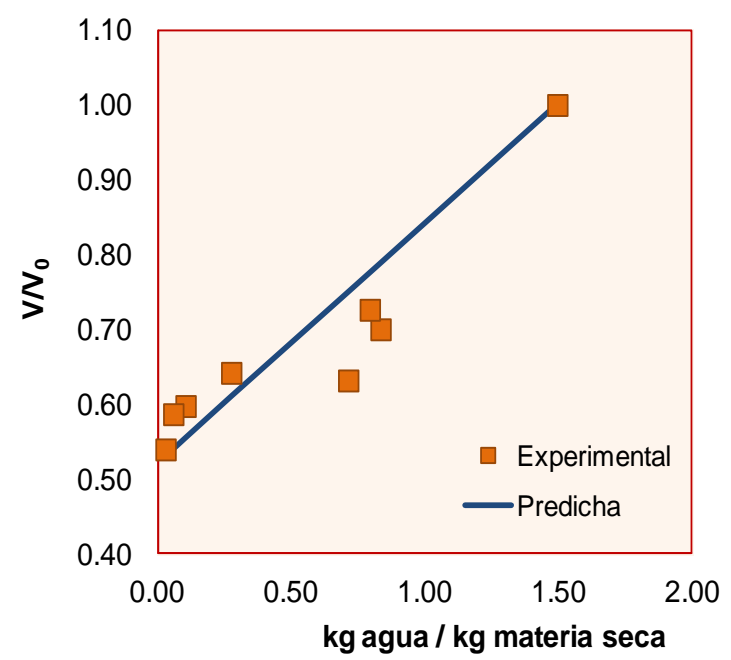

(d)

Figura 2.4. Volumen de grano de soja entero (normalizado con su valor inicial) en función del contenido de humedad durante la fluidización. Los valores predichos por la Ec. (2.10) (Línea sólida) y datos experimentales (símbolos) se graficaron para las siguientes muestras: $(a)$ humectada y secada a $60^{\circ} \mathrm{C},(b)$ remojada y secada a $60^{\circ} \mathrm{C},(c)$ remojada y secada-tostada a $140^{\circ} \mathrm{C}, \mathrm{y}(d)$ remojada, cocida y secada-tostada a $140^{\circ} \mathrm{C}$. 


\subsubsection{Predicción de la densidad de partícula como función del contenido de humedad.}

En la Figura 2.6, se graficaron las densidades experimentales de grano entero de soja en función del contenido de humedad, junto con los valores predichos por el modelo (Ec. (2.12)). Esta expresión utiliza la densidad inicial de partícula y el coeficiente de contracción de equilibrio presentado en la Tabla 2.3. Los valores de densidad decrecen con la reducción del contenido de humedad en todos los tratamientos en lecho fluidizado, en concordancia con una investigación llevada a cabo previamente por Kashaninejad y col., (2008), quienes estudiaron cuatro variedades de soja en el rango de humedades perteneciente a post-cosecha $(0.087-0.316 \mathrm{~kg}$ agua $/ \mathrm{kg}$ materia seca). Otros autores también encontraron comportamientos similares en semillas de mijo (Baryeh, 2002), semillas de quinoa (Vilche y col., 2003), y granos de cacao (BartPlange y Baryeh, 2003). Ellos describieron la densidad como una función de la humedad mediante modelos lineales empíricos.

Con respecto al análisis estadístico, el test de Tukey indicó que las curvas del volumen y densidad de soja para contenidos de humedad decrecientes durante la fluidización fueron significativamente diferentes $(\mathrm{p}<0.05)$ en los cuatro tratamientos.

Las predicciones de la Ecuación (2.12) son adecuadas para las muestras humectadas-secadas (HS) y remojadas, secadas-tostadas (RST). Sin embargo, en granos remojados-secados (RS) las densidades calculadas fueron menores que los valores experimentales, mientras, en las muestras remojadas, cocidas y secadas-tostadas (RCST), se halló una situación opuesta, con predicciones más altas que los valores medidos. 


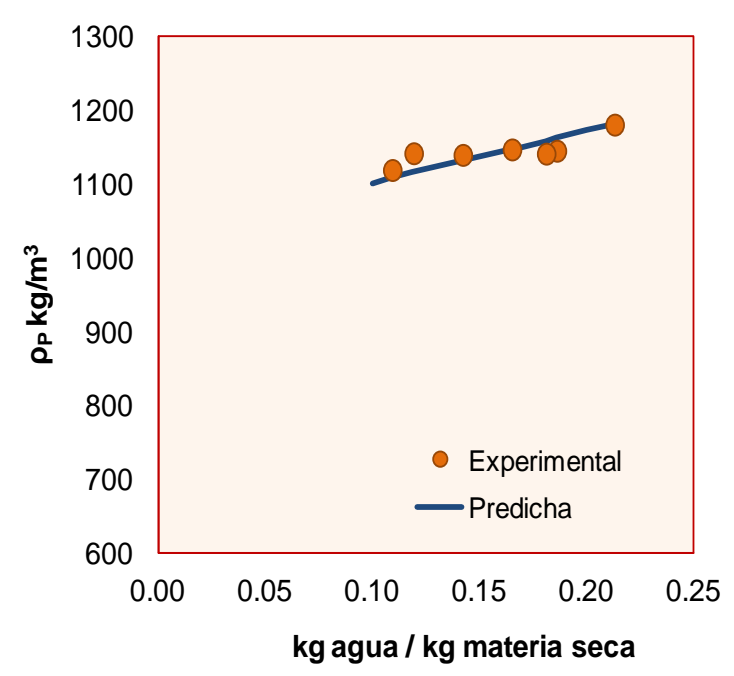

(a)

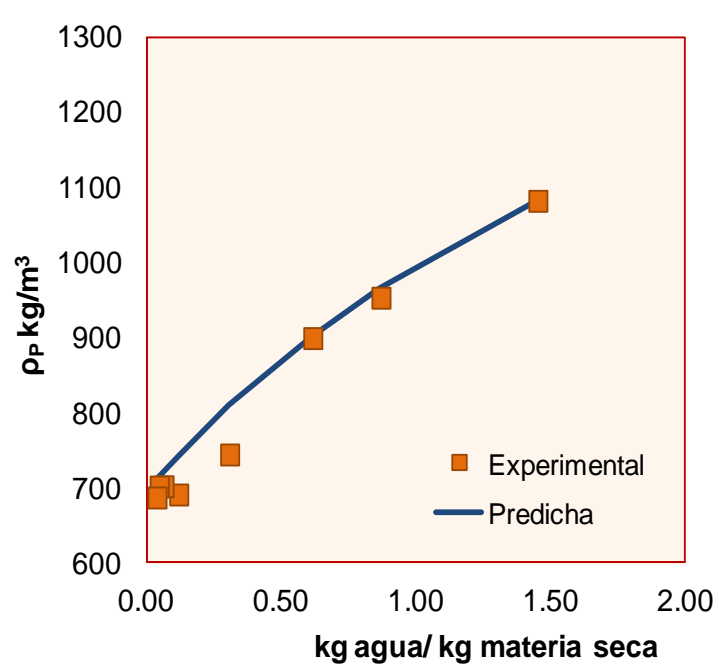

(c)

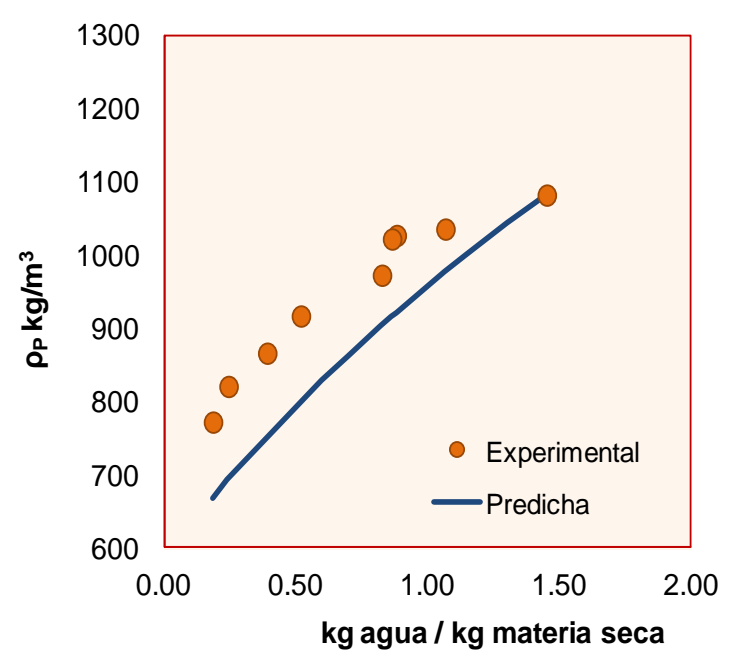

(b)

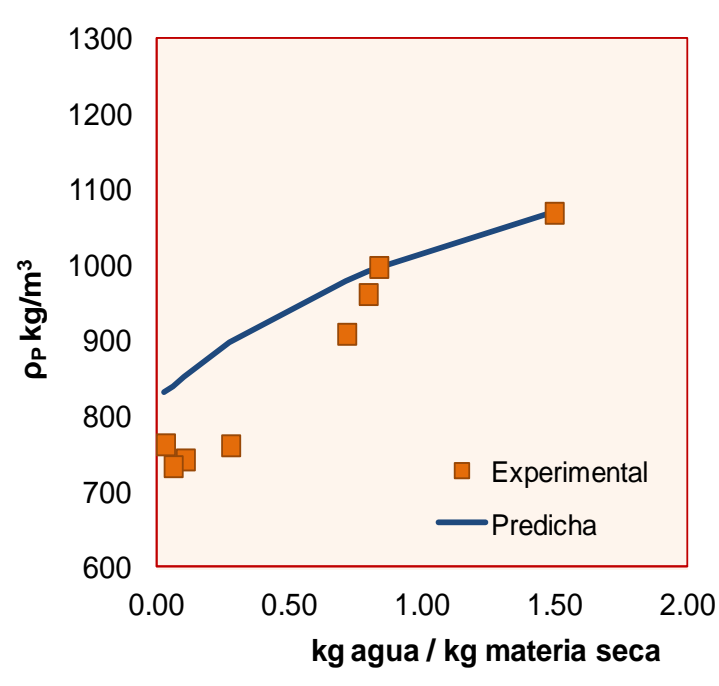

(d)

Figura 2.5. Densidad de grano entero de soja como función del contenido de humedad, valores predichos por la Ec. (2.12) (Línea sólida) y datos experimentales (símbolos) para las siguientes muestras: $(a)$ humectada y secada a $60^{\circ} \mathrm{C},(b)$ remojada y secada a $60^{\circ} \mathrm{C},(c)$ remojada y secada-tostada a $140^{\circ} \mathrm{C}$, y $(d)$ remojada, cocida y secada-tostada a $140^{\circ} \mathrm{C}$.

Como la calidad predictiva general fue bastante irregular, se llevó a cabo un estudio de sensibilidad variando el valor de la densidad inicial $\left(\rho_{0}\right)$ en la Ecuación (2.12) 
para la muestra RCST. Se emplearon tres valores: $\rho_{0}$ que es el valor experimental, 1.05 $\rho_{0}$ y $0.95 \rho_{0}$. Esta variación de $\rho_{0}$ en un $( \pm 5 \%)$ se encuentra dentro del error experimental y representa un $\pm 10 \%$ del valor de densidad predicho a $W=0$. Los resultados se graficaron en la Fig. 2.6.

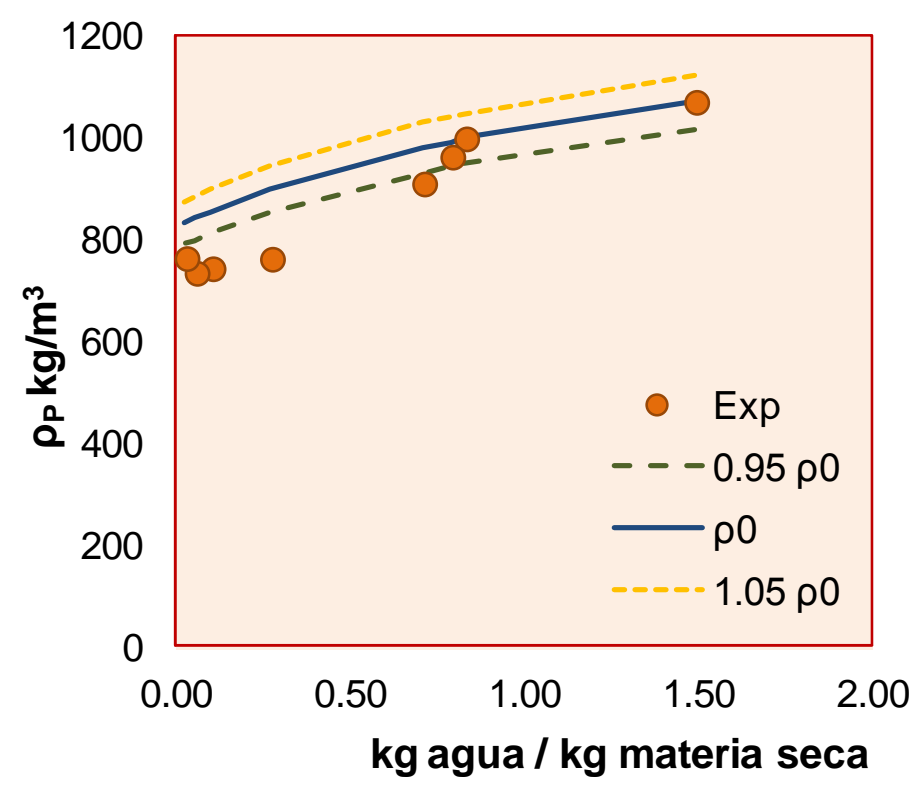

Figura 2.6. Densidad de soja remojada, cocida y secada-tostada, en función del contenido de humedad durante el secado-tostado en lecho fluidizado a $140^{\circ} \mathrm{C}$. Valores calculados por la Ec. (2.12) usando los siguientes valores de densidad inicial $\left(\rho_{0}\right)$ : $1016.18(--), 1066.69(-), 1123.14(--)$ en $\mathrm{kg} / \mathrm{m}^{3}$. Los datos picnométricos (•) también se incluyeron.

Los valores calculados muestran una alta sensibilidad a los cambios en $\rho_{0}$ dentro del error experimental. Dada esta fuerte sensibilidad, se consideró más adecuada una versión semi-empírica de las Ecuaciones (2.11) y (2.12). La modificación consistió en reemplazar el producto

$\left[a \rho_{0}\right]$ por un parámetro ajustado, $K_{v}$. Entonces, la Ecuación (2.11) se transformó en la Ecuación (2.16): 


$$
\frac{V}{V_{0}}=1-K_{v} \frac{\left(W_{0}-W\right)}{\rho_{w}\left(1+W_{0}\right)}
$$

Los resultados de este nuevo ajuste se muestran en la Tabla 2.4.

Tabla 2.4. Ajuste alternativo del modelo de volumen de soja como función del contenido de humedad (Ec. (2.16)) durante el tratamiento en lecho fluidizado para determinar el parámetro semi-empírico $\mathrm{K}_{v}$, relacionado con el producto del coeficiente de contracción y la densidad inicial del producto.

\begin{tabular}{lccc}
\hline \multicolumn{1}{l}{ Tratamiento } & & $K_{v}$ & $r^{2}$ \\
\hline Humectado-secado a $60^{\circ} \mathrm{C}$ & $(\mathrm{HS})$ & $292.92(179.34)$ & 0.999 \\
Remojado-secado a $60^{\circ} \mathrm{C}$ & $(\mathrm{RS})$ & $421.39(51.77)$ & 0.997 \\
Remojado, secado-tostado a $140^{\circ} \mathrm{C}$ & $(\mathrm{RST})$ & $614.13(33.64)$ & 0.997 \\
Remojado, cocción, secado-tostado a $140^{\circ} \mathrm{C}$ (RCST) & $797.18(53.09)$ & 0.992 \\
\hline
\end{tabular}

Aunque las predicciones de la Ecuación (2.16) son igual de satisfactorias que las de la Ecuación (2.11), esta provee el coeficiente de ajuste $K_{v}$ el cual es requerido para modificar el modelo de densidad, y reemplazar el producto $\left[a \rho_{0}\right]$.

$$
\rho=K_{\rho} \frac{(1+W)}{\left[1+W_{0}-K_{v} \frac{\left(W_{0}-W\right)}{\rho_{w}}\right]}
$$

Por su parte, la Ecuación (2.17) se ajustó a los datos experimentales de densidadcontenido de humedad, usando $K_{\rho}$ como parámetro de ajuste, reemplazando al valor de 
la densidad inicial $\rho_{0}$. Los resultados del ajuste por cuadrados mínimos se muestran en la Tabla 2.5.

Tabla 2.5. Ajuste del modelo de densidad de grano de soja como función del contenido de humedad (Ec. (2.17)) durante el tratamiento en lecho fluidizado para determinar el parámetro semi-empírico $K_{\rho}$, relacionado con la densidad inicial del producto. En esta versión del modelo, se utilizan los valores del parámetro $K_{v}$ previamente presentados en la Tabla 2.4.

\begin{tabular}{lccc}
\hline \multicolumn{1}{l}{ Tratamiento } & & $K_{\rho}$ & $r^{2}$ \\
\hline Humectado-secado a $60^{\circ} \mathrm{C}$ & $(\mathrm{HS})$ & $1183.31(6.21)$ & 1.000 \\
Remojado-secado a $60^{\circ} \mathrm{C}$ & $(\mathrm{RS})$ & $1180.87(21.21)$ & 0.997 \\
Remojado, secado-tostado a $140^{\circ} \mathrm{C}$ & $(\mathrm{RST})$ & $1055.37(11.22)$ & 0.997 \\
Remojado, cocción, secado-tostado a $140^{\circ} \mathrm{C}$ (RCST) & $999.70(22.73)$ & 0.996 \\
\hline
\end{tabular}

Las predicciones de la Ecuación (2.17) se graficaron en función del contenido de humedad durante la etapa de fluidización (Fig. 2.7), para los cuatro tratamientos llevados a cabo (HS, RS, RST y RCST). La calidad predictiva del modelo modificado de densidad fue mejor y más uniforme respecto de las obtenidas por la Ecuación (2.12). 


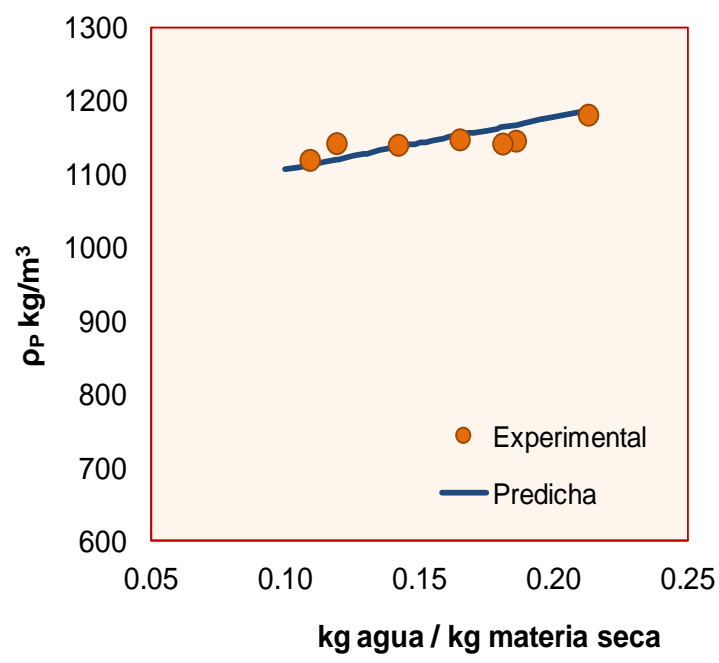

(a)

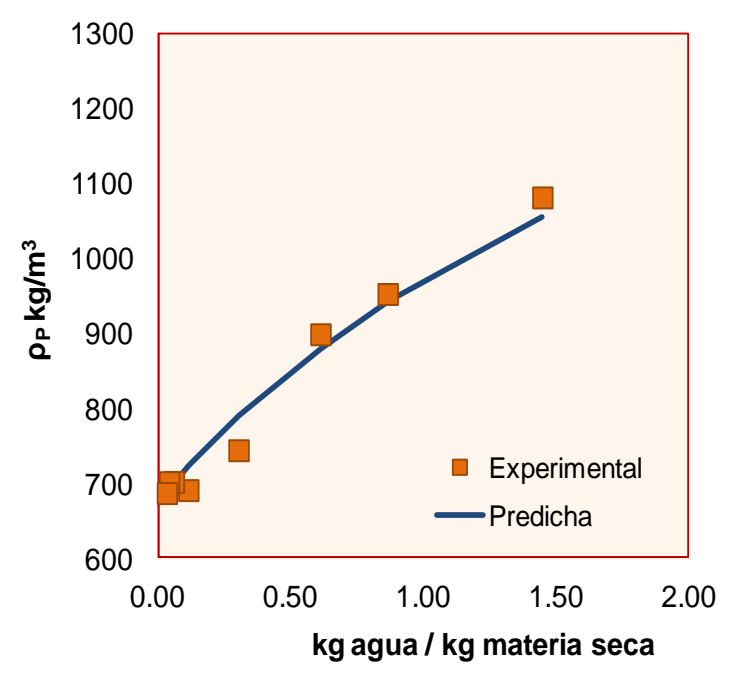

(c)

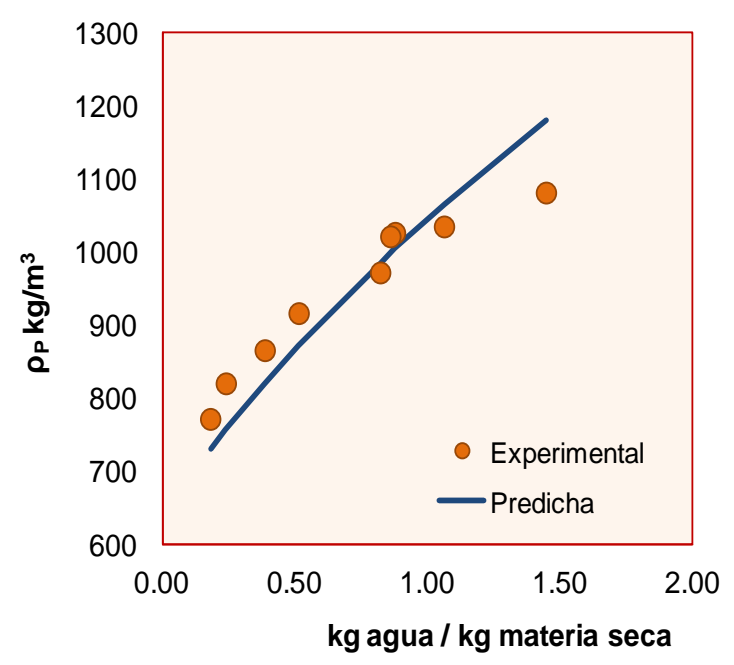

(b)

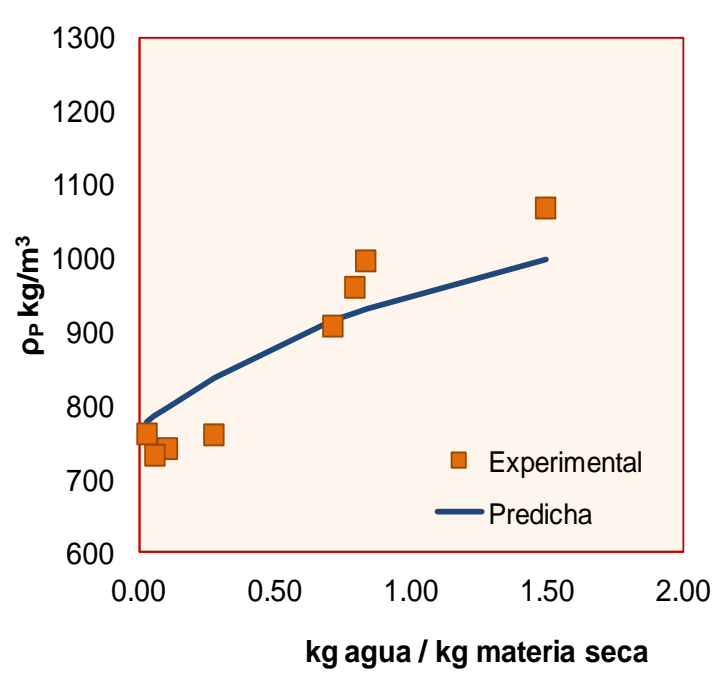

(d)

Figura 2.7. Densidad de grano de soja en función del contenido de humedad. Valores predichos por la Ec. (2.17) (Línea continua) y datos experimentales (símbolos) para las siguientes muestras: $(a)$ humectada y secada a $60^{\circ} \mathrm{C},(b)$ remojada y secada a $60^{\circ} \mathrm{C},(c)$ remojada y secada-tostada a $140^{\circ} \mathrm{C}, \mathrm{y}(d)$ remojada, cocida y secada-tostada a $140^{\circ} \mathrm{C}$.

Se estimó un coeficiente de encogimiento aparente $a_{a}$ mediante la relación $\mathrm{K}_{v} \approx \mathrm{K}_{\rho} a_{a}$, la cual surge al transformar la Ec. (2.11) en la Ec. (2.16), y la Ec. (2.12) en la Ec. (2.17). De esta manera observamos que los valores de $a_{a}$ que se presentan en la 
Tabla 2.6 muestran concordancia con los valores de $a$ mostrados en la Tabla 2.3. Por tanto, se considera que los modelos semi-empíricos modificados (Ec. (2.16) y Ec. (2.17)) mantienen su sentido físico.

Tabla 2.6. Un coeficiente de encogimiento aparente $a_{a}$ estimado por la relación $\mathrm{K}_{v} \approx \mathrm{K}_{\rho} a_{a}$. Como los valores presentados son similares a los del coeficiente $a$ presentados en la Tabla 2.3, los modelos semi-empíricos mantienen su sentido físico.

Tratamiento $a_{a}$

Humectado-secado a $60^{\circ} \mathrm{C}(\mathrm{HS})$ 0.247

Remojado-secado a $60^{\circ} \mathrm{C}(\mathrm{RS})$ 0.357

Remojado, secado-tostado a $140^{\circ} \mathrm{C}$ (RST) 0.582

Remojado, cocción, secado-tostado a $140^{\circ} \mathrm{C}$ (RCST) 0.797 


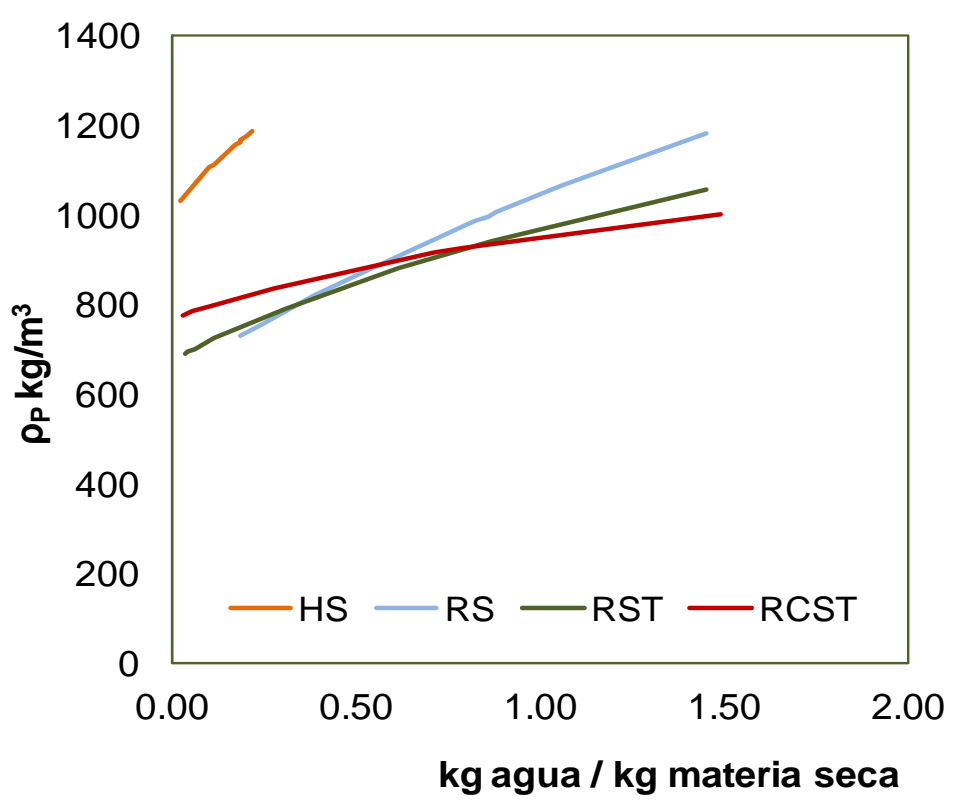

Figura 2.8. Densidad de grano de soja en función del contenido de humedad. Valores predichos por la Ec. (2.17), para las siguientes muestras: (a) humectada y secada a $60^{\circ} \mathrm{C}$ (HS), (b) remojada y secada a $60^{\circ} \mathrm{C}(\mathrm{RS}),($ c $)$ remojada y secada-tostada a $140^{\circ} \mathrm{C}(\mathrm{RST})$, y $(d)$ remojada, cocida y secada-tostada a $140^{\circ} \mathrm{C}(\mathrm{RCST})$.

Los granos de soja son sistemas complejos y su comportamiento es gobernado por la transición de fases de los polímeros como los hidratos de carbono y proteínas dicho fenómeno se ve afectado por el contenido de agua. El agua actúa como un plastificante, disminuyendo la temperatura de transición vítrea de la matriz (Bhandari y Howes, 1999). En vista de la disminución de la densidad con el contenido de humedad, los cambios más relevantes en la estructura durante el tratamiento en lecho fluidizado son la creación de poros los cuales están ausentes en el grano crudo, esto conduce a la creación de un producto crocante y fácil de consumir. 


\subsection{Extensión del análisis previo en condiciones de temperaturas elevadas.}

Dado que el desarrollo propuesto para la elaboración de producto tipo snack a base de grano entero de soja, involucra temperaturas del orden de $140^{\circ} \mathrm{C}$. Se consideró conveniente extender el análisis de las propiedades físicas y geométricas del grano remojado y secado-tostado a cuatro temperaturas: $100,120,140$ y $160^{\circ} \mathrm{C}$.

Se seleccionó el tratamiento RST en lugar del tratamiento RCST porque si bien ambos productos presentan la apariencia propia de un alimento tostado, el mayor grado de contracción experimentado en el tratamiento RCST origina un producto no tan poroso. Además el tratamiento de cocción incrementa el tiempo de proceso y el gasto energético.

La metodología de trabajo es la misma que se describió en la Sección de Materiales y métodos de este Capítulo. Los resultados encontrados se detallan a continuación.

\subsubsection{Determinación del factor de encogimiento $a$ en equilibrio durante los tratamientos en lecho fluidizado a elevadas temperaturas.}

La Tabla 2.7 muestra los resultados del ajuste de uno de los parámetros de la ecuación de volumen (Ec. (2.11)) a los datos experimentales de $\mathrm{V} / \mathrm{V}_{0}$ como función de W. En cada tratamiento el coeficiente de contracción $a$ se determinó en base al procedimiento de cuadrados mínimos. 
Tabla 2.7 Ajuste del modelo de volumen de grano de soja como función del contenido de humedad (Ec. (2.11)) durante el tratamiento en lecho fluidizado para determinar el coeficiente promedio de encogimiento $a$. Entre paréntesis se brinda el valor del error estándar de los parámetros ajustados

\begin{tabular}{lcc}
\hline Tratamiento & coeficiente de encogimiento $a$ & $r^{2}$ \\
\hline $100^{\circ} \mathrm{C}$ & $0.604(0.013)$ & 0.981 \\
$120^{\circ} \mathrm{C}$ & $0.578(0.001)$ & 0.992 \\
$140^{\circ} \mathrm{C}$ & $0.567(0.031)$ & 0.997 \\
$160^{\circ} \mathrm{C}$ & $0.559(0.030)$ & 0.997 \\
\hline
\end{tabular}

Al igual que lo observado en la Tabla 2.3, entre los tratamientos HS, RS, RST y RCST, en este caso el coeficiente de contracción volumétrica fue diferente para cada tratamiento. Un análisis estadístico de los resultados mediante un test de Tukey al 95\% de confianza demostró que existe diferencia significativa entre los valores de $a$ determinados.

En este caso el coeficiente de contracción volumétrica presentó la siguiente tendencia $a_{100}>a_{120}>a_{140}>a_{160}$. El aumento de la temperatura disminuye el encogimiento de la partícula remojada durante el secado-tostado del grano.

Si comparamos estos resultados con los del tratamiento a RCST a $140^{\circ} \mathrm{C}$ (Tabla 2.3) podemos observar, que el valor del coeficiente de contracción determinado para el tratamiento RCST fue muy superior $(a=0.745)$. Esto puede atribuirse a los efectos sobre la estructura del grano que pueden generarse por el tratamiento de cocción adicional. Si analizamos ahora, los resultados de la Tabla 2.7 el valor presentado por el tratamiento a $100^{\circ} \mathrm{C}$ fue mayor al resto, evidenciando que este tratamiento origina un mayor grado de contracción en la estructura del producto. La raíz de este fenómeno puede estar 
relacionada con la ebullición del agua. A $100^{\circ} \mathrm{C}$, el agua está en estado líquido, mientras que a temperaturas superiores, el pasaje de estado líquido a vapor se realiza probablemente en el interior del grano, expandiendo su estructura y compensando en parte la contracción al reducirse el contenido de agua.

A continuación, en la Figura 2.9, se puede apreciar el ajuste obtenido en cada situación. Los valores para el tratamiento a $140^{\circ} \mathrm{C}$ corresponden a la muestra denominada anteriormente como RST. 


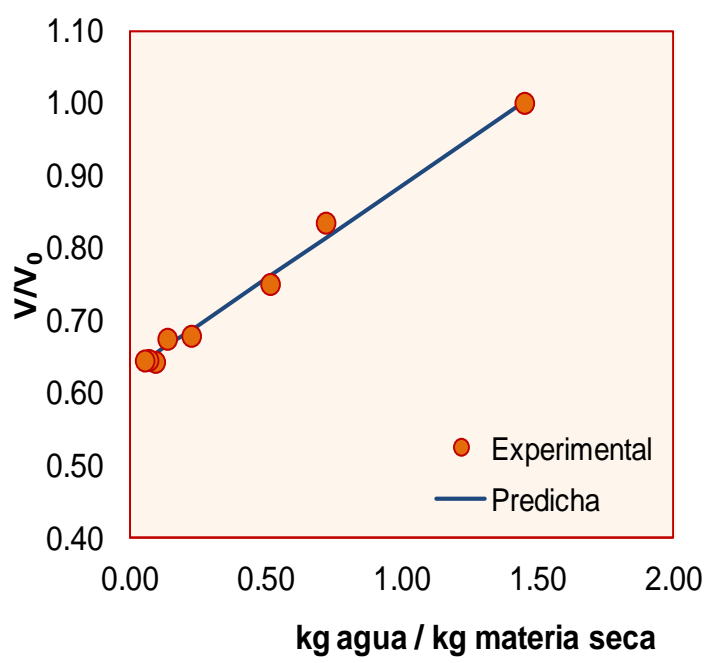

(a)

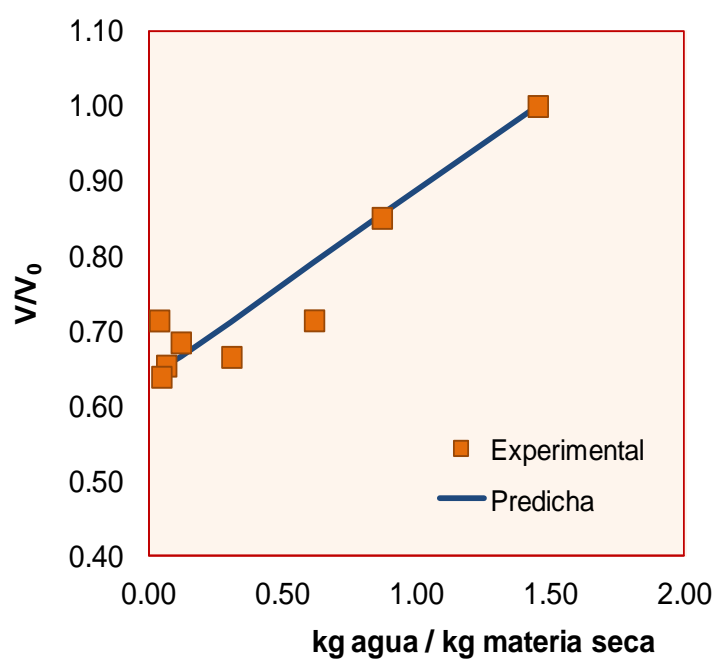

(c)

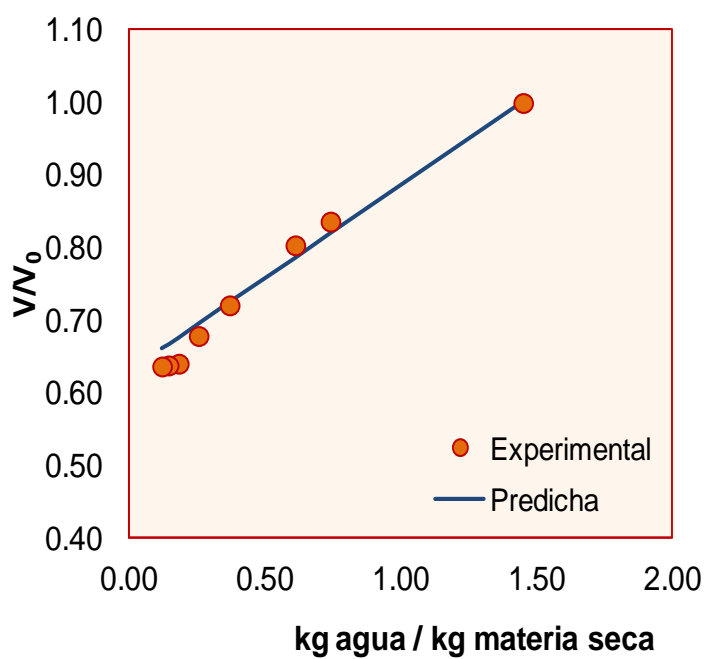

(b)

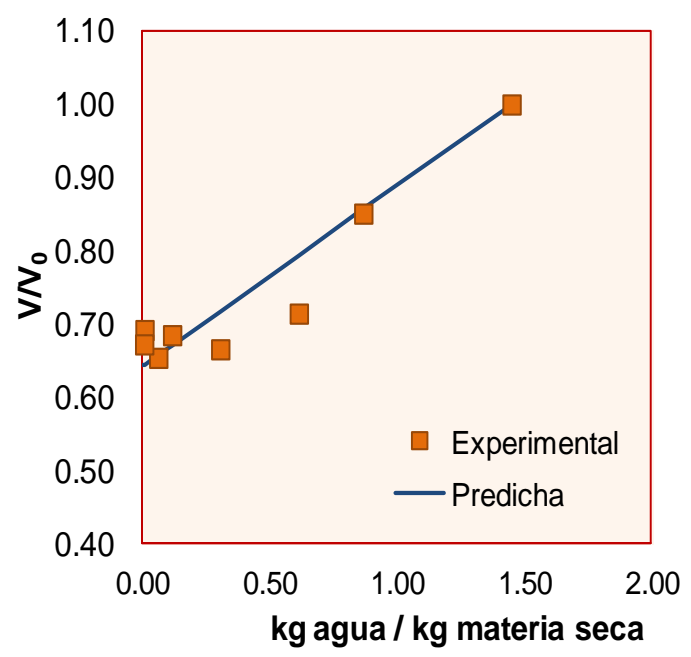

(d)

Figura 2.9. Volumen normalizado de grano de soja entero de grano entero de soja remojado y secado-tostado como función del contenido de humedad durante la fluidización. Los valores predichos por la Ec. (2.10) (Línea sólida) y datos experimentales (símbolos) se graficaron para los siguientes tratamientos: $(a) 100^{\circ} \mathrm{C},(b)$ $120^{\circ} \mathrm{C},(c) 140^{\circ} \mathrm{C}, \mathrm{y}(d) 160^{\circ} \mathrm{C}$. 
Tal como se puede apreciar en la Figura 2.9, el ajuste obtenido en todos los casos fue satisfactorio, concordando con los valores de los coeficientes de correlación presentados en la Tabla 2.7.

\subsubsection{Predicción de la densidad de partícula como función del contenido de humedad a temperaturas elevadas.}

En la Figura 2.10, se graficaron las densidades experimentales de grano entero de soja como función del contenido de humedad, junto con los valores predichos por el modelo (Ec. (2.12)). Tal como se describió en secciones previas, esta primera predicción se realizó empleando los valores del coeficiente de contracción mostrados en la Tabla 2.7 


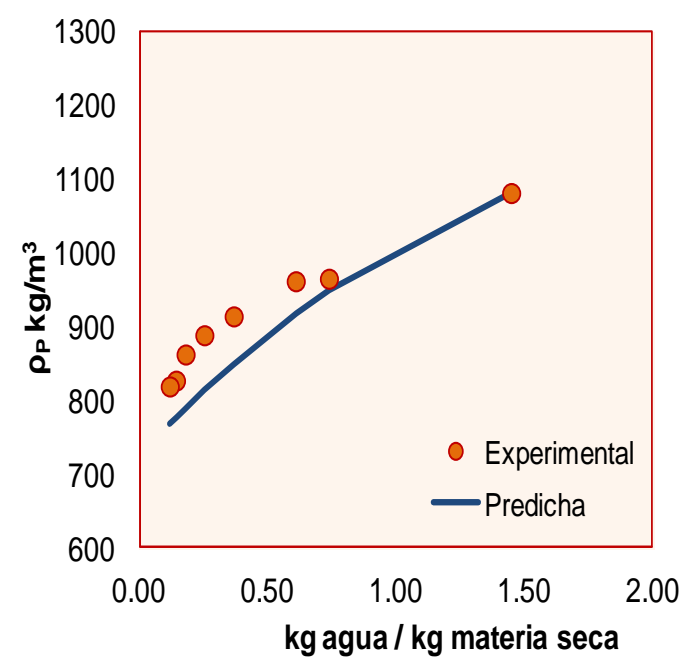

(a)

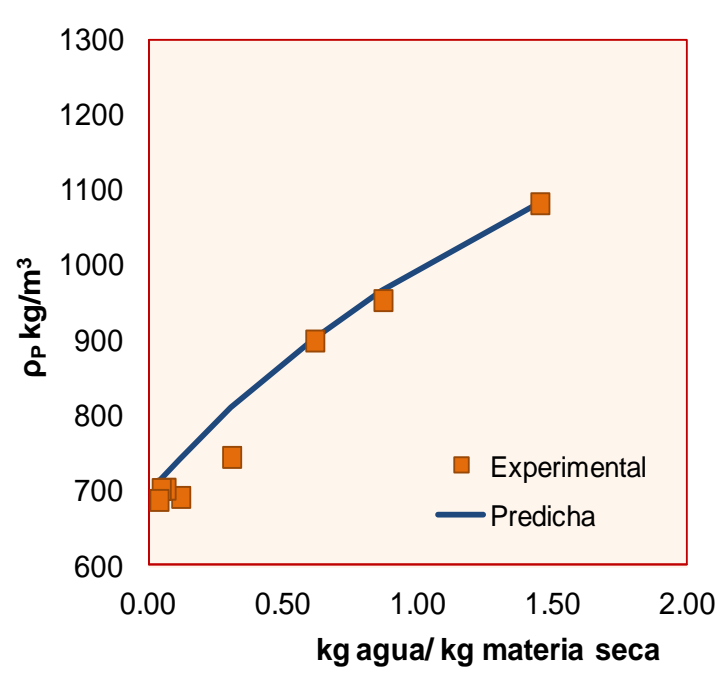

(c)

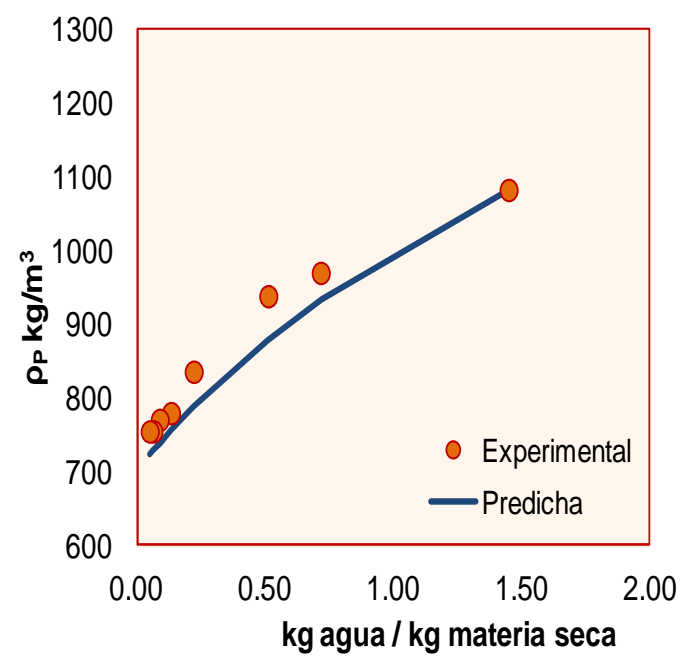

(b)

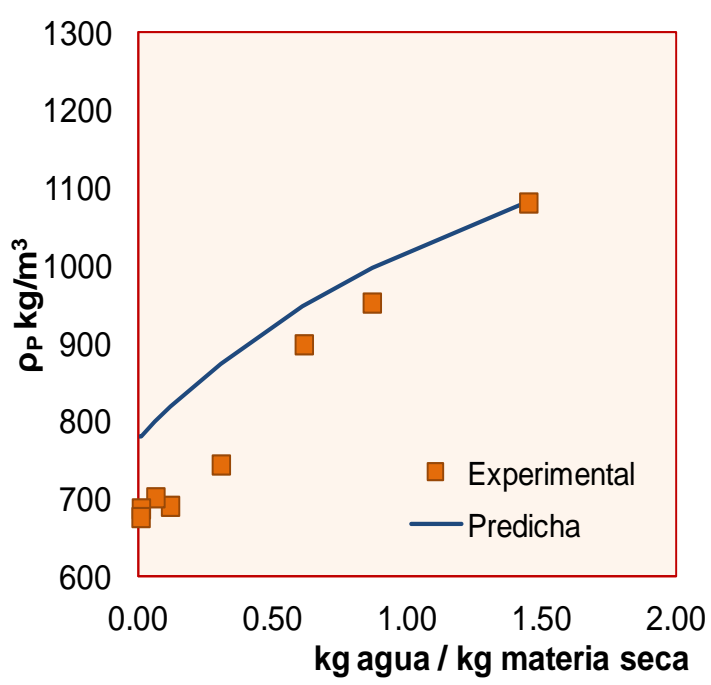

(d)

Figura 2.10. Densidad de grano entero de soja remojado y secado-tostado, como función del contenido de humedad, valores predichos por la Ec. (2.12) (Línea sólida) y datos experimentales (símbolos) para los siguientes tratamientos: (a) $100^{\circ} \mathrm{C},(b) 120^{\circ} \mathrm{C}$, (c) $140^{\circ} \mathrm{C}, \mathrm{y}(d) 160^{\circ} \mathrm{C}$.

El comportamiento descrito para cada temperatura presentó una tendencia similar a los tratamientos analizados anteriormente, es decir, se produce una disminución de la densidad a medida que se redujó el contenido de humedad. En este caso, también se observó una desviación de los valores predichos en algunas 
temperaturas. Por tal motivo, tal como se describió en la sección 2.4.4 de este capítulo, se determinaran los parámetros $K_{v}$ y $K_{\rho}$ por ajuste.

A continuación se presentan los valores obtenidos a cada temperatura, en primer lugar los correspondientes a $K_{v}$ y posteriormente los de $K_{\rho}$, con sus correspondientes coeficientes de ajuste y error asintótico estándar.

Tabla 2.8. Ajuste alternativo del modelo de volumen de soja como función del contenido de humedad (Ec. (2.16)) durante el tratamiento en lecho fluidizado para determinar el parámetro semi-empírico $\mathrm{K}_{v}$, relacionado con el producto del coeficiente de contracción y la densidad inicial del producto.

\begin{tabular}{lcc}
\hline Tratamiento & $K_{v}$ & $r^{2}$ \\
\hline $100^{\circ} \mathrm{C}$ & $654.13(14.59)$ & 0.981 \\
$120^{\circ} \mathrm{C}$ & $625.75(8.47)$ & 0.992 \\
$140^{\circ} \mathrm{C}$ & $614.13(33.64)$ & 0.997 \\
$160^{\circ} \mathrm{C}$ & $604.25(32.10)$ & 0.997 \\
\hline
\end{tabular}


Tabla 2.9 Ajuste del modelo de densidad de grano de soja como función del contenido de humedad (Ec. (2.17)) durante el tratamiento en lecho fluidizado para determinar el parámetro semi-empírico $\mathrm{K}_{\rho}$, relacionado con la densidad inicial del producto. En este procedimiento, los valores del parámetro $\mathrm{K}_{v}$ (previamente presentados en la Tabla 2.8) fueron empleados.

\begin{tabular}{lcc}
\hline Tratamiento & $K_{\rho}$ & $r^{2}$ \\
\hline $100^{\circ} \mathrm{C}$ & $1165.19(20.23)$ & 0.997 \\
$120^{\circ} \mathrm{C}$ & $1153.24(17.41)$ & 0.998 \\
$140^{\circ} \mathrm{C}$ & $1055.37(11.22)$ & 0.997 \\
$160^{\circ} \mathrm{C}$ & $1060.94(10.62)$ & 0.977 \\
\hline
\end{tabular}




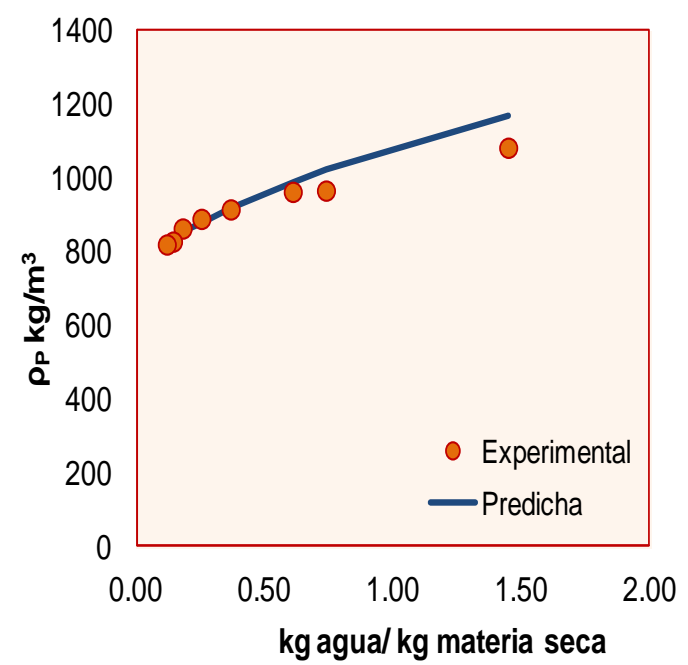

(a)

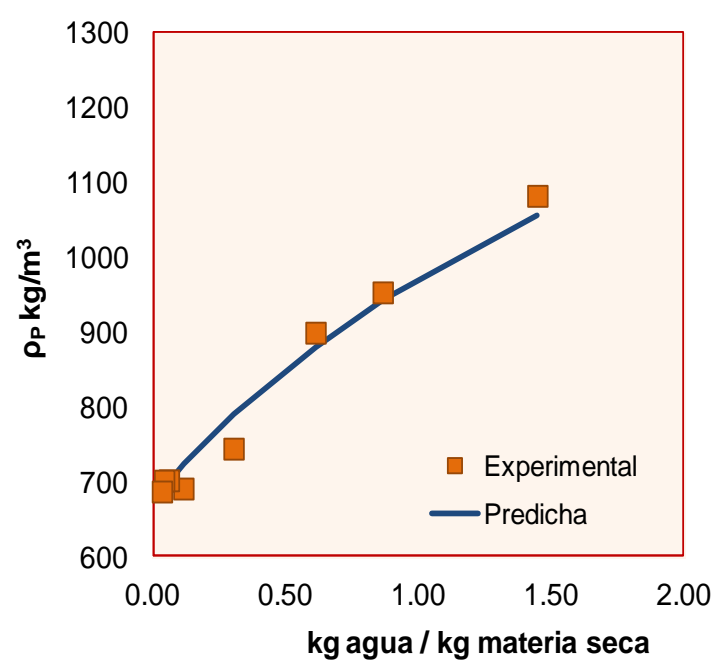

(c)

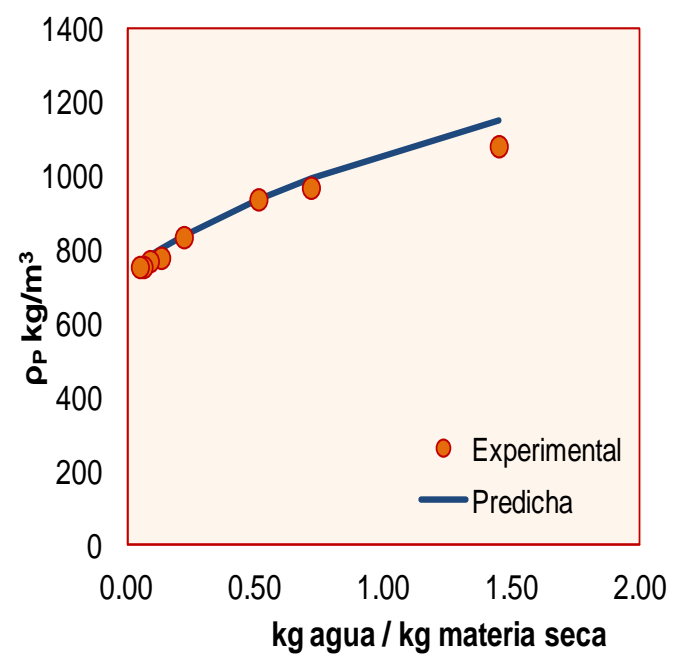

(b)

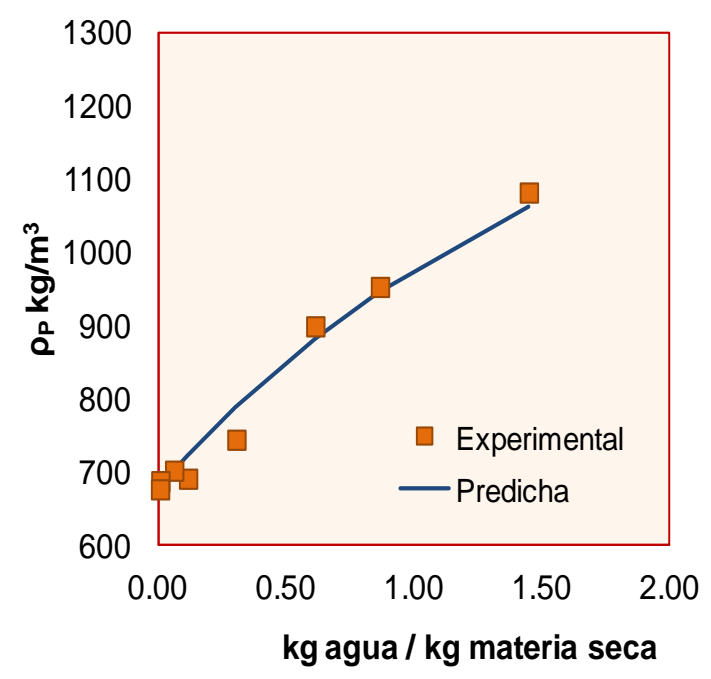

(d)

Figura 2.11. Densidad de grano de soja remojado y secado-tostado como función del contenido de humedad. Valores predichos con la Ec. (2.17) (Línea sólida) y datos experimentales (símbolos) para los siguientes tratamientos: (a) $100^{\circ} \mathrm{C},(b) 120^{\circ} \mathrm{C},(c)$ $140^{\circ} \mathrm{C}, \mathrm{y}(d) 160^{\circ} \mathrm{C}$.

Las predicciones a través de la Ecuación (2.17), para cada uno de los tratamientos presentaron más uniformidad y mejoro considerablemente los resultados obtenidos con la ecuación (2.12) 


\subsection{Conclusiones.}

Se evaluaron tres etapas de un proceso de remojado, cocción y secado-tostado a $140^{\circ} \mathrm{C}$ (RCST) en lecho fluidizado para desarrollar un snack a base de grano entero de soja, así como también, un método en dos etapas en el cual las muestras remojadas fueron directamente secadas-tostadas (RST) sin incorporar la cocción en agua. Se estudiaron otros dos procesos a modo comparativo para evaluar la variación del volumen y la densidad del grano entero de soja en función del contenido de humedad durante la fluidización: remojado-secado a $60^{\circ} \mathrm{C}(\mathrm{RS})$, y humectación seguida de un secado en lecho fluidizado a $60^{\circ} \mathrm{C}(\mathrm{HS})$.

Los modelos de volumen y densidad de grano en función del contenido de humedad, basado en conceptos físicos bien fundados, se dedujeron para interpretar la expansión del grano de soja durante el remojado, y la contracción durante el secado o secado-tostado en lecho fluidizado. Los coeficientes de hinchamiento o contracción se determinaron por ajuste del modelo de volumen a los datos experimentales. El coeficiente de hinchamiento entre las muestras crudas y humectadas fue de 0.831 mientras que el valor hallado entre los estados crudo y remojado fue de 0.895 indicando que el grano se expande en menor proporción que el volumen de agua absorbida, siendo algo mayor la expansión durante el proceso de remojado.

Por su parte, los coeficientes de contracción fueron 0.248 (HS), 0.389 (RS), 0.567 (RST) y 0.745 (RCST). A medida que el tratamiento era más severo (RCST >RST $>$ RS >HS) los coeficientes de contracción fueron más altos, posiblemente porque la estructura del tejido celular fue más blanda (podría interpretarse como más gomosa experimentando un mayor colapso durante la deshidratación). 
Como los coeficientes de hinchamiento fueron más altos que los del encogimiento, el volumen de los granos después de la fluidización fue mayor que el original aun con menor contenido de humedad resultando, en consecuencia más poroso que los granos crudos.

Para mejorar la predicción del modelo de la densidad del grano de soja en función de la humedad durante el tratamiento térmico, se requirió de la definición de nuevos parámetros fenomenológicos estrechamente relacionados a la densidad de soja remojada, cocida o humectada, y al coeficiente de contracción.

Dado que el proceso propuesto para el desarrollo de un snack a base de grano entero de soja implica tratamientos con temperaturas de secado tostado de $140^{\circ} \mathrm{C}$, los coeficientes de contracción se determinaron también a otras temperaturas de tostado $\left(100,120\right.$ y $\left.160^{\circ} \mathrm{C}\right)$ al punto de ebullición se realizó un análisis adicional a temperaturas elevadas. Los coeficientes de contracción determinados mostraron la siguiente tendencia $\operatorname{RST}(100)>\operatorname{RST}(120)>\operatorname{RST}(140)>\operatorname{RST}(160)$. Esto puede deberse no solo a la modificación de la estructura del grano remojado sino también estar relacionado con la ebullición del agua. A $100^{\circ} \mathrm{C}$, por lo general el agua está en estado líquido, mientras que a mayores temperaturas, el pasaje a vapor se realiza probablemente dentro del grano, expandiendo su estructura y compensando en parte la contracción al reducirse el contenido de agua. Con respecto a la densidad, fue necesario el empleo de los nuevos parámetros de ajuste definidos en el análisis previo. Estos resultados, podrán ser de utilidad más adelante en el estudio de la cinética de secado-tostado de soja en capa delgada. 


\section{CAPÍTULO III}

ESTUDIO FLUIDODINAMICO DEL PROCESO

TÉRMICO DE FLUIDIZACIÓN DE SOJA 


\section{Introducción.}

La tecnología del secado en lecho fluidizado ha sido empleada en secadores industriales para procesar de diferentes clases de materiales como soluciones, suspensiones y partículas sólidas entre otros. En general, el desempeño de esta operación es satisfactoria para cualquier mecanismo de control de secado (sea control interno o externo). La uniformidad de la temperatura alcanzada en el lecho brinda al producto una mejor calidad en comparación con los secaderos convencionales (Fito y col., 2001).

A raíz del intenso intercambio de calor y materia gas-partícula y la distribución uniforme de la temperatura, el secado en lecho fluidizado ha ido ganando posiciones en la industria de los alimentos particularmente donde se agrega valor a las materias primas. Por ejemplo, hoy se la emplea para secar maíz precocido para polenta instantánea y como parte de procesos de producción de leche en polvo. Desde el punto de vista energético, se trata de un proceso que, si bien requiere la utilización de velocidades elevadas de aire para sustentar el lecho, presenta un elevado potencial para la recuperación de energía. Este hecho permite utilizar aire caliente a temperaturas más elevadas que en otras técnicas de secado (Di Mattia y col., 1996, Senadeera y col., 2006).

Los estudios llevados a cabo hasta el momento abarcan una gran variedad de aspectos relacionados al secado en lecho fluidizado: por ejemplo, Di Felice y Gibilaro (2004) investigaron el efecto de las paredes de la cámara de secado en la caída de presión a través del lecho, Nitz y Taranto (2007) por su parte realizaron un estudio comparativo entre un secado convencional en lecho fluidizado y uno asistido por microondas, mientras que Senadeera y col. (2006) evaluaron la influencia de la 
geometría de partícula en la cinética de secado en lecho fluidizado. En relación al secado de granos, diversos son los trabajos encontrados en la bibliografía. Entre ellos podemos mencionar el de Tosi y col. (1988) que llevaron adelante un estudio del secado en lecho fluidizado de soja, sorgo y triticale, dentro del rango de humedad post-cosecha, analizando la influencia de la altura de lecho en los parámetros fluidodinámicos para cada grano. Por su parte, Osella y col. (1997) y Soponronnarit y col. (2001) llevaron a cabo estudios de secado en lecho fluidizado a altas temperaturas en granos de soja cruda, también en condiciones de humedad post-cosecha, donde las características físicas del grano se mantenían constantes y los parámetros fluidodinámicos no variaban a lo largo del proceso. Sin embargo, no se encontraron estudios con soja remojada, o cocida y secada-tostada en lecho fluidizado. En el capítulo anterior, el estudio de la densidad y volumen de grano entero de soja remojada y cocida durante la fluidización, reveló que las partículas se encogían durante el tratamiento, y al mismo tiempo se volvían menos densas, por lo que los parámetros fluidodinámicos, por ejemplo la velocidad de mínima fluidización podrían cambiar con el tiempo durante el proceso. Por tanto, los objetivos de este capítulo fueron: (1) determinar las posibles variaciones en la velocidad de mínima fluidización $\left(V_{m f}\right)$ de la muestra remojada-cocida y parcialmente secada-tostada producida por aire caliente a $140^{\circ} \mathrm{C}$ en lecho fluidizado y (2) evaluar la influencia de la temperatura de aire en el valor de $V_{m f}$. 


\subsection{Materiales y Métodos.}

\subsubsection{Plan experimental.}

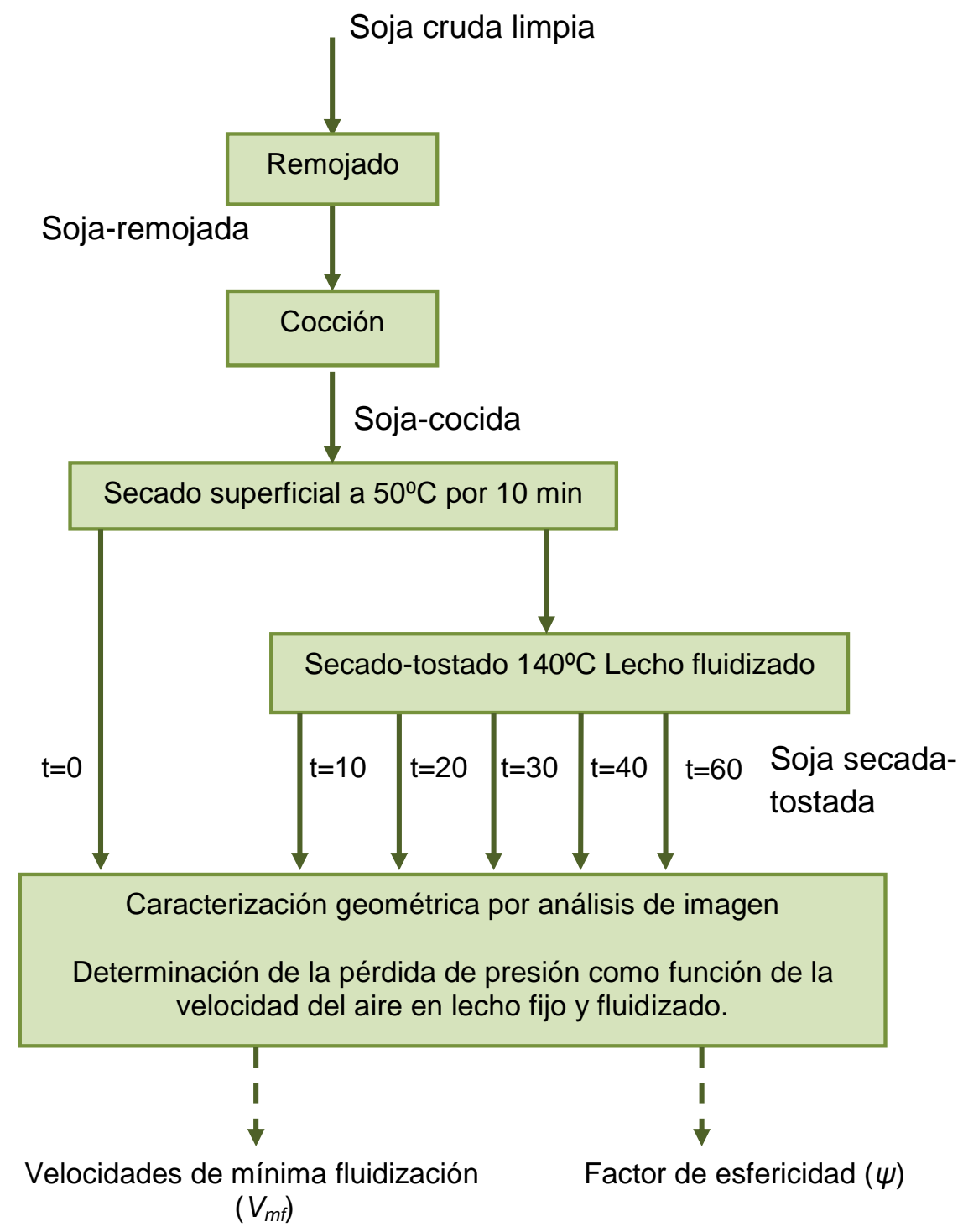

Figura 3.1. Diagrama de flujo representando el plan experimental llevado a cabo. Flujo de información (---), flujo de materiales (-).

La caracterización geométrica y la determinación de los parámetros de fluidización se llevó a cabo con las muestras obtenidas a los diferentes tiempos de tratamiento térmico. 


\subsubsection{Determinación de la densidad de lecho fijo y porosidad.}

La densidad de lecho se midió en la cámara de secado con las muestras preparadas tal como se describió en la Figura 3.1. Cada muestra $(500$ - 550 g) se pesó en una balanza de precisión OHAUS (Resolución 0.01 g) y se cargó a la cámara de secado. A efectos de normalizar el empaque del lecho, el ventilador se encendió para llevar las muestras a un estado fluido, y luego se apagó el mismo, para recuperar la condición de lecho fijo. Se ajustó levemente la masa de la muestras con el fin de obtener una altura de lecho fijo de $0.10 \mathrm{~m}$. La densidad de lecho fijo $\left(\rho_{B 0}\right)$ se calculó dividiendo la masa de la muestra por el volumen de lecho, formado por el volumen de partículas más el de los espacios vacíos que existen entre ellas.

Por otro lado, para cada muestra, la relación entre la densidad de lecho fijo y la densidad de partícula provee la fracción del lecho ocupado por los sólidos. Por tanto, la fracción de huecos del lecho se calculó mediante la siguiente ecuación:

$\varepsilon_{0}=1-\frac{\rho_{B 0}}{\rho_{P}}$

donde $\rho_{p}$ es la densidad de partícula.

\subsubsection{Preparación de las muestras por secado-tostado en lecho fluidizado.}

El proceso de secado-tostado fue llevado a cabo con aire caliente a $140^{\circ} \mathrm{C}$ en el equipo de lecho fluidizado descrito en la sección 3.2.8, del Capítulo 2. Para evitar una pérdida de material liviano por la intensa fluidización, la velocidad de aire se disminuyó manualmente desde $3.5 \mathrm{~m} / \mathrm{s}$ a t=0 a $1.7 \mathrm{~m} / \mathrm{s}$, manteniéndose el último valor entre $\mathrm{t}=40$ y 
$\mathrm{t}=60$ minutos. Las velocidades fueron suficientes para mantener un alto grado de mezclado y así generar un tratamiento térmico uniforme. Todas las experiencias se realizaron por triplicado. Se extrajeron muestras a distintos tiempos entre 0 y 60 minutos de proceso, las que se colocaron en frascos herméticos a $10^{\circ} \mathrm{C}$ por $24 \mathrm{~h}$ para asegurar una distribución uniforme de humedad. Este aspecto se consideró muy importante para la determinación picnométrica del volumen y densidad de la soja, como se ha informado en el Capítulo 2 del presente trabajo.

\subsubsection{Caracterización geométrica mediante análisis de imagen.}

Se modificó un programa Matlab previamente, desarrollado por Goñi y Purlis, (2010) para calcular los ejes del grano de soja de distintas muestras, usando fotografías digitales. Las imágenes fueron tomadas con una cámara digital Kodak M753, usando una resolución de 2292 x 3056 pixeles. Se tomaron dos fotografías de cada muestra (20 granos), una de ellas mostrando los granos desde el plano frontal y otra desde una vista lateral. El programa Matlab lee imágenes en formato JPG junto con un factor de conversión, un cuadrado completamente blanco de dimensiones conocidas, que permite convertir píxeles en milímetros. Como resultado intermedio del programa, se muestra un histograma de intensidades a partir del cual debe seleccionarse manualmente un umbral para ajustar el contraste de la imagen; el programa genera así una imagen binaria de los granos de soja en blanco y del fondo en negro, a partir de la cual se calculan automáticamente los ejes en cada imagen. El fondo y la incidencia de la luz deben seleccionarse adecuadamente para mejorar el contraste y asegurar una buena segmentación. 
Se seleccionó una geometría elipsoidal para los granos de soja. La siguiente fórmula se empleó usando los tres ejes de los granos como dato, con el objetivo de calcular el área superficial (Gastón y col., 2002):

$A_{P}=\frac{\pi}{2} l_{1} l_{m}\left[\frac{l_{m}}{l_{1}}+\frac{1}{E} \operatorname{sen}^{-1} E\right]$

donde

$E=\frac{\left(l_{1}^{2}-l_{m}^{2}\right)^{1 / 2}}{l_{1}}$

El símbolo $l_{l}$ corresponde al eje mayor, siendo el símbolo $l_{m}$ el promedio del eje intermedio $\left(l_{2}\right)$ y el más pequeño $\left(l_{3}\right)$, en mm.

El factor de esfericidad, definido como la relación del área superficial de una esfera de igual volumen que la partícula, y el área superficial de ésta o una estimación de la misma, (Senadeera y col., 2006), se expresa a continuación en forma matemática

$$
\phi=\frac{\pi D_{e}^{2}}{A_{P}}
$$

donde $D_{e}$ es el diámetro equivalente de los granos de soja, calculado a partir de los datos picnométricos del Capítulo 2 e informado en la Tabla 2.2. El diámetro efectivo $D_{P}$ o diámetro de la esfera con la misma relación superficie/volumen de una partícula se calculó de acuerdo a la fórmula siguiente: 


$$
D_{P}=\phi D_{e}
$$

Los valores de $D_{P}$ son relevantes como dimensión característica de las partículas en los estudios de fluidodinámica de lechos fijos (Di Felice y Gibilaro, 2004).

\subsubsection{Análisis estadístico.}

Las determinaciones realizadas en las muestras obtenidas a los diferentes tiempos de secado-tostado, detallados en la Fig.(3.1) se llevaron a cabo por triplicado. Las diferencias entre los parámetros geométricos de las distintas muestras se evaluaron mediante el Test de Tukey (Montgomery, 1991) con un nivel de confianza del 95\%.

\subsubsection{Estudio de la fluidodinámica en condiciones de lecho fijo y fluidizado.}

Las características fluidodinámicas de las muestras preparadas por cocción más los periodos de secado-tostado de 0 a 60 minutos, se estudiaron experimentalmente para determinar las correspondientes velocidades de mínima fluidización $\left(V_{m f}\right)$. Este procedimiento se llevó a cabo a $20^{\circ} \mathrm{C}$ a través de la medición de pérdida de presión a través del lecho en función de la velocidad superficial del aire para las zonas de lecho fijo y fluidizado. La ecuación de Ergun (Ec. 3.7) se ajustó a los datos de lecho fijo a los fines de determinar sus dos parámetros $\left(K_{1}\right.$ y $\left.K_{2}\right)$. Mientras que, el valor de $V_{m f}$ se calculó a partir de un procedimiento matemático usando información de los estados fijos y fluidizados. 


\subsubsection{Determinación de los parámetros de la ecuación de Ergun.}

Para cada una de las muestras utilizadas, los datos medidos de pérdida de presión de aire por unidad de altura del lecho $\left(\Delta_{\mathrm{p}} / \mathrm{L}_{0}\right)$ se graficaron en función de la velocidad superficial del aire $\left(V_{0}\right)$. Estos últimos, se corrigieron en la región de lecho fijo, multiplicándolos por $f_{c}$, denominado factor de Coulson. Este toma en cuenta los posibles "efectos de pared" causados por el imperfecto empaque del lecho en la zona cercana a las paredes de la cámara de secado (Coulson y Richardson, 2000).

$$
f_{c}=\frac{1}{\left[1+\frac{\left(\frac{4}{D}\right)}{2\left(\frac{6}{D_{e}}\right)}\right]^{2}}
$$

donde $D$ representa el diámetro interno de la cámara de secado. El valor de $f_{\mathrm{c}}$ fue de 0.95 para la soja remojada-cocida, y 0.96 para el producto totalmente secado-tostado, por lo cual, los efectos de pared fueron considerados de poca magnitud. Aun así, dicho factor se consideró a la hora de realizar los cálculos fluidodinámicos.

La ecuación tipo Ergun se ajustó a los datos experimentales de la zona de lecho fijo:

$$
\frac{\Delta p}{L_{0}}=K_{1} \frac{\left(1-\varepsilon_{0}\right)^{2} \mu_{a} V_{0}}{\varepsilon_{0}^{3} D_{p}{ }^{2}}+K_{2} \frac{\left(1-\varepsilon_{0}\right) \rho_{a} V_{0}^{2}}{\varepsilon_{0}^{3} D_{p}}
$$


donde $\mu_{0}$ es la viscosidad de aire en $\mathrm{kg} / \mathrm{m} \mathrm{s}, \rho_{a}$ la densidad de aire, $\mathrm{kg} / \mathrm{m}^{3}$. Al investigar las características fluidodinámicas de partículas pequeñas de origen inorgánico, Ergun (1952) encontró coeficientes de los términos laminar y turbulento $\left(K_{1}\right.$ y $\left.K_{2}\right)$ iguales a 150 y 1.75 , respectivamente. Sin embargo, estos valores dependen en realidad de las características del producto (Delele y col., 2008), especialmente en partículas grandes, y deben determinarse por ajuste de la ecuación a los datos experimentales.

\subsubsection{Determinación de la velocidad de mínima fluidización $\left(V_{m f}\right)$.}

La velocidad de mínima fluidización $\left(V_{m f}\right)$ se alcanza cuando la pérdida de presión del fluido a través del lecho multiplicada por la sección transversal de éste iguala el peso del producto en el fluido. Este último se obtiene a través de la diferencia entre el peso del producto y la fuerza de empuje en el fluido (Werther, 1999). Dado que la sección transversal aparece en ambos miembros de la ecuación y se cancela la expresión matemática obtenida de esta manera resulta

$$
\Delta p=\left(\rho_{p}-\rho_{a}\right) g\left(1-\varepsilon_{m f}\right) L_{m f}
$$

donde $L_{m f}$ y $\varepsilon_{m f}$ son la altura de lecho y la fracción de huecos a $V_{0}=V_{m f}$, mientras que $g$ es la aceleración de la gravedad. Sin embargo, como se puede asumir que la masa de sólidos permanece constante durante el pasaje entre los estados fijo y fluidizado, la siguiente expresión resulta cierta

$$
\left(1-\varepsilon_{m f}\right) L_{m f}=\left(1-\varepsilon_{0}\right) L_{0}
$$


Por tanto, la Ecuación (3.9) se reemplazó en la Ecuación (3.8) para obtener

$$
\frac{\Delta p}{L_{0}\left(1-\varepsilon_{0}\right)}=\left(\rho_{p}-\rho_{a}\right) g
$$

El miembro izquierdo de la Ec.(3.10) puede reemplazarse por el miembro derecho de la Ecuación-tipo Ergun Ec. (3.7), evaluada a $V_{m f}$. Esto es posible porque, nominalmente, la $V_{m f}$ pertenece tanto a los estados fijo como al fluidizado. Trabajando algebraicamente se llega a una ecuación polinómica de $2^{\circ}$ grado

$$
K_{2} \frac{\rho_{a}}{D_{P} \varepsilon_{0}^{3}} V_{m f}^{2}+K_{1} \frac{\left(1-\varepsilon_{0}\right) \mu_{a}}{D_{P}^{2} \varepsilon_{0}^{3}} V_{m f}-\left(\rho_{p}-\rho_{a}\right) g=0
$$

donde $V_{m f}$ es la solución con sentido físico de la Ec.(3.11). Se utilizó la aproximación $\varepsilon_{\mathrm{mf}} \approx \varepsilon_{\mathrm{o}}$, porque la determinación de $\varepsilon_{m f}$ es imprecisa durante la fluidización de partículas grandes, y el procedimiento no provee un valor considerablemente distinto de $\varepsilon_{0}$ (Formisani y col., 1998).

\subsection{Resultados y Discusión.}

\subsubsection{Caracterización geométrica del grano de soja.}

La Figura 3.2, muestra un ejemplo del proceso de análisis de imagen para la muestra RCST 20 (secada-tostada por 20 minutos). El programa lee la fotografía de la imagen de soja y produce un resultado intermedio, una imagen en blanco y negro donde 
los granos aparecen en blanco. Entonces el programa procede a calcular los ejes principales.
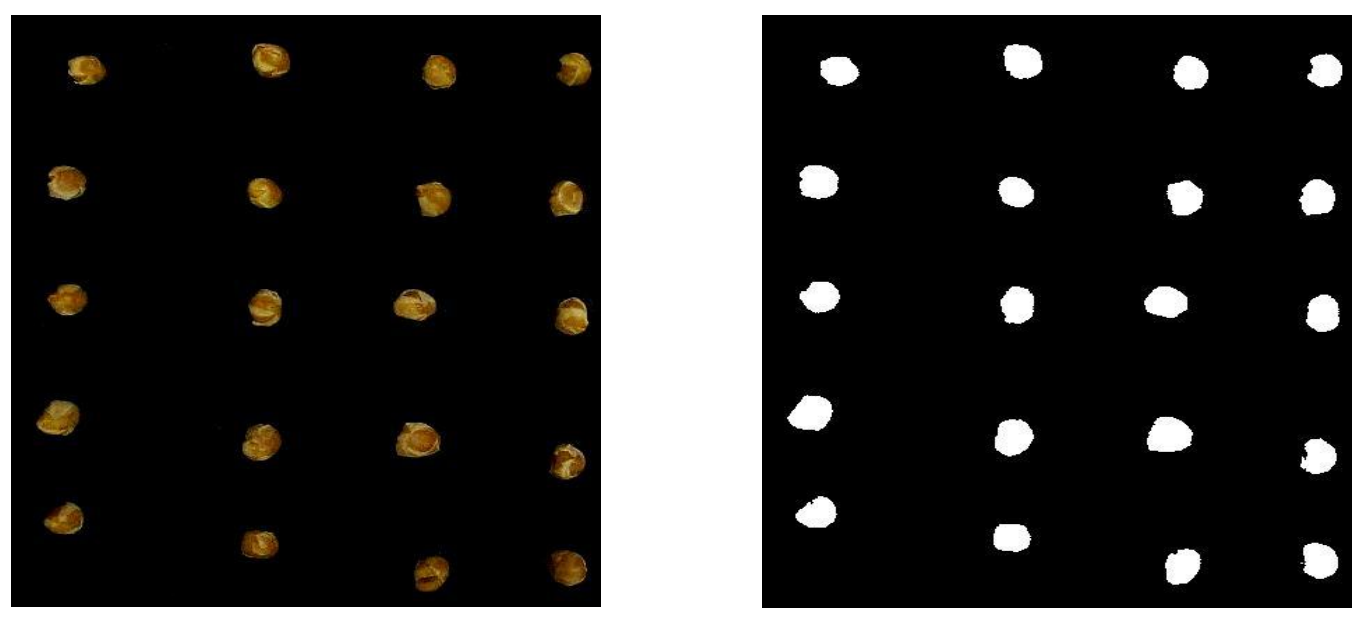

(a)
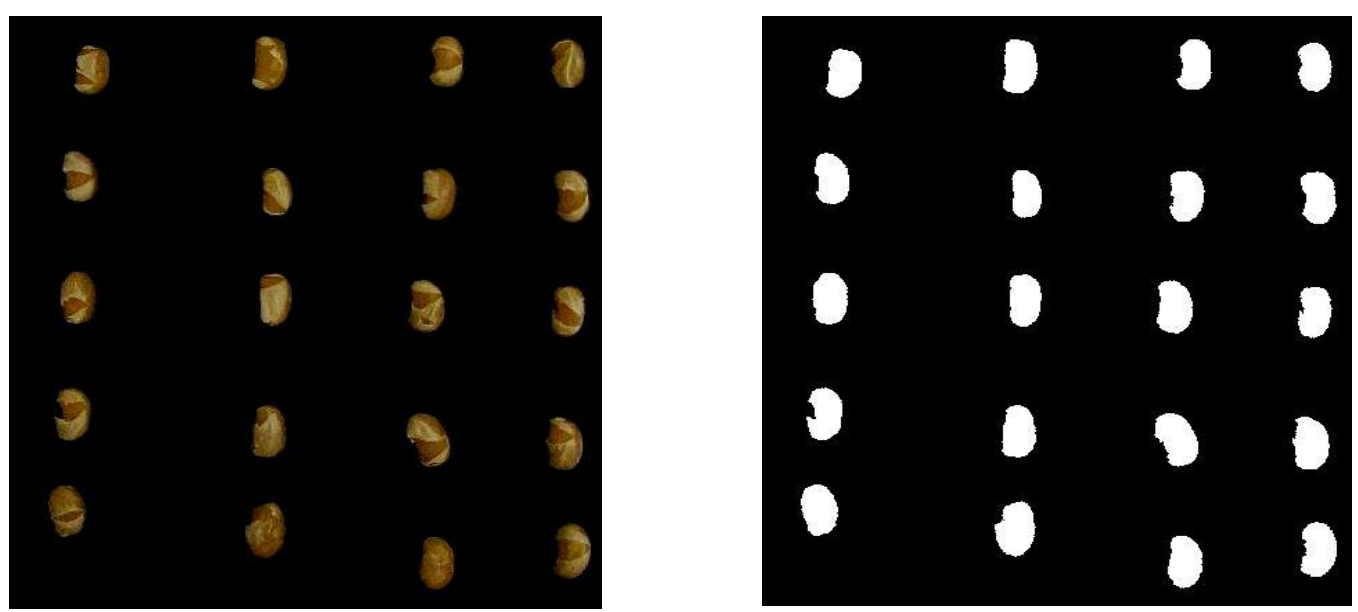

(b)

Figura 3.2. Segmentación de la imagen para la muestra remojada-cocida y secadatostada por 20 minutos: (a) vista superior, y (b) vista lateral.

La Figura 3.3 muestra un dibujo de la soja en vista superior y lateral, la cual especifica los ejes tomados para llevar adelante los cálculos. 

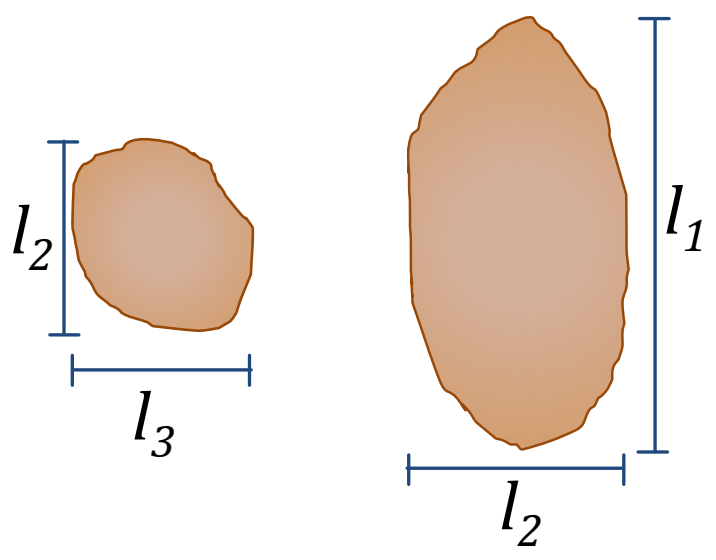

Figura 3.3. Dibujo de la vista superior y lateral del grano y sus respectivos ejes $l_{1}, l_{2}$ y $l_{3}$ determinadas por análisis de imagen y empleados para el cálculo del área superficial y el factor de esfericidad.

La Tabla 3.1, muestra los valores de los ejes principales, área superficial, factor de esfericidad y diámetro equivalente de la partícula. El diámetro efectivo calculado mediante la Ecuación (3.5), también se incluye en la Tabla 3.1, y es posiblemente el valor más relevante porque se utiliza en la ecuación de Ergun. El factor de esfericidad disminuye gradualmente durante el secado-tostado desde 0.96 a 0.94 a medida que la partícula cambia desde su forma inicial, característica de un poroto, a una más irregular luego de la contracción volumétrica y la deformación.

A medida que el contenido de humedad decrece durante el secado-tostado, los ejes principales disminuyen considerablemente. Comparando la muestra remojadacocida (RC) y la totalmente secada-tostada (ST 60), los valores de $D_{e}$ y $A_{p}$ disminuyen $18.2 \%$ y $27.4 \%$, respectivamente. El test de Tukey confirma que la dimensiones geométricas de las muestras RC y DT 60, presentadas en la Tabla 3.1, difieren significativamente $(\mathrm{p}<0.05)$. 
Tabla 3.1. Parámetros geométricos del grano entero de soja a diferentes contenidos de humedad durante el secado-tostado en lecho fluidizado. La primera línea de la tabla presenta los valores de la soja cruda.

\begin{tabular}{|c|c|c|c|c|c|c|c|}
\hline \multicolumn{8}{|c|}{ Secado-tostado a $140^{\circ} \mathrm{C}$} \\
\hline$W$ & $l_{1}$ & $l_{2}$ & $l_{3}$ & $A_{p}$ & $\phi$ & $D_{e}$ & $D_{p}$ \\
\hline $\mathrm{kg} \mathrm{H}_{2} \mathrm{O} / \mathrm{kg}$ materia seca & $m m$ & $m m$ & $m m$ & $m m^{2}$ & adimensional & $m m$ & $m m$ \\
\hline 0.113 & 6.93 & 6.25 & 5.51 & 121.9 & 0.99 & 6.32 & 6.26 \\
\hline 1.494 & 10.67 & 7.34 & 6.85 & 207.4 & 0.96 & 8.29 & 7.96 \\
\hline 0.711 & 10.32 & 6.66 & 5.48 & 172.6 & 0.95 & 7.14 & 6.78 \\
\hline 0.273 & 10.49 & 6.63 & 5.38 & 172.6 & 0.94 & 7.13 & 6.70 \\
\hline 0.102 & 10.18 & 6.53 & 5.29 & 165.4 & 0.95 & 6.98 & 6.63 \\
\hline 0.056 & 9.85 & 6.29 & 5.33 & 157.9 & 0.94 & 6.91 & 6.49 \\
\hline 0.026 & 9.83 & 6.32 & 4.88 & 150.6 & 0.94 & 6.78 & 6.37 \\
\hline
\end{tabular}

Estas diferencias indican la presencia de cambios en la estructura del producto durante el secado-tostado.

\subsubsection{Estudio de la fluidodinámica en lecho fijo y fluidizado.}

\subsubsection{Determinación de los parámetros de la ecuación de Ergun.}

De acuerdo al plan experimental presentado en la Fig.3.1, se llevó a cabo el estudio de la fluidodinámica de las muestras de soja remojadas, cocidas y secadastostadas a diversos tiempos. 
En la Fig.3.4, la pérdida de presión por unidad de altura de lecho fijo se graficó en función de la velocidad superficial del aire para la soja remojada-cocida y totalmente secada-tostada a $140^{\circ} \mathrm{C}$ por 60 minutos. Las muestras parcialmente secadas-tostadas (para tiempos mayores que $0 \mathrm{y}$ menores que $60 \mathrm{~min}$ ) exhiben un comportamiento fluidodinámico intermedio y no se incluyeron en la Fig.3.4.

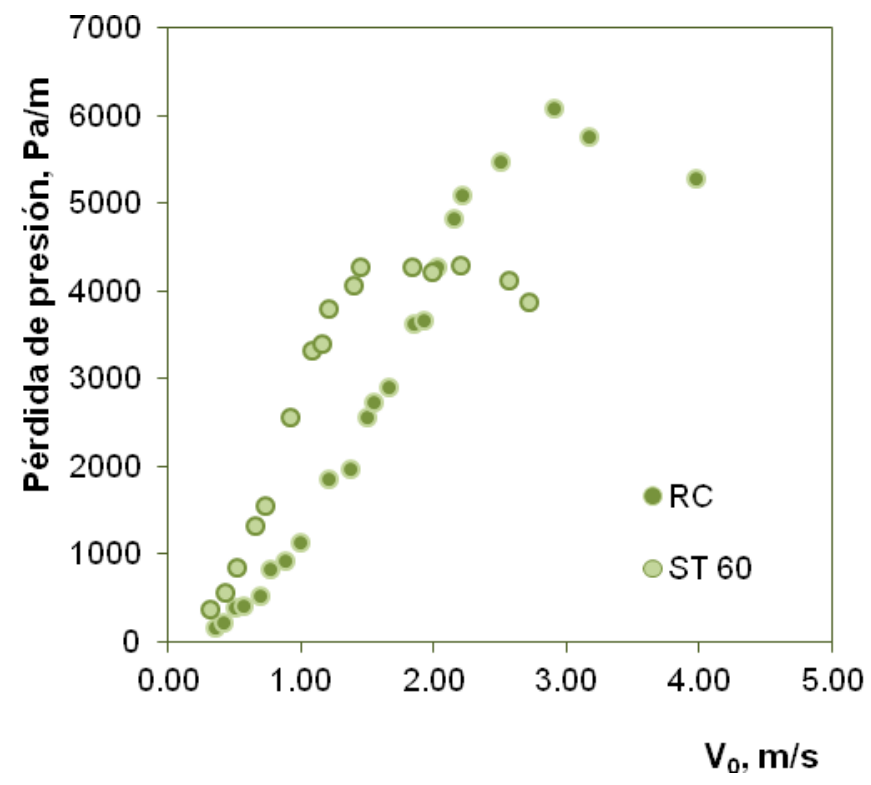

Figura 3.4. Valores de pérdida de presión por unidad de altura de lecho como una función de la velocidad del aire superficial, para soja remojada y cocida (•) y soja secada-tostada (•) por 60 minutos.

En la región de lecho fijo de la Figura 3.4, al mismo valor de $V_{0}$, la caída de presión en la muestra ST 60 fue más alta que en la muestra RC. La principal causa, de acuerdo al modelo de Ergun (Ec.(3.7)), se debe al menor diámetro efectivo de la muestra ST 60 (Tabla 3.1).

A altas velocidades, en la región de lecho fluido, la pérdida de presión (la cual está definida por el peso del producto), tiende a disminuir. Esto puede haber ocurrido 
por pérdidas de material liviano originado en la ruptura de tegumento, que resulta arrastrada por un transporte neumático indeseado.

A bajas velocidades, existe un comportamiento característico de lecho fijo, con una pendiente creciente. A altas velocidades, la pendiente disminuye (comportamiento de transición e, incluso a mayores velocidades tiende a ser horizontal (comportamiento de lecho fluidizado). Sin embargo, la Figura 3.4 no muestra una separación clara de los datos de lecho fijo y fluidizado en la región de transición, como se ha visto en la fluidización de otras partículas grandes (Yang, 2003).

La zona de lecho fijo en cada muestra se determinó por observación de las curvas, y se limitó a la región donde los datos muestran una tendencia creciente de la pendiente de la pérdida de presión por unidad de altura de lecho en función de la velocidad superficial del aire.

Una vez delimitados los datos de lecho fijo, se ajustó el modelo de la ecuación de Ergun (Ec.(3.7)) a ellos, usando la fracción de huecos en el lecho y el diámetro efectivo presentados en la Tabla 3.2. Los resultados de este ajuste no lineal se obtuvieron por el método de los cuadrados mínimos, determinándose $K_{I}$ (coeficiente laminar) y $K_{2}$ (coeficiente turbulento). Los parámetros del ajuste se exhiben en la Tabla 3.3 junto con su error asintótico estándar (ASE) y su coeficiente de determinación corregido $\left(r^{2}\right)$. 
Tabla 3.2. Propiedades de lecho fijo determinadas para las muestras preparadas por secado-tostado en lecho fluidizado (ST) a varios tiempos (incluye la muestra inicial remojada y cocida $(\mathrm{RC}))$.

\begin{tabular}{ccccc}
\hline Muestra & $W$ & $\rho_{p}$ & $\rho_{B 0}$ & $\varepsilon_{0}$ \\
& $\mathrm{~kg} \mathrm{H} \mathrm{H}_{2} / \mathrm{kg}$ materia seca & $\mathrm{kg} / \mathrm{m}^{3}$ & $\mathrm{~kg} / \mathrm{m}^{3}$ & \\
\hline RC & 1.494 & 1069 & 680.6 & 0.36 \\
ST 10 & 0.711 & 909 & 559.5 & 0.38 \\
ST 20 & 0.273 & 760 & 509.7 & 0.33 \\
ST 30 & 0.102 & 743 & 427.9 & 0.42 \\
ST 40 & 0.056 & 743 & 453.9 & 0.39 \\
ST 60 & 0.026 & 750 & 437.2 & 0.42 \\
\hline
\end{tabular}

Tabla 3.3. Parámetros determinados por el ajuste de la ecuación de Ergun (Ec.(3.7)) a los datos experimentales de pérdida de presión vs velocidad superficial de aire en zona de lecho fijo. Entre paréntesis se incluye el error asintótico estándar $(A S E)$ de $\mathrm{K}_{1}$ y $\mathrm{K}_{2}$.

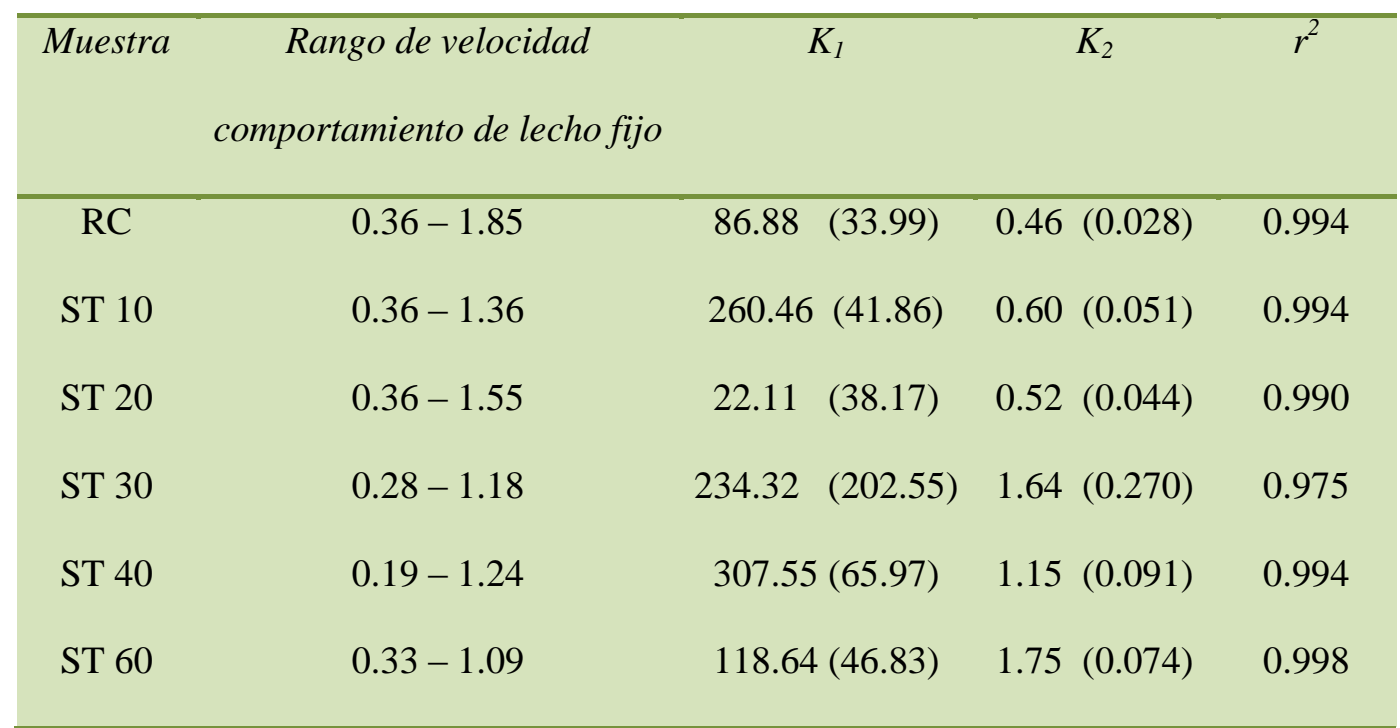


Así como se mencionó en la Sección 3.1.7, los valores de los coeficientes laminar y turbulento dependen de las características del producto. En vista de ello, Escardino y col., (1974) trabajaron con varios cereales como por ejemplo arroz cáscara, trigo, cebada y maíz para obtener los valores de $K_{1}$ y $K_{2}$ por ajuste. En dicho trabajo, determinaron valores desde 242 a 867 para $K_{1}$ y desde 3.17 a 6.54 para $K_{2}$, los cuales son mucho más altos que los encontrados por Ergun en 1952 (150 y 1.75). Atribuyeron estas diferencias a la rugosidad de la superficie de cada cereal y, además a la anisotropía del medio, característica de los lechos formados por partículas de forma irregular. Respecto de los valores obtenidos en el presente trabajo (Tabla 3.3), el coeficiente laminar $\left(K_{l}\right)$ se determinó con un alto grado de error debido a que, por las altas velocidades empleadas el término laminar tiene baja influencia. Así, los cambios observados entre muestras no son relevantes. A su vez, el coeficiente turbulento $\left(K_{2}\right)$ es menor que el correspondiente parámetro en la ecuación de Ergun para la muestra remojada-cocida, posiblemente debido al carácter liso o ablandamiento del tegumento húmedo del grano de soja. Por su parte, las muestras secadas-tostadas, que experimentaron encogimiento, deformación y rotura con pérdida parcial de tegumento, mostrando un contorno irregular explica la tendencia de $K_{2}$ a aumentar a medida que las muestras se expusieron más tiempo al secado-tostado. Las variaciones en la fracción de huecos (Tabla 3.2) que dependen de la densidad de partícula y lecho, tendieron a aumentar para mayores tiempos de secado-tostado, lo que sería causado por el peor empaque de granos de forma irregular.

En la Figura 3.5, la pérdida experimental de presión (símbolos) por unidad de lecho $\left(\Delta \mathrm{p} / \mathrm{L}_{0}\right)$ y las curvas calculadas correspondientes, se graficaron en función de la velocidad superficial del aire, usando los parámetros de la Tabla 3.3. El ajuste fue satisfactorio en todos los casos. 

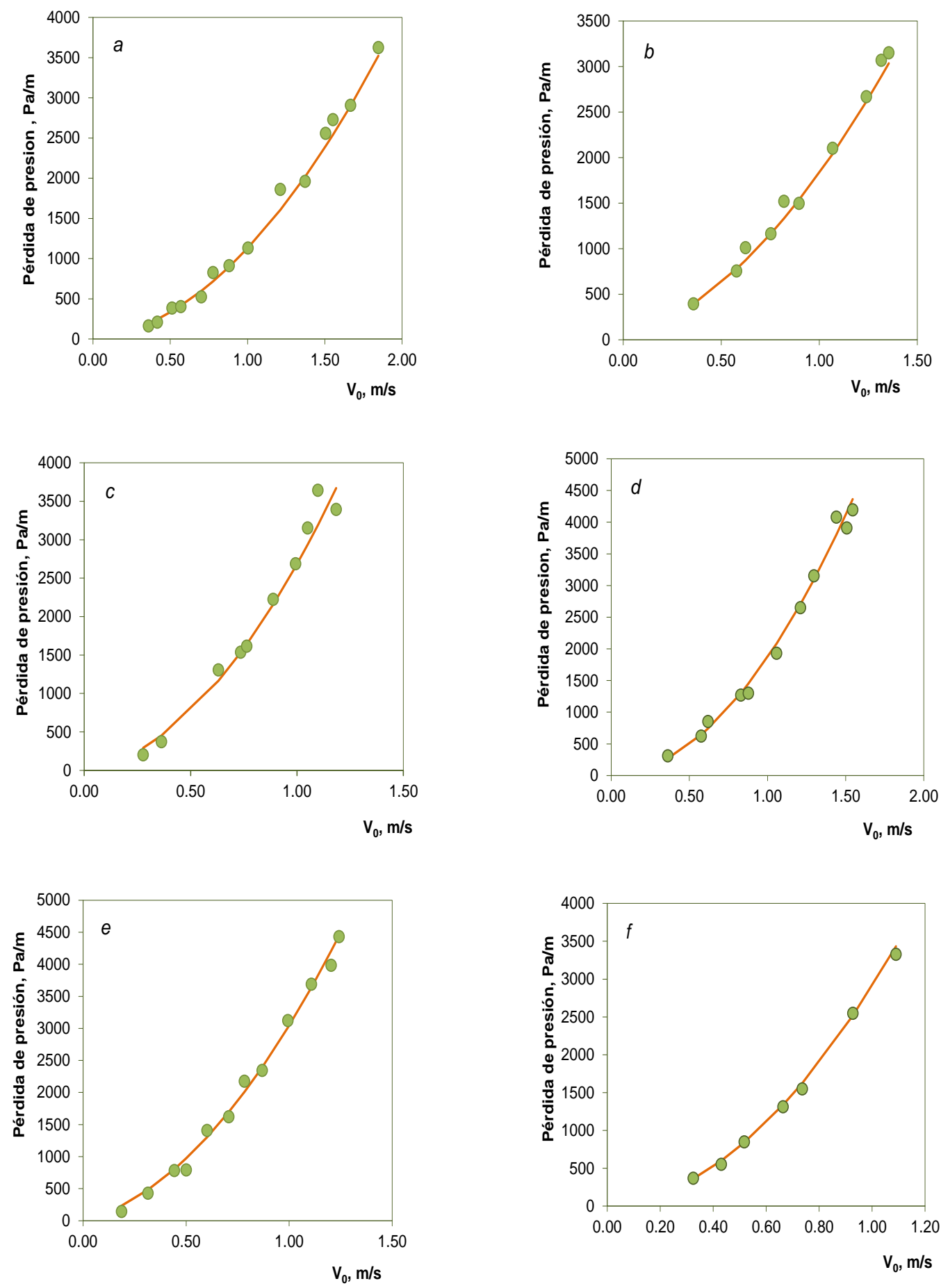

Figura 3.5. Pérdida de presión por altura de lecho como función de la velocidad superficial. Experimental (•) y los valores predichos (-): (a) remojada-cocida (RC), (b) secada-tostada por $10 \mathrm{~min}$, (c) secado-tostada por $20 \mathrm{~min}$, (d) secada-tostada por 30 min, (e) secada-tostada por $40 \mathrm{~min}$ y (f) secada-tostada por $60 \mathrm{~min}$. 


\subsubsection{Determinación de la velocidad operativa de fluidización.}

La Figura 3.6 muestra que la velocidad de mínima fluidización, determinada con la Ec. (3.11), disminuye a medida que se reduce el contenido de humedad. En el caso de la muestra ST 60, el valor de $V_{m f}$ es visiblemente menor en comparación con el de la muestra RC. Por tanto, se requieren menores valores de $V_{m f}$ a medida que progresa el secado-tostado. Si la velocidad del aire no se controlara, la misma naturalmente aumentará debido a la disminución del peso del lecho sometido al secado (pérdida de presión decreciente). Esto aumentaría el gasto energético para mantener constante la temperatura de aire a la entrada lo que, además, puede ocasionar pérdida de material por transporte neumático hacia afuera del lecho.

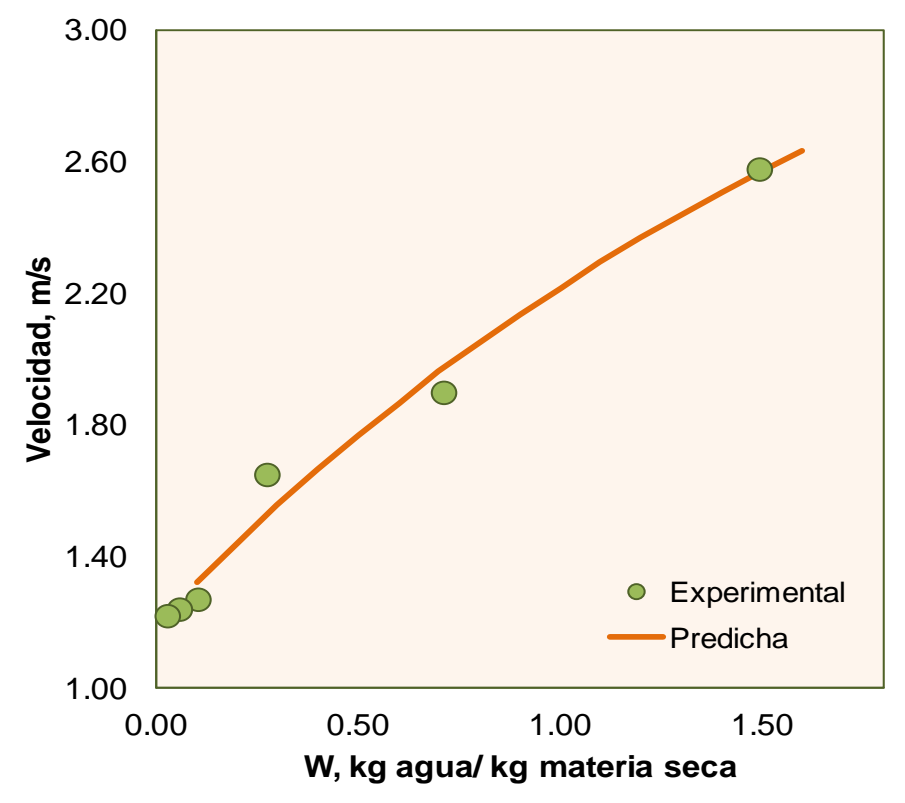

Figura 3.6. Velocidades de mínima fluidización de las muestras fluidizadas a distintos tiempos de secado-tostado en función de sus correspondientes valores de humedad. Valores determinados por la Ec.(3.11) (•). Una correlación empírica (-) provee una buena descripción para fines prácticos. 
Empleando los datos obtenidos en el presente trabajo, la velocidad de mínima fluidización se relacionó con el contenido de humedad del grano de soja. Senadeera y col. (2006) y Di Mattia y col. (1996) también encontraron una relación entre la $\mathrm{V}_{m f}$ y el contenido de humedad, ajustando los datos con una expresión lineal. En el presente trabajo (Fig. (3.6)), los valores experimentales de $V_{m f}$ (determinados con la Ec.(3.11)) se vincularon al contenido de humedad mediante una ecuación empírica de tipo exponencial (Ec.(3.12)), con un $r^{2}$ de 0.983 .

$V_{f}=2.649(1-\exp (-0.490 W))+1.189$

A su vez, la correlación correspondiente entre la $V_{m f}$ y el tiempo, que puede ser de utilidad en la automatización del proceso de secado-tostado, resultó

$V_{m f}=1.437 \exp (-0.0638 t)+1.159$

mostró un excelente ajuste con los datos $\left(r^{2}=0.999\right)$.

En la Figura 3.6 los valores experimentales de $\mathrm{V}_{m f}$ se graficaron en función del contenido de humedad junto con las predicciones de la Ec.(3.12). Sin embargo, la fluidización de partículas grandes como la soja requiere el uso de velocidades operativas de fluidización $\left(V_{f}\right)$ más altas que la $V_{m f}$ con el fin de generar un adecuado grado de mezclado y por tanto un tratamiento térmico uniforme. El exceso $\left(V_{f}-V_{m f}\right)$ atraviesa el lecho en forma de burbujas (Kunii y Levenspiel, 1997), las cuales se rompen en la superficie, causando un intenso mezclado. El valor de $V_{f}$ se estima como un valor de compromiso entre el logro de un tratamiento térmico homogéneo y el ahorro energético y de inversión de capital. Soponronnarit y col. (2001) y Srinivasakannan y 
Balasubramanian (2009) usaron valores de $V_{f}$ de $1.5 V_{m f}$ y $2 V_{m f}$, respectivamente. Para nuestro sistema, el factor 1.5 resultó satisfactorio. Los valores de $V_{f}$ obtenidos se graficaron en la Figura 3.7 como función del tiempo. Esta información puede ser útil para el diseño de un algoritmo y equipo con control automático durante el proceso donde el valor deseado de velocidad operativa de fluidización disminuya con el tiempo.

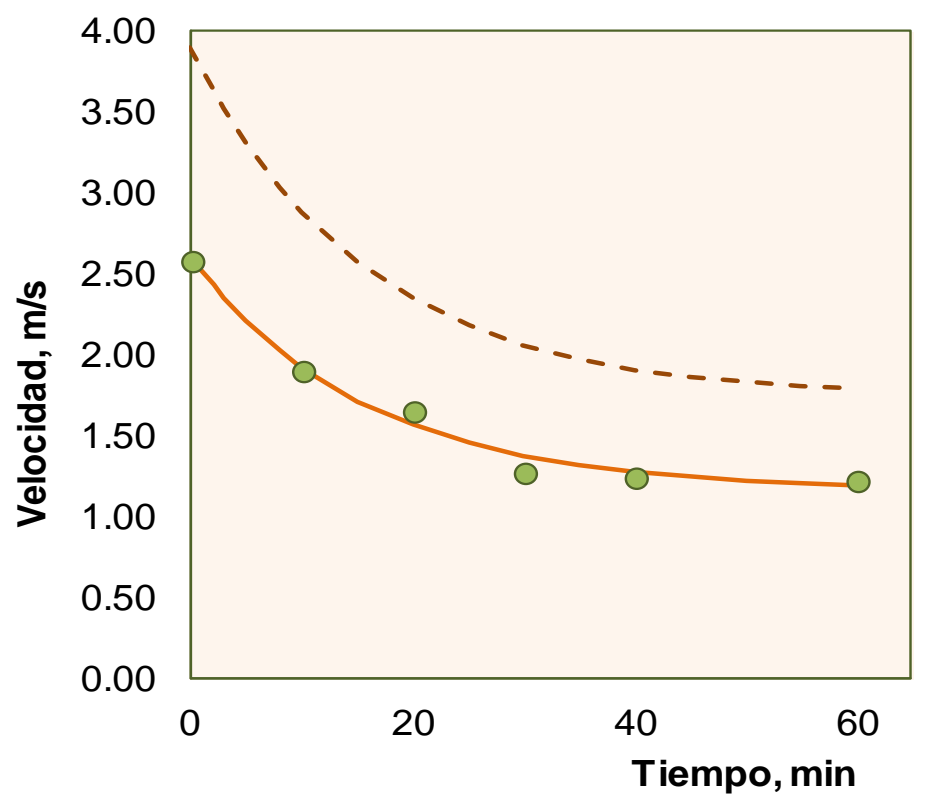

Figura 3.8. Velocidades experimentales de mínima fluidización a $20^{\circ} \mathrm{C}(\bullet)$ a varios tiempos, junto con los valores predichos por la correlación empírica (-). La curva superior (---) representa la velocidad operativa de fluidización como función del tiempo.

\subsubsection{Efecto de la temperatura del aire sobre la velocidad de mínima fluidización.}

En esta sección, se realizó un estudio con el fin de encontrar el efecto de la temperatura en la velocidad de mínima fluidización determinadas a temperatura ambiente. Con este propósito, la densidad y viscosidad del aire, $\rho_{a} \mathrm{y} \mu_{a}$, respectivamente se expresaron como función de la temperatura Ec.(3.11) (Formisani y col., 1998). 
$\rho_{a}=\frac{p M_{a}}{R\left(T_{c}+273.2\right)}$

$\mu_{a}=1.735 \times 10^{-5}+4.318 \times 10^{-8} T_{c}$

donde $p$ es la presión absoluta en $\mathrm{Pa}, M_{a}$ la masa molar de aire, $28.84 \mathrm{~kg} / \mathrm{kmol}, R$ la constante de los gases, $8314 \mathrm{~J} / \mathrm{kmol} \mathrm{K}$ y $T_{k}$ la temperatura absoluta del aire en Kelvin, siendo $T_{c}$ la temperatura del aire en ${ }^{\circ} \mathrm{C}$. Considerando que el término turbulento es más importante para la $V_{m f}$ y que, la densidad del aire disminuye a medida que su temperatura aumenta, de acuerdo a la ecuación (3.11) resultaría necesario un incremento de la $V_{m f}$ para compensar y alcanzar la misma pérdida de presión para igualar el mismo peso del lecho. Este efecto debe ser tomado en cuenta para corregir los valores de la $V_{f}$ calculada para $20^{\circ} \mathrm{C}$ en la Figura 3.9. Por esta razón, la Ec. (3.14) y (3.15) se reemplazaron en la Ecuación (3.11) y la velocidad de mínima fluidización resultante se graficó en la Figura 3.8 en función de la temperatura, para el rango de 20 a $160^{\circ} \mathrm{C}$. A esta última temperatura, la velocidad de mínima fluidización para la muestra remojadacocida fue de $3.05 \mathrm{~m} / \mathrm{s}$, cerca de un $20 \%$ mayor que el valor registrado a $20^{\circ} \mathrm{C}$. 


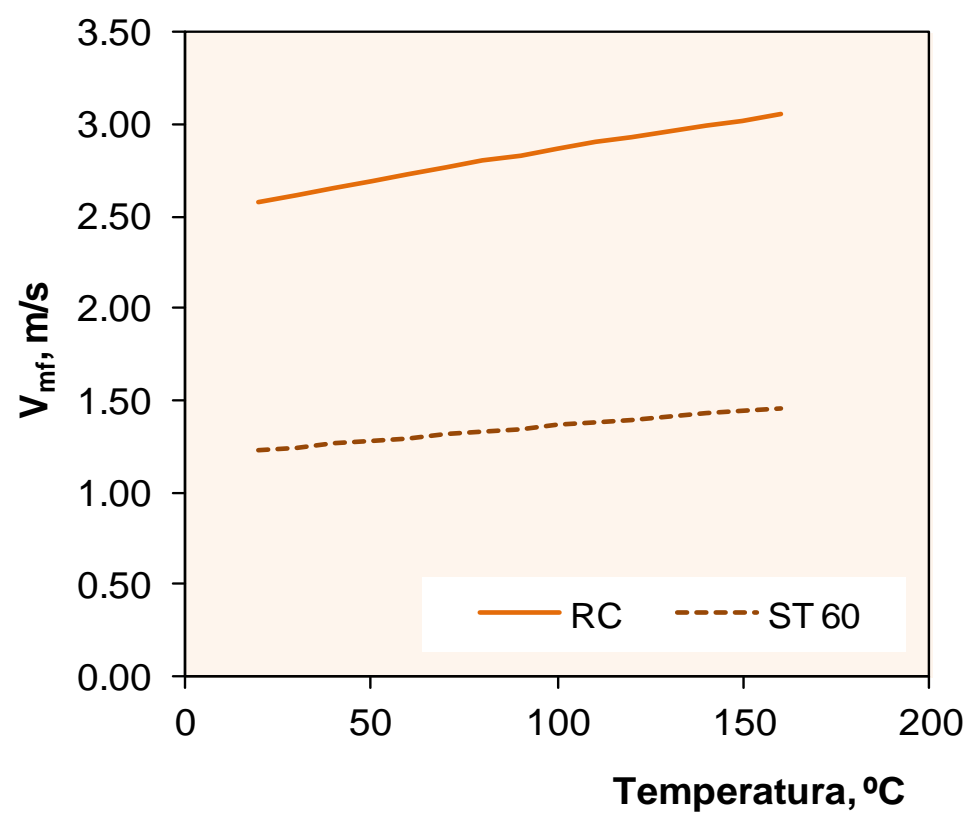

Figura 3.8. Efecto de la temperatura sobre la velocidad de mínima fluidización en las muestras remojada-cocida (RC), y secada-tostada por 60 min (ST 60).

Por tanto, considerando el efecto adicional de la temperatura la velocidad operativa de fluidización requerida por el proceso debe disminuir de 4.7 a $2.2 \mathrm{~m} / \mathrm{s}$. 


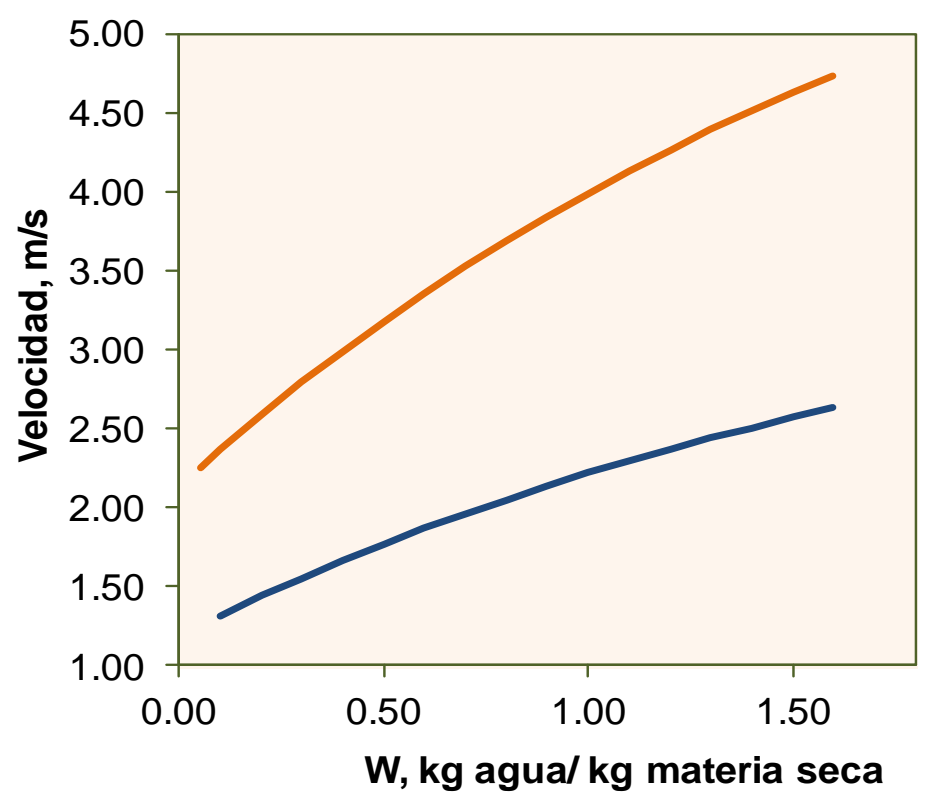

Figura 3.9 Variación de las velocidades experimentales de mínima fluidización determinadas a $20^{\circ} \mathrm{C}(-)$ vs velocidad operativa de fluidización considerando el factor $1.5 V_{m f}$, y el efecto adicional de la temperatura (-).

\subsection{Conclusiones.}

Las muestras preparadas a mayores tiempos de secado-tostado exhibieron menores contenidos de humedad y, menor diámetro de partícula, con una tendencia a presentar menores densidades de lecho fijo y mayores valores de fracción de huecos en el lecho. Asímismo, el parámetro turbulento $\left(K_{2}\right)$ de la Ecuación de Ergun también tiende a incrementarse a medida que decrece el contenido de humedad, posiblemente reflejando el efecto de la creciente rugosidad de partícula a medida que se deforma y su tegumento se rompe.

La velocidad de mínima fluidización a $20^{\circ} \mathrm{C}$ varió entre 2.6 a $1.2 \mathrm{~m} / \mathrm{s}$ durante los 60 minutos de la etapa de secado-tostado. Estos valores deben incrementarse alrededor 
de un 50\% para obtener velocidades prácticas de fluidización que disminuirán de 3.9 a $1.8 \mathrm{~m} / \mathrm{s}$ durante el proceso.

El proceso de secado-tostado debe ser controlado automáticamente, en vista de que el sistema requiere una disminución de la velocidad de fluidización con el tiempo, de lo contrario la velocidad del aire tenderá a aumentar por la menor pérdida de carga del sistema, generando un consumo excesivo de energía y la posible pérdida de material por transporte neumático.

La velocidad de mínima fluidización se incrementa alrededor de un 20\% entre 20 y $160^{\circ} \mathrm{C}$, debido principalmente a la disminución en la densidad del aire. Este efecto debe ser tomado en cuenta en vista de que el proceso estudiado en este trabajo se lleva a cabo a $140^{\circ} \mathrm{C}$. 
EQULIBRIO SORCIONAL 


\section{Introducción.}

Desde el punto de vista de su composición, un alimento puede ser definido como un sistema multicomponente constituido por una fase continua acuosa y una pequeña fracción de fase sólida. En la fase acuosa encontramos disueltos azúcares, sales y otros compuestos de bajo peso molecular, mientras que la fase sólida contiene biopolímeros insolubles como almidón, proteínas y celulosa (Moreria y col., 2009). El estado del agua en el producto juega un rol fundamental en la preservación de los materiales biológicos tanto crudos como procesados (Blahovec, 2004). Por tanto, el control del contenido de humedad durante el procesamiento de los alimentos es uno de los métodos más antiguos de preservación, que se lleva a cabo mediante la remoción del agua del alimento hasta niveles donde éste se vuelva estable frente al crecimiento microbiano en primer lugar y a su vez, inhiba reacciones químicas de deterioro (Al-Muhtaseb, 2002). La propiedad que relaciona mejor la presencia de agua en los alimentos con el crecimiento microbiano es la actividad de agua (Blahovec, 2004).

La isoterma relaciona gráficamente, a una temperatura constante, el contenido en humedad de un producto con la actividad del agua del mismo. Las isotermas son importantes para el análisis y diseño de varios procesos de transformación de alimentos. Además son útiles para predecir los cambios en la estabilidad de los alimentos y en la elección del material de envase adecuado (Gálvez y col., 2006).

Se han propuesto varias ecuaciones empíricas y semiempíricas para correlacionar el contenido de humedad de equilibrio con la actividad de agua de un alimento. El problema de caracterizar las propiedades físicas y químicas de los componentes de un cereal $\mathrm{u}$ oleaginosa, por ejemplo, es la complejidad de sus interacciones con el agua y el efecto que esta ejerce sobre su estructura interna 
(Menkov, 2000). Giner y Gely (2005) señalaron que una ecuación teórica que pueda tener en cuenta todos los fenómenos sorcionales sería demasiado compleja y tendría demasiados parámetros como para ser utilizada, y reconocen que el número de parámetros a ser evaluados simultáneamente con precisión razonable no puede ser mayor que 4 .

Sin embargo, a pesar de la gran cantidad de estudios realizados sobre equilibrio sorcional disponibles en la bibliografía, no se han hallado hasta el momento trabajos en muestras de grano entero de soja remojado que hayan sido preparados por secadotostado a elevadas temperaturas.

En este capítulo el objetivo es analizar la isoterma de sorción de las muestras mencionadas y encontrar el modelo matemático más conveniente para describir la funcionalidad de la actividad acuosa con el contenido de humedad. Con la expresión de equilibrio sorcional elegida, se deducirá una expresión para el cálculo del calor de desorción $\left(\mathrm{L}_{\mathrm{w}}\right)$, en función de la temperatura y contenido de humedad del grano. $\mathrm{El} \mathrm{L}_{\mathrm{w}}$ aparece en los modelos matemáticos de secado y representa la principal contribución a la demanda de energía de dicha operación.

\subsection{Consideraciones teóricas.}

\subsubsection{Actividad de agua.}

La actividad acuosa es una propiedad termodinámica definida como el cociente entre la presión de vapor del agua en una solución o alimento $\left(p_{\mathrm{v}}\right)$ que depende del contenido de humedad y de la temperatura (Moreira y col., 2009) y la presión de saturación de vapor del agua pura a la misma temperatura $\left(p_{\mathrm{s}}\right)$ (Rahman, 2009). Esta 
propiedad puede determinarse a partir de una atmósfera de aire en equilibrio que rodee la muestra en una pequeña cámara:

$a_{w}=\frac{p_{v}}{p_{s}}=\frac{\operatorname{HRE}(\%)}{100}$

Donde HRE es la humedad relativa de equilibrio (\%) del aire. De hecho, la definición de la actividad acuosa del aire coincide con la de su humedad relativa expresada en forma decimal y es igual a la del alimento, en el equilibrio (Gely y Giner, 2000; Blahovec, 2004). En una atmósfera de humedad relativa y temperatura constantes, el contenido de humedad del producto que surja de la isoterma se puede llamar $\mathrm{W}_{\mathrm{e}}=\mathrm{f}\left(\mathrm{h}_{\mathrm{ra}}\right.$, $\mathrm{T}_{\mathrm{a}}$ ), "humedad de equilibrio". En consecuencia, un material dado de humedad W se secará si $\mathrm{W}>\mathrm{W}_{\mathrm{e}}$, estará en equilibrio si $\mathrm{W}=\mathrm{W}_{\mathrm{e}} \mathrm{y}$ se hidratará cuando $\mathrm{W}<\mathrm{W}_{\mathrm{e}}$. Las variables termodinámicas relevantes para el establecimiento del equilibrio sorcional son la humedad relativa del aire $\left(\mathrm{h}_{\mathrm{r}}\right)$ y la actividad acuosa del alimento $\left(a_{\mathrm{w}}\right)$.

La actividad del agua pura se considera igual a la unidad, de manera que la de una solución o alimento es siempre inferior. Esto se debe a la reducción de la presión de vapor debido a los diferentes tipos de unión que forma el agua con los sólidos del alimento (Aguilera, 2003; Cheftel y Cheftel, 1992). Termodinámicamente el estado del agua en los alimentos es representado por la actividad de agua, de acuerdo a la definición de potencial químico como una función del contenido de humedad

$$
\mu_{w}=\mu_{w}^{0}+R T \ln a_{w}
$$


El potencial químico constituye una variable de "campo" que en el equilibrio, resulta igual a ambos lados de la interface alimento-aire. La utilización de la actividad de agua como variable de campo constituye en consecuencia una aproximación aceptada en la tecnología de los alimentos.

\subsubsection{Isotermas de sorción.}

En la literatura es posible encontrar un número considerable de investigaciones realizadas sobre isotermas de sorción llevadas a cabo con una amplia variedad de alimentos (Al-Muhtaseb y col., 2002). Por definición se tiene que

$a_{w}=\frac{p_{v}(W, T)}{p_{s}(T)} \Rightarrow a_{w}=g(W, T)$

La actividad acuosa, estrictamente, sólo informa cuanto se ha reducido la presión de vapor del agua, respecto del valor para agua pura a la misma temperatura. Si el alimento no presenta gradientes de presión de vapor internos, es decir está en equilibrio químico, el $a_{\mathrm{w}}$ será representativo de toda la muestra de alimento. Si se reordena la Ecuación (4.3), se puede despejar

$W=f\left(a_{w}, T\right)$

y si consideramos que la temperatura es constante, tenemos finalmente, para cada curva

$W=f\left(a_{w}\right)$ 
que se denomina "Isoterma de sorción". A continuación podemos observar una isoterma típica de un alimento

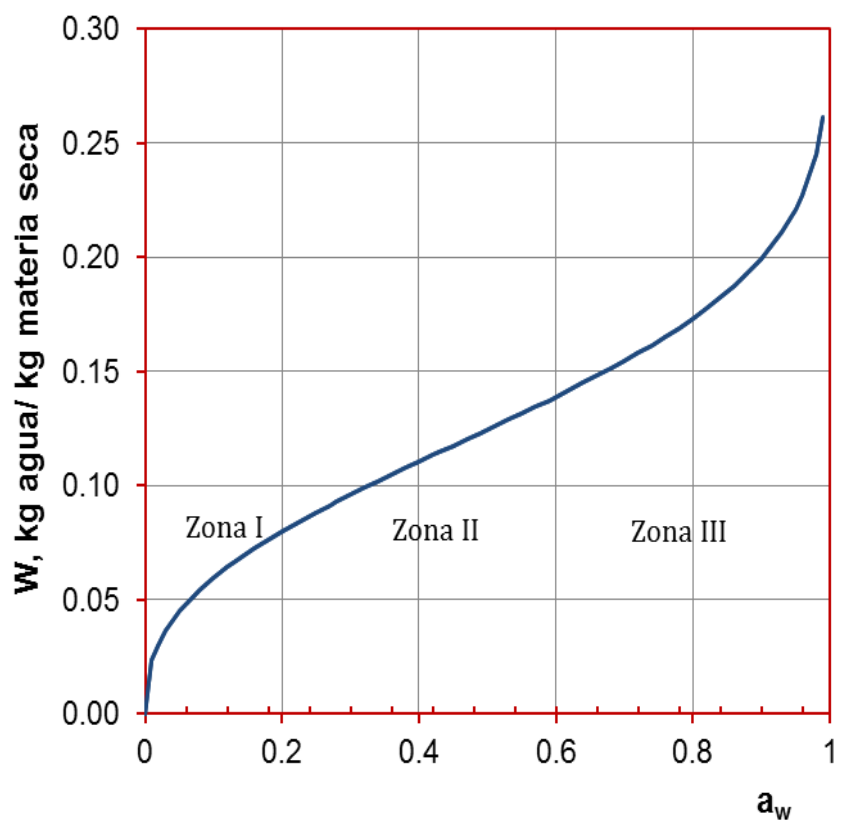

Figura 4.1 Isoterma típica de sorción.

Las isotermas de tipo sigmoideo son características de la mayoría de los alimentos, así como también la diferencia entre las isotermas de adsorción y desorción para un mismo producto. Las frutas, alimentos azucarados y extractos de café que contienen azúcares y componentes solubles presentan forma de "J" (Fennema, 2010; Roos, 1995).

En una isoterma de sorción tal como se aprecia en la Figura 4.1 se pueden delimitar tres regiones asociadas a las distintas vinculaciones entre agua y materia seca.

La región I, se ubica en el intervalo de $a_{w}$ comprendido entre valores de 0 y 0.2 0.3 que corresponde al agua que forma una monocapa de moléculas de agua unidas a los grupos polares de ciertos componentes, y probablemente al agua de cristalización de sales y azúcares. Esta agua es difícil de extraer durante el secado, no es congelable a temperaturas de $-40^{\circ} \mathrm{C}$ y no está disponible para actuar como reactivo o solvente. El 
límite entre la región I y II se ha asociado al contenido de "humedad de monocapa" del alimento (Aguilera, 1997).

La región II, corresponde al agua cuyo intervalo de $a_{w}$ es de 0.25 a 0.65 . En esta región el agua estaría formando capas adicionales por encima de la monocapa, denominándose "agua de multicapa". Ésta a su vez presenta propiedades diferentes a las del agua pura, constituyendo junto al agua de la región I un 5\% del agua total presente en los alimentos frescos.

La región III cuyos valores de $a_{w}$ son superiores a 0.65 presenta propiedades similares a las de una solución diluida o bien a las del agua pura. Es congelable, puede actuar como solvente y es suficientemente abundante como para permitir reacciones de deterioro o el crecimiento microbiano (Fennema, 2010).

\subsubsection{Cambios producidos en los alimentos por la $a_{w}$.}

La actividad de agua es un factor de gran importancia en la pérdida de calidad de los productos deshidratados dado que influencia las reacciones bioquímicas y de estabilidad de estos productos (Menkov, 2000). Durante el almacenamiento, el estudio de la estabilidad de los productos deshidratados involucra el conocimiento de las velocidades de reacción, en función del tiempo, la temperatura y el $a_{w}$ (Al-Muhtaseb y col., 2002).

La disminución de la $a_{w}$ inhibe el crecimiento de los microorganismos (en este orden: bacterias, levaduras y mohos) de tal forma que detiene totalmente su crecimiento a valores de 0.6 o inferiores. Igualmente, la velocidad de las reacciones químicas que tienen lugar en un alimento, tanto enzimáticas como no enzimáticas, es en función de la actividad de agua. A medida que disminuye la $a_{w}$ la velocidad de reacción se va 
haciendo más lenta. A valores comprendidos entre 0.2 y 0.3 presentan un mínimo. La excepción la constituye la oxidación lipídica que es mínima a estos valores pero aumenta a medida que la $a_{w}$ sigue descendiendo. Por tanto, la máxima estabilidad de los alimentos para actividades acuosas entre 0.2 y 0.3 (Ordoñez, 1998). Sin embargo, Chirife y Buera (1995), destacan que los microorganismos más habituales no pueden crecer en medios con $a_{\mathrm{w}}<0.7$. En esta situación, $a_{\mathrm{w}}=0.7$, la interacción agua-producto es lo suficientemente fuerte como para que el agua no esté disponible para el crecimiento microbiano al menos durante un largo tiempo generalmente mayor al tiempo durante el cual el producto está almacenado. El valor de humedad de granos en post-cosecha determinado a este valor de $a_{\mathrm{w}}$ se denomina por lo general humedad de seguridad, para él almacenamiento.

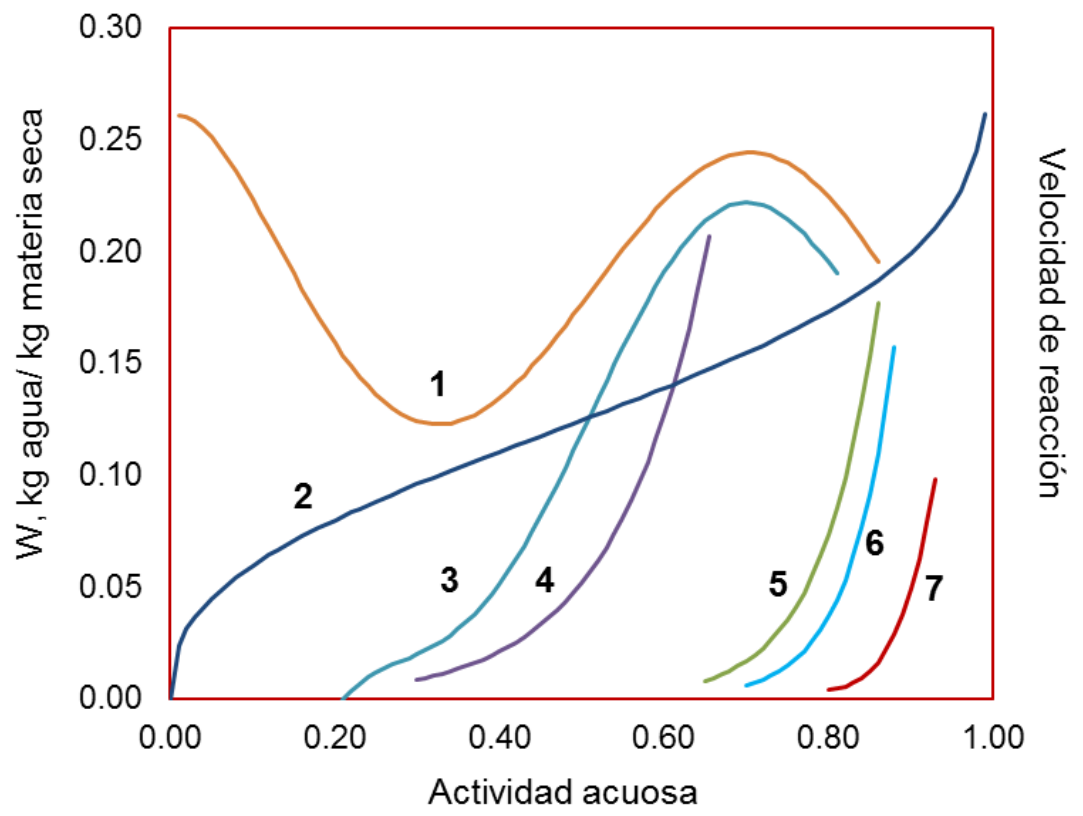

Figura 4.2 Velocidad de alteración de los alimentos en función de la actividad de agua: 1- Oxidación de lípidos, 2- Isoterma de sorción (lectura de las ordenadas del lado derecho), 3- Pardeamiento no enzimático, 4- Actividad enzimática, 5- Mohos, 6Levaduras, 7- Bacterias (Cheftel y Cheftel, 1992). 
Además de afectar las reacciones químicas y del crecimiento microbiano, el $a_{w}$ también influye en la textura de los alimentos secos y semisecos. Por ejemplo, establece el límite para retener la crocancia de las galletas, pochoclos y snacks de papas fritas (chips); para evitar el apelmazamiento de azúcar, leche en polvo y café instantáneo. El valor máximo de $a_{w}$ que se puede tolerar en los alimentos secos sin incurrir en pérdidas de propiedades deseables, está en el intervalo de 0.35 a 0.5 dependiendo del producto (Fennema, 2010).

Más allá de predecir la estabilidad físico-química o microbiológica de los alimentos, la utilidad de determinar experimentalmente y modelar matemáticamente la isoterma de sorción se debe a su importancia para fines ingenieriles ya que permite resolver problemas concretos tales como humedad de almacenamiento, cálculos de tiempos de secado en diseño de equipos y estimación de demandas energéticas entre otros (Fellows, 1994).

\subsubsection{Análisis de modelos matemáticos para la predicción de las isotermas de sorción.}

En numerosas ocasiones se ha intentado, a partir de conceptos termodinámicos de adsorción/desorción, desarrollar expresiones matemáticas para predecir el contenido de humedad en función de la actividad de agua y que al mismo tiempo, permitan su ajuste a los datos experimentales (García y Martínez, 2006). Los modelos estudiados con mayor frecuencia en la literatura se describen a continuación. 
Ecuación de Henderson-Thompson o Henderson modificada

Uno de los modelos usados ampliamente para relacionar la actividad de agua con el contenido de humedad y la temperatura es la ecuación de Henderson-Thompson o Henderson modificada (Osborn y col., 1989)

$\mathrm{W}=0.01\left[\frac{-\ln \left(1-a_{\mathrm{w}}\right)}{\mathrm{K}(T+C)}\right] 1 / \mathrm{N}$

Esta ecuación junto con la de Chung-Pfost modificada fueron adoptadas como estándares por la ASAE para la descripción del contenido de humedad de equilibrio y la actividad de agua de cereales y oleaginosas (Aviara y col., 2006; Al-Muhtaseb y col., 2002).

Ecuación de Chung-Pfost modificada

Esta ecuación desarrollada por Chung-Pfost (Menkov, 2000) se escribe de la siguiente manera

$\mathrm{W}=-\frac{0.01}{\mathrm{C}_{3}} \ln \left(-\frac{\left(\mathrm{T}+\mathrm{C}_{2}\right) \ln a_{\mathrm{w}}}{\mathrm{C}_{1}}\right)$

Chen y Morey (1989) observaron que esta ecuación resultó adecuada para predecir la humedad de equilibrio en granos con alto contenido de almidón y materiales fibrosos. 
Ecuación de Oswin modificada

Oswin desarrollo un modelo empírico, a partir de las curvas tipo sigmoide (AlMuhtaseb y col., 2002)

$W=0.01\left(C_{1}+C_{2} T\right)\left[\frac{a_{w}}{1-a_{w}}\right]^{C_{3}}$

Por lo general, suele mostrar buenos ajustes para alimentos ricos en almidón como ciertas variedades de trigo y maíz, e incluso se ha extendido su uso exitosamente a carnes y vegetales (Aviara y col., 2006).

Ecuación de Halsey modificada

La siguiente ecuación, fue desarrollada por Halsey (Giner y Gely, 2005), y provee una expresión para la condensación de multicapas a una distancia relativamente grande de la superficie. Halsey considero que la magnitud del parámetro $R$ caracteriza el tipo de interacción entre el vapor y el sólido

$$
\mathrm{W}=0.01\left[\frac{-\exp (\mathrm{bT}+\mathrm{C})}{\ln a_{\mathrm{w}}}\right]^{1 / \mathrm{R}}
$$

El modelo de Halsey presentó los mejores ajustes para productos ricos en aceite y proteínas. Nellist y Bruce (1995) y Giner y Gely (2005) la recomiendan especialmente para oleaginosas, como girasol y soja. 


\subsubsection{Análisis de modelos teóricos de sorción.}

Los modelos que se usan con mayor frecuencia son los propuestos por Langmuir, Freundlich y Brunauer, Emett y Teller (B.E.T) a nivel de monocapa y Guggenheim, Anderson, De Boer (G.A.B), para adsorción en multicapa. La ecuación de G.A.B. ha sido reconocido como el modelo de mayor fundamento teórico para describir los fenómenos termodinámicos del agua en los alimentos (García y Martínez, 2006).

Modelo de Guggenheim, Anderson y De Boer (G.A.B)

$$
W=\frac{W_{m} C_{G} k_{G} a_{w}}{\left(1-k_{G} a_{w}\right)\left(1-k_{G} a_{w}+C_{G} k_{G} a_{w}\right)}
$$

Una ventaja del modelo de G.A.B es que sus coeficientes $W_{m}, C_{G}$ y $k_{G}$ tienen una interpretación física. El coeficiente $W_{m}$ representaría el contenido de humedad de monocapa, (García y Martínez, 2006; Menkov, 2000). La obtención de los valores de $W_{m}$ es importante, toda vez que el agua está fuertemente asociada al alimento debajo de este valor y no se encuentra disponible ni como solvente ni como sustrato (sí para oxidación de lípidos). Los parámetros $C_{G}$ y $k_{G}$ se relacionan con la temperatura y con el calor isostérico durante la adsorción de agua en las semillas (Aviara y col., 2006). 


\subsection{Materiales y métodos.}

\subsubsection{Plan experimental.}

A continuación se presenta un diagrama de flujo que esquematiza los procedimientos realizados en este capítulo

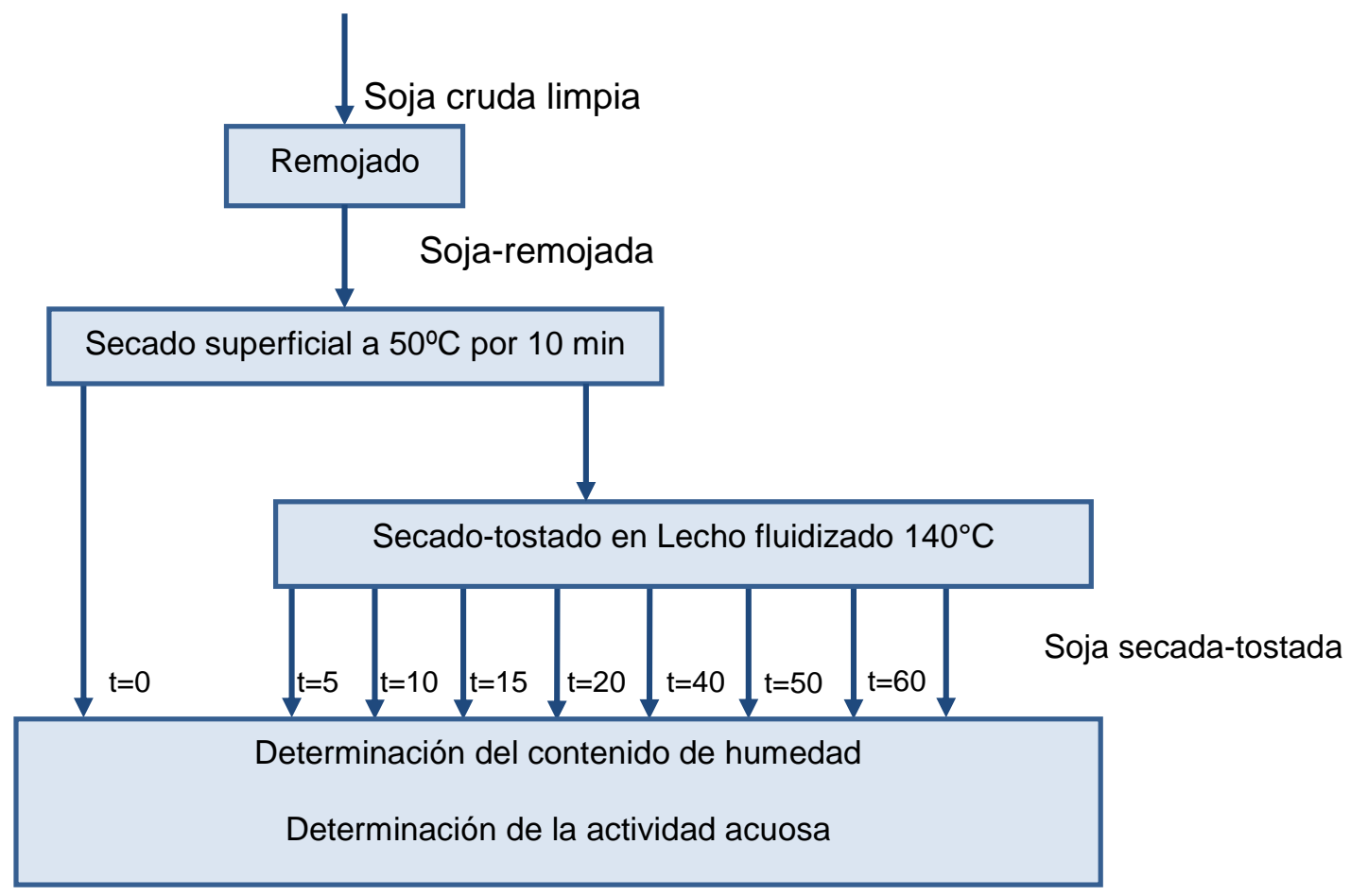

Figura 4.3. Diagrama de flujo del procedimiento experimental realizado.

\subsubsection{Determinación de la isoterma de sorción.}

Las muestras secadas-tostadas parcialmente a diferentes tiempos se almacenaron en recipientes herméticos durante 24 hs para alcanzar una distribución homogénea del agua en el interior del grano. Las isotermas de sorción fueron determinadas de acuerdo al método higrométrico a tres temperaturas: 16, 25 y $40^{\circ} \mathrm{C}$. El mismo consistió en 
colocar una muestra de granos en un recipiente hermético pequeño (masa de granos $\gg$ masa del aire confinado) de manera de lograr que la $h_{r}$ del aire evolucione a un equilibrio con la $a_{w}$ del grano, sin que éste modifique en forma detectable su contenido de humedad durante la aproximación al equilibrio. Para que la determinación sea representativa de toda la muestra, ésta no debe representar gradientes de actividad de agua en su interior. Así, el $a_{w}$ del grano se mide directamente a través de la $h_{r}$ del aire de equilibrio. Repitiendo el procedimiento para las muestras de granos secados-tostados a distinta humedad, se puede construir la isoterma de equilibrio. A continuación se presenta un figura con el equipo empleado para tal determinación.
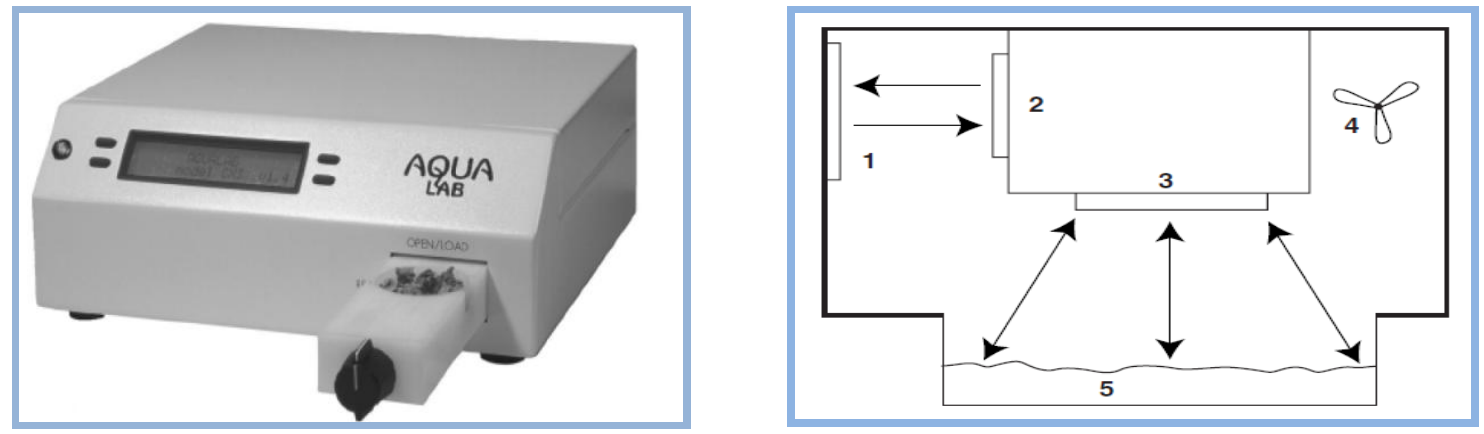

Figura 4.4 (a) Equipo AQUALAB Serie 3 empleado para las determinaciones de $a_{w}$, (b) modelo del funcionamiento interno del AQUALAB (1-espejo, 2-sensor óptico, 3termómetro infrarrojo, 4-micro ventilador, 5-porta muestra cargado)

El equipo AQUALAB serie 3 (Figura 4.4 a), emplea el método de determinación de punto de rocío. La muestra se equilibra con el aire presente en el espacio de cabeza de una cámara sellada que contiene un espejo, un sensor óptico, un ventilador y un termómetro infrarrojo (Figura 4.4 b). El ventilador interno genera una circulación de aire que reduce el tiempo de equilibrio entre la muestra y el espacio de cabeza. El equilibrio se logra sin pérdida ni ganancia considerable de humedad para la muestra en 
virtud de que ésta es mucho mayor a la del aire y, sobre todo, que la del vapor contenido en él.

En el equilibrio, la humedad relativa del aire en la cámara es la misma que la actividad acuosa de la muestra. Una celda termoeléctrica por efecto Peltier controla la temperatura del espejo. Un diodo emisor de luz ilumina directamente al espejo, siendo esta luz reflejada hacia el sensor óptico, que registra un cambio en la reflectividad cuando se produce condensación sobre el espejo. Al cabo de una sucesión de condensaciones y evaporaciones, un sensor de temperatura embutido en el espejo mide la temperatura de rocío. Adicionalmente un termómetro infrarrojo sin contacto mide la temperatura de la superficie de la muestra, que está en equilibrio con la temperatura de bulbo seco del aire del espacio de cabeza. Las dos temperaturas mencionadas se utilizan para calcular la humedad relativa del aire, que en equilibrio con la muestra se visualiza como actividad acuosa de ésta.

El rango de medición de $a_{w}$ se encuentra entre 0.03 y 1, con una resolución de \pm 0.001 . La medición normalmente se logra en 5 minutos. El equipo exhibe los datos de actividad acuosa y temperatura de equilibrio en un visor digital.

\subsection{Resultados y discusión.}

\subsubsection{Isoterma de equilibrio experimental.}

A continuación podemos observar las isotermas de equilibrio obtenidas, para cada temperatura estudiada 


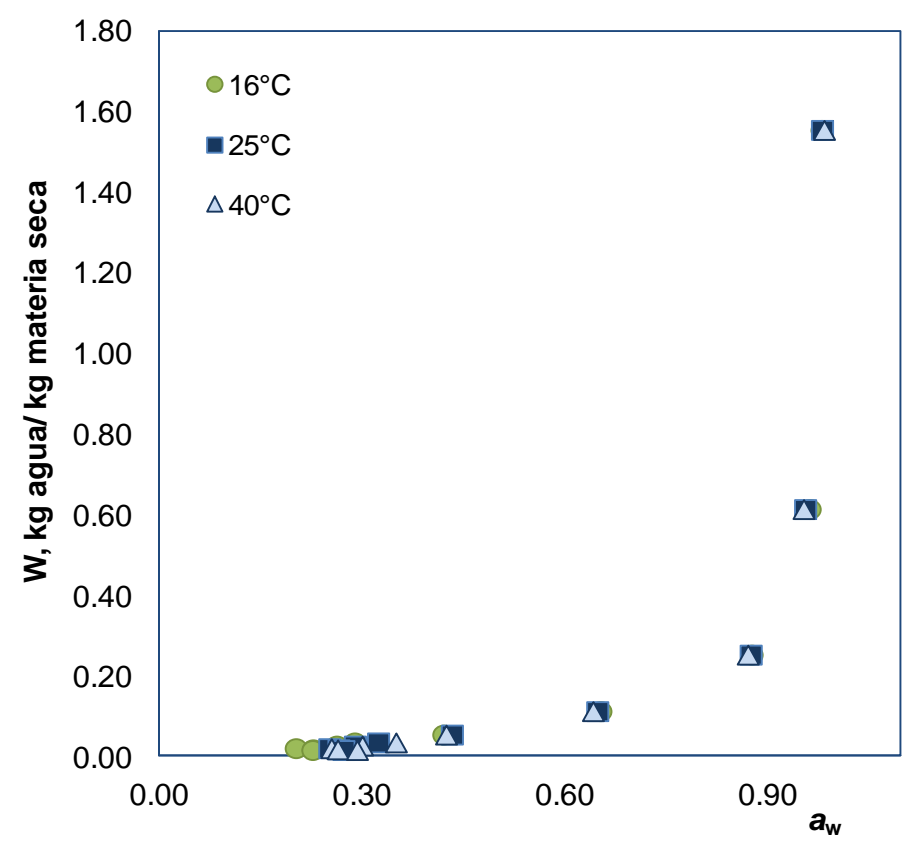

(a)

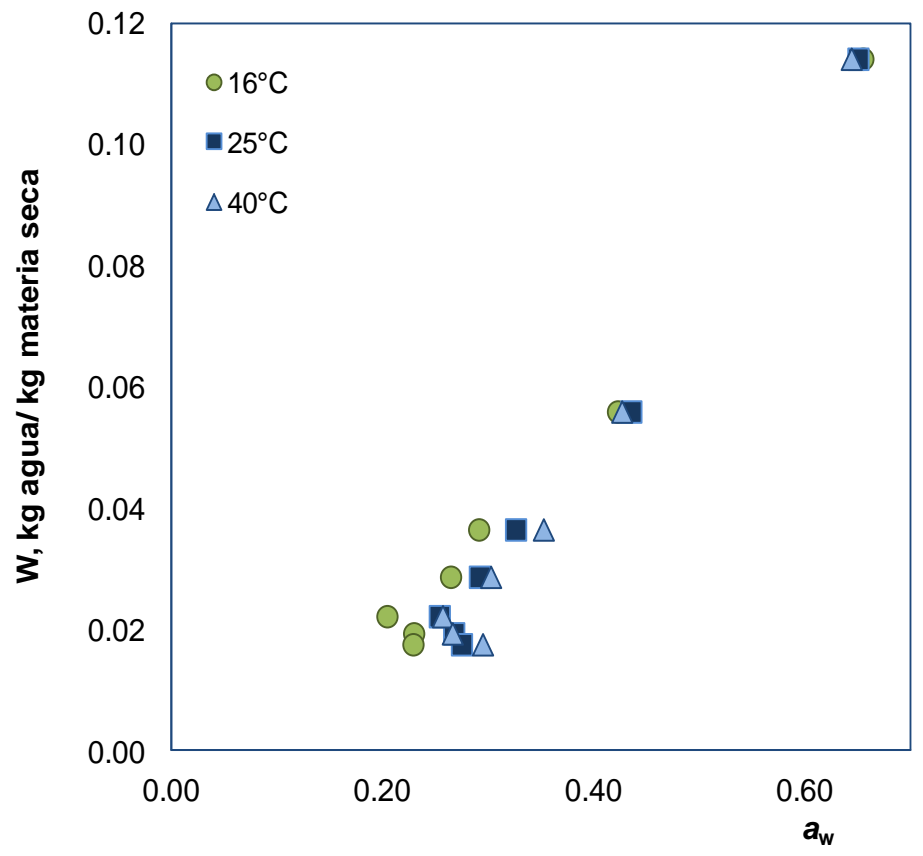

(b)

Figura 4.5 Valores experimentales de la actividad de agua en función del contenido de humedad a las tres temperaturas estudiadas: (a) rango completo de actividad de agua, (b) zona de baja humedad entre 0 y 0.6 de actividad acuosa. 
Un análisis estadístico mediante el test de Tukey (Montgomery, 1991), con un nivel de confianza de 95\% reveló que no existieron diferencias significativas entre los valores determinados de $a_{w}$ a las diferentes temperaturas. Por tanto, no es posible en este caso en particular, considerar una dependencia clara con dicho parámetro. Moreira y col., (2009) estudiando las características sorcionales en diversas frutas y legumbres, encontraron en estas últimas que la temperatura no ejercía un efecto claro, probablemente por la gran cantidad de compuestos no solubles que poseían en su composición. Por su parte, Osborn y col. (1989), investigando las características sorcionales de soja cruda, entre 10 y $40^{\circ} \mathrm{C}$, no encontraron una funcionalidad demasiado importante con la temperatura.

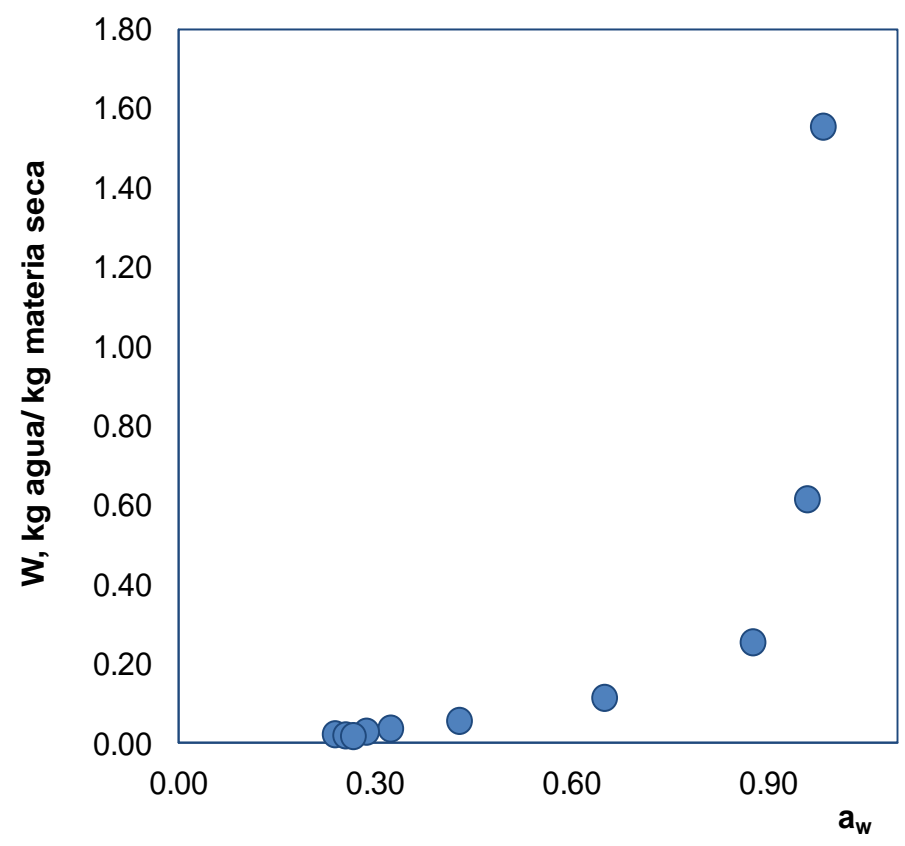

Figura 4.6 Valores de actividad de agua en función del contenido de humedad, promediados a partir de los resultados obtenidos a cada temperatura.

La isoterma presentó una forma similar a la de una "J" que de acuerdo a lo especificado en la Sección 4.1.2 de este Capítulo, correspondería a frutas y alimentos 
azucarados entre otros, que contienen componentes solubles. Sin embargo dado, que los valores se concentran en valores próximos a un $a_{\mathrm{w}}$ igual a 0.3 , resulta complicado establecer la forma general de la misma. Con relación a este punto, es conveniente mencionar que la soja contiene alrededor de un $20 \%$ de aceite, el cual probablemente influya en las propiedades higroscópicas del mismo. Dado su carácter hidrofóbico, el agua del grano de soja está vinculada a la materia seca libre de aceite. Giner y Gely (2005) destacan que el aceite probablemente absorbe una cantidad despreciable de agua, sin embargo, por efectos estéricos, pueden obstruir la absorción de agua en el grano.

Dado que las condiciones más habituales para el almacenamiento de productos deshidratados suele ser estar próximos a $\operatorname{los} 25^{\circ} \mathrm{C}$, los ajustes posteriores se realizarán a esta temperatura.

\subsubsection{Ajuste de las ecuaciones matemáticas a los datos experimentales.}

Dado que no existió una dependencia con la temperatura, en las ecuaciones 4.6, 4.7, 4.8 y 4.9, el parámetro o término que consideraba el efecto térmico se redujo a un solo parámetro de ajuste.

Ecuación de Henderson-Thompson modificada

$$
W=0.01\left[\frac{-\operatorname{Ln}\left(1-a_{w}\right)}{K_{H T M}}\right] 1 / N_{\text {HTM }}
$$

Ecuación de Chung-pfost modificada 
$W=-\frac{0.01}{C P_{3}} \operatorname{Ln}\left(-\frac{C P_{2} \operatorname{Ln} a_{w}}{C P_{1}}\right)$

Ecuación de Oswin modificada

$W=0.01 C M_{1}\left[\frac{a_{w}}{1-a_{w}}\right]^{C M_{2}}$

Ecuación de Halsey modificada

$$
W=0.01\left[\frac{-\exp \left(A_{H M}\right)}{\operatorname{Ln} a_{w}}\right] 1 / R_{H M}
$$

Los resultados obtenidos a partir del ajuste, se presentan a continuación en la Tabla 4.1 
Tabla 4.1 Parámetros determinados para los diferentes modelos utilizados a partir de los datos experimentales a las tres temperaturas analizadas.

\begin{tabular}{|c|c|c|c|}
\hline $\begin{array}{c}\text { Temperatura } \\
{ }^{\circ} \mathrm{C}\end{array}$ & modelo & Coeficientes & $r^{2}$ \\
\hline & Henderson-Thompson & $K_{H T M}=0.859(0.135)$ & 0.988 \\
\hline & & $N_{\text {НтM }}=0.312(0.032)$ & \\
\hline & Chung-Pfost & $C P_{1}=0.243(6.375)$ & 0.814 \\
\hline & & $C P_{2}=0.218(5.721)$ & \\
\hline \multirow[t]{5}{*}{25} & & $C P_{3}=0.037(0.007)$ & \\
\hline & Oswin & $C M_{1}=3.929(0.604)$ & 0.997 \\
\hline & & $C M_{2}=0.891(0.039)$ & \\
\hline & Halsey & $A_{H M}=1.346(0.178)$ & 0.998 \\
\hline & & $R_{H M}=1.086(0.039)$ & \\
\hline
\end{tabular}

Como puede apreciarse en los valores informados en la Tabla 4.1, el modelo que presento el menor coeficiente de correlación fue la ecuación de Chung-Pfost modificada, por tanto, no se tuvo en cuenta para los cálculos posteriores.

En relación a las ecuaciones restantes, si bien el ajuste mostró ser bueno en todos los casos $\left(r^{2}>0.95\right)$, el mejor valor lo presento el modelo de Halsey, en coincidencia con lo informado por otros autores como Aviara y col. (2006). 
A continuación se presenta, una figura con los datos experimentales y los predichos empleando esta última ecuación (Ec. (4.14))

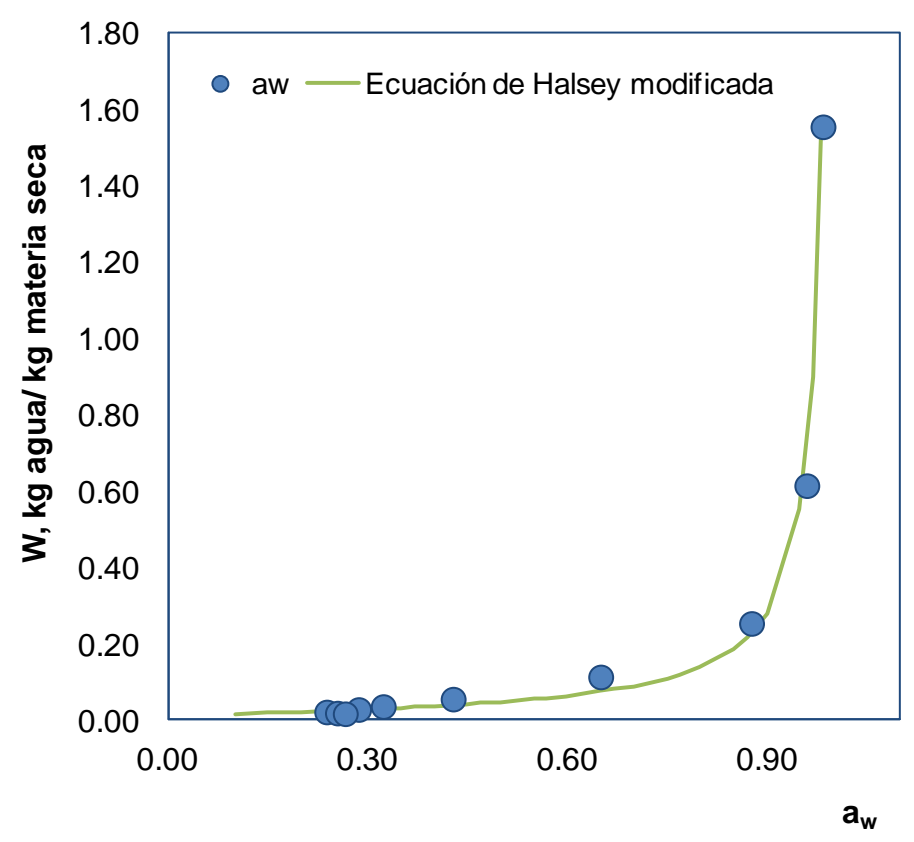

Figura 4.7 Ajuste mediante la ecuación de Halsey modificada a $25^{\circ} \mathrm{C}$, en el rango completo de actividades acuosas.

Dado que se observó una predicción inferior a los valores experimentales en el intervalo próximo a la humedad de seguridad, entre 0.6 y 0.8 . Se realizó a continuación un nuevo ajuste de los datos de sorción, ahora trabajando en dos intervalos de actividades acuosas: uno entre $0.8-0.98$ correspondiente a la zona denominada de “alta humedad" y otro entre $0-0.8$ correspondiente a la zona de "baja humedad". Los resultados de este procedimiento se presentan a continuación en la Figura 4.8 


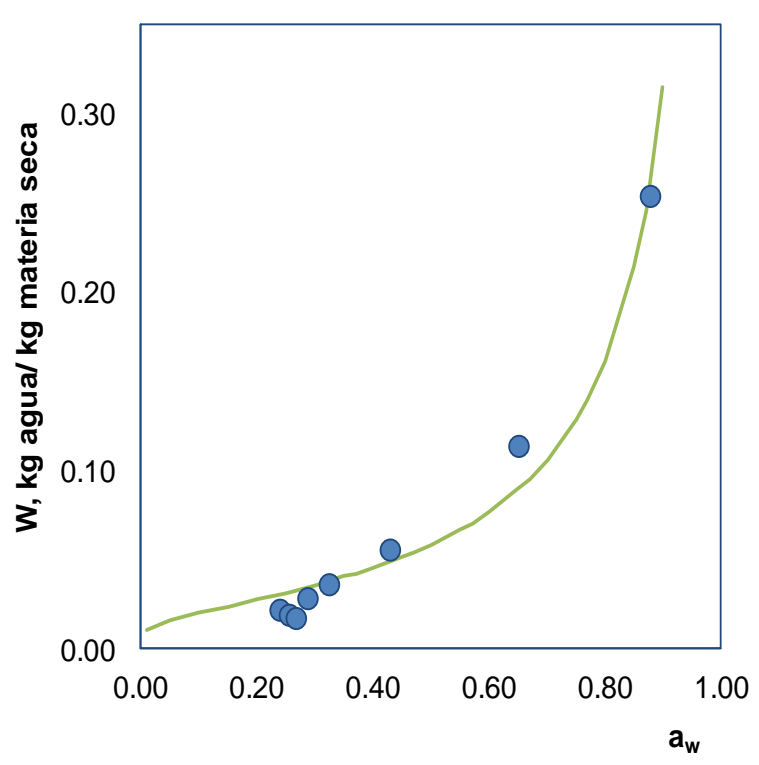

(a)

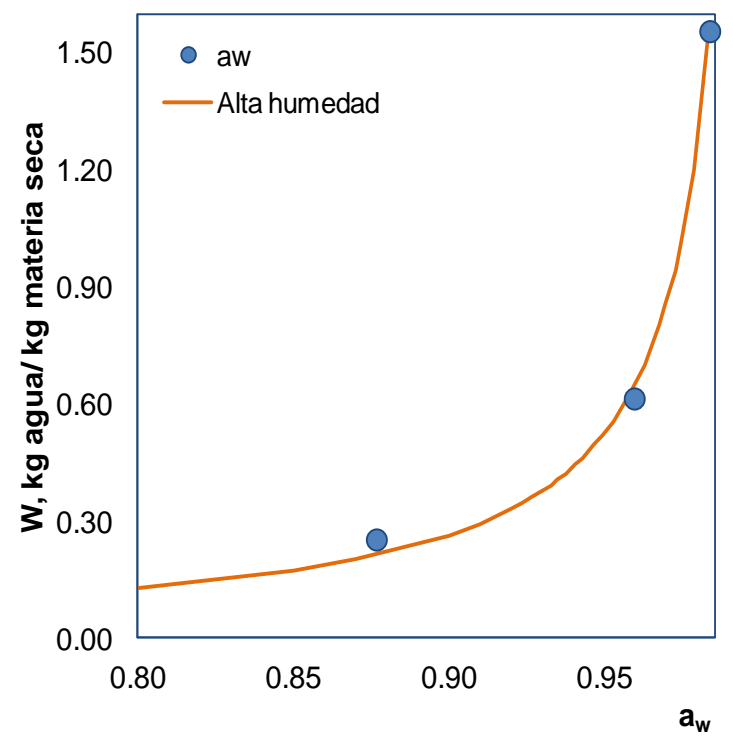

(b)

Figura 4.8 Las figuras muestran el ajuste mediante la ecuación de Halsey modificada (4.14) en las zonas correspondientes a bajas humedades $\left(0-0.8\right.$ de $\left.a_{\mathrm{w}}\right)$ y altas humedades (0.8- 0.98 de $\left.a_{\mathrm{w}}\right)$.

A continuación se presenta la Tabla 4.2 con lo valores de los parámetros obtenidos mediante el ajuste en las zonas de baja y alta humedad. 
Tabla 4.2 Parámetros ajustados de la Ecuación de Halsey modificada, en las zonas correspondientes a altos y bajos contenidos de humedad.

\begin{tabular}{cccc}
\hline \multicolumn{3}{c}{ Halsey modificado } \\
\hline $\begin{array}{c}\text { Temperatura } \\
{ }^{\circ} \mathrm{C}\end{array}$ & modelo & Coeficientes & $r^{2}$ \\
\hline & Alta humedad & $A_{H M}=1.176(0.333)$ & 0.998 \\
25 & $0.8-0.98$ & $R_{H M}=1.039(0.068)$ & \\
& Baja humedad & $A_{H M}=1.595(0.269)$ & 0.973 \\
& $0-0.8$ & $R_{H M}=1.117(0.086)$ & \\
\hline
\end{tabular}

El producto secado-tostado posee un contenido final de humedad de 0.018 dec., b.s., lo cual significo un $a_{w}$ de 0.274 . Para esta actividad de agua el modelo de Halsey correpondiente a la zona de baja humedad predijo una humedad de equilibrio de 0.033 dec., b.s., mientras que el modelo para contenidos acuosos elevados predijo un valor de 0.024, ambos superiores al valor experimental. De acuerdo, a lo propuesto por Fennema (2010) un producto en el cual se desea mantener la crocancia debería almacenarse en un rango de $a_{\mathrm{w}}$ no superior a 0.45 , reemplazando este valor en nuestro modelo, el valor práctico de humedad sería de 0.051 dec, b.s., por tanto el producto deshidratado, secado-tostado a base de grano entero de soja, en condiciones adecuadas de almacenamiento y envase hérmetico mantendría su crocancia.

Dado que la gran mayoría de los estudios sorcionales hallados en bibliografía se llevaron adelante con granos de soja en rangos de humedad post-cosecha se determinó la isoterma de sorción a $25^{\circ} \mathrm{C}$ de grano de soja crudo con diferentes niveles de humedad de entre 0.05 y 0.8 dec., b.s. Este procedimiento se realizó con el fin de comparar el 
modelo determinado en este trabajo con el modelo de Halsey con parámetros para soja cruda determinados por Osborn y col. (1989) en un trabajo ampliamente conocido.

Los granos de soja cruda se humectaron mediante el procedimiento descripto con más detalle en la sección 2.3.4 del capítulo 2. Esto permitió generar muestras en un rango de humedades de 0.05 a 0.8 dec., b.s, cuyas actividades de agua se determinaron por el método ya descripto. Los resultados (datos no mostrados) se ajustaron mediante la ecuación de Halsey modificada (Ec.(4.14)). Los parámetros obtenidos fueron los siguientes $A_{H M}=2.261(0.075)$ y $R_{H M}=1.279(0.027)$ con un $R^{2}$ de 0.999 .

A continuación se comparan las isotermas predichas para la muestra cruda y la remojada y secada-tostada, con las predicciones de Osborn y col. (1989), $b=-0.005$, $C=2.87$ y $R=1.38$, para soja cruda.

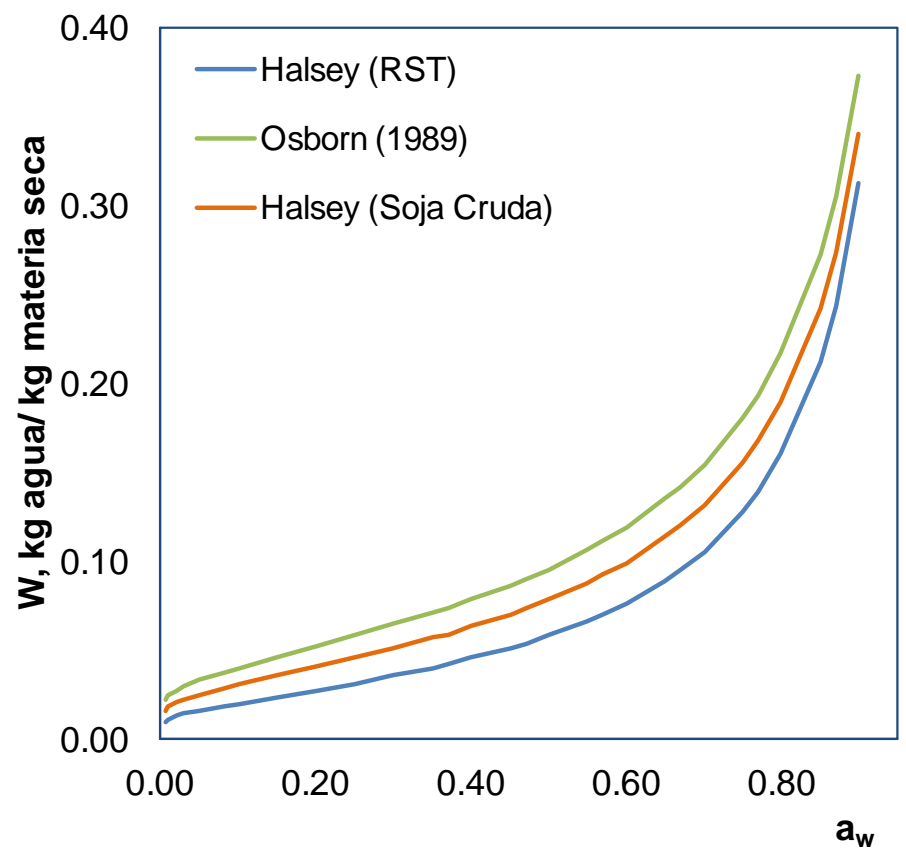

Figura 4.9 Comparación de isotermas de soja cruda con la determinada a partir de la muestra remojada, secada y tostada. 
Como puede observarse, existen diferencias entre las predicciones. La isoterma de soja cruda determinada en este trabajo se aproxima más a los datos determinados por Osborn y col. (1989). Si comparamos ambas predicciones para soja cruda con las de la muestra RST la diferencia es mayor. La causa de este comportamiento probablemente esté relacionada con la historia previa del producto bajo estudio. Osborn y col. (1989), desarrollaron este modelo para granos de soja crudos en condiciones de humedad moderada dentro de 5 a $20 \%$ b.h. mientras que en este estudio se partió de un grano remojado con un contenido inicial de $50 \%$ b.h. Además cabe la posibilidad de que el producto secado-tostado haya perdido minerales, sustancias hidrofílicas, por solubilización durante el remojado mientras que dado el carácter hidrofóbico de los lípidos estos se mantuvieron asociados a la matriz del grano. Este fenómeno originaría una mayor concentración de lípidos por gramo de materia seca en el producto final lo cual, como se discutió anteriormente en la sección 4.3.1 disminuye la cantidad de agua adsorbida a igual actividad de agua..

\subsubsection{Ajuste del modelo teórico de G.A.B.}

A continuación se presentan los valores obtenidos de los parámetros de la ecuación de G.A.B como resultado del ajuste a los datos experimentales 
Tabla 4.3 Parámetros de ajuste de la ecuación de G.A.B, determinados a partir de datos experimentales de sorción a $25^{\circ} \mathrm{C}$.

\begin{tabular}{ccccc}
\hline $\begin{array}{c}\text { Temperatura } \\
{ }^{\circ} \mathbf{C}\end{array}$ & \multicolumn{3}{c}{ Coeficientes Ecuación de G.A.B } & $\boldsymbol{r}^{2}$ \\
\hline 25 & $\boldsymbol{W}_{\boldsymbol{m}}$ & $\boldsymbol{C}_{\boldsymbol{G}}$ & $\boldsymbol{K}_{\boldsymbol{G}}$ & \\
\hline & $0.028(0.001)$ & $14.416(25.820)$ & $0.999(0.001)$ & 0.998 \\
\hline
\end{tabular}

De acuerdo a la definición de los estos parámetros (Sección 4.3.4) los tres parámetros de la ecuación de G.A.B caracterizan las interacciones del agua con los macrocomponentes de alimento. Giner (1999) realizando un análisis de los parámetros de la ecuación de G.A.B en trigo, encontró que tanto el valor de $C_{G}$ como el de $K_{G}$ no mostraron un comportamiento claro en función de la temperatura, y que superado un valor de 10 , el $\mathrm{C}_{\mathrm{G}}$ se volvía irrelevante.

Con respecto al valor de monocapa $W_{m}$, este fue menor al informado por García y Martinez (2006) que realizaron una investigación en diferentes cereales para el desayuno a base de arroz, maíz y trigo. A su vez, también resulto ser menor al valor informado por Aviara y col. (2004), que investigaron la humedad monocapa en granos de soja cruda. 


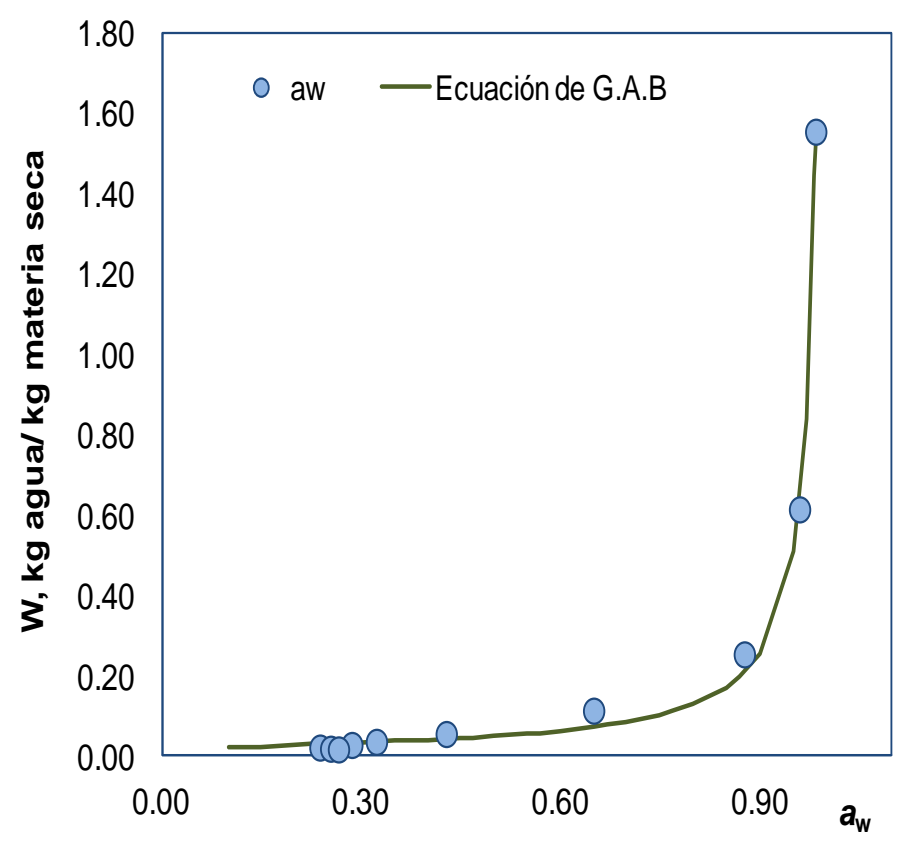

Figura 4.7 Ajuste mediante la Ecuación de G.A.B a $25^{\circ} \mathrm{C}$, en el rango completo de actividades acuosas.

Si bien, el ajuste mediante la ecuación de G.A.B, presentó un ajuste tan bueno como el de la ecuación de Halsey $\left(r^{2}=0.998\right)$, para cálculos futuros se utilizará la segunda, dado que la misma solo posee dos parámetros de ajuste, mientras que la de G.A.B tiene tres. Esto contribuiría a mantener la sencillez del cálculo sin perder precisión predictiva además Halsey es recomendada en particular para oleaginosas.

\subsubsection{Determinación del calor de sorción.}

De acuerdo, al análisis realizado en secciones anteriores el $a_{w}$ no mostró funcionalidad con la temperatura. Sin embargo, a fines prácticos se cree conveniente describir en la siguiente sección, el procedimiento necesario para el cálculo de esta propiedad termodinámica, dado que el calor de sorción corresponde a la energía latente 
que debe ser provista a efectos de evaporar el agua presente en el producto (Bahloul y col., 2008).

Para llevar adelante este análisis, se empleará la Ecuación de Halsey modificada (Ec.(4.8)).

\subsubsection{Método de Clapeyron-isoterma de sorción.}

El calor de vaporización podía calcularse en función de la temperatura por medio de la ecuación de Clapeyron (Chen, 2006):

$$
L_{w}=\frac{R T_{K}^{2}}{M_{v}} \frac{d \ln p_{s}}{d T_{K}}
$$

Dicha ecuación predice un decrecimiento suave de $L_{w}$ con la temperatura. Ratti (1991) ha mostrado que la Ecuación de Clapeyron puede usarse también para agua adsorbida:

$$
L_{g}=\frac{R T_{K}^{2}}{M_{v}}\left(\frac{\partial \ln p_{v}}{\partial T_{K}}\right)_{W}
$$

Si reemplazamos $p_{v}$ en la Ec. (4.16) por $a_{w} p_{s}$, la expresión resultante es

$$
L_{g}=\frac{R T_{K}^{2}}{M_{v}}\left[\frac{d \ln p_{s}}{d T_{K}}+\left(\frac{\partial \ln a_{w}}{\partial T_{K}}\right)_{W}\right]
$$

que puede reescribirse de forma más sencilla de la siguiente manera 
$L_{g}=L_{w}+\frac{R T_{K}^{2}}{M_{v}}\left(\frac{d \ln a_{w}}{d T_{K}}\right)_{W}$

Por tanto, el calor de sorción en granos está compuesto por el calor de vaporización de agua pura $\left(L_{w}\right)$ más un término debido a la energía adicional de atracción entre las moléculas de agua y los componentes de la materia seca higroscópica del grano. Ese término resulta de la isoterma de sorción.

No obstante, en virtud de que las isotermas determinadas en este trabajo para el producto remojado y parcial y totalmente secado-tostado no mostraron efecto de la temperatura sobre el valor de actividad acuosa, se considerará el calor de desorción aproximadamente igual al calor de vaporización

\subsection{Conclusiones.}

La isoterma experimental determinada para los granos de soja, remojados y secados-tostados presento una forma complicada de caracterizar en comparación con otros tipos de isotermas existentes. Probablemente esto guarde relación con la historia previa del producto, es decir el alto contenido de humedad inicial y las elevadas temperaturas de requeridas durante el proceso para llevarlo a valores muy bajos de humedad.

A partir de los datos experimentales de contenido de humedad vs $a_{w}$ a cada temperatura, se determinó que no existió un efecto neto de la temperatura sobre el comportamiento sorcional, por lo que, no fue posible evaluar la influencia de este parámetro. Esto, permite con vistas al estudio de la cinética de secado-tostado y 
posteriormente en lecho fluidizado, considerar para el planteo y resolución de los modelos matemáticos el valor del calor de evaporación del agua pura.

De todos los modelos empleados para el ajuste de los datos experimentales, el modelo de Halsey mostró los mejores resultados, lo cual concuerda con lo informado por diferentes autores en la bibliografía, que recomendaron está ecuación especialmente para oleaginosas. De esta manera, en capítulos posteriores, destinados al estudio de la cinética de secado-tostado en capa delgada y más adelante en lecho fluidizado se utilizará este modelo para el cálculo de la humedad de equilibrio. 


\section{CAPÍTULO V}

\section{CINÉTICA DE SECADO-TOSTADO DE GRANO}

\section{ENTERO DE SOJA}




\section{Introducción.}

La deshidratación es una operación en la que se da el transporte simultáneo de calor y masa. En esta operación debe aportarse el calor sensible y aquél necesario para la evaporación, o sublimación, mientras el agua o el vapor de agua se transportan por el interior del alimento hasta la superficie donde el vapor de agua se transfiere desde el alimento hacia el medio circundante (Fito y col., 2001). Por remover agua en alimentos, secado y deshidratación son sinónimos.

La deshidratación constituye uno de los métodos más antiguos de preservación de los alimentos, que se realiza principalmente para evitar el crecimiento microbiano, lo que permite la conservación por largos períodos a temperatura ambiente (Lewicki, 2006). En relación a esto, Luangmalawat y col., (2008) mencionan que la calidad de un alimento es muy sensible a la temperatura de secado. Cambios en el color, el tamaño, la presencia de sustancias nutricionales, la habilidad para rehidratarse y otras modificaciones estructurales pueden afectar la aceptabilidad del producto final por parte del consumidor. Aguilera y col. (2003) destacan la importancia de este tipo de operación no sólo como método de preservación sino también como un proceso útil en el desarrollo de nuevos productos capaces de satisfacer las necesidades de un mercado que demanda constantemente productos innovadores. Por tanto, un conocimiento más profundo de los fenómenos que suceden durante el secado es necesario, si se desea optimizar el proceso y mejorar no solo la eficiencia sino también la calidad del producto final (Di Scala y Crapiste, 2008).

La deshidratación en corriente de aire, es un proceso dominado por dos resistencias principales (1) la externa, o del medio de secado (2) la interna o del producto. Generalmente la primera se asocia con la resistencia de la película estanca de aire que rodea al producto, mientras que la segunda, con la difusión del agua dentro del 
producto (en estado líquido o vapor) hasta su remoción hacia el medio de secado. Al iniciar la deshidratación de productos de alta humedad, las resistencias externas e internas son importantes. En la zona de bajas humedades de producto, la resistencia interna a la migración de agua se vuelve controlante. La mayor parte de los estudios relacionados con el secado de alimentos han sido dirigidos hacia la comprensión de los complejos fenómenos para posibilitar un mejor entendimiento de los mecanismos intervinientes, así como para contribuir a generar productos deshidratados de mejor calidad (Mensah y col., 1985; Akpinar, 2006).

La cinética de secado de un producto es uno los datos más relevantes para el diseño y simulación de secadores (Ratti, 2009). Con el propósito de describir la cinética de secado, en la mayoría de los estudios el alimento se seca bajo condiciones constantes de aire para confinar las variaciones al producto, y poder determinar sus parámetros, en relación a tales condiciones de aire, las que se varían de una experiencia a la otra (Mohapatra y Rao, 2005; Ratti, 2009). En la bibliografía se han encontrado numerosos trabajos en relación al estudio de la cinética de secado como Sun y Woods, (1994), en cebada, Gely y Giner, (2000) en distintos cultivares de soja cruda y Nilton y col. (2012) en granos de café, entre otros, pero hasta el momento no se informaron resultados del estudio de la cinética de secado-tostado de grano entero de soja remojada o previamente cocida. A su vez, son muy pocos los trabajos que consideraron el encogimiento del producto durante el secado en la resolución de los modelos planteados.

En vista de lo analizado en capítulos previos, el objetivo principal de este capítulo es analizar la cinética de secado-tostado en lecho fluidizado de grano entero de soja remojado, a través de diferentes modelos matemáticos, con el propósito de desarrollar un modelo cinético realista que pueda, posteriormente, ser utilizado dentro un algoritmo de diseño de equipos de lecho fluidizado. 


\subsection{Materiales y Métodos.}

\subsubsection{Plan experimental.}

A continuación se presenta un diagrama de flujo que esquematiza los procedimientos realizados en este capítulo

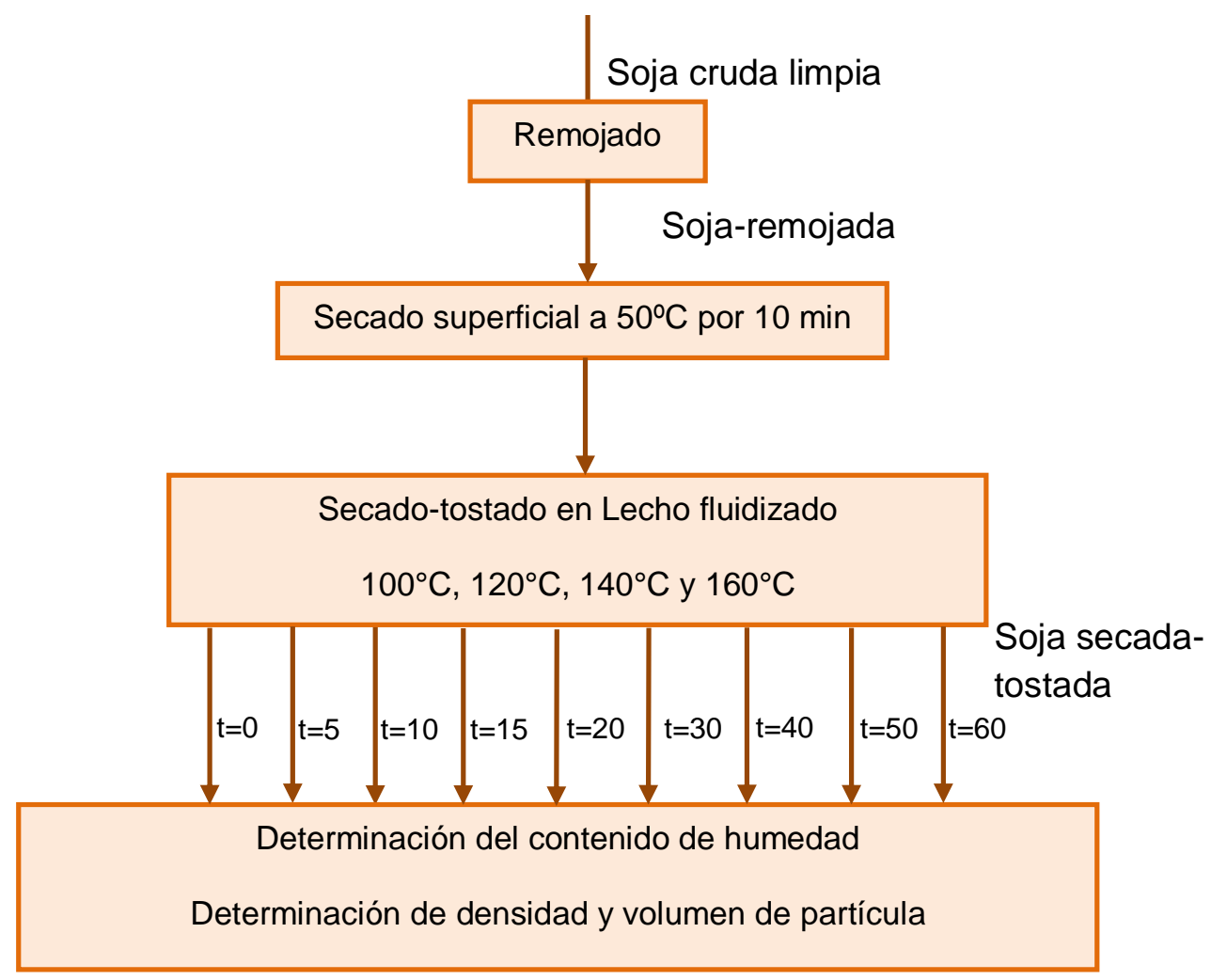

Figura 5.1. Diagrama de flujo del procedimiento experimental realizado.

\subsubsection{Secado-tostado en capa delgada en condiciones de fluidización.}

Se trabajó con 4 temperaturas de aire: $100,120,140$ y $160^{\circ} \mathrm{C}$, y una velocidad promedio de $2.5 \mathrm{~m} / \mathrm{s}$. Una vez que se alcanzaron las condiciones de velocidades y temperatura de aire, se cargó una capa delgada de porotos en la cámara de secado en el equipo descrito en el Capítulo 2, Sección 2.3.8. A todas las temperaturas, se extrajeron 
muestras a tiempos de $5,10,15,20,25,30,40,50$ y 60 minutos, tratando en lo posible de no alterar el sistema durante dicha extracción. Dicho procedimiento se llevó a cabo con una cuchara alargada de acero inoxidable. Las humedades se determinaron mediante la técnica descrita en la Sección 2.3.3 del Capítulo 2. Para determinar la historia térmica de los granos se utilizó un equipo Testo 830, que funciona en base a tecnología infrarroja y permite medir la temperatura ambiente y de superficie sin contacto y con bastante precisión $\left( \pm 0.5^{\circ} \mathrm{C}\right)$.

\subsection{Resultados y Discusión.}

\subsubsection{Curvas de secado experimental.}

Se presentan los valores de humedad determinados para cada temperatura, durante el tratamiento de secado-tostado en lecho fluidizado.

Tabla 5.1 Contenidos de humedad experimental determinados a cada temperatura.

\begin{tabular}{ccccc}
\hline Tiempo & \multicolumn{4}{c}{ Temperatura, ${ }^{\circ} \mathrm{C}$} \\
& 100 & 120 & 140 & 160 \\
\cline { 2 - 5 } & W, kg H $\mathrm{H}_{2}$ / kg m.s. & W, $\mathrm{kg} \mathrm{H}_{2} 0 / \mathrm{kg}$ m.s. & W, $\mathrm{kg} \mathrm{H}_{2} 0 / \mathrm{kg} \mathrm{m} . \mathrm{s}$. & $\mathrm{W}, \mathrm{kg} \mathrm{H}$ O/ kg m.s. \\
\hline 0 & 1.483 & 1.472 & 1.485 & 1.436 \\
5 & 0.825 & 0.682 & 0.605 & 0.371 \\
10 & 0.551 & 0.443 & 0.214 & 0.077 \\
15 & 0.457 & 0.314 & 0.068 & 0.026 \\
20 & 0.322 & 0.221 & 0.052 & 0.013 \\
25 & 0.294 & 0.151 & 0.036 & 0.011 \\
30 & 0.237 & 0.140 & 0.030 & 0.014 \\
40 & 0.192 & 0.089 & 0.019 & 0.009 \\
60 & 0.118 & 0.061 & 0.010 & 0.003 \\
\hline
\end{tabular}


A continuación se presentan las curvas de secado experimental determinadas mediante la metodología de capa delgada. En las mismas se representa el contenido de humedad adimensionalizada vs el tiempo de secado

$$
W_{a d}=\frac{W-W_{e}}{W_{0}-W_{e}}
$$

donde $W_{e}$ es la humedad de equilibrio estimada mediante la ecuación de Halsey modificada Ec.(4.14) ajustada a datos de baja humedad, con los parámetros $\mathrm{A}_{\mathrm{HM}}=1.595$ y $\mathrm{R}_{\mathrm{HM}}=1.117$ (Capítulo 4, Sección 4.3.2). Los valores de $W_{e}$ fueron los siguientes 0.012 dec., b.s., a $100^{\circ} \mathrm{C}, 0.010$ dec., b.s., a $120^{\circ} \mathrm{C}, 0.009$ dec., b.s., a $140^{\circ} \mathrm{C}$ y 0.008 dec., b.s., a $160^{\circ} \mathrm{C}$. La isoterma de Halsey no depende de la temperatura pero sí de la humedad relativa, por eso el valor de $\mathrm{W}_{\mathrm{e}}$ es distinto a cada temperatura de secado. Las condiciones del aire de secado (temperatura y humedad) y la humedad inicial del grano $\left(W_{0}\right)$ se tienen en cuenta mediante esta adimensionalización. 


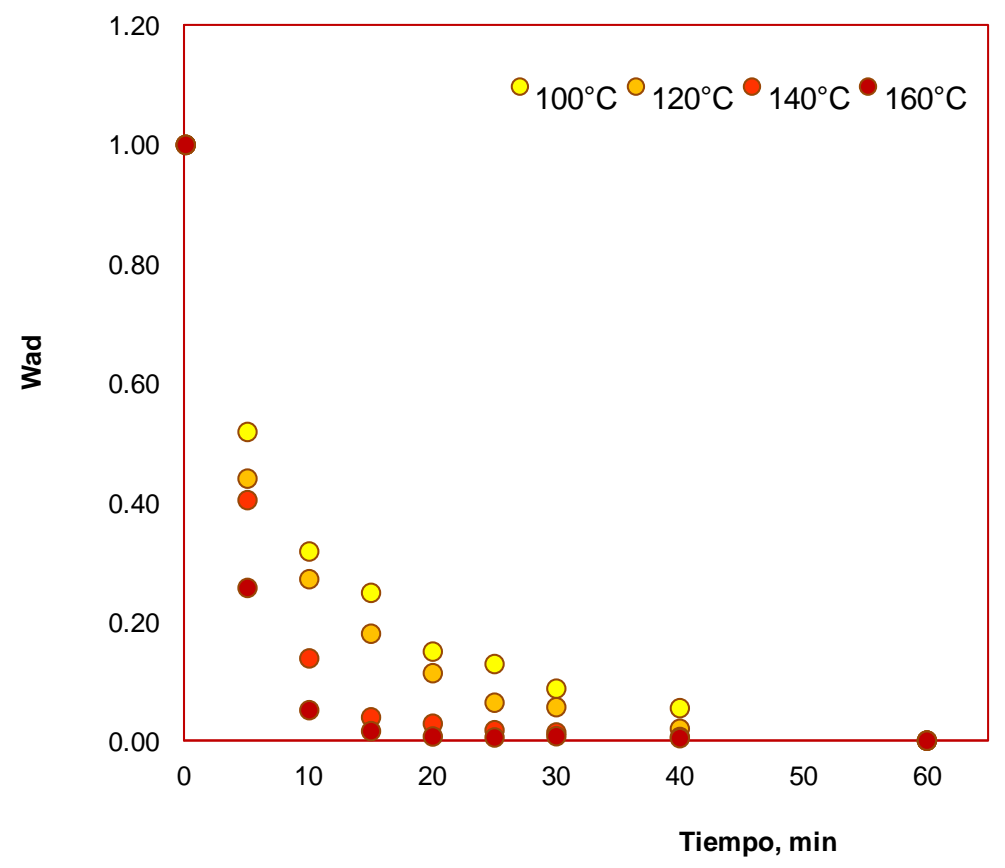

Figura 5.2 Curvas de secado experimental de grano entero de soja representada como $W_{a d}$ en función del tiempo para cada temperatura analizada.

De acuerdo a la Figura 5.2, las curvas de secado obtenidas mediante las experiencias de capa delgada muestran un decrecimiento brusco del contenido de humedad con el tiempo. Esta disminución se vuelve aún más pronunciada a mayores temperaturas. Si comparamos las curvas obtenidas a 140 y $160^{\circ} \mathrm{C}$, con las de 100 y $120^{\circ} \mathrm{C}$ observamos que se alcanzan bajos contenidos de humedad en mucho menos tiempo a mayores temperaturas. Gely y Santalla (2007) publicaron resultados comparables estudiando el secado en capa delgada de granos de quinoa, en un rango de temperaturas de 30 a $90^{\circ} \mathrm{C}$. Su análisis mostró que a medida que la temperatura fue en aumento, se necesitó menos tiempo en alcanzar contenidos bajos de humedad. 


\subsubsection{Modelado matemático.}

\subsubsection{Balance microscópico de materia con transporte difusivo.}

Se va a desarrollar un modelo que, partiendo de simplificaciones, posibilite la descripción del fenómeno en forma razonablemente realista. Tomando el volumen del grano constante como sistema y considerando que el movimiento de agua dentro del grano se lleva a cabo por un mecanismo difusivo, el balance microscópico de materia en estado no estacionario se puede expresar en la forma siguiente (Crank, 1975; Pabis y col., 1998)

$$
\frac{\partial W_{l}}{\partial t}=\nabla\left(D_{e f f} \nabla W_{l}\right)
$$

donde $D_{\text {eff }}$ es el coeficiente de difusión efectivo. Para flujo de materia unidimensional radial en geometría esférica, considerando coeficiente de difusión dependiente del contenido de humedad y la temperatura, la ecuación anterior puede desarrollarse para dar (Pabis y col., 1998)

$$
\frac{\partial W_{l}}{\partial t}=D_{e f f}\left(\frac{\partial^{2} W_{l}}{\partial r^{2}}+\frac{2}{r} \frac{\partial W_{l}}{\partial r}\right)+\frac{\partial W_{l}}{\partial r} \frac{\partial D_{e f f}}{\partial r}
$$

La ecuación planteada vale en cada punto interior del sólido, y expresa al contenido de agua local o humedad en base seca $\left(W_{l}\right)$ del componente que difunde como función del tiempo $(t)$ y la coordenada $r$, cuyos ejes son siempre perpendiculares a la superficie, y cuyo origen de coordenadas está en el centro de simetría. 
Para $D_{\text {eff }}$ independiente del valor de humedad local durante el secado, se obtiene:

$$
\frac{\partial W_{l}}{\partial t}=D_{e f f}\left(\frac{\partial^{2} W_{l}}{\partial r^{2}}+\frac{2}{r} \frac{\partial W_{l}}{\partial r}\right)
$$

En este análisis preliminar, se despreciará el encogimiento del grano y las posibles variaciones del coeficiente de difusión con el contenido de humedad.

\subsection{Condiciones iniciales y de contorno en transferencia de materia.}

Las condiciones iniciales y de contorno planteadas para resolver la ecuación diferencial a derivadas parciales (Ec. (5.4)), son:

Condición inicial:

$$
t=0 \quad W_{l}=W_{0} \quad 0 \leq r \leq R
$$

donde $W_{0}$ es el contenido de humedad inicial y $R$ el radio del grano.

Condición de contorno en el centro:

En el centro del grano, el flujo de materia es nulo por simetría

$$
r=0 \quad \frac{\partial W_{l}}{\partial r}=0 \quad t>0
$$




\section{Condición de contorno en la superficie}

El flujo de agua que migra en el interior del grano se iguala a aquel que atraviesa la capa límite de fluido que lo rodea. La forma general de expresarla es la siguiente

$$
-\rho_{s} D_{e f f} \frac{\partial W_{s}}{\partial r}=k_{p}\left(p_{v s}-p_{v a}\right)
$$

donde $\rho_{s}$ es la densidad de materia seca, $\mathrm{kg} / \mathrm{m}^{3} ; k_{p}$ es el coeficiente de transferencia de materia aire-grano basado en la presión de vapor, $\mathrm{kg} / \mathrm{m}^{2} \mathrm{~s} \mathrm{~Pa} ; p_{v s}$ presión de vapor de agua en la superficie del grano, $\mathrm{Pa} ; p_{v a}$ presión parcial de vapor de agua en el aire, $\mathrm{Pa}$.

Esta última ecuación supone una aproximación gradual de la presión de vapor del agua en la superficie del grano $p_{v s}$ hacia la presión parcial del vapor en el seno del aire $p_{v a}$, es decir un acercamiento paulatino de la humedad de superficie del grano al valor asintótico $W_{e}($ Giner y Mascheroni, 2001).

Un caso particular de la condición de contorno, puede representarse de la siguiente manera:

$$
r=R \quad W_{s}=W_{e} \quad t>0
$$

donde $W_{s}$ es un valor impuesto de $W$ en la superficie. Esta ecuación es válida para altos números de Biot de materia $\left(B i_{m}\right)$ (Giner y col., 2010). Dadas las altas velocidades de aire empleadas durante el secado-tostado por la fluidización la resistencia externa prácticamente desaparece $\mathrm{y}$, el número de $B i_{m}$ se incrementa lo suficiente como para establecer una condición de contorno prescripta en nuestro caso, lo que significa un control interno estricto de la transferencia de materia. 


\subsection{Solución Analítica de la Ecuación de Difusión.}

Para este modelo y condiciones iniciales y de contorno podemos emplear la solución analítica de la ecuación de difusión no estacionaria en esferas (Ec. (5.3)) con condición prescripta en la superficie considerando encogimiento despreciable y coeficiente de difusión constante. Si se integran las humedades locales en el volumen de la esfera se llega a la siguiente ecuación (Kitic y Viollaz, 1984; Luangmalawat y col., 2008; Doymaz y Ísmail, 2011), que describe la variación de la humedad media del grano con el tiempo.

$$
W_{a d}=\frac{W-W_{e}}{W_{0}-W_{e}}=\frac{6}{\pi^{2}} \sum_{n=1}^{n=\infty} \frac{1}{n^{2}} \exp \left[-n^{2} \pi^{2}\left(\frac{D_{e f f} t}{R^{2}}\right)\right]
$$

El grupo $\left(\mathrm{D}_{\text {eff }} \mathrm{t} / \mathrm{R}^{2}\right)$ es el tiempo adimensional o número de Fourier $\left(F_{o}\right)$ para transferencia de materia (Pabis y col., 1998). Por conveniencia, se puede definir un grupo adimensional $X$ tal que $F_{o}=X^{2} / 9$. Reescribiendo la serie infinita en términos de $X$, se tiene

$$
W_{a d}=\frac{W-W_{e}}{W_{0}-W_{e}}=\frac{6}{\pi^{2}} \sum_{n=1}^{n=\infty} \frac{1}{n^{2}} \exp \left[-\frac{n^{2} \pi^{2}}{9} X^{2}\right]
$$

donde $X^{2}=a_{\mathrm{v}}^{2} D_{e f f} t$, siendo $a_{v}$ él área superficial de la partícula por unidad de volumen de partícula $a_{\mathrm{v}}=3 / R$ para una esfera. Para cada tiempo, y especialmente a tiempos adimensionalmente cortos, la serie infinita requiere sumar un número considerable de términos para obtener convergencia. 
A tiempo largos, la serie infinita converge en un solo término, pero esta simplificación es válida para $\mathrm{X}>1$ ó $W_{a d}<0.3$, lo cual no se halla totalmente dentro del rango práctico de secado de alimentos de alto contenido acuoso (Mabellini y col., 2010).

$W_{a d}=\frac{W-W_{e}}{W_{0}-W_{e}}=\frac{6}{\pi^{2}} \exp \left[-\frac{n^{2} \pi^{2}}{9} X^{2}\right]$

Esta ecuación puede graficarse como una recta en un diagrama semilogarítmico.

El valor de $W_{a d}$ es inicialmente igual a 1 para $t=0$ no $6 / \pi^{2}$ como predice la Ecuación 5.8. Por lo tanto, la serie infinita completa (Ec.(5.7)) sería necesaria para realizar el ajuste. Giner y Mascheroni (2001) han utilizado una ecuación difusiva equivalente, más simple, para tiempos adimensionalmente cortos $\mathrm{X} \leq 1$, propuesta originalmente por Becker (1959).

Esta ecuación con solo tres términos predice la curva de secado entre $0.2<W_{a d}<$ 1 ó $\mathrm{X}<1$ con gran exactitud, coincidente a la obtenida mediante la serie infinita.

$$
W_{a d}=\frac{W-W_{e}}{W_{0}-W_{e}}=1-\frac{2}{\sqrt{\pi}} a_{v} \sqrt{D_{e f f} t}+0.331 a_{v}^{2} D_{e f f} t
$$

La ecuación anterior ha sido aplicada con éxito en el estudio de la cinética de secado post-cosecha de soja (Gely y Giner, 2000). Dado su buen comportamiento en la post-cosecha, se exploró su aptitud para los datos medidos en secado-tostado de soja, empleando el valor del radio inicial para llevar adelante los cálculos. 


\subsection{Ajuste de la solución analítica difusiva aproximada. Ecuación de Becker.}

De esta manera se seleccionó la Ecuación 5.9 para ajustarla a los datos experimentales y determinar los respectivos coeficientes de difusión del agua en el grano entero de soja, a cada temperatura. Los resultados obtenidos, mediante un software estadístico (Systat, 1990) se muestran en la Tabla 5.1

Tabla 5.1. Coeficientes de difusión efectivos obtenidos a partir del ajuste de la ecuación de Becker a los datos experimentales. Se presentan junto con el coeficiente de determinación, el error estándar del parámetro y el desvío típico de la estima.

\begin{tabular}{ccccc}
\hline $\mathrm{T}^{\circ} \mathrm{C}$ & $\begin{array}{c}D_{\text {eff }} \\
\text { x }\end{array}$ & $S\left(D^{9} \mathrm{~m}^{2} / \mathrm{s}\right)$ & $r^{2}$ & $s_{y}$ \\
\hline 100 & 1.463 & $\times 10^{22}$ & & \\
120 & 2.266 & 2.762 & 0.990 & 0.0380 \\
140 & 2.766 & 6.594 & 0.950 & 0.0738 \\
160 & 3.050 & 9.871 & 0.887 & 0.1104 \\
\hline
\end{tabular}

El desvió típico de la estima, se calculó de la siguiente manera.

$s_{y}=\sum_{i=1}^{n} \sqrt{\frac{\left(y_{\exp (i)}-y_{\text {pre }(i)}\right)^{2}}{n-1}}$

donde $\mathrm{y}_{\exp (\mathrm{i})}$ representan los datos experimentales, mientras que $\mathrm{y}_{\text {pred(i) }}$ los valores predichos. El $r^{2}$, o coeficiente de determinación se calculó a través de la siguiente ecuación 


$$
r^{2}=1-\frac{\sum_{i=1}^{n}\left(y_{\operatorname{pred}(i)}-y_{\exp (i)}\right)^{2}}{\sum_{i=1}^{n}\left(y_{\exp (i)}-y_{m}\right)^{2}}
$$

donde $y_{i}$ son los valores predichos y $y_{m}$ el valor medio de los datos experimentales.

Los valores de los coeficientes de difusión presentados se encuentran dentro del rango, de $10^{-9}$ a $10^{-11} \mathrm{~m}^{2} / \mathrm{s}$ que se suele encontrar publicado para diversos materiales biológicos (Perea-Flores y col., 2012). Sin embargo, no se encontraron en la bibliografía valores de $D_{\text {eff }}$ determinados en condiciones similares a las de este trabajo. La mayoría de los autores trabajan dentro un rango de temperaturas de 25 a $110^{\circ} \mathrm{C}$, y rangos de humedad inferiores.

La Figura 5.3 muestra los valores de $W_{a d}$ experimentales y aquellos predichos mediante la Ecuación 5.9, empleando los coeficientes de difusión presentados en la Tabla 5.1 


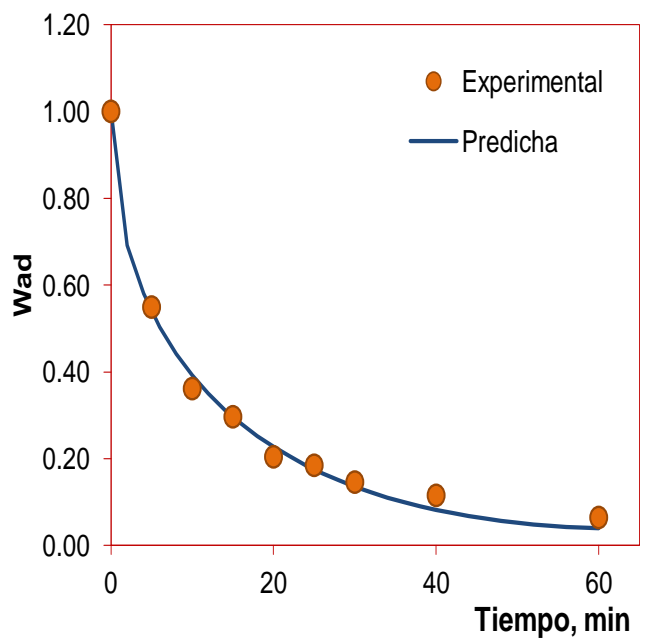

(a)

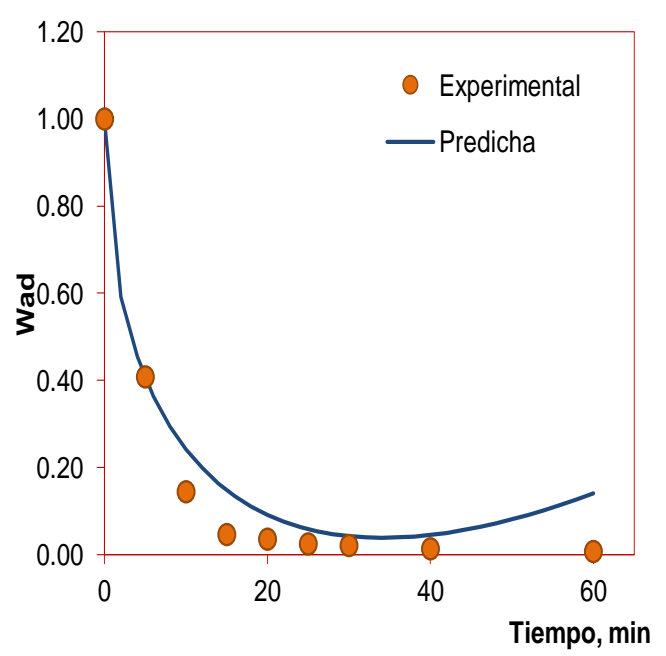

(c)

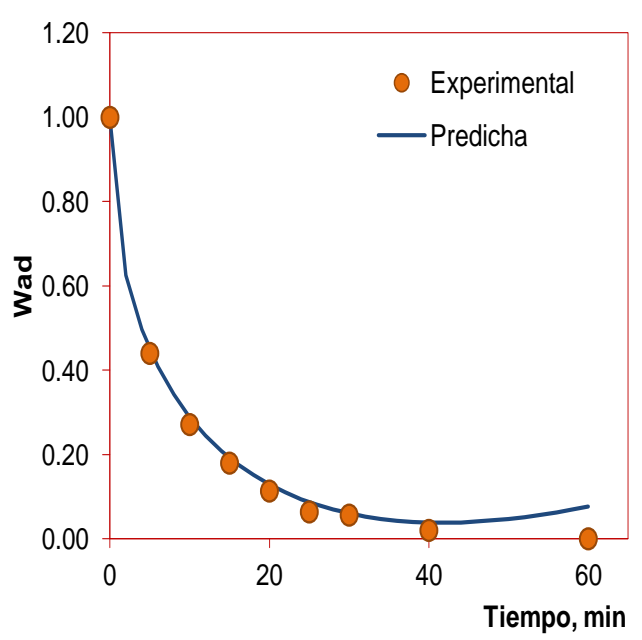

(b)

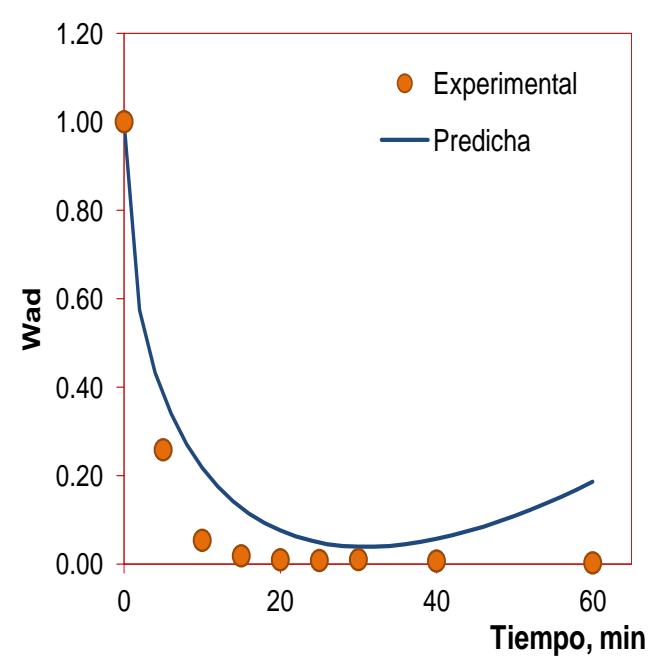

(d)

Figura 5.3. Humedad adimensional experimental y predicha por el modelo difusivo de Becker para tiempos cortos en función del tiempo para las distintas temperaturas: (a) $100^{\circ} \mathrm{C}$, (b) $120^{\circ} \mathrm{C}$, (c) $140^{\circ} \mathrm{C}$ y (d) $160^{\circ} \mathrm{C}$.

Efectivamente, la ecuación de Becker presenta una predicción adecuada dentro de su rango de validez $\left(0.2<W_{a d}<1\right)$, fuera del mismo los valores predichos comienzan a aumentar, debido a la influencia del término positivo en la Ecuación 5.9.

Se puede realizar un análisis interesante para corroborar la validez de esta ecuación, si tomamos en cuenta un valor del coeficiente de difusión efectivo para trigo 
estimado a $60^{\circ} \mathrm{C}$, igual a $1.6 \times 10^{-11} \mathrm{~m}^{2} \mathrm{~s}^{-1}$ (Giner y Mascheroni, 2001). De la definición de $X^{2}$ dada por $a_{v} D_{e f f} t$, si fijamos el valor de $X$ en 1 , y empleamos el radio equivalente $(R)$ típico de un grano de trigo como $2 \times 10^{-3} \mathrm{~m}$, entonces $a_{v}$ dado por $3 / R$ toma el valor de $1500 \mathrm{~m}^{-1}$. Así, se encuentra el tiempo máximo permitido de $7.5 \mathrm{~h}$, que puede ser considerado como "tiempo adimensionalmente corto" en el cual la Ecuación 5.9 es válida. En nuestro caso particular, si empleamos el valor de radio de partícula para soja remojada, determinado a partir del volumen presentado en la Tabla 2.2 del Capítulo 2 (Sección 2.4.2), 4 x 10 $0^{-3} \mathrm{~m}$, y el coeficiente de difusión presentado en la Tabla 5.1 para el tratamiento a $140^{\circ} \mathrm{C}, 3.703 \times 10^{-9} \mathrm{~m}^{2} / \mathrm{s}$, el tiempo calculado fue igual a $8 \mathrm{~min}$, por lo tanto los resultados presentados anteriormente son comprensibles, y se comprueba que la Ecuación de Becker no resulta adecuada para el rango de elevadas temperaturas de secado.

\subsection{Ajuste mediante la serie infinita.}

En esta sección se realizará el ajuste de los datos experimentales utilizando 10 términos de la Ecuación 5.6, tal cantidad de términos se mostro suficiente a tiempos muy cortos que es el lapso más demandante de la curva de secado. Los resultados obtenidos se muestran en la Figura 5.4 


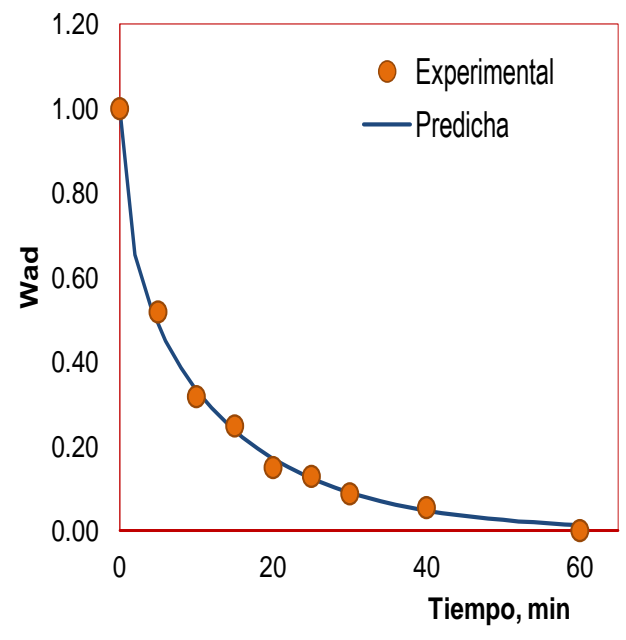

(a)

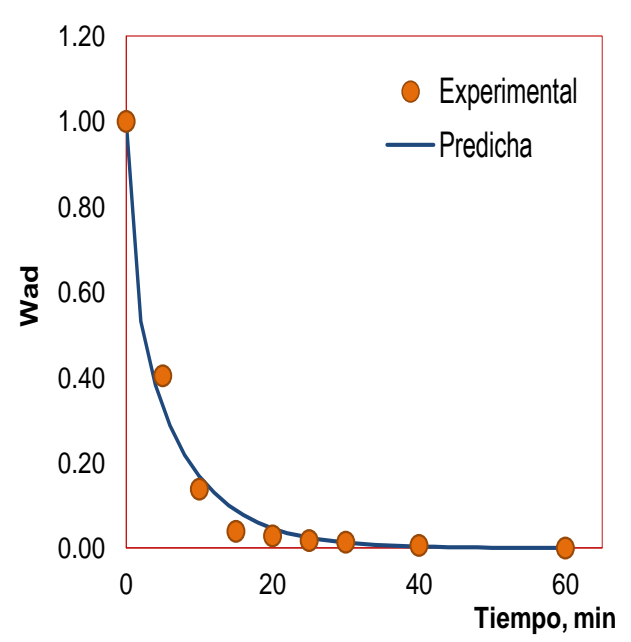

(c)

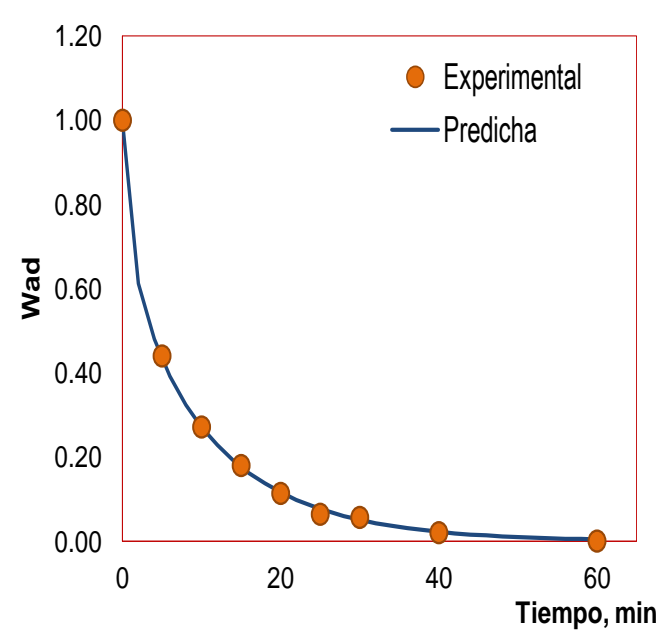

(b)

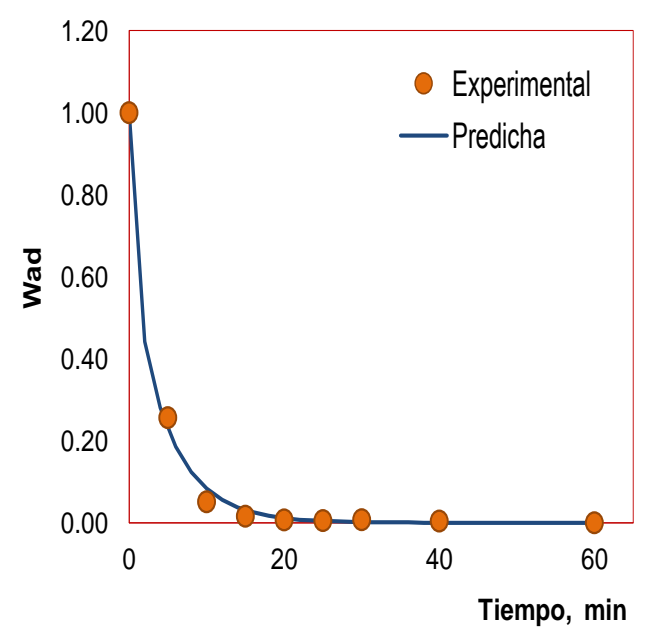

(d)

Figura 5.4. Curvas de secado en capa delgada de grano de soja remojada. Datos experimentales $(\bullet)$, valores predichos $(-)$ mediante la resolución de la serie infinita, para cada temperatura: (a) $100^{\circ} \mathrm{C}$, (b) 120 , (c) $140^{\circ} \mathrm{C} \mathrm{y} \mathrm{(d)} 160^{\circ} \mathrm{C}$.

Estas curvas muestran muy buena concordancia entre los datos experimentales y los predichos a pesar de las suposiciones de volumen y coeficiente de difusión constante en cada condición de secado. La cinética de secado de los granos de soja observada indica que el fenómeno ocurre en el período de velocidad decreciente, lo que sugiere que la 
superficie del material se deshidrata rápidamente y que el secado es controlado por el fenómeno de difusión interna.

Diversos autores coinciden en que este tipo de mecanismo es adecuado para interpretar matemáticamente el secado de productos tales como semillas, granos y vegetales (Kitic y Viollaz, 1984; Vega-Galvéz y col., 2001) aunque tal comportamiento no estaba corroborado a mayores niveles de humedad inicial y temperaturas superiores a las del punto de ebullición, al menos en soja.

A continuación se presentan en la Tabla 5.2, los valores de los coeficientes de difusión efectivos obtenidos mediante el ajuste de la Ecuación (5.7) a los datos experimentales y los correspondientes parámetros representativos de bondad de ajuste.

Tabla 5.2. Coeficientes de difusión efectivos obtenidos a partir del ajuste de la serie infinita a los datos experimentales. Se presentan junto con el coeficiente de correlación y el desvío típico de la estima.

\begin{tabular}{ccccc}
\hline $\mathrm{T}$ & $D_{\text {eff }}$ & $S\left(D_{\text {eff }}\right)$ & $r^{2}$ & $s_{y}$ \\
${ }^{\circ} \mathrm{C}$ & $x 10^{9} \mathrm{~m}^{2} / \mathrm{s}$ & $x 10^{22}$ & & \\
\hline 100 & 1.460 & 2.691 & 0.989 & 0.0302 \\
120 & 2.147 & 2.137 & 0.994 & 0.0239 \\
140 & 3.703 & 3.442 & 0.986 & 0.0385 \\
160 & 5.815 & 2.344 & 0.994 & 0.0263 \\
\hline
\end{tabular}

Los valores informados del $r^{2}$ y el $s_{y}$, confirman que el ajuste del modelo fue muy bueno, si comparamos estos resultados con los presentados en la Tabla 5.1, la calidad predictiva en este último caso se mantiene inalterada al aumentar la temperatura del tratamiento. Sin embargo, el estudio realizado en el Capítulo 2 (Sección 2.4.2) 
reveló una contracción volumétrica no despreciable en el grano de soja durante el mismo tratamiento, por lo que encontrar resultados tan precisos considerando tamaño constante e igual al inicial resulta sorprendente.

\subsection{Ecuaciones de contracción volumétrica.}

Para evaluar la contracción volumétrica del grano entero de soja durante el tratamiento, se utilizará la ecuación deducida en el Capítulo 2 de esta tesis, que permitirá relacionar la variación del radio de partícula con el contenido de humedad media

$$
\frac{V}{V_{0}}=1-K_{v} \frac{\left(W_{0}-W\right)}{\rho_{w}\left(1+W_{0}\right)}
$$

donde $V$ es el volumen de partícula al tiempo $\mathrm{t}, \mathrm{m}^{3} ; V_{0}$ el volumen inicial de partícula, $\mathrm{m}^{3} ; \rho_{w}$, la densidad del agua, $\mathrm{kg} / \mathrm{m}^{3} ; K_{v}$ coeficiente de ajuste determinado a partir de datos experimentales. Los valores de $K_{v}$, se calcularon previamente en el Capítulo 2 (Sección 2.5).

De acuerdo a la definición del volumen de una esfera $\left(V=4 / 3 \pi R^{3}\right)$, podemos reordenar la Ecuación (5.12) y expresarla en función de la relación entre el radio de partícula al tiempo inicial $(t=0)$ y el valor del radio al tiempo $t$. La suposición que se realiza es que esta ecuación de contracción volumétrica en condiciones de equilibrio para el grano entero, vale también en condiciones instantáneas y locales. 


$$
\frac{\frac{4}{3} \pi R_{t}^{3}}{\frac{4}{3} \pi R_{0}^{3}}=1-K_{v} \frac{\left(W_{0}-W\right)}{\rho_{w}\left(1+W_{0}\right)}
$$

realizando las simplificaciones correspondientes, obtenemos la siguiente relación

$$
R_{(t)}=R_{(0)}\left(1-K_{v} \frac{\left(W_{0}-W\right)}{\rho_{w}\left(1+W_{0}\right)}\right)^{1 / 3}
$$

a partir de la Ec.(5.14), se puede predecir la variación del radio de partícula en función del contenido de la humedad y por tanto, del tiempo de tratamiento.

La Figura 5.5 muestra la variación del radio de grano entero de soja remojado en función del contenido de humedad media durante el tratamiento de secado-tostado (a) predicha con la Ec.(5.14). A su vez, en la relación W-t permite graficar R vs t en la figura $5.5 \mathrm{~b}$.

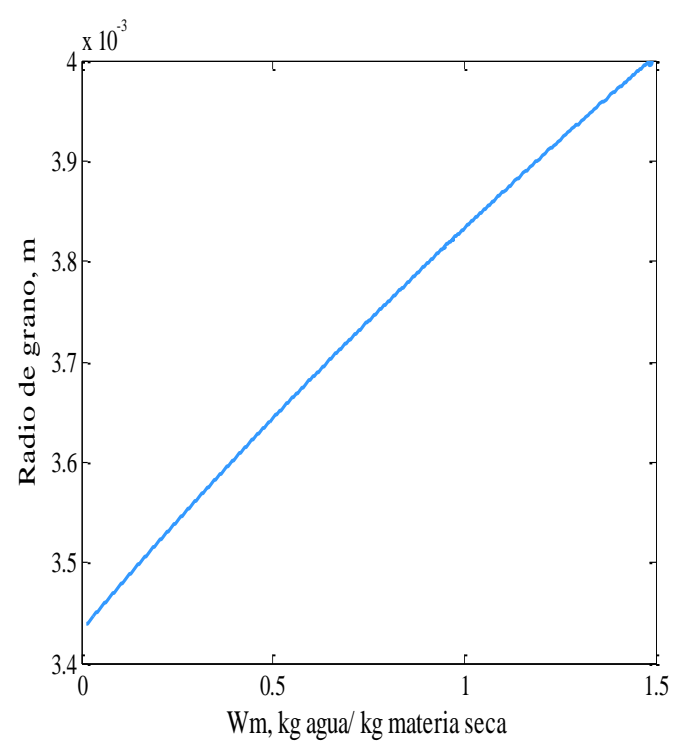

(a)

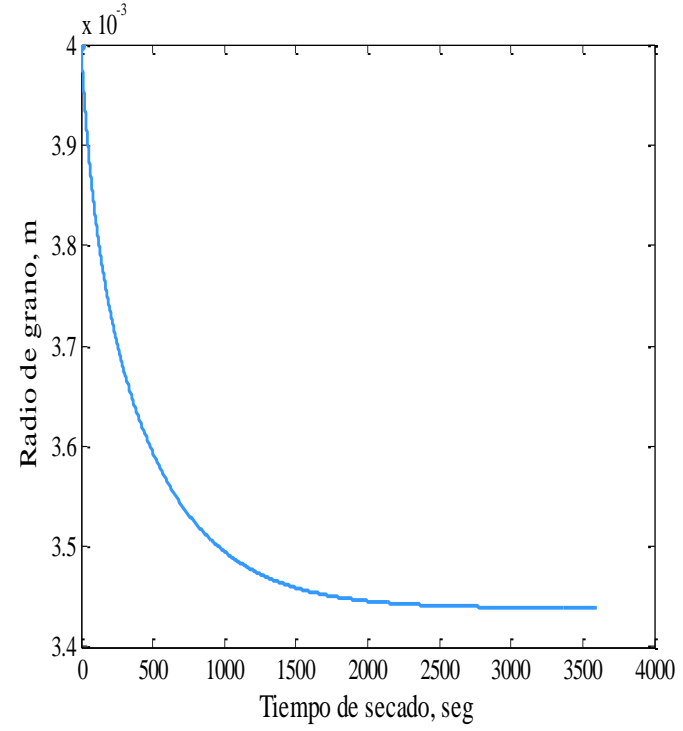

(b)

Figura 5.5 Radio de grano entero de soja durante el secado-tostado a $140^{\circ} \mathrm{C}$ (RST). En función de (a) humedad media del grano y (b) tiempo de secado. 
El producto evidentemente experimenta una variación de tamaño durante el tratamiento térmico. El radio equivalente de partícula se reduce en aproximadamente un $10.6 \%$, mientras que la reducción en el volumen alcanza el $28.4 \%$, tal como se informa en la Tabla 2.2 (Sección 2.4.2, Capítulo 2). La reducción del radio en función del contenido de humedad (Figura 5.5-a) mostró un comportamiento similar al informado por Misra y Young (1980) al estudiar la cinética de transferencia de materia en granos de soja cruda. Por lo tanto, si $R$ no es constante, entonces es el cociente $D_{\text {eff }} / R^{2}$, presente en la serie (Ec. (5.6)), debe permanecer aproximadamente constante para que la solución analítica presente una exactitud tan alta. Por tanto, a pesar de que la ecuación no describe con realismo el comportamiento físico del grano, sí predice el cambio de humedad con el tiempo en forma precisa.

Esta expresión $D_{\text {eff }} / R^{2}$ constante, nos brindará la posibilidad de establecer una funcionalidad cuantitativa entre el coeficiente de difusión efectivo y el contenido de humedad. En función de los resultados obtenidos y habida cuenta de la necesidad de predecir el fenómeno en forma más realista se realizará un replanteo del modelo de balance microscópico considerando contracción volumétrica y difusividad variable. Dado que dicho modelo debe incluir un coeficiente de difusión que depende de la variable a calcular, resulta en una ecuación diferencial parcial no lineal, siendo necesaria una solución numérica para obtener los valores de las incógnitas en función de la posición y el tiempo.

\subsection{Correlación de los coeficientes de difusión efectivos con la temperatura.}

De acuerdo a diversos estudios realizados en el secado de alimentos se observó que el incremento de la temperatura conduce a un aumento del coeficiente de difusión 
efectivo. (Kitic y Viollaz, 1984; Gastón y col., 2002; Gely y Giner, 2000; Mabellini y col., 2010; Perea-Flores, 2012). Esta dependencia se describe por lo general empleando una ecuación del tipo Arrhenius con el propósito de obtener la energía de activación $\left(E_{a}\right)$ a partir los coeficientes de difusión determinados. Este valor de $E_{a}$ podría considerarse como la barrera de energía que debe ser superada para permitir el movimiento difusivo de agua. Altos valores de energía de activación están asociados con materiales en los cuales el agua está asociada fuertemente a la estructura del alimento (Perea-Flores, 2012). La ecuación empleada en este trabajo fue la siguiente:

$\ln D_{e f f}=\ln D_{\infty}-\frac{E_{a}}{R\left(T_{c}+273.2\right)}$

donde $T_{c}$ es la temperatura del aire en ${ }^{\circ} \mathrm{C} ; D_{\infty}$ es el factor pre-exponencial en $\mathrm{m}^{2} / \mathrm{s} ; E_{a}$ la energía de activación, kJ/mol; y $R$ la constante universal de los gases 8314 J/ mol K. En la Figura 5.6 se presenta el $\ln \mathrm{D}_{\text {eff }}$ vs $1 / \mathrm{T}_{\mathrm{abs}}$, con los valores obtenidos 


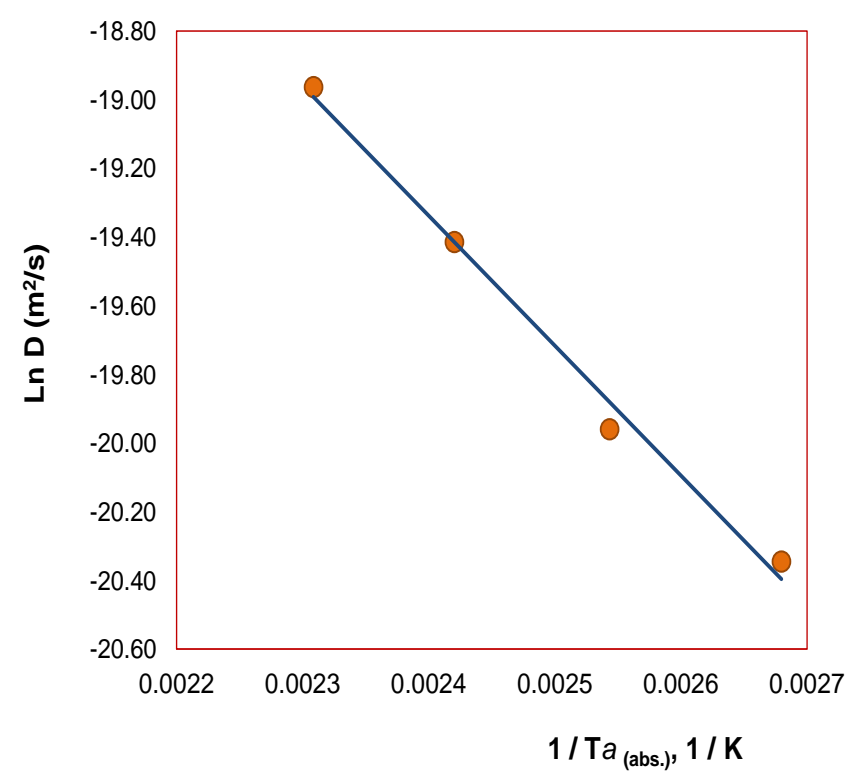

Figura 5.6. Correlación tipo Arrhenius para la funcionalidad del coeficiente de difusión efectivo de agua en los granos de soja con la temperatura.

Se puede apreciar un ajuste adecuado de los datos experimentales, lo cual está en concordancia con lo informado por otros autores empleando una ecuación tipo Arrhenius (Perea-Flores, 2012; Doymaz e Ísmail, 2011; Di Scala y Crapiste, 2008; Mabellini y col., 2010; Gely y Giner, 2000; Doymaz, 2005; Mohapatra y Rao, 2005; Gastón y col., 2002). A partir de la Ecuación (5.16), se obtuvo el valor de la $E_{a}=31.4$ $\mathrm{kJ} / \mathrm{mol}$ y un factor pre-exponencial $D_{\infty}=3.483 \times 10^{-5} \mathrm{~m}^{2} / \mathrm{s}$, el valor de coeficiente de correlación, $r^{2}$ fue de 0.991 lo cual indica que la relación tipo Arrhenius predice en forma precisa la dependencia del coeficiente de difusión con la temperatura. A pesar de que las condiciones para cada tratamiento fueron poco comunes (altas temperaturas y elevados contenidos de humedad inicial) el valor de la $E_{a}$ encontrado se halla dentro del rango informado por diversos autores: Gely y Giner, (2000) en granos de soja, $E_{a}=27.3$ - $26.7 \mathrm{~kJ} / \mathrm{mol}$; Gely y Santalla, (2007) en semillas de quinoa, $E_{a}=32-40 \mathrm{~kJ} / \mathrm{mol}$; Di Scala y Crapiste (2008), en pimienta $E_{a}=33.83 \mathrm{~kJ} / \mathrm{mol}$; Doymaz, (2005) en porotos $E_{a}$ 
$=35.43 \mathrm{~kJ} / \mathrm{mol}$. La mayoría de estos autores llevaron a cabo sus experiencias en condiciones de humedades bajas y temperaturas de 25 y $90^{\circ} \mathrm{C}$.

\subsection{Resolución numérica mediante diferencias finitas.}

Las ecuaciones diferenciales parciales se resolvieron usando unidades de concentración volumétrica de agua como variable dependiente lo cual permite trabajar con volúmenes variables. Para llevar esto adelante, se dedujo una ecuación que relaciona el contenido de humedad en base seca con la concentración volumétrica del agua en $\mathrm{kg} / \mathrm{m}^{3}$

$W_{l}=\frac{C_{l}}{\rho-C_{l}}$

donde $C_{l}$ es la concentración local de agua en $\mathrm{kg}$ de agua $/ \mathrm{m}^{3}$ de producto, $\rho$ la densidad del sólido, $\mathrm{kg} / \mathrm{m}^{3}$ reordenando dicha ecuación, obtenemos

$$
C_{l}=\frac{\rho W_{l}}{1+W_{l}}
$$

El balance microscópico de materia puede expresarse de la siguiente manera

$$
\frac{\partial C_{l}}{\partial t}=\nabla\left(D_{e f f} \nabla C_{l}\right)
$$


para evaluar la variación del coeficiente de difusión efectivo con la posición o radio de partícula, está última ecuación puede reescribirse de la siguiente forma,

$\frac{\partial C_{l}}{\partial t}=D_{e f f}\left(\frac{\partial^{2} C_{l}}{\partial r^{2}}+\frac{2}{r} \frac{\partial C_{l}}{\partial r}\right)+\frac{\partial C_{l}}{\partial r} \frac{\partial D_{e f f}}{\partial r}$

donde $C_{l}$ es la concentración volumétrica local de agua en $\mathrm{kg} / \mathrm{m}^{3}$.

Las condiciones iniciales y de contorno planteadas para resolver la ecuación diferencial (Ec. (5.18)) se escriben a continuación

Condición inicial:

$$
t=0 \quad C_{l}=C_{0} \quad 0 \leq r \leq R
$$

donde $C_{0}$ es la concentración volumétrica de humedad inicial del grano.

Condición de contorno en el centro:

$$
r=0 \quad \frac{\partial C_{l}}{\partial r}=0 \quad t>0
$$

Condición de contorno en la superficie

$$
r=R \quad C_{s}=C_{e} \quad t>0
$$

un caso particular del modelo se presenta para $r=0$. En este punto, el término 
$\frac{2}{r} \frac{\partial C_{l}}{\partial r}$

presente en la Ecuación (5.20) resulta en una indeterminación en $r=0$. A efectos de eliminar esta singularidad empleamos la regla de L'Hôpital, de manera tal que la Ecuación (5.19), quede expresada de la siguiente forma para $r=0$

$$
\frac{\partial C_{l}}{\partial t}=3 D_{e f f} \frac{\partial^{2} C_{l}}{\partial r^{2}}
$$

\subsection{Estudio de la relación entre el coeficiente de difusión y el contenido de} humedad.

A partir de la Ecuación (5.14), deducida para el análisis de la contracción volumétrica y la suposición de que el cociente $D_{\text {eff }} / R^{2}$ se mantuvo constante durante el tratamiento térmico (Sección 5.3.2.6) se planteó el estudio de la variación del coeficiente de difusión efectivo con el contenido de humedad de manera indirecta.

Para llevar adelante este estudio se estableció una relación entre el coeficiente de difusión y la variación del radio en función del tiempo durante el secado-tostado

$$
D_{(t)}=D_{0}\left(\frac{R_{(t)}}{R_{(0)}}\right)^{2}
$$

Reemplazando la Ec. (5.14) en esta última expresión, obtenemos 


$$
D_{(t)}=D_{0}\left(1-K_{v} \frac{\left(W_{0}-W_{l}\right)}{\rho_{w}\left(1+W_{0}\right)}\right)^{2 / 3}
$$

El término "indirecto" se refiere en este caso, a que la funcionalidad de $D_{\text {eff }}$ con la humedad se evalúa a través de la variación del radio de partícula cuya dependencia con la humedad se determinó previamente. La concentración volumétrica local se convierte en humedad local mediante la expresión (5.17).

\subsubsection{Balance microscópico de Energía.}

En un primer momento, se planteó el balance microscópico de energía para esferas, considerando flujo de calor por conducción (García, 2005).

$$
\rho_{s o} C_{p} \frac{\partial T_{l}}{\partial t}=k_{T}\left(\frac{\partial^{2} T_{l}}{\partial r^{2}}+\frac{2}{r} \frac{\partial T_{l}}{\partial r}\right)
$$

Donde $\mathrm{C}_{\mathrm{p}}$ es el calor específico en $\mathrm{J} / \mathrm{kg}^{\circ} \mathrm{C}, \mathrm{y} \mathrm{k}_{\mathrm{T}}$ la conductividad térmica "efectiva" del grano húmedo, $\mathrm{J} / \mathrm{s}^{\circ} \mathrm{C} \mathrm{m}$, ambas dependientes del contenido de agua medio en el grano (W). El valor $\mathrm{k}_{\mathrm{T}}$ debería incorporar posibles efectos convectivos causados por la difusión de vapor de agua durante el secado. El factor $\rho_{\text {so }}$ es la masa seca de grano referida a volumen inicial, $\mathrm{kg} / \mathrm{m}^{3}$. 


\subsection{Condiciones iniciales $y$ de contorno en transferencia de calor con evaporación superficial.}

Para la Ecuación 5.25, las condiciones iniciales y de contorno que pueden plantearse, despreciando efectos de radiación, son las siguientes:

Condición inicial:
$t=0$
$T_{l}=T_{0}$
$0 \leq r \leq R$

Condición de contorno en el centro:

$$
r=0 \quad \frac{\partial T_{l}}{\partial r}=0 \quad t>0
$$

Condición de contorno en la superficie

$$
r=R \quad k_{T} \frac{\partial T_{l}}{\partial r}=h_{T}\left(T_{a}-T_{l}\right)-L_{g}\left(-\frac{d W}{d t}\right) m_{s} \quad t>0
$$

la condición de contorno para $r=R$ es de tipo conductivo-convectivo-evaporativa, indicando que el flujo de calor que ingrese al grano por conducción- utilizado para aumentar la temperatura del mismo- será la diferencia entre el calor cedido desde el aire por convección forzada y el utilizado por el grano para evaporar la humedad en la superficie. Puede indicarse, incidentalmente, que si el secado ocurriera en el período de velocidad constante, tal diferencia sería nula, esto es, todo el calor transferido del aire al 
grano se utilizaría en la evaporación del agua, manteniendo constante la temperatura de la superficie.

\subsection{Curvas de evolución de temperatura experimental en el grano.}

A continuación se presentan las curvas experimentales de temperatura determinadas para cada tratamiento, mediante la metodología descrita en la Sección 5.1.3

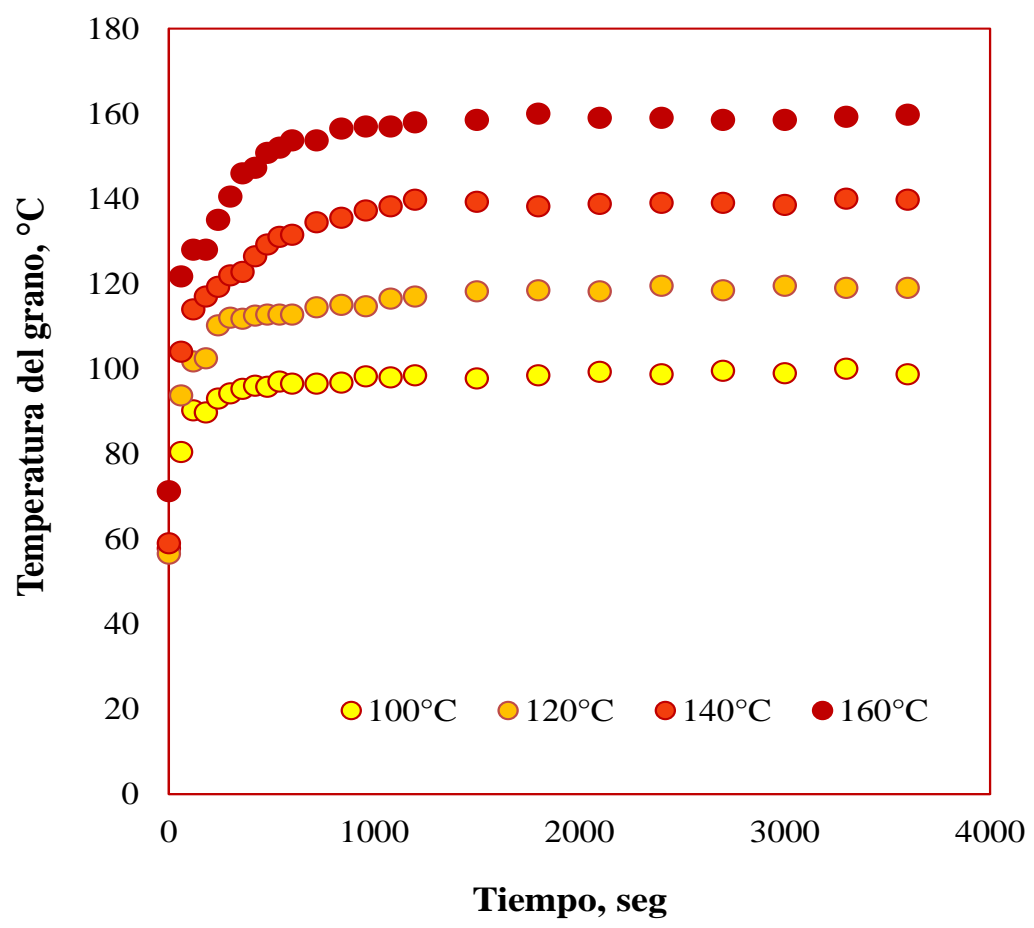

Figura 5.7 Historias térmicas experimentales de grano entero de soja representadas en función del tiempo, para cada temperatura de aire analizada.

Puede observarse, que existe un incremento rápido de la temperatura en el grano, alcanza valores similares a la temperatura del aire en menos de 20 minutos. Al cabo de ese tiempo, las fluctuaciones en su temperatura no son considerables. Conceptos similares fueron informados por Syahrul y colab., (2002) quienes realizaron un estudio de secado en capa delgada de maíz en lecho fluidizado. 
Una de las causas por las cuales se alcanza un equilibrio térmico tan rápido, es el pequeño tamaño de los granos $\left(R=4 \times 10^{-4} \mathrm{~m}\right)$ y la reducción en el radio $(10.6 \%)$ que experimenta durante el secado-tostado. Por tanto, no resultaría erróneo suponer que la resistencia interna del mismo a la transferencia de calor, es muy inferior a la externa. El análisis anterior propone que la transferencia de calor aire-grano es un fenómeno gobernado por control externo, es decir los perfiles internos de temperatura se consideran planos pero no constantes con el tiempo.

En vista de que se desea modelar en primer lugar, una capa delgada y más adelante un lecho fluidizado de granos, que implica agregar una mayor grado de dificultad al análisis, se tratará de mantener el modelo tan simple como sea posible manteniendo un sustento físico. Por tal razón, se considerara perfil plano de temperaturas, evitándose así la resolución del balance microscópico de energía (Markowski y colab., 2010).

La ecuación para llevar adelante la determinación del perfil de la evolución de temperaturas en el tiempo para un grano de soja

$$
\rho_{s o} C_{p} \frac{d T}{d t}=h_{T} a_{v}\left(T_{a}-T\right)-\rho_{s o}\left(-\frac{d W}{d t}\right) L_{w}
$$

donde (-dW/dt) es la velocidad de secado al tiempo t, basada en la humedad media del grano. Se obtiene entonces una ecuación diferencial ordinaria de coeficientes variables cuya condición inicial es $\mathrm{t}=0, \mathrm{~T}=\mathrm{T}_{0}$. Las derivadas temporales son totales en razón de que para $\mathrm{T}$ el perfil es plano mientras que para $\mathrm{W}$, siendo un valor medio de las $\mathrm{W}_{1}$ en la esfera, sólo existe variación temporal.

El valor $\mathrm{L}_{\mathrm{w}}$ es el calor de sorción, dependiente de la humedad y la temperatura del grano. Sin embargo, de acuerdo al análisis realizado en el capítulo anterior (Sección 
4.4.1), al no existir una influencia de la temperatura en las isotermas de sorción no fue posible desarrollar una expresión matemática para el cálculo de $\mathrm{L}_{\mathrm{g}}$. Por tanto, en la resolución del modelo se empleará el calor de vaporización del agua pura $\mathrm{L}_{\mathrm{w}}$.

Para estudiar la variación del calor específico del grano $\left(\mathrm{C}_{\mathrm{p}}\right)$ en función del contenido de humedad en base seca se modificó una ecuación previamente deducida por Moshenin (1980) para granos de soja basada originalmente en el contenido de humedad en base húmeda. Esta ecuación es válida en el rango de 0 a 0.7 dec., b.s.

$C_{p}=1638.08+3566.19 \mathrm{~W}$

A partir de la ecuación planteada por Siebel (Mohsenin, 1980), para carne, frutas y vegetales en general, para contenidos de humedad superiores a 0.7 dec., b.s.

$C_{p}=837.4+4187 \mathrm{~W}$

donde $\mathrm{W}$, ahora representa el contenido de humedad media del grano en base seca, y el calor específico se obtiene en unidades de $\mathrm{J} / \mathrm{kg}$ materia seca ${ }^{\circ} \mathrm{C}$. Esta ecuación es muy similar a la informada por Pabis y col. (1998) para granos de soja.

\subsection{Determinación del coeficiente de transferencia de calor efectivo aire- grano durante el secado-tostado.}

El coeficiente de transferencia de calor aire-grano, $\mathrm{h}_{\mathrm{T}}$, se determinó experimentalmente mediante una técnica de estado no estacionario, resolviendo para este propósito el balance macroscópico de energía en el grano. Este método es muy útil 
porque provee un coeficiente efectivo válido en las condiciones de trabajo empleadas en esta tesis. Esta técnica fue empleada previamente por Ratti y col. (1995). La ecuación empleada fue la siguiente:

$$
h_{T}=\frac{\rho_{s o} C_{p} \frac{d T}{d t}+\rho_{s o}\left(-\frac{d W}{d t}\right) L_{w}}{a_{v}\left(T_{a}-T\right)}
$$

donde $\mathrm{T}_{a}$ es la temperatura del aire y $\mathrm{T}$ es la temperatura media del producto al tiempo $\mathrm{t}$. A su vez, $L_{w}$, es el calor de desorción del agua y $a_{v}$ es el área específica de transferencia de calor. El símbolo dT/dt y dW/dt son las derivadas de correlaciones empíricas determinadas para la temperatura y el contenido de humedad en función del tiempo. Estas correlaciones fueron ajustadas con el solo propósito de calcular sus derivadas. Los valores medios obtenidos junto la desviación estándar se presentan a continuación

Tabla 5.3 Coeficiente de transferencia de energía medio determinado para cada temperatura. Entre paréntesis se presenta la desviación estándar de cada valor.

\begin{tabular}{cc}
\hline $\begin{array}{c}\text { Temperatura } \\
{ }^{\circ} \mathbf{C}\end{array}$ & $\begin{array}{c}\mathbf{h}_{\mathbf{T}} \\
\mathbf{W} /{ }^{\circ} \mathbf{C ~ m}^{2}\end{array}$ \\
\hline 100 & $249.7(52.7)$ \\
120 & $205.2(35.5)$ \\
140 & $220.0(53.9)$ \\
160 & $225.4(43.3)$ \\
\hline
\end{tabular}

Estos valores se encuentran dentro del rango mencionado por Souraki y col., (2009) de $100 \mathrm{a} 400 \mathrm{~W} /{ }^{\circ} \mathrm{C} \mathrm{m}^{2}$ para dicho coeficiente en tratamientos térmicos en lecho fluidizado. Estos autores consideraron que estos valores se deben al alto grado de mezclado y 
agitación experimentado por las partículas. Vázquez y Calvelo (1980) utilizando correlaciones empíricas encontraron valores similares para este coeficiente en arvejas y esferas de aluminio.

\subsubsection{Resolución del modelo.}

El modelo a ser resuelto se presentó en la Sección 5.3.4, y está formado por la ecuación 5.20, las condiciones iniciales y de contorno planteadas en la sección previamente mencionada. El método numérico de las diferencias finitas consiste en el reemplazo de las derivadas continuas por cocientes de incrementos, las diferencias finitas. Con este fin, se transforman las ecuaciones diferenciales parciales en un sistema de ecuaciones algebraicas, que se resuelven tiempo a tiempo en puntos específicos, establecidos por la discretización de las variables independientes o dominio tiempoespacio.

En cilindros y esferas, la discretización a iguales intervalos de radio conduce a elementos de volumen crecientes a medida que la coordenada $\mathrm{r}$ crece. Por tanto, usar $\Delta r$ constante significa cometer un error considerable. 


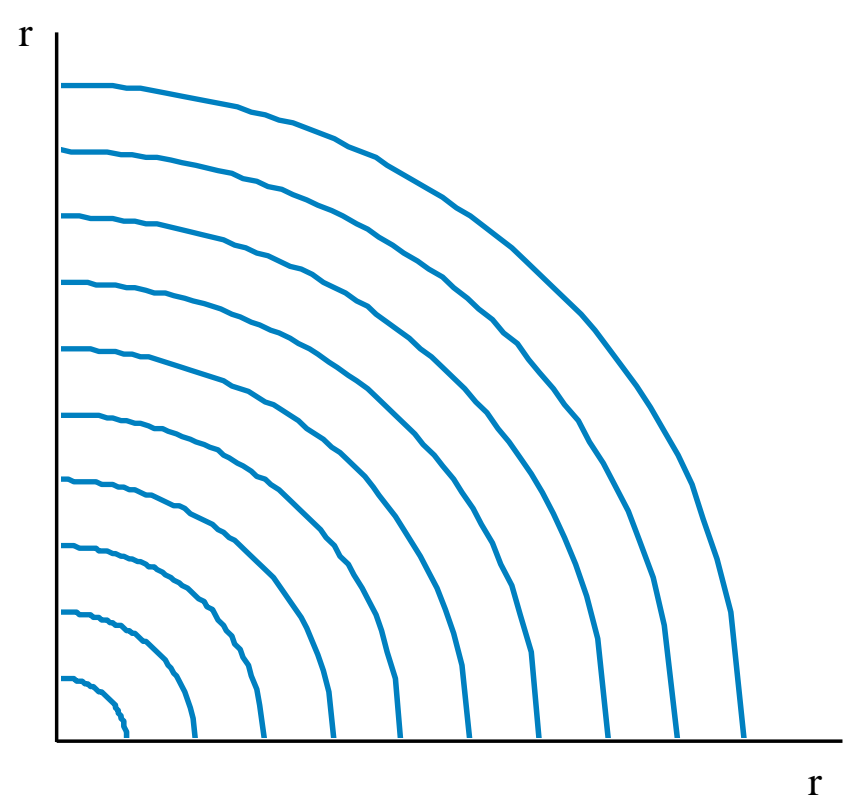

Figura 5.8 Discretización de una esfera con $\Delta \mathrm{r}$ constante y $\Delta \mathrm{V}$ variable.

Considerando tamaño constante, la discretización del dominio en espacio y tiempo, sería

$\Delta r=(i-1) \Delta r$

y las derivadas del balance microscópico pueden reemplazarse con las diferencias finitas siguientes

$$
\begin{aligned}
& \frac{\partial C_{l}}{\partial t}=\frac{C_{l(i, n+1)}-C_{l(i, n)}}{\Delta t} \\
& \frac{\partial C_{l}}{\partial r}=\frac{C_{l(i+1, n+1)}-C_{l(i-1, n+1)}}{2 \Delta r}
\end{aligned}
$$


$\frac{\partial^{2} C_{l}}{\partial r^{2}}=\frac{C_{l(i-1, n+1)}-2 C_{l(i, n+1)}+C_{l(i+1, n+1)}}{(\Delta r)^{2}}$

Podemos calcular la fracción del volumen total que representan diferentes $\Delta V$, entre dos puntos próximos al centro de la esfera en primer lugar y luego cercanos a la superficie. Para llevar adelante este estudio, se tomaron 10 elementos de volumen. Los resultados indicaron que próximos a $r=0$, un $\Delta V$ representa alrededor del $0.2 \%$ del total mientras que cuando nos acercamos a $r=R$ el valor encontrado fue del $33 \%$.

Chau y Gaffney (1990), desarrollaron un esquema con elementos de volumen constante, para solucionar este problema. El mismo consistió en dividir la esfera en I-1 volúmenes concentricos de igual volumen $\Delta V$, donde $\Delta V=V /$ (I-1), siendo $V$ el volumen total del cuerpo. Con esta metodología se genera una concentración más alta de puntos de la malla cerca de la superficie que es la zona donde los cambios son más rápidos, lo que contribuye disminuir el error al calcular los perfiles de concentración.

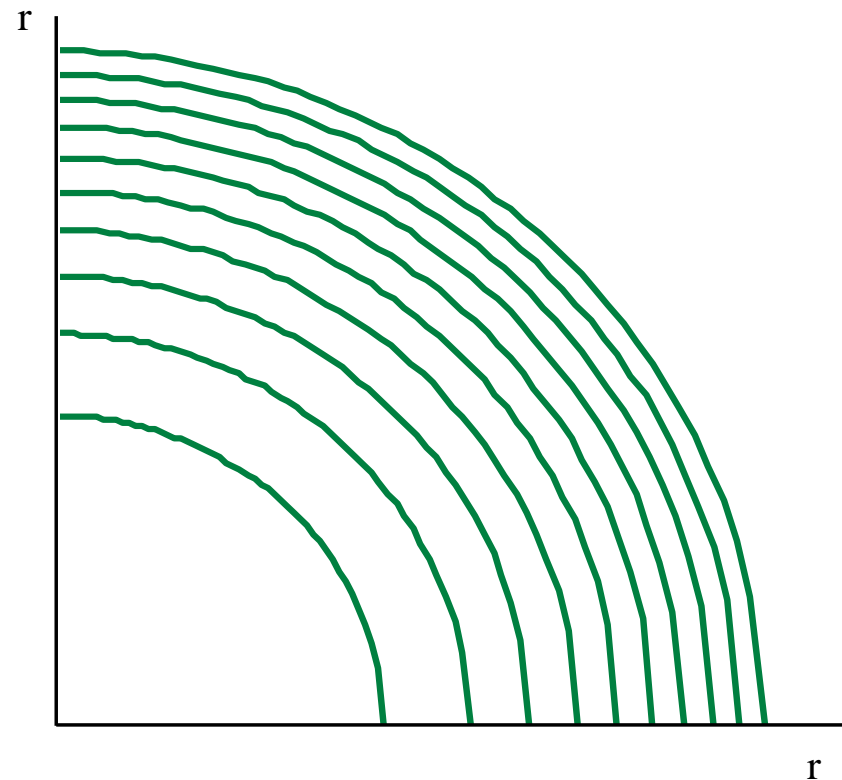

Figura 5.9. Esquema del método numérico de integración utilizado, $\Delta \mathrm{r}$ variable y $\Delta \mathrm{V}$ constante. 
Aplicando esta metodología, las derivadas quedan expresadas ahora de la siguiente manera

$$
\frac{\partial C_{l}}{\partial r}=\frac{C_{l(i+1, n+1)}-C_{l(i-1, n+1)}}{\Delta r_{(i-1)}+\Delta r_{(i)}}
$$

$\frac{\partial^{2} C_{l}}{\partial r^{2}}=\frac{\left(\frac{C_{l(i+1, n+1)}-C_{l(i, n+1)}}{\Delta r_{(i)}}\right)-\left(\frac{C_{l(i, n+1)}-C_{l(i-1, n+1)}}{\Delta r_{(i-1)}}\right)}{0.5\left(\Delta r_{(i-1)}+\Delta r_{(i)}\right)}$

Para simplificar la notación, a partir de aquí el $D_{\text {eff }}$ pasará a denominarse simplemente como $D$.

$\frac{\partial D}{\partial r}=\frac{D_{(i+1, n)}-D_{(i-1, n)}}{\Delta r_{(i)}+\Delta r_{(i-1)}}$

Por tanto, al reemplazar estas diferencias finitas en las derivadas parciales, discretizando la Ecuación (5.20), obtenemos

Para $i=1$

$$
\left[1+\frac{3 \Delta t D_{(1, n)}}{r_{(1)}\left(\Delta r_{(1)}\right)}+\frac{3 \Delta t D_{(1, n)}}{r_{(1)}\left(\Delta r_{(2)}\right)}\right] C_{(1, n+1)}+\left[-\frac{3 \Delta t D_{(1, n)}}{r_{(1)}\left(\Delta r_{(1)}\right)}-\frac{3 \Delta t D_{(1, n)}}{r_{(1)}\left(\Delta r_{(2)}\right)}\right]=C_{l(1, n)}
$$


Ecuación general para los puntos intermedios, $i=2: \mathrm{I}-1$

$$
\begin{aligned}
& {\left[-\frac{D_{(i, n)} \Delta t}{0.5\left(\Delta r_{(i)}+\Delta r_{(i-1)}\right)\left(\Delta r_{(i-1)}\right)}+\frac{2 D_{(i, n)} \Delta t}{r_{(i)}\left(\Delta r_{(i+1)}+\Delta r_{(i-1)}\right)}+\frac{\left(D_{(i+1, n)}-D_{(i-1, n)}\right) \Delta t}{\left(\Delta r_{(i)}-\Delta r_{(i-1)}\right)^{2}}\right] C_{l(i-1, n+1)}+\ldots} \\
& {\left[1+\frac{D_{(i, n)} \Delta t}{0.5\left(\Delta r_{(i)}-\Delta r_{(i-1)}\right)\left(\Delta r_{(i)}\right)}+\frac{D_{(i, n)} \Delta t}{0.5\left(\Delta r_{(i)}+\Delta r_{(i-1)}\right)\left(\Delta r_{(i-1)}\right)}\right] C_{l(i, n+1)}+\ldots} \\
& {\left[-\frac{D_{(i, n)} \Delta t}{0.5\left(\Delta r_{(i)}+\Delta r_{(i-1)}\right)\left(\Delta r_{(i)}\right)}-\frac{2 D_{(i, n)} \Delta t}{r_{(i)}\left(\Delta r_{(i)}+\Delta r_{(i-1)}\right)}-\frac{\left(D_{(i+1, n)}-D_{(i-1, n)}\right) \Delta t}{\left(\Delta r_{(i)}-\Delta r_{(i-1)}\right)^{2}}\right] C_{l(i+1, n+1)}=C_{l(i, n)}}
\end{aligned}
$$

\section{Para $i=I$}

Al considerar condición de contorno prescripta

$$
C_{l(I, n+1)}=C_{e}
$$

El perfil de $C$ en función del $r$ se calcula resolviendo un sistema lineal para el cual se evalúa el D en el tiempo anterior.

Para cada tiempo se calcula la concentración media

$$
C_{m}=\frac{3}{R_{c(n)}{ }^{3}} \int C_{l} r^{2} d r
$$


que fue resuelta numéricamente por el método de los trapecios con discretización variable. La humedad media se calculo con

$W_{m}=\frac{C_{m}}{\rho_{m}-C_{m}}$

Calculamos el valor de la densidad media con

$$
\rho_{m}=\frac{K_{\rho}\left(1+W_{m}\right)}{\left(1+W_{0}-\frac{K_{v}\left(W_{0}-W_{m}\right)}{\rho_{w}}\right)}
$$

y la humedad local empleando la expresión que sigue

$$
W_{l}=\frac{C_{l}}{\rho-C_{l}}
$$

A continuación se presenta el algoritmo de cálculo para determinar el valor de radio al tiempo t. 


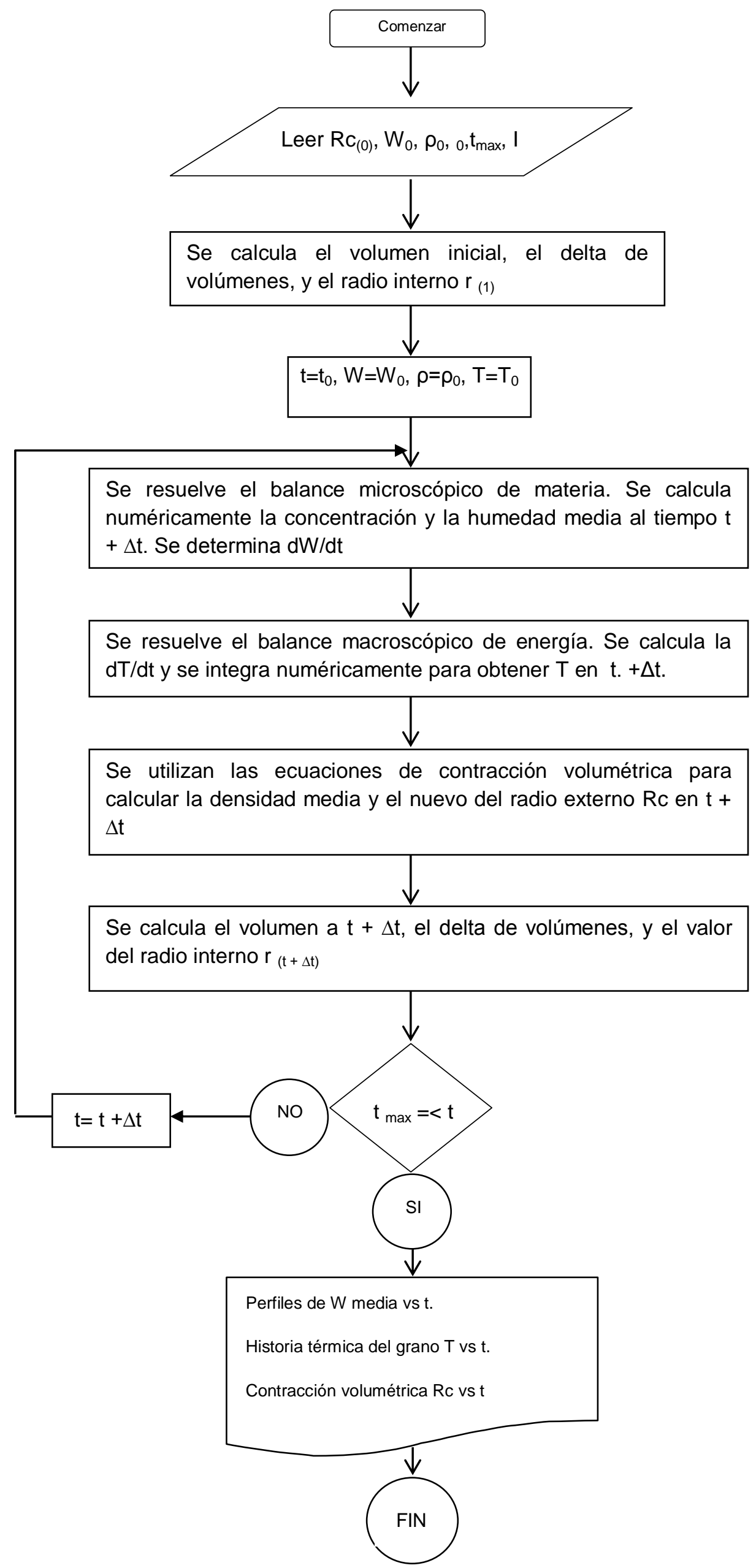


Los resultados obtenidos, se presentan a continuación en la Figura 4.7

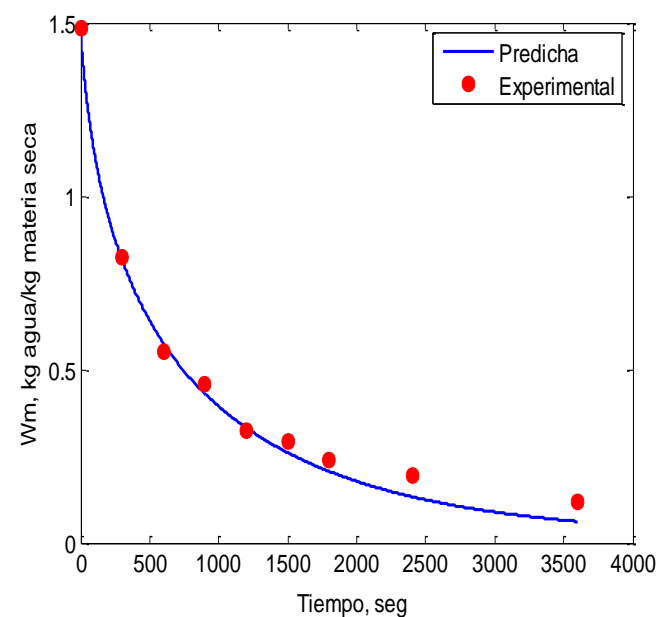

(a)

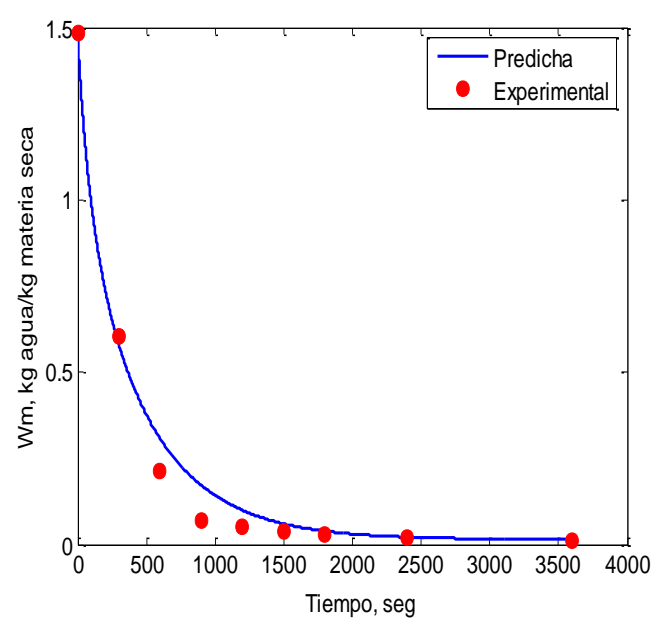

(c)

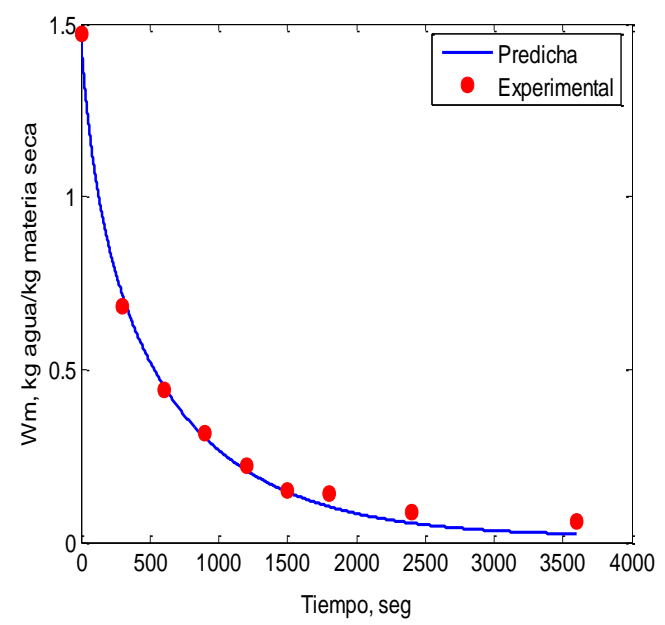

(b)

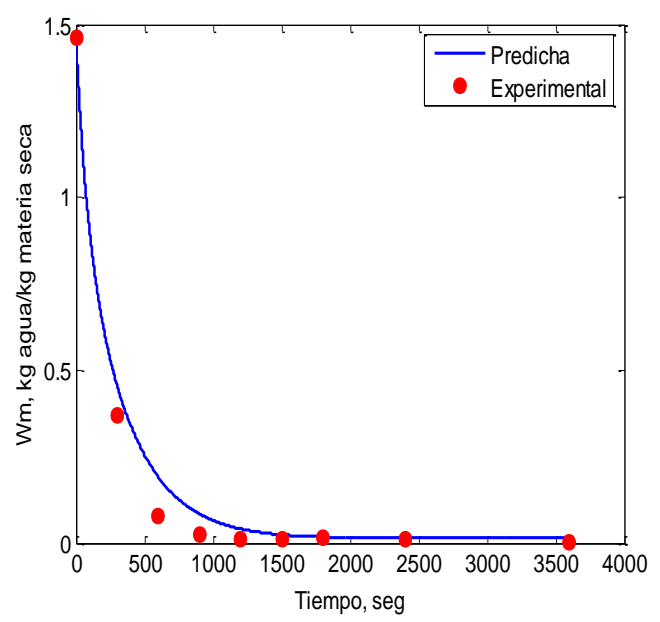

(d)

Figura5.10 Ajuste del modelo de cálculo numérico resuelto por diferencias finitas a los datos experimentales. Para cada tratamiento: (a) $100^{\circ} \mathrm{C}$, (b) $120^{\circ} \mathrm{C}$, (c) $140^{\circ} \mathrm{C} \mathrm{y} \mathrm{(d)}$ $160^{\circ} \mathrm{C}$

El ajuste obtenido en todos los casos fue bastante satisfactorio, tal como se observa en la Figura 5.10. Una concordancia entre los resultados experimentales y predichos similar, fue informada Misra y Young (1980) quienes investigaron la variación del coeficiente de difusión con la humedad y el encogimiento de grano durante el secado de soja en rangos de temperatura y humedad moderados. Los autores 
emplearon un método de elementos finitos para resolver el problema e incorporaron un modelo lineal para predecir el encogimiento.

A continuación, se presenta la variación del contenido medio de humedad en función de la posición radial en la esfera, en los primeros 10 minutos de tratamiento.

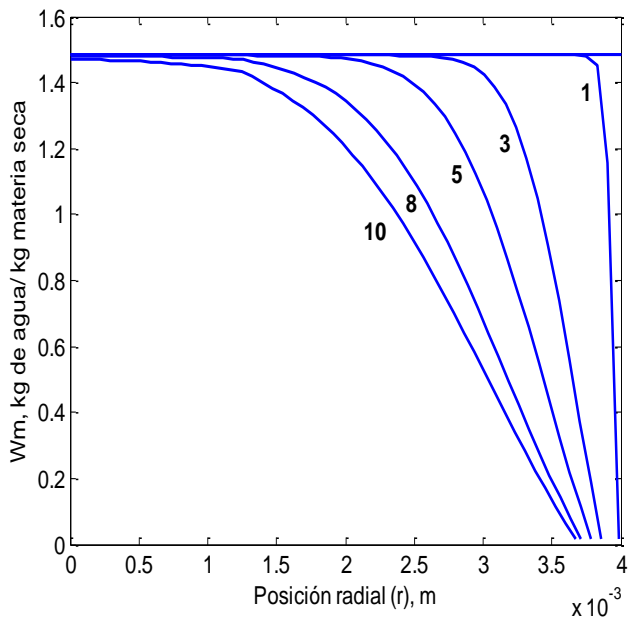

(a)

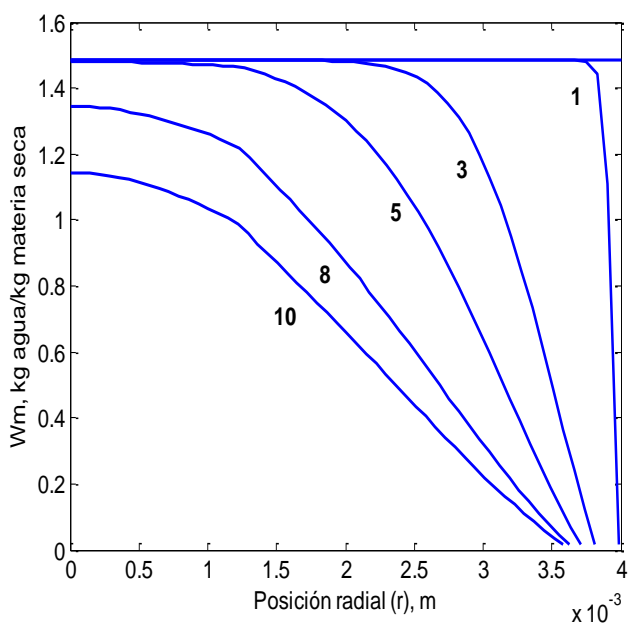

(c)

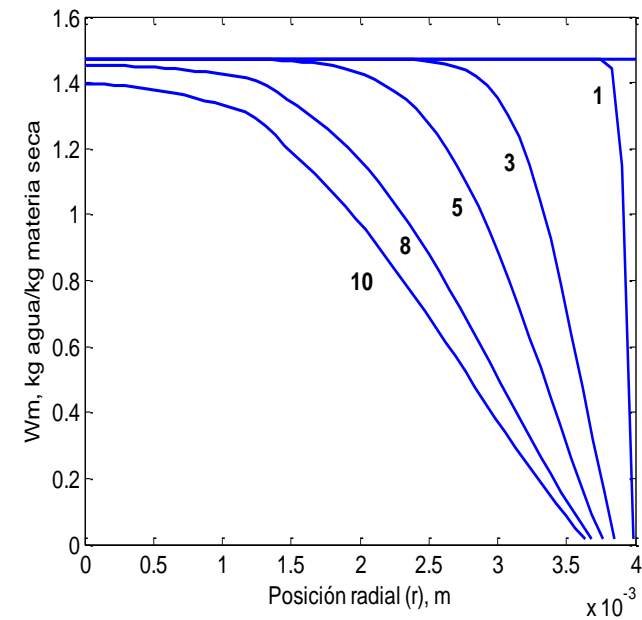

(b)

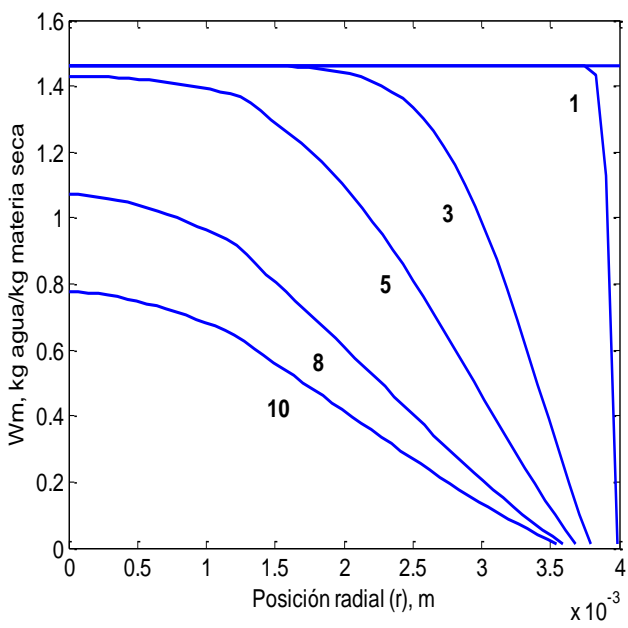

(d)

Figura 5.11 Perfiles de humedad media para los primeros 10 minutos de secado-tostado en función de la posición radial en la esfera. Para cada tratamiento: (a) $100^{\circ} \mathrm{C}$, (b) $120^{\circ} \mathrm{C}$, (c) $140^{\circ} \mathrm{C} \mathrm{y} \mathrm{(d)} 160^{\circ} \mathrm{C}$. 
El corrimiento hacia la izquierda del valor radial máximo demuestra la variación del contenido de humedad media en función del tiempo de proceso. Es evidente, incluso solo considerando los primeros 10 minutos de proceso, el efecto que la temperatura ejerció sobre los perfiles hallados principalmente en los tratamientos a 140 y $160^{\circ} \mathrm{C}$.

Con respecto a la predicción de la temperatura en el grano durante el tratamiento térmico, los resultados obtenidos se presentan a continuación

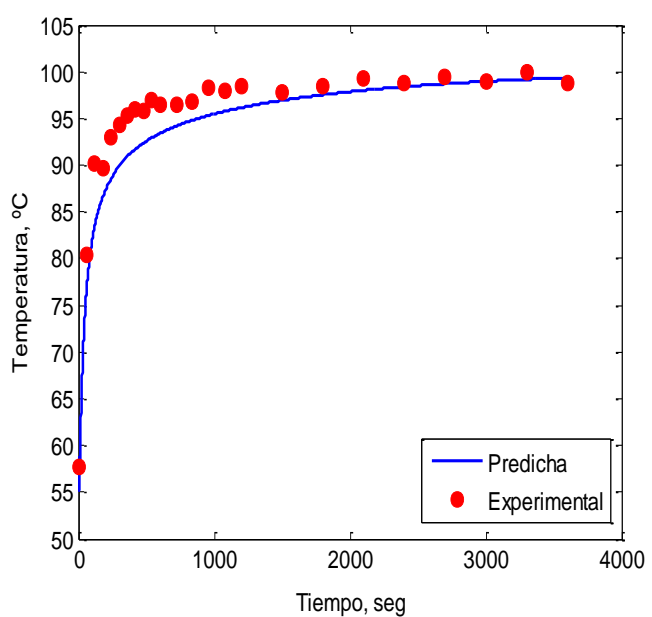

(a)

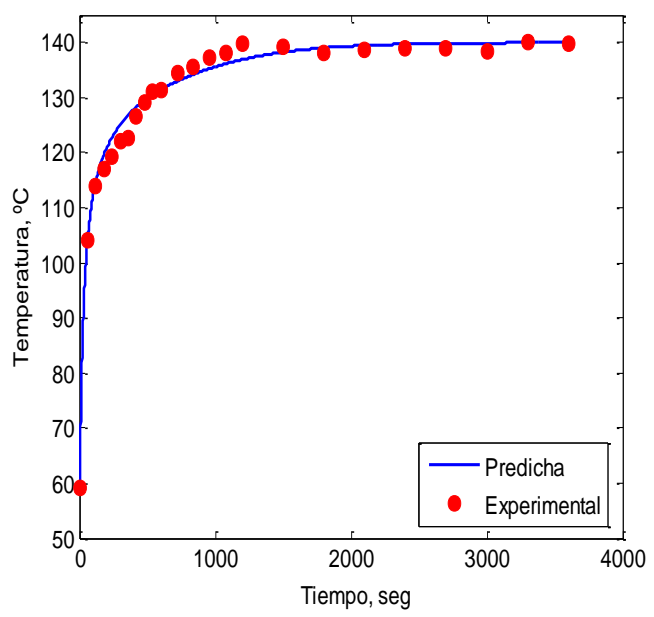

(c)

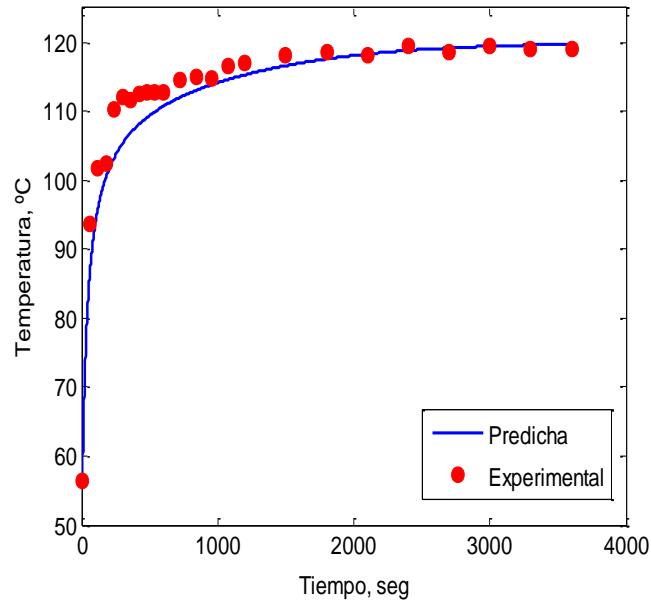

(b)

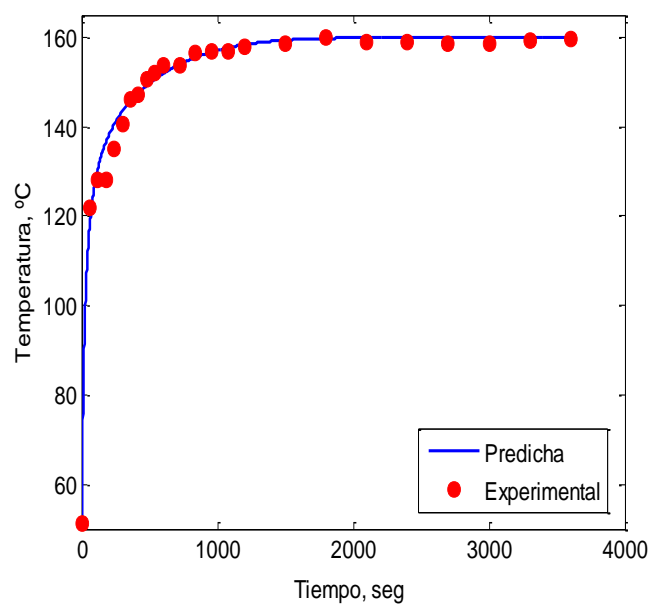

(d)

Figura 5.12 Ajuste del modelo de cálculo numérico resuelto por diferencias finitas a los datos experimentales de temperatura en el grano. Para cada tratamiento: (a) $100^{\circ} \mathrm{C}$, (b) $120^{\circ} \mathrm{C}$, (c) $140^{\circ} \mathrm{C} \mathrm{y} \mathrm{(d)} 160^{\circ} \mathrm{C}$. 
La concordancia obtenida mediante la resolución del balance de energía combinado al de materia fue satisfactoria en general. Principalmente dentro del rango práctico de este estudio. El grano incrementa súbitamente su temperatura dentro de los primeros 100 segundos y alcanza la temperatura del aire en un tiempo de alrededor de los 1000 segundos de proceso.

\subsection{Conclusiones.}

El estudio de la cinética de secado-tostado de grano entero de soja reveló que el fenómeno se lleva adelante en el periodo de velocidad decreciente, mediante transporte difusivo con control interno. Considerando tamaño y coeficiente de difusión constante, se aplicaron dos modelos para describir el proceso.

El modelo de Becker, ecuación para tiempos adimensionalmente cortos resultó inadecuado para el ajuste de los datos experimentales debido a las altas temperaturas empleadas, mostrando discrepancias considerables en las etapas finales del secadotostado.

La solución analítica en serie infinita, presentó resultados sorprendentemente precisos en el ajuste, a pesar de que estudios previos revelaron que el grano experimentaba un encogimiento del $10.6 \%$ durante el secado-tostado. La buena correlación obtenida por este modelo, radica probablemente en el hecho de que la relación $D_{\text {eff }} / R^{2}$, presente en la ecuación, permanece sustancialmente constante a lo largo del proceso. Esta aproximación permitió relacionar el coeficiente de difusión con la humedad.

Los valores del $D_{\text {eff }}$ obtenidos por la solución analítica se hallan dentro de los rangos esperados en productos de características similares. La funcionalidad de los 
coeficientes de difusión obtenidos con la temperatura se evaluó mediante una ecuación del tipo Arrhenius, los ajustes realizados muestran una buena correlación. El valor de la energía de activación determinado $\left(E_{a}=31.4 \mathrm{~kJ} / \mathrm{mol}\right)$ está dentro del rango reportado por otros autores para diversas semillas y granos.

Para realizar una descripción más realista del proceso, se planteó un modelo matemático considerando contracción volumétrica y variación del coeficiente de difusión efectivo con la humedad, tomando en cuenta lo anterior. Los resultados obtenidos tanto para el balance de materia como el de energía mediante el empleo de este modelo fueron muy satisfactorios, principalmente dentro del rango práctico de nuestro estudio.

El análisis de la transferencia de calor en capa delgada, se basó en un balance macroscópico de energía que supone control externo. Por tanto, se propuso transferencia de calor aire-grano con control externo minimizando la complejidad del modelado evitando de esta manera resolver un balance microscópico de energía. 


\section{CAPÍTULO VI}

MODELADO DEL SECADO-TOSTADO EN LECHO

FLUIDIZADO 


\section{Introducción.}

A lo largo de los capítulos previos se han determinado y modelado la densidad y el volumen de muestras remojadas y parcialmente secadas-tostadas en lecho fluidizado en función del tiempo, encontrándose que tanto el volumen de los granos como su densidad decrecen durante el proceso, lo que las convierte en materiales más porosos que los crudos a igual humedad. Luego se han determinado parámetros fluidodinámicos del proceso de secado tostado en lecho fluidizado, especialmente la variación (reducción) de la velocidad superficial del aire necesaria para mantener una fluidización, y un mezclado intenso, limitando así el consumo de energía del proceso y estableciendo una base para su automatización. A posteriori se realizó un estudio del equilibrio sorcional de las muestras remojadas y parcial y totalmente secadas-tostadas, donde no se observó efecto significativo de la temperatura en las isotermas, y se modeló la isoterma medida a $25^{\circ} \mathrm{C}$ eligiéndose el modelo de Halsey como el más preciso, lo que coincide con estudios realizados en otras oleaginosas y en soja cruda. Se llegó luego a un estudio cinético de una capa delgada de granos de soja, ventilada a velocidades de fluidización con aire caliente a diferentes temperaturas. Para condiciones constantes de aire en cada experiencia, las variaciones se limitaron a los granos. El resultado final de ese estudio fue la resolución del balance microscópico de materia asumiendo flujo difusivo de agua en un dominio que experimenta contracción volumétrica y donde, como consecuencia, el coeficiente de difusión efectivo del agua varía con el contenido de humedad, lo que es equivalente a decir que varía con el cambio de estructura promovido por la contracción volumétrica, que es desigual yendo del centro a la periferia puesto que acompaña el gradiente de humedades que se establece durante la deshidratación. Acoplado con este balance, se resuelve el balance macroscópico de 
energía planteado en el grano, debido a la suposición, justificada en estudios previos en otros granos para el rango de postcosecha, de que el control de la transferencia de calor durante el secado es externo (Giner y col., 2010).

En el lecho fluidizado, que aquí se estudió partiendo de una altura de lecho fijo de $0.10 \mathrm{~m}$ de granos previamente remojados, implicará que las condiciones del aire experimentarán cambios cuantificables durante el secado, tanto en su humedad absoluta y relativa, como en su temperatura. Por tanto, las condiciones de salida del aire variarán en el tiempo y serán diferentes a las de entrada, que permanecerán constantes en cada experiencia (Giner, 1999). Por tanto, el desarrollo de un modelo predictivo en lecho fluidizado requiere ahora del cálculo de los cambios en el aire y de condiciones de contorno de los granos variables en el tiempo.

Yang (2003) menciona que desde el desarrollo e incorporación de la tecnología de fluidización en diverso tipo de industrias, el estudio de la transferencia de calor y materia que tiene lugar durante dicho proceso, ha sido uno de los principales objetivos de diversos investigadores. Madhiyanon y col. (2006) y Markowski y col. (2010) destacan que el modelado en lecho fluidizado requiere en primer lugar del análisis y entendimiento de la distribución de humedad y temperatura en el grano. En este aspecto coinciden Giner y Calvelo (1987), pero ellos además mencionan que también reviste de importancia la comprensión de las características fluidodinámicas de la partícula en estudio.

Autores como Vatani y col. (2011), Delele y col. (2008) y Groenewold y col. (2007) realizaron análisis más detallados, involucrando la descripción matemática de los fenómenos involucrados, pero con partículas inorgánicas y de aplicación en reactores químicos. Con respecto a su aplicación en alimentos, en la bibliografía se encontraron trabajos de secado en lecho fluidizado en soja, por ejemplo Osella y col. (1997), 
Prachayawarakorn y col. (2006) y Soponronnarit y col. (2001), aunque ninguno incluía una interpretación o modelado de las condiciones de transferencia de materia y energía en el lecho. Un análisis, interesante acerca de estos fenómenos lo realizó Wiriyaumpainwong (2002) en soja, pero trabajando en una variante de la tecnología de fluidización como es el denominado “spouted bed". Por tanto, es limitada la información relacionada al estudio matemático de la fluidización particularmente en soja remojada y los mecanismos de transferencia involucrados.

En este trabajo, se desarrolló un modelo y un programa de simulación de lecho fluidizado en lenguaje Matlab que utiliza el estudio cinético realizado en el capítulo anterior y lo relaciona con balances macroscópicos de materia (agua) y energía en el equipo, a los fines de calcular la variación de la humedad y temperatura del aire a la salida, dadas las condiciones de entrada además de las variaciones de la temperatura y contenido de humedad de los granos en el lecho. El modelo se validó con experiencias donde se midieron las historias térmicas y las curvas de secado del producto, a distintas temperaturas de aire.

\subsection{Consideraciones teóricas.}

\subsubsection{Modelo matemático para el secado en lecho fluidizado.}

Un modelo matemático de lecho fluidizado debe ser capaz de predecir la evolución de cuatro variables fundamentales del secado: humedad media del grano $\left(\mathrm{W}_{\mathrm{m}}\right)$, temperatura media del grano $\left(\mathrm{T}_{\mathrm{m}}\right)$, temperatura del aire a la salida $\left(\mathrm{T}_{\mathrm{a} 2}\right)$ y humedad absoluta del aire a la salida $\left(\mathrm{h}_{\mathrm{a} 2}\right)$, en función del tiempo. Así que deben deducirse 4 ecuaciones independientes. 


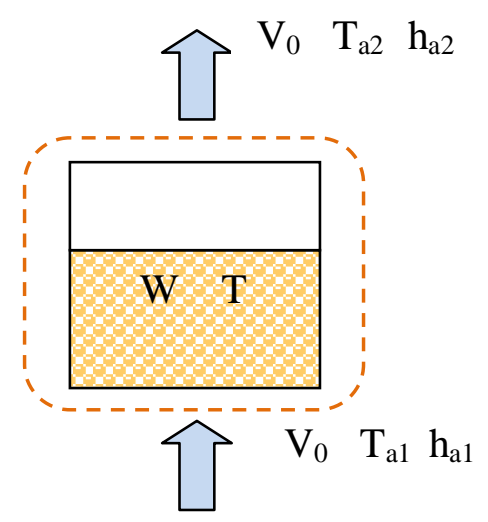

Figura 6.1 Sistema aire intergranular y granos para el desarrollo de los balances de materia y energía.

La Figura 6.1, representa esquemáticamente el comportamiento de las partículas y el aire en el lecho fluidizado.

Las suposiciones realizadas son las siguientes

1) Las pérdidas de calor en el lecho fluidizado son despreciables frente a la transferencia de aire grano

2) Los términos de acumulación en el aire son despreciables frente a los correspondientes aportes convectivos

3) El mezclado de aire y granos dentro del lecho es perfecto

4) Debido a la suposición 3), la temperatura de salida del aire puede aproximarse igual a la temperatura del lecho

5) Debido a la suposición 3), la velocidad de secado en el lecho (-dW/dt) representa al total del lecho, al igual que la variación de temperatura del producto (dT/dt).

6) La distribución de velocidad del aire en la sección transversal del lecho es uniforme. 
Consideraciones adicionales

a) La velocidad de secado se calculará con el modelo cinético de partícula, de volumen y difusividad variable, desarrollado en el capítulo 5. La diferencia es que ahora esa velocidad será uniforme en todo el lecho en cada tiempo, aunque la condición de contorno prescripta se calculará con la isoterma de sorción en equilibrio con el aire, cuya condición es variable con el tiempo en el lecho fluidizado.

b) La evolución de la temperatura de los granos del lecho en el tiempo dependerá de la pérdida de temperatura del aire en su paso por el lecho, y de la demanda de calor establecida por la desorción de agua desde el grano

\subsubsection{Ecuaciones del modelo de secado en lecho fluidizado.}

\subsubsection{Balances en los granos del lecho}

Balance microscópico de materia

El cálculo de la velocidad de secado se realiza con un balance microscópico de materia que predice un perfil de humedad local en función de la coordenada espacial de la partícula. Ese perfil luego se integra en el volumen del grano y, como en un lecho fluidizado se supone que todos los granos experimentan la misma historia térmica y la misma curva de secado, al multiplicar por la masa de lecho, el cálculo concluye determinando la masa de agua que se transfiere al aire de fluidización, por unidad de tiempo 


$$
m_{W}=m_{S L}\left(-\frac{d W}{d t}\right)
$$

donde

$$
m_{S L}=\rho_{s 0}\left(1-\varepsilon_{0}\right) S Z_{\max }
$$

corresponde a la masa seca del lecho, basada en la altura de lecho fijo, $Z_{\max }, \rho_{\mathrm{s} 0}$ la relación entre la masa seca y el volumen inicial del grano, $\mathrm{kg} / \mathrm{m}^{3}, \varepsilon_{0}$ la fracción de huecos en el lecho o porosidad correspondiente al estado de lecho fijo y S representa la sección transversal de la cámara de secado, en m.

\section{Balance macroscópico de energía}

El balance macroscópico de energía se aplica a todos los granos del lecho, se diferencia del propuesto para un solo grano en que ahora se considera la masa seca del lecho y que la diferencia de temperatura entre el grano y el aire es un valor medio de los que existen a la entrada y la salida

$$
C_{p} m_{S L} \frac{d T}{d t}=h_{T} a_{v}\left(1-\varepsilon_{0}\right) S Z_{\max }\left[\frac{\left(T_{a 1}-T\right)-\left(T_{a 2}-T\right)}{\ln \frac{T_{a 1}-T}{T_{a 2}-T}}\right]-m_{S L}\left(-\frac{d W}{d t}\right) L_{W}
$$

donde $C_{p}$ es la capacidad calorífica del grano en base seca, $\mathrm{J} / \mathrm{kg}$ grano seco ${ }^{\circ} \mathrm{C}, m_{S L}$ es la masa seca del lecho, en $\mathrm{kg}, h_{T}$ coeficiente efectivo de transferencia de calor aire-grano, $\mathrm{W} /{ }^{\circ} \mathrm{C} \mathrm{m}{ }^{2}, a_{\mathrm{v}}$ el área específica de la partícula por unidad de volumen de la partícula 
3/ $R$ para una esfera, $L_{w}$ el calor de vaporización del agua a la temperatura del lecho, $\mathrm{J} / \mathrm{kg}, T_{a 1} \mathrm{y} T_{a 2}$ las temperaturas del aire a la entrada y la salida respectivamente, en ${ }^{\circ} \mathrm{C}$, mientras que $\mathrm{T}$ representa la temperatura de los granos del lecho.

\subsubsection{Balances en el aire de secado}

Balance macroscópico de materia

La ganancia de humedad absoluta por parte del aire se debe a la pérdida de agua en todo el lecho

$$
\rho_{a} V_{0} S\left(h_{a 2}-h_{a 1}\right)=m_{S L}\left(-\frac{d W}{d t}\right)
$$

Obsérvese que $h_{a 2}$ va a depender del tiempo, a diferencia de $h_{a 1}$ que se mantendrá constante. El miembro derecho de la ecuación es la masa de agua por unidad de tiempo que se transfiere desde el sólido al aire en un instante de tiempo. Si bien el balance es macroscópico para el aire,

$h_{a 2}=h_{a 1}+\frac{\left(-\frac{d W}{d t}\right) \rho_{s o}\left(1-\varepsilon_{0}\right) Z_{\max }}{\rho_{a} V_{0}}$

Balance de macroscópico de energía 
Para el balance de energía a partir de las consideraciones realizadas previamente se propuso el siguiente desarrollo. Se considera que la energía pérdida por el aire es igual a la que se transfiere a los granos

$-\rho_{a} V_{0} S C_{p a}\left(T_{a 2}-T_{a 1}\right)=h_{T} a_{v}\left(1-\varepsilon_{0}\right) S Z_{\max }\left[\frac{\left(T_{a 1}-T\right)-\left(T_{a 2}-T\right)}{\ln \frac{T_{a 1}-T}{T_{a 2}-T}}\right]$

Reemplazando el término izquierdo de la ecuación 6.5 en la correspondiente al balance macroscópico de los granos en el lecho Ec. (6.2) y distribuyendo el signo negativo en este término.

$$
C_{p} m_{S L} \frac{d T}{d t}=\rho_{a} V_{0} S C_{p a}\left(T_{a 1}-T_{a 2}\right)-m_{S L}\left(-\frac{d W}{d t}\right) L_{W}
$$

Si se asume que el aire deja el lecho en equilibrio térmico con los sólidos del lecho, $\mathrm{T}_{\mathrm{a} 2} \approx \mathrm{T}$.

$C_{p} m_{S L} \frac{d T}{d t}=\rho_{a} V_{0} S C_{p a}\left(T_{a 1}-T\right)-m_{S L}\left(-\frac{d W}{d t}\right) L_{W}$

La ecuación 6.7 nos dice que la evolución de la temperatura de los granos en el lecho con el tiempo dependerá de la pérdida de temperatura del aire en su paso por el lecho y de la demanda de calor establecida por la desorción de agua. Obsérvese que no aparece aquí el coeficiente de transferencia de calor determinado en el capítulo anterior, debido a la suposición de equilibrio térmico mencionada. 


\subsubsection{Resolución numérica del modelo de secado en lecho fluidizado.}

Sistema de ecuaciones

El sistema a resolver, está compuesto por el balance microscópico de materia con volumen variable de partícula y difusividad variable, que se resuelve aquí para una condición de contorno $\mathrm{W}_{\mathrm{e}}=\left(\mathrm{W}_{\mathrm{e} 1}+\mathrm{W}_{\mathrm{e} 2}\right)$, siendo $\mathrm{W}_{\mathrm{e} 1}=\mathrm{f}\left(\mathrm{T}_{\mathrm{a} 1}, \mathrm{~h}_{\mathrm{ra} 1}\right)$ y $\mathrm{W}_{\mathrm{e} 2}=\mathrm{f}\left(\mathrm{T}_{\mathrm{a} 2}, \mathrm{~h}_{\mathrm{ra} 2}\right)$, siendo $\mathrm{W}_{\mathrm{e} 1}$ constante y $\mathrm{W}_{\mathrm{e} 2}$ variable, por tanto $\mathrm{W}_{\mathrm{e}}$ varia con el tiempo.

$d W / d t=$ modelo cinético con volumen y difusividad variable, descripto y validado en el capítulo 5, que aproxima la $d W / d t$ mediante $\left(\mathrm{W}_{\mathrm{t}+\Delta \mathrm{t}}-\mathrm{W}_{\mathrm{t}}\right) / \Delta \mathrm{t}$, siendo $\mathrm{W}_{\mathrm{t}+\Delta \mathrm{t}} \mathrm{y} \mathrm{W}_{\mathrm{t}}$ las humedades medias de partícula, que fueron integradas como se describió en el capítulo 5 a partir de las humedades locales calculadas dentro de la partícula a los tiempos $t$ y $t+\Delta \mathrm{t}$, respectivamente.

Las condiciones iniciales para los granos son:

en el interior de cada grano y por tanto en el lecho:

$$
\mathrm{t}=0 \quad \mathrm{~W}=\mathrm{W}_{0}
$$

con respecto al balance macroscópico de energía en los granos, reordenando la ecuación (6.7), obtenemos finalmente la ecuación diferencial ordinaria que predice la variación de la temperatura media de los granos en el lecho

$$
\frac{d T}{d t}=\frac{\rho_{a} V_{0} C p_{a}}{\rho_{\text {so }}\left(1-\varepsilon_{0}\right) Z_{\max 0} C_{p}}\left(T_{a 1}-T\right)-\frac{L_{w}}{C_{p}}\left(-\frac{d W}{d t}\right)
$$


Las condiciones iniciales para los granos son:

$$
\mathrm{t}=0 \quad \mathrm{~T}=\mathrm{T}_{0},
$$

Por su parte, las ecuaciones para la variación de la fase aire surgen de balances macroscópicos, asumiendo $\mathrm{T}_{\mathrm{a} 1}$ y $\mathrm{h}_{\mathrm{a} 1}$ constantes

$h_{a 2}=h_{a 1}+\frac{\left(-\frac{d W}{d t}\right) \rho_{\text {so }}\left(1-\varepsilon_{0}\right) Z_{\max }}{\rho_{a} V_{0}}$

Mientras que la temperatura del aire a la salida, en cada tiempo, se aproxima igual a la temperatura del lecho

$$
\mathrm{T}_{\mathrm{a} 2} \approx \mathrm{T}
$$

Queda por tanto un sistema que resuelve (1) Un balance microscópico de materia con volumen de grano y difusividad variable en el grano y (2) la integración en el tiempo de la temperatura del lecho se realizó mediante el método numérico de Euler, para la resolución de ecuaciones diferenciales ordinarias:

$$
T_{t+\Delta t}=T_{t}+\left(\frac{d T}{d t}\right) \Delta t
$$

\subsubsection{Algoritmo de cálculo}

A continuación se presenta el algoritmo de cálculo empleado 


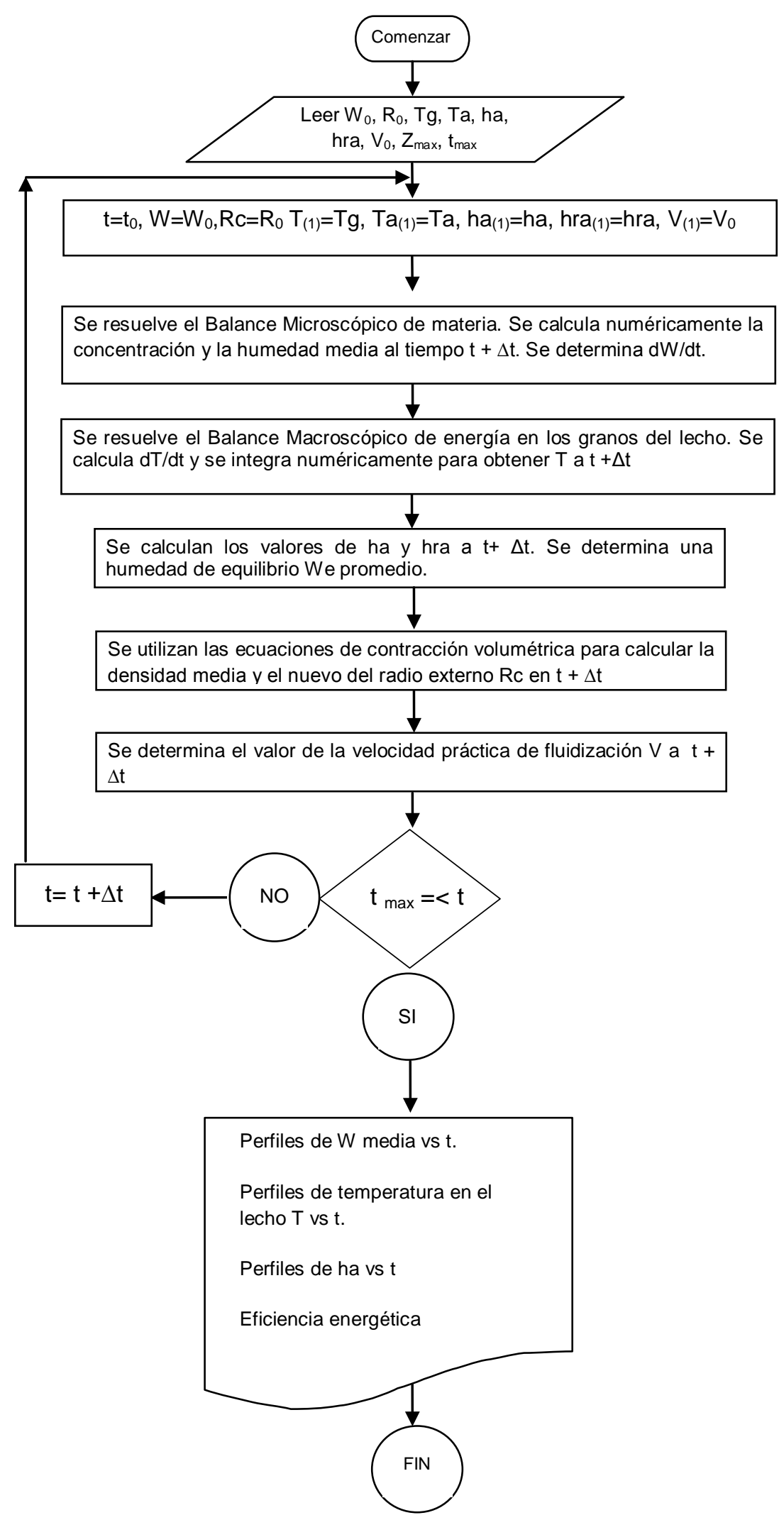


6.1.3.2. Parámetros del modelo (propiedades geométricas, físicas, térmicas y de transporte).

\subsubsection{Propiedades del agua y del aire}

Calor especifico. Aire seco:

$C_{p a}=1008 \mathrm{~J} / \mathrm{kg}^{\circ} \mathrm{C}$

Presión de saturación líquido-vapor de agua pura

$$
p_{s}=\operatorname{Exp}\left(A-\frac{B}{(T+273.16)}-C \ln (T+273.16)\right), \mathrm{Pa}
$$

$A=54.119, B=6547.1, C=4.23$

Presión parcial del vapor en el aire

$$
p_{v a}=\frac{p h_{a}}{\left(\frac{M_{v}}{M_{a}}+h_{a}\right)}, \mathrm{Pa}
$$

$M_{v}=18 \mathrm{~kg} / \mathrm{kmol}, M_{a}=28.8 \mathrm{~kg} / \mathrm{kmol}, p=1.01325 \times 10^{5}, \mathrm{~Pa}$

Humedad relativa del aire

$$
h_{r a}=\frac{p_{v a}}{p_{s}}
$$

Densidad del aire

$$
\rho_{a}=\frac{p M_{a}}{R T_{k}}
$$

$R=8314, \mathrm{~J} / \mathrm{kmol} \mathrm{K}$ 
Calor latente de vaporización de agua pura

Dado que no se halló una funcionalidad de $\mathrm{L}_{\mathrm{w}}$ con la temperatura (Capítulo 4) se utilizará el calor latente de vaporización del agua pura, en unidades de J/kg, en función de $\mathrm{T}$

$L_{w}=\left(\frac{R}{M_{v}}\right)(B-C(T+273.16))$

Los valores de B y C son los mismos de la correlación de $\mathrm{p}_{\mathrm{s}}$. Esta ecuación se reordena para su utilización en ${ }^{\circ} \mathrm{C}$, obteniéndose

$$
L w=2.490 \times 10^{6}-1953.8 \mathrm{~T}, \mathrm{~J} / \mathrm{kg}
$$

\subsubsection{Propiedades del grano y el lecho.}

Ecuación de isoterma de sorción

$$
\mathrm{We}=0.01\left[\frac{-\exp \left(\mathrm{A}_{\mathrm{HM}}\right)}{\operatorname{lnh} r_{\mathrm{a}}}\right]^{1 / \mathrm{R}_{\text {нм }}}
$$

$\mathrm{A}_{\mathrm{HM}}=1.595, \mathrm{R}_{\mathrm{HM}}=1.117$.

Velocidad operativa de fluidización

$$
V_{f}=1.5(2.649(1-\exp (-0.490 W))+1.189)
$$




\subsection{Materiales y métodos.}

\subsubsection{Secado-tostado en lecho fluidizado.}

La muestra de soja remojada se introdujo en la cámara de secado del equipo de lecho fluidizado. Para todas las experiencias la altura de lecho fijo fue igual a $0.1 \mathrm{~m}$. Se trabajó con 4 temperaturas de aire: $100,120,140$ y $160^{\circ} \mathrm{C}$, y una velocidad operativa de fluidización variable entre 3.9 y $1.8 \mathrm{~m} / \mathrm{s}$ tal como se determinó en el capítulo 3 de este trabajo (sección 3.2.3). A todas las temperaturas, se extrajeron muestras a tiempos de 5, 10, 15, 20, 25, 30, 40, 50 y 60 minutos. Dicho procedimiento se llevó a cabo con una cuchara alargada de acero inoxidable. Las humedades se determinaron mediante la técnica descrita en la Sección 2.3.3 del Capítulo 2. Para determinar la historia térmica del lecho de partículas se utilizó un equipo infrarrojo marca Testo 830 que permite medir la temperatura de superficies sin contacto. Las mediciones se realizaron en intervalos de 2 min aproximadamente. Cada experiencia fue realizada por triplicado.

\subsection{Resultados y discusión.}

\subsubsection{Validación de modelo de predicción de humedad y temperatura en lecho fluidizado.}

En primer lugar se presentan los resultados obtenidos para la predicción del humedad en lecho 


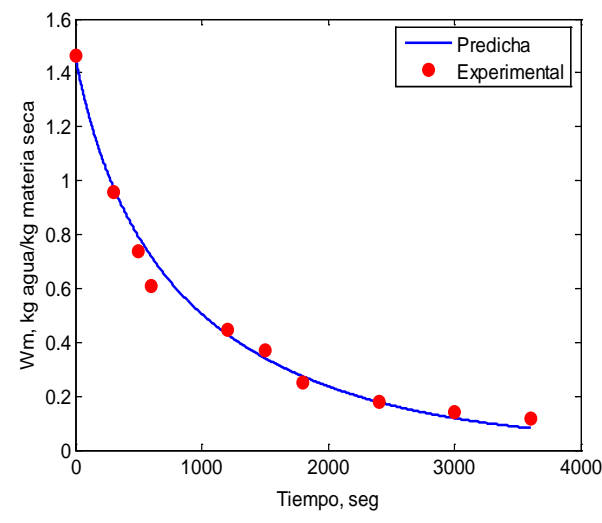

(a)

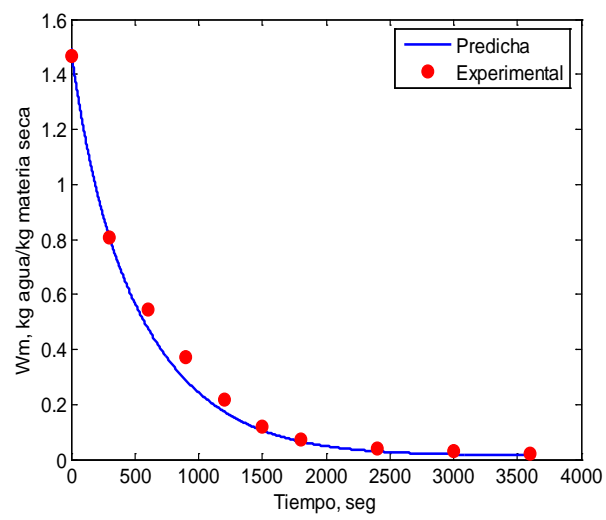

(c)

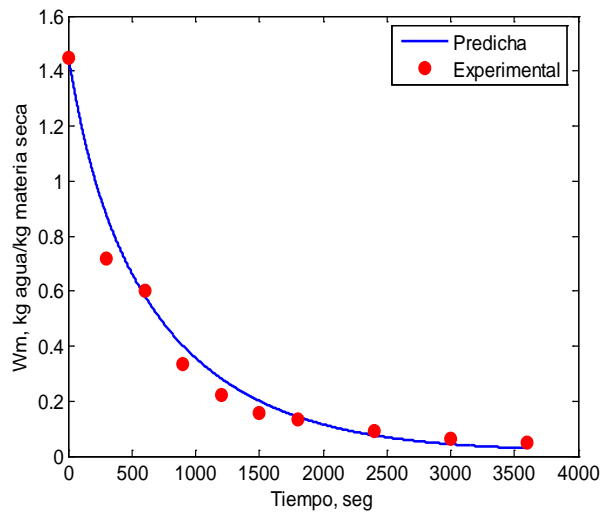

(b)

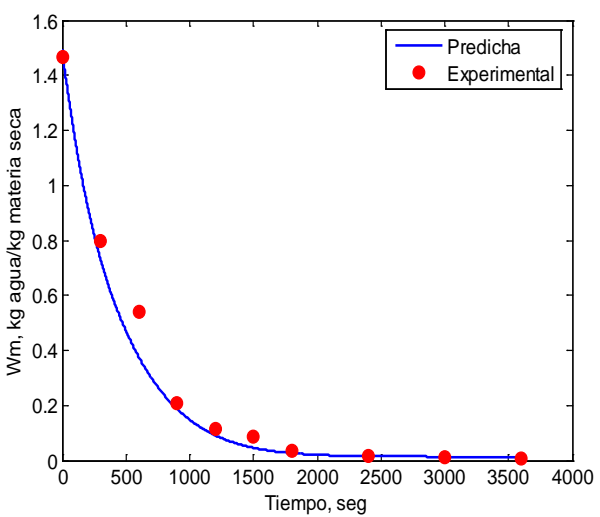

(d)

Figura 6.2 validación del modelo de secado en lecho fluidizado con datos experimentales de contenido de humedad del lecho en función del tiempo para cada tratamiento realizado: (a) $100^{\circ} \mathrm{C}$, (b) $120^{\circ} \mathrm{C}$, (c) $140^{\circ} \mathrm{C}$ y (d) $160^{\circ} \mathrm{C}$.

Los resultados del ajuste en general fueron satisfactorios. El contenido de humedad disminuyó considerablemente dentro de los primeros 20 a 25 minutos de proceso. Este comportamiento fue similar a lo reportado por Soponronnarit y col. (2001) y Osella y col. (1997) quienes estudiaron el secado de soja cruda en lecho fluidizado en rangos de humedad postcosecha con temperaturas aire de entre 100 y $140^{\circ} \mathrm{C}$.

Con respecto a la temperatura la Figura 6.3 presenta los resultados correspondientes 


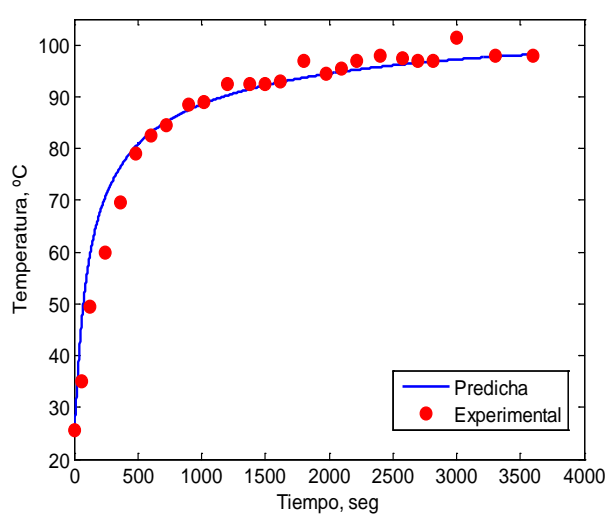

(a)

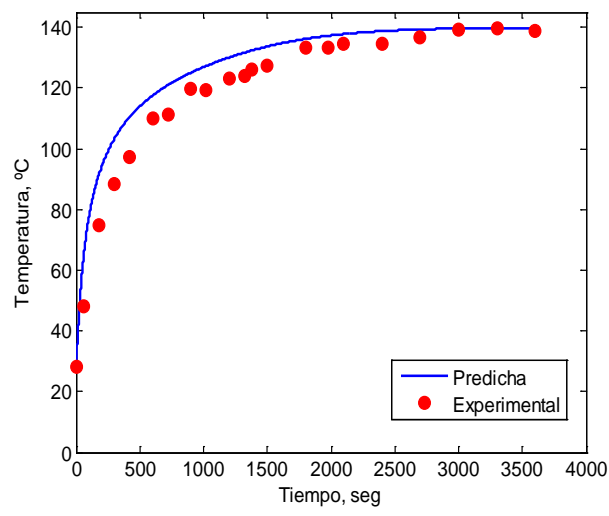

(c)

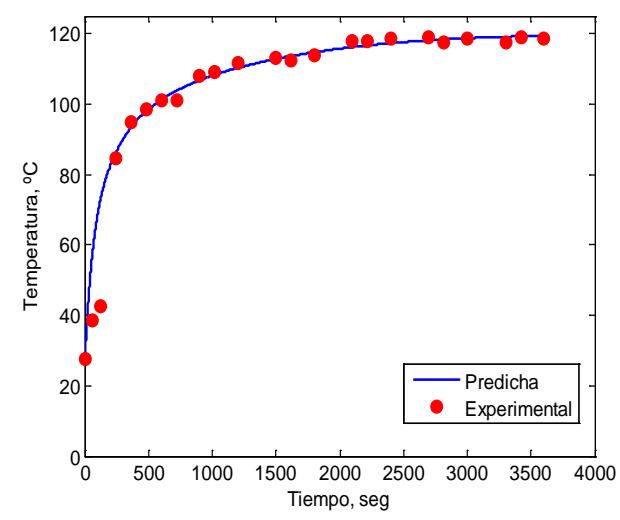

(b)

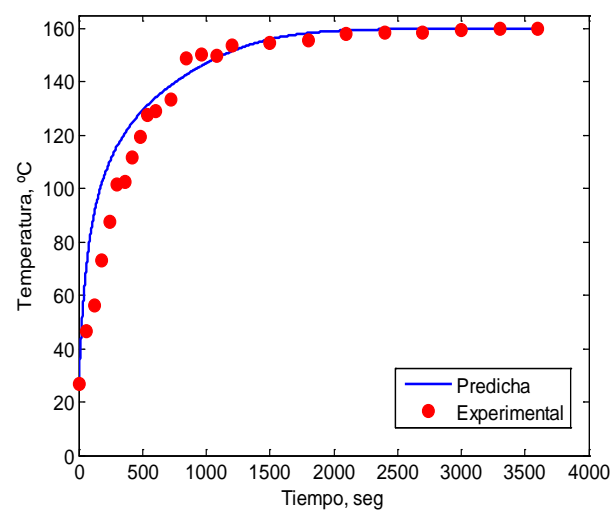

(d)

Figura 6.3 validación del modelo de secado en lecho fluidizado con datos experimentales de temperatura del producto en función del tiempo para cada tratamiento realizado: (a) $100^{\circ} \mathrm{C}$, (b) $120^{\circ} \mathrm{C}$, (c) $140^{\circ} \mathrm{C} \mathrm{y} \mathrm{(d)} 160^{\circ} \mathrm{C}$.

A pesar de observarse algunas desviaciones entre los valores predichos y los experimentales, la predicción en general fue satisfactoria. Al respecto, Markowski y col. (2010) quienes estudiaron el secado de zanahoria en un equipo de lecho fluidizado tipo spouted bed informaron también resultados semejantes a los presentados en la figura 6.3. Estos autores atribuyeron este tipo de desviaciones a las propiedades térmicas de los productos bajo estudio. 


\subsubsection{Evolución de la humedad absoluta y relativa del aire durante el secado-} tostado.

En la mayoría de los estudios de secado, la humedad del aire es un parámetro muy importante a considerar, tanto como la temperatura y la velocidad (Lin y Chen, 2005). La capacidad de predecir con precisión la variación de la humedad absoluta del aire resulta en una herramienta importante para el diseño y desarrollo de cualquier tipo de operación en lecho fluidizado (Maronga, 1998). Resolviendo la Ecuación 6.6 se calculó la variación de la humedad absoluta en el aire de secado.

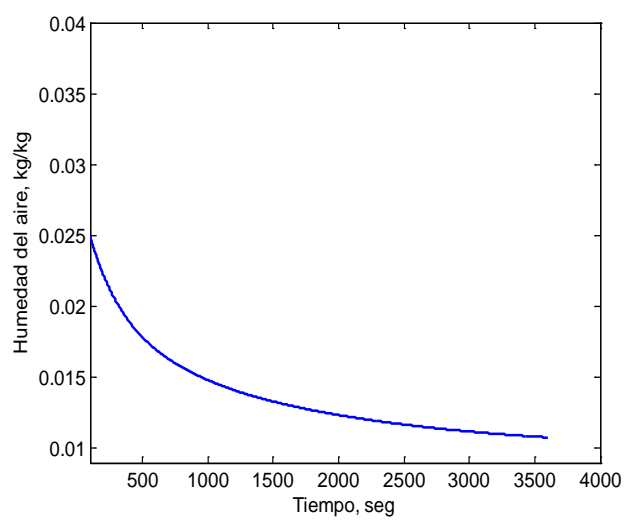

(a)

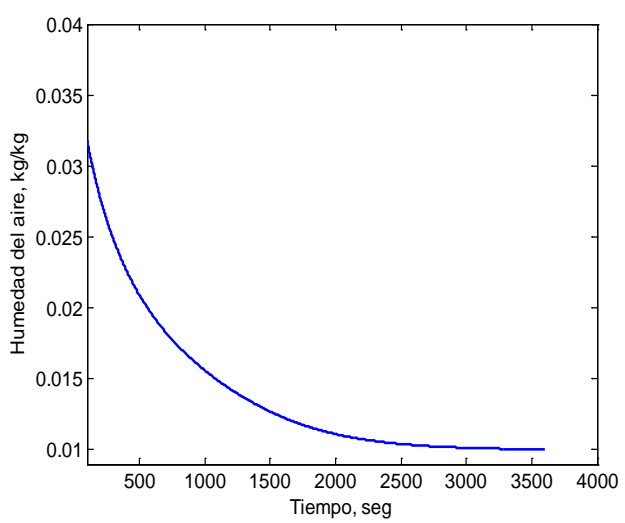

(c)

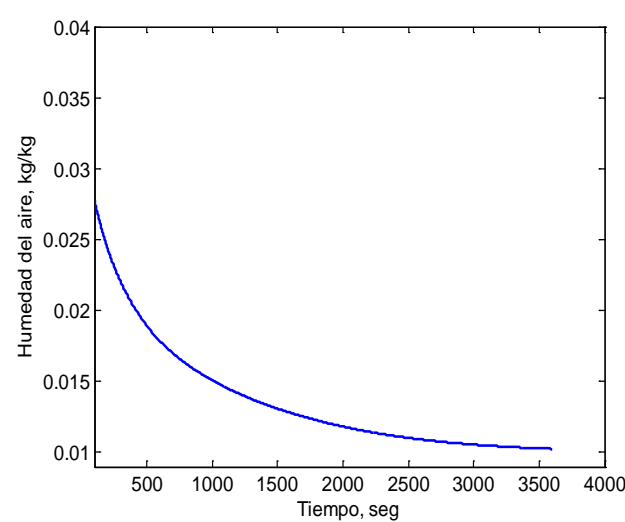

(b)

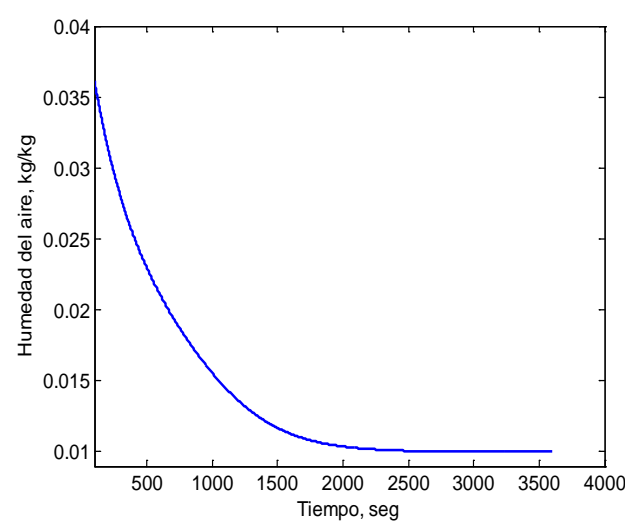

(d)

Figura 6.4 Evolución del contenido de humedad absoluta en el aire durante el tratamiento de secado-tostado, para cada temperatura: (a) $100^{\circ} \mathrm{C}$, (b) $120^{\circ} \mathrm{C}$, (c) $140^{\circ} \mathrm{C} \mathrm{y}$ (d) $160^{\circ} \mathrm{C}$. 
En todos los casos este aire ingreso al sistema con una $h_{a}$ de $0.01 \mathrm{~kg} / \mathrm{kg}$. De acuerdo a lo observado en la figura anterior, el aire presentó una ganancia considerable de humedad al principio del proceso, correspondiente a su paso a través del lecho húmedo de partículas. A medida que el producto se fue deshidratando, el aire también arrastró consigo cada vez menos humedad, tendiendo hacia el final del proceso al valor inicial de humedad que tenía al ingresar a la cámara de secado. Srivasta y John (2002) quienes analizaron el comportamiento del aire en el secado de arroz a temperaturas moderadas encontraron un comportamiento similar. Estos autores atribuyeron este hecho a la disminución de la velocidad de secado conforme el producto se deshidrata. Autores como Lin y Chen (2005) destacan que si lo que se busca es mejorar la eficiencia del proceso, es conveniente usar aires de secado con bajas humedades absolutas y relativas. En nuestro caso, las humedades relativas del aire a la entrada fueron a $100^{\circ} \mathrm{C}$ de $1.6 \%$, a $120^{\circ} \mathrm{C}$ de $0.8 \%$, a $140^{\circ} \mathrm{C}$ de $0.4 \%$ y a $160^{\circ} \mathrm{C}$ el valor fue de $0.3 \%$. 


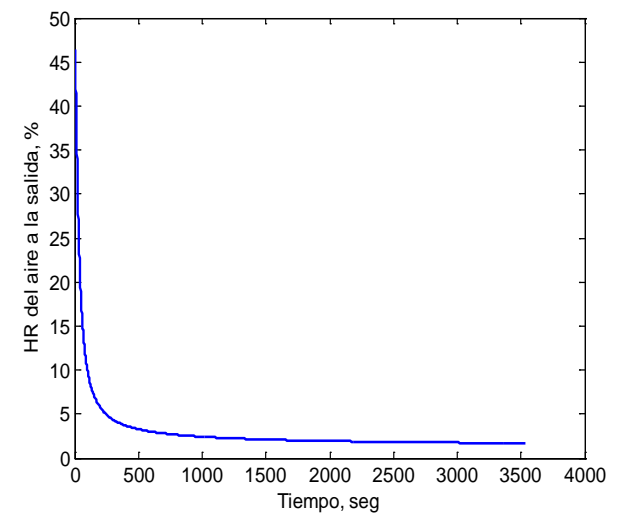

(a)

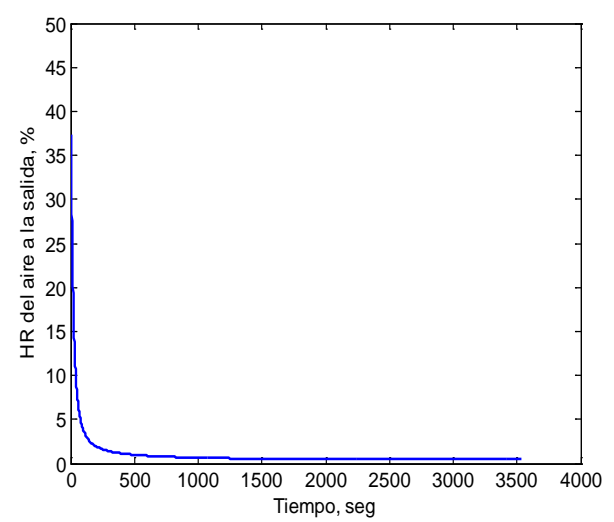

(c)

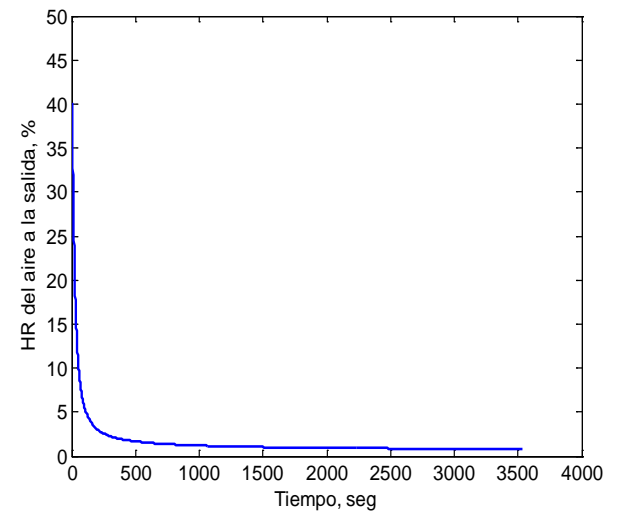

(b)

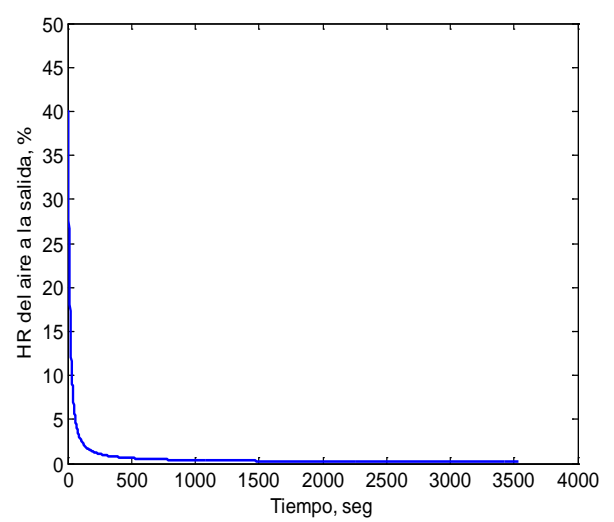

(d)

Figura 6.5 Evolución la humedad relativa del aire durante el tratamiento de secadotostado, para cada temperatura: (a) $100^{\circ} \mathrm{C}$, (b) $120^{\circ} \mathrm{C}$, (c) $140^{\circ} \mathrm{C}$ y (d) $160^{\circ} \mathrm{C}$.

La figura anterior muestra que tal como se observó para el caso de la humedad absoluta, la humedad relativa muestra un incremento considerable durante las etapas iniciales de proceso, para luego disminuir hasta valores bajos próximos a los de entrada. Estos resultados pueden ser de gran utilidad en caso de que se desee recircular parte del aire de secado. Kim y col., (2011) quienes estudiaron la aplicación de tratamientos térmicos en lechos fluidizados para productos farmacéuticos, recomendaron que la combinación más conveniente para el secado en este tipo de tecnología son altas velocidades de fluidización, altas temperaturas y bajas humedades relativas del aire de secado. 
A continuación se realizó un estudio para evaluar la influencia de la altura de lecho $\left(Z_{\max }\right)$ en el secado tostado a $140^{\circ} \mathrm{C}$.

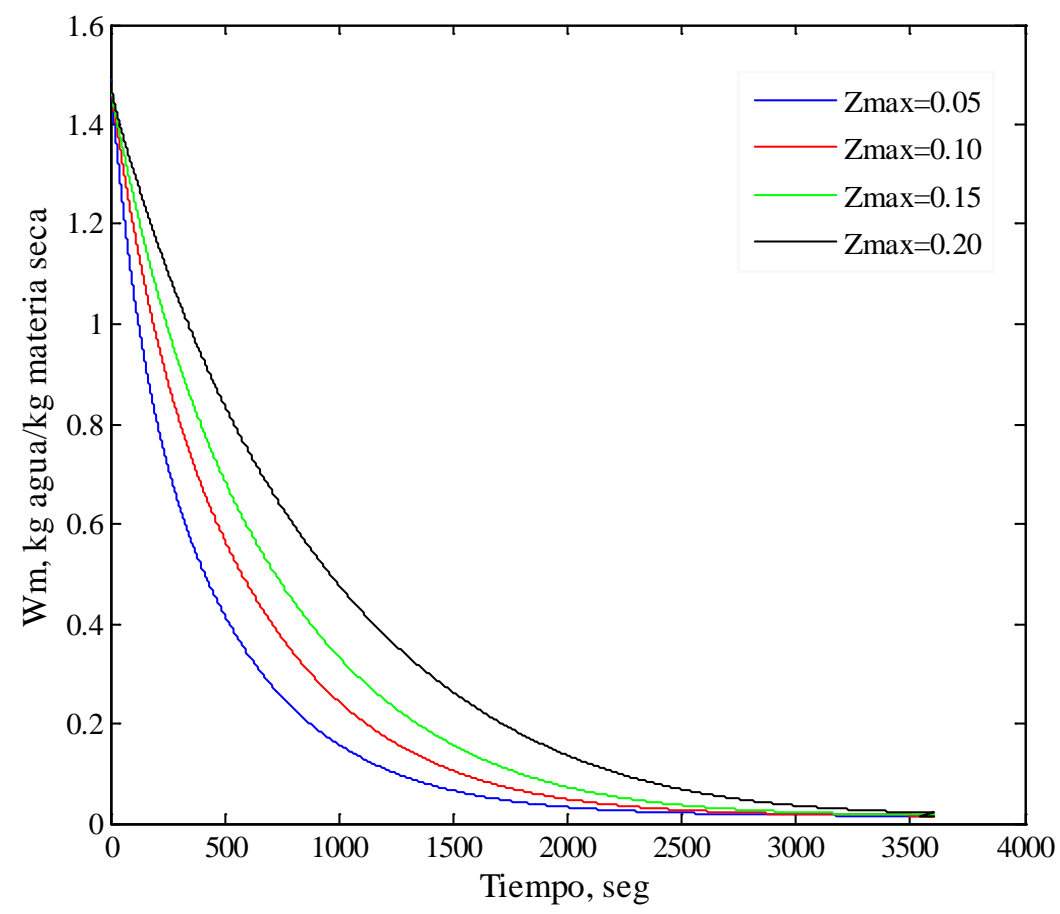

Figura 6.6 Efecto de la altura de lecho fijo en el secado tostado a $140^{\circ} \mathrm{C}$.

Los resultados indican que el aumento en la altura de lecho incrementa el tiempo necesario para alcanzar el contenido de humedad deseado. Esto está de acuerdo con lo informado por Giner y Calvelo (1987) quienes estudiaron el efecto de este parámetro en el secado de trigo en lecho fluidizado. Otros autores como Srivastava y John (2002) sugirieron que no solo el tiempo de secado puede verse afectado por la altura del lecho sino también la humedad del aire de salida, que saldrá ahora con mayor humedad dado que incrementar la altura también implica una mayor cantidad de materia húmeda. 


\subsection{Diseño del proceso con recirculación de aire.}

A fin de optimizar el consumo de energía en los procesos de secado resulta conveniente llevar a cabo estudios de la eficiencia energética del proceso, de manera que sea posible determinar las condiciones para las cuales se obtengan productos finales de alta calidad y al mismo tiempo un consumo energético moderado (Syahrul y col., 2002). Las altas velocidades de aire requeridas para la fluidización producen un alto grado de mezclado permitiendo un tratamiento térmico uniforme como así también altos valores de los coeficientes de transferencia de materia y energía (Yang, 2003; Senadeera y col., 2006). No obstante, el hecho de forzar el paso de grandes volúmenes de aire a través de un lecho de partículas implica un consumo mayor de energía (Madhiyanon y col., 2006). Autores como Syahrul y col. (2002) y Giner y Calvelo (1987) mencionan que la posibilidad de aplicar esta metodología de secado a nivel industrial depende fuertemente del uso eficiente de energía.

Giner y De Michelis (1988) encontraron un alto potencial para la recuperación de energía durante el proceso de fluidización en secado de trigo postcosecha, dado que en su paso por el lecho, el aire sale con elevada temperatura y baja humedad. Por tanto, a continuación se llevará a cabo un estudio de la eficiencia térmica del proceso planteado para el desarrollo del snack a base de grano entero de soja considerando la posibilidad de recircular una cierta fracción del aire de secado.

La eficiencia térmica es el parámetro más conveniente para relacionar el consumo de energía en un secador con el usado para evaporar agua. La definición más representativa de la eficiencia térmica de una operación de secado es la siguiente (Giner y De Michelis, 1988): 


$$
E_{f}=\frac{\text { Calor latente requerido para evaporar la humedad del grano }}{\text { Calor añadido al aire de secado }}
$$

La cual expresada en términos de las variables operativas queda de la siguiente manera:

$$
E_{f}=\frac{\rho_{s o}\left(1-\varepsilon_{0}\right) Z_{\max }\left(W_{0}-W_{f}\right) L_{w}}{\rho_{a} V_{m} C_{p a}\left(T_{a 1}-T_{M}\right) t_{s}}
$$

Donde $t_{s}$ es el tiempo de residencia o tiempo total del proceso, en segundos; $V_{m}$ representa el valor promedio de la velocidad operativa de fluidización calculada a partir de la ecuación 6.14 y deducida previamente en el capítulo 3; $L_{w}$, un calor latente de vaporización promedio, $\varepsilon_{0}$ la porosidad de lecho fijo, $T_{a 1}$ y $T_{M}$ la temperatura en ${ }^{\circ} \mathrm{C}$, del aire de secado y el aire ambiente, respectivamente; $\rho_{\text {so }}$ es la masa seca de grano referida a volumen inicial, $\mathrm{kg} / \mathrm{m}^{3}, W_{0}$ y $W_{f}$ la humedad inicial y final respectivamente en unidades de base seca.

Considerando una temperatura de aire de $140^{\circ} \mathrm{C}$ con una humedad absoluta de $0.01 \mathrm{~kg} / \mathrm{kg}$. La eficiencia energética calculada fue igual a 7.12\%, este valor se encuentra en el dentro del rango informado por Syahrul y col. (2002) en el secado de maíz con temperaturas de entre 50 y $63^{\circ} \mathrm{C}$, en lecho fluidizado. A efectos de explorar el potencial de recirculación, se planteó un secador continuo equivalente con las siguientes características: 


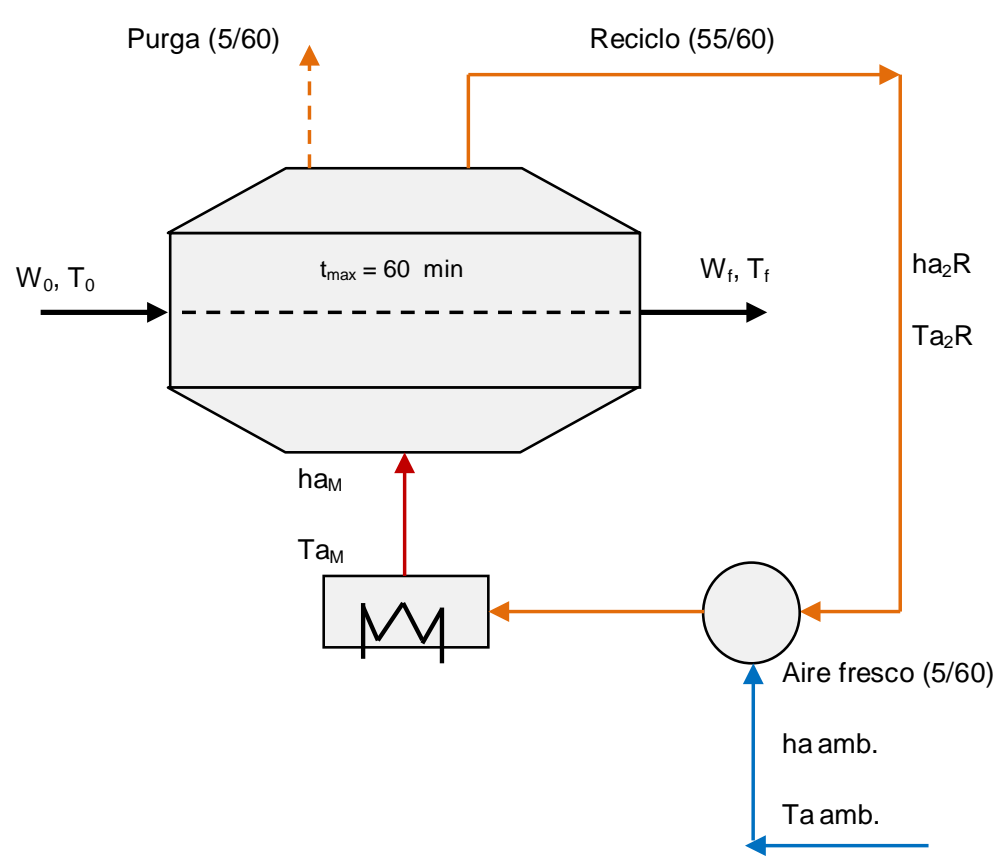

Figura 6.7 Esquema de un equipo de lecho fluidizado con recirculación de aire.

Para realizar el cálculo correspondiente se consideró purgar el caudal de aire correspondiente a los primeros 5 minutos de proceso (fracción 5/60) y recircular la otra fracción (55/60). Considerando las condiciones iniciales para el aire planteadas anteriormente, la corriente de aire recirculada sale del secadero con una temperatura promedio de $132.9^{\circ} \mathrm{C}$ y una $h_{a}$ igual a $0.013 \mathrm{~kg} / \mathrm{kg}$. Si esta corriente se mezcla ahora con aire fresco (fracción 5/60) a una temperatura de $20^{\circ} \mathrm{C}$ y una humedad absoluta de 0.01 $\mathrm{kg} / \mathrm{kg}$, se tendrá una corriente de aire con una temperatura $\mathrm{T}_{\mathrm{aM}}$ igual a $113.2^{\circ} \mathrm{C}$ y una $\mathrm{h}_{\mathrm{aM}}$ de $0.0124 \mathrm{~kg} / \mathrm{kg}$.

Como el proceso descripto necesita temperaturas más elevadas la nueva corriente de aire recirculado debe calentarse antes de ingresar. Sin embargo, elevar ahora su temperatura hasta el valor deseado no implicaría una demanda considerable de energía. Esta serie de consideraciones dio lugar a una eficiencia térmica del 42 \%, este 
valor es cercano al informado por Giner y De Michelis (1988) quienes estudiaron la recirculación del aire de secado de trigo en lecho fluidizado.

Madhiyanon y col. (2006) investigaron la aplicación del tratamiento térmico en lecho fluidizado para la desinfestación en arroz cáscara con un reciclo del 20\% del aire para mantener consumos moderados de energía. Por su parte, Wiriyaumpaiwong (2002) trabajando en un lecho fluidizado tipo spouted bed reporto que los caudales óptimos de recirculación en este tipo de secadero se hallan entre el 80 y 90\%, que coinciden con el criterio empleado en este trabajo.

\subsection{Conclusiones.}

Se plantearon balances de materia y energía para el aire de lecho fluidizado, con base en el modelo de capa delgada desarrollado en el Capítulo 5. Las predicciones obtenidas se validaron con datos experimentales determinados durante el secadotostado.

La predicción de la evolución del contenido de humedad en el tiempo fue satisfactoria en general. Resultados similares se observaron en el caso de la temperatura, si bien existieron algunas diferencias que podrían estar relacionadas con las propiedades térmicas del grano e inclusive una subestimación del calor de sorción.

La evolución del contenido de humedad absoluta en el aire mostró una ganancia considerable de agua en los primeros minutos de proceso, conforme el secado progreso y la cantidad de agua removida del producto fue menor los valores de humedad en el aire se acercaron a sus valores iniciales. Con respecto a los valores determinados para la humedad relativa del aire estos fueron muy bajos a la salida entre 0.3 a $1.6 \%$. 
Por tanto, el hecho de contar con aire caliente y de baja humedad a la salida del secadero dio lugar al análisis de la eficiencia térmica del proceso con y sin recirculación de aire. Los resultados fueron satisfactorios se encontró un incremento de este valor de 7.12 a $42 \%$ con recirculación. 


\section{CAPÍTULO VII}

\section{EVALUACIÓN DE LA CALIDAD DEL GRANO ENTERO DE SOJA SECADO-TOSTADO}




\section{Introducción.}

Debido a su alto contenido proteico y buen balance de aminoácidos la soja es una excelente fuente de proteínas para el ser humano. Sin embargo, la composición de este grano incluye sustancias antinutricionales que reducen el aprovechamiento de la proteína durante el proceso digestivo (Soponronnarit y col., 2001). Tales sustancias, sobre todo los inhibidores de tripsina, pueden presentar alta resistencia al tratamiento térmico y también a la proteólisis, por tanto los tratamientos a elevadas temperaturas son necesarios para su inactivación. Estos tratamientos promueven también la desnaturalización de las proteínas, lo que en parte favorece su hidrólisis por enzimas digestivas. Sin embargo, si los tratamientos son demasiado severos, pueden afectar negativamente la calidad nutricional de la proteína (Soponronnarit y col., 2001, Bartholomai y col., 2001).

A nivel industrial, la intensidad o severidad de los tratamientos térmicos pueden evaluarse mediante la determinación de diferentes parámetros: Sadeghi y col. (2006) que estudiaron el efecto del tratamiento térmico en harinas de soja sugirieron la electroforesis SDS-PAGE como un método adecuado para evaluar estos efectos en las proteínas. Sin embargo, uno de los test más empleados es el de la solubilidad de las proteínas en una solución de Hidróxido de potasio al 0.2\%. Caprita y col. (2010) consideraron que el ensayo es útil para medir la intensidad del tratamiento térmico aplicado. Al respecto, Tromp y col. (1995) plantearon la posibilidad de utilizar este índice para estimar la inactivación del factor antitríptico en soja, sin embargo no encontraron una correlación directa entre el valor de este parámetro y la inactivación de los antinutrientes. 
Por tanto, el estudio de los efectos de los tratamientos en las proteínas de soja implica conocer en primer lugar que tan intenso o severo fue el tratamiento mediante alguno de los test mencionados anteriormente y a continuación determinar los niveles residuales de los factores antitrípticos.

Recientemente, diversos estudios como los de Georgetti y col. (2008) y Kim y col. (2011) proponen evaluar el efecto de los tratamientos térmicos midiendo la actividad antioxidante de soja y sus productos derivados. La soja es rica en compuestos fenólicos principalmente isoflavonas las cuales poseen propiedades antioxidantes beneficiosas para la salud. Por tanto, la preservación o el incremento de dichas sustancias al cabo de cualquier tratamiento que involucre altas temperaturas representa también un buen indicador de los cambios en la calidad (Devi y col., 2009; Tyug y col, 2010; Kim y col., 2011).

En bibliografía, se han encontrado varios trabajos que realizaron estudios en porotos de soja tratada a diferentes temperaturas (Hsu y Satter, 1995; Osella y col., 1997; Soponronnarit y col., 2001; Wiriyaumpaiwong y col., 2004), recomendando temperaturas del orden de $140^{\circ} \mathrm{C}$ para la inactivación de los factores antinutricionales, sin perjudicar considerablemente el perfil nutritivo. Sin embargo, la mayoría de ellos trabajaron con aire caliente en rangos de humedad post-cosecha, mucho más estrechos a los empleados en este trabajo.

A raíz de esto, los objetivos en este capítulo fueron determinar los parámetros de calidad y aptitud nutricional de los porotos de soja remojados o remojados y cocidos, procesados luego mediante un tratamiento de secado-tostado en lecho fluidizado con aire caliente a $140^{\circ} \mathrm{C}$. La intensidad del tratamiento térmico se evaluará a partir de la determinación de diversos parámetros como la solubilidad proteica y corridas electroforeticas, el nivel residual del factor antitríptico y la capacidad antioxidante. Otro 
parámetro de calidad, del tipo organoléptico se determinará mediante un análisis sensorial por panel no entrenado.

\subsection{Materiales y Métodos.}

\subsubsection{Plan experimental.}

A continuación se presenta el diagrama de flujo experimental realizado 


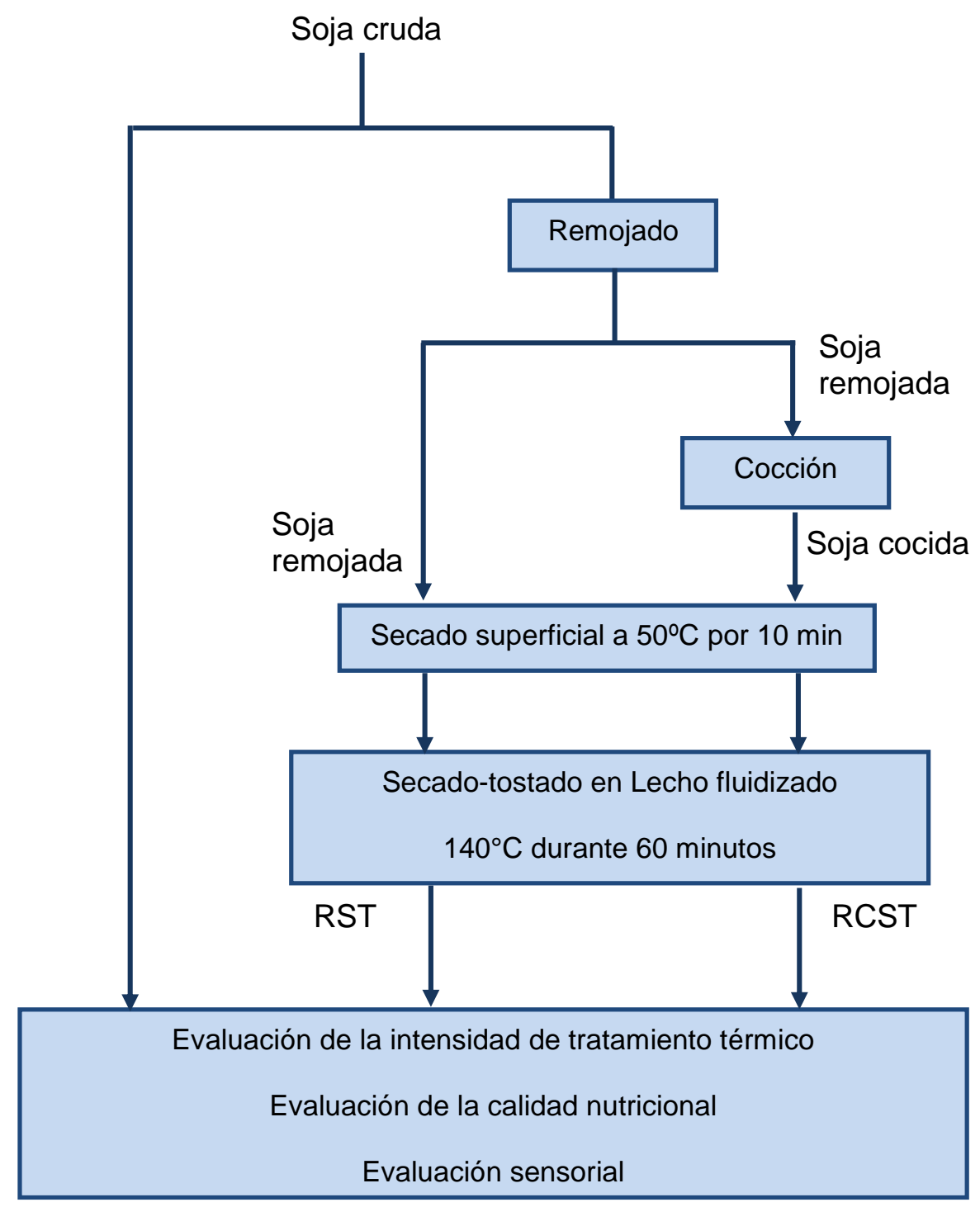

Figura 7.1 Diagrama de flujo experimental, llevado adelante en muestras de soja cruda, remojadas y secadas-tostadas (RST), y muestras remojadas, cocidas y secadas-tostadas (RCST).

\subsubsection{Caracterización química del grano de soja}

Se determinó la composición química del grano de soja (Glycine max) cultivar 5.5i de Don Mario Semillas utilizado en el desarrollo de este trabajo. Para llevar adelante la caracterización química se emplearon las siguientes metodologías: 


\subsubsection{Método de Kjeldahl o nitrógeno total (AOAC 955.04) para determinar el porcentaje de proteínas.}

Fundamento: El método de Kjeldahl es una digestión de la materia orgánica que utiliza ácido sulfúrico concentrado, catalizador y sales. Lo que se mide es el nitrógeno total en la muestra proveniente de proteínas y otras fuentes (ADN, creatina, pigmentos y nitrógeno no proteico). Mediante un factor de conversión se estima la cantidad de proteína en la muestra.

Reactivos: $\mathrm{H}_{2} \mathrm{SO}_{4}$ concentrado, una solución de $\mathrm{H}_{2} \mathrm{SO}_{4}$ valorada de $0.01 \mathrm{~N}$, una solución de $\mathrm{H}_{3} \mathrm{BO}_{3} 4 \%$ (p/p) (ácido bórico), $\mathrm{NaOH}$ al $40 \%$ (p/p), indicador de Mortimer.

Procedimiento: Se coloca la cantidad adecuada de muestra (de acuerdo al contenido estimado de nitrógeno) en un balón de Kjeldahl. Se agrega aproximadamente 2 gramos de catalizador (relación: $10 \mathrm{~g}$ de $\mathrm{K}_{2} \mathrm{SO}_{4}+1 \mathrm{~g}$ de $\mathrm{CuSO}_{4} .5 \mathrm{H}_{2} \mathrm{O}$ ) y entre 15 y $20 \mathrm{ml} \mathrm{de} \mathrm{H}_{2} \mathrm{SO}_{4}$ concentrado. La solución se calienta a elevadas temperaturas en un equipo adecuado. Por lo general, la digestión de la muestra demanda entre 1 y 2 hs. El punto final de la reacción se observa cuando la solución se vuelve translúcida y de color débilmente verdoso o azul verdoso. Posteriormente, la solución se neutraliza con $\mathrm{NaOH}$ al $40 \%$ y se destila durante 8 minutos aproximadamente. El destilado se recoge en un Erlenmeyer sobre $50 \mathrm{ml} \mathrm{de} \mathrm{H}_{3} \mathrm{BO}_{3}$ al 4\%. El destilado final se titula con la solución valorada de $\mathrm{H}_{2} \mathrm{SO}_{4}$ usando indicador de Mórtimer. El porcentaje de proteína se calcula de la siguiente manera:

\%proteína $=\frac{\left(V_{M}-V_{B}\right) \times N_{H^{+}} \times P_{N} \times f_{k} \times 100}{g \text { de muestra }}$ 
donde $V_{M}$ y $V_{B}$ representan los mililitros gastados en la titulación de la muestra y el blanco respectivamente, $\mathrm{N}_{\mathrm{H}}{ }^{+}$es la normalidad del ácido sulfúrico concentrado, meq/ml, $\mathrm{P}_{\mathrm{N}}$, el peso equivalente de Nitrógeno, $\mathrm{g} \mathrm{N} / \mathrm{meq}, f_{k}$ es el factor de conversión nitrógeno a proteína(6.25 g proteína/ g nitrógeno).

\subsubsection{Método de Soxhlet para el cálculo de la materia grasa (AOAC 963.15).}

Fundamento: el método de Soxhlet es un sistema de extracción cíclica de los componentes solubles en éter que están presentes en un alimento.

Procedimiento: en un cartucho de papel de filtro se coloca la muestra seca y pesada. Posteriormente se introduce en un tubo extractor, a continuación se pesa un balón de soxhlet y se conecta al tubo. Por la parte superior del mismo se agrega el solvente adecuado (éter etílico, éter de pétroleo o una mezcla de ambos) en cantidad abundante. Se conecta a una fuente calorífica y se calienta aproximadamente durante 2 hs. Al finalizar se apaga la fuente de calor, se retira el cartucho, se desconecta el balón y se lleva a una estufa para eliminar el contenido de solvente presente y se pesa. Esta determinación suele denominarse extracto etéreo, porque además de los lípidos se extraen otros compuestos solubles en el solvente. El cálculo se realiza de la siguiente manera:

$\%$ lípidos $=\frac{P_{B L}-P_{b}}{m} \times 100$

Donde $P_{B L}$ es el peso del balón con grasa, $P_{b}$ el peso del balón solo y $m$ la cantidad de muestra pesada, todas en expresadas en gramos. 
En caso de tener muestras muy húmedas se recomienda deshidratarlas previo a la determinación. Altos contenidos de humedad pueden originar la formación de una emulsión durante la extracción.

\subsubsection{Cenizas totales por el método directo (AOAC 940.26).}

Fundamento: se denomina como cenizas el residuo inorgánico que queda después de incinerar la materia orgánica generalmente a temperaturas de entre 500 y $550^{\circ} \mathrm{C}$. Este método es eficiente ya que determina tanto cenizas solubles en agua como insolubles, y solubles en medio ácido.

Procedimiento: se pesa aproximadamente $10 \mathrm{mg}$ de muestra en una cápsula de porcelana previamente calcinada y tarada. Se calienta sobre triangulo de pipas o tela metálica hasta obtener un residuo carbonoso. A continuación se calcina en mufla a temperaturas de entre 500 a $550^{\circ} \mathrm{C}$ hasta observar cenizas blancas o de color gris claro. Se enfria en desecador y se pesa. Los cálculos se realizan de la siguiente manera

$\%$ Cenizas $=\frac{P_{C}-P}{m} \times 100$

Donde Pc es el peso de la cápsula con cenizas, $\mathrm{P}$ el peso de la cápsula sola y m la cantidad de muestra pesada, todos los valores se expresan gramos.

Es conveniente aclarar que el porcentaje de hidratos de carbono en la muestra se determinó por diferencia. 


\subsubsection{Acondicionamiento de las muestras.}

Antes de realizar cualquier determinación, los porotos de soja cruda, RST y RCST, se molieron en un equipo marca Connoisserve durante $90 \mathrm{seg}$.

\subsubsection{Determinación de la solubilidad proteica en KOH $0.2 \%$.}

Araba y Dale (1990) propusieron el uso del test de solubilidad proteica como una manera de determinar el sobrecalentamiento de porotos de soja y al mismo tiempo estimar el daño ocasionado en las proteínas. En general, cuanto más desnaturalizada esté la proteína más difícil resulta la solubilización puesto que se verifican interacciones proteína-proteína con formación de agregados y precipitación (Dergal, 1990). Se procedió de acuerdo al método de Araba y Dale (1990). Se pesó 0.2 g de muestra, se colocó en un vaso de precipitado y se agregó $10 \mathrm{ml}$ de Hidróxido de Potasio al 0.2\%. Se agitó por 20 minutos sobre agitador magnético y posteriormente se centrifugó a 2700 rpm durante 15 min. Se tomó $2 \mathrm{ml}$ del sobrenadante, y se colocó en tubos de Kjeldahl, se adicionaron $12.5 \mathrm{ml}$ de $\mathrm{H}_{2} \mathrm{SO}_{4}$ concentrado y $2 \mathrm{ml} \mathrm{de} \mathrm{H}_{2} \mathrm{O}_{2}$, entonces se procedió a determinar $\mathrm{N}$ total por el método de Kjeldahl (AOAC 955.04).

\subsubsection{Electroforesis SDS-PAGE}

Fundamento: La electroforesis se define como el movimiento de partículas cargadas en un campo eléctrico. La movilidad electroforética de una proteína depende del voltaje aplicado, de su carga neta (las proteínas presentan carga cuando se encuentran a un $\mathrm{pH}$ 
diferente de su punto isoeléctrico, en el cual su carga neta es cero) así como también de su tamaño y conformación (Clark y Switzer, 1977; Dergal, 1991).

Durante la electroforesis el voltaje se mantiene constante por lo que la movilidad de la molécula dependerá de su carga, forma y tamaño: a mayor carga neta, la molécula migrará más rápido; a su vez, a mayor fricción, la movilidad será menor. Es decir la movilidad depende de la relación carga/masa de la proteína.

La electroforesis de proteínas se realiza generalmente sobre matrices tipo gel, la más común utiliza geles de poliacrilamida y se denomina PAGE, por sus siglas en inglés (Poly Acrylamide Gel Electrophoresis). Los geles de poliacrilamida poseen propiedades tales como alta reproducibilidad, estabilidad (a $\mathrm{pH}$, temperatura, fuerza iónica), transparencia, elasticidad, porosidad controlable, compatibilidad con una gran variedad de compuestos químicos e inercia química. Estos geles se forman por copolomerización de dos compuestos, la acrilamida y la bis-acrilamida (N,N'-metilenbis-acrilamida) en una reacción iniciada por la tetrametiletiléndiamina (TEMED) y el persulfato de amonio (Clark y Switzer, 1977).

En presencia del detergente aniónico dodecilsulfato de sodio (SDS) el sistema se denomina generalmente como electroforesis SDS-PAGE, y constituye una electroforesis desnaturalizante dado que las muestras bajo estudio se desnaturalizan por acción de este detergente, que actúa como agente disociante de las proteínas. Dos de los agentes desnaturalizantes mayormente utilizados son el SDS, que rompe interacciones nocovalentes y confiere a la proteína carga neta negativa, y el $\beta$-mercaptoetanol ( $\beta$-ME). Luego de un tratamiento con SDS+ $\beta$-ME, las proteínas de la muestra se encuentran totalmente desnaturalizadas y cargadas negativamente. Por tanto, durante la corrida electroforética las proteínas con mayor PM migrarán más lento que las proteínas con un 
menor PM. Cuando se comparan estos resultados con un marcador de PM conocido, es posible estimar el PM de la proteína bajo estudio.

La muestra se siembra en primer lugar en un gel apilador o "stacking" que cumple la función de soporte y concentración de las proteínas, de tal forma que entren en el gel separador uniformemente. El gel separador presenta una porosidad menor a la del apilador, contribuyendo a la separación de las diferentes fracciones de proteínas. Un colorante, generalmente azul de bromofenol, se añade a la muestra e indica el frente de migración y por tanto el momento de detener el ensayo. Una vez que se detiene, el gel es recuperado y se tiñe con un colorante como el azul de Coomassie que pone en evidencia a las proteínas (Figura 7.2).

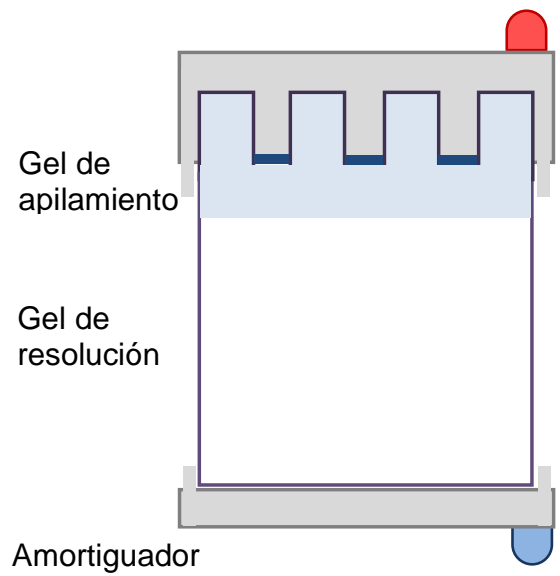

A

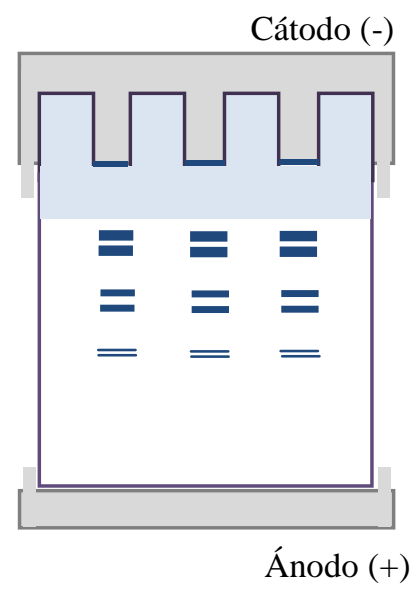

B

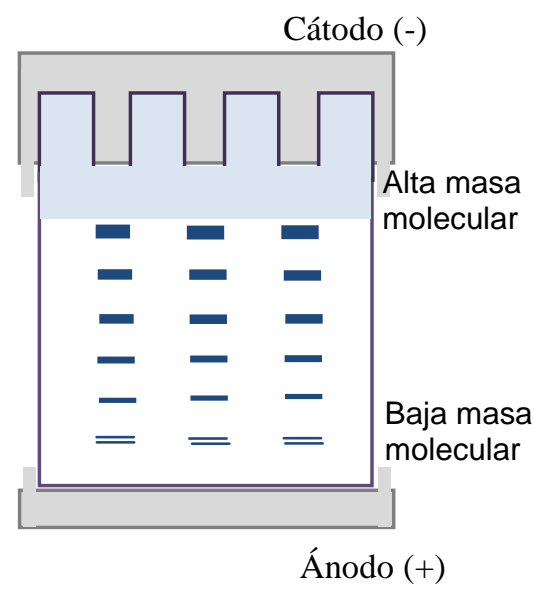

$\mathrm{C}$

Figura 7.2 Diagrama de una electroforesis SDS-PAGE. a) se cargan las muestras en el gel apilador, b) se aplica el voltaje que da lugar a la migración de las proteínas, c) las proteínas se mueven de acuerdo a su peso molecular. 


\section{Procedimiento:}

Preparación de buffer de muestra: Se empleó como buffer de extracción una solución conteniendo Tris base $0.086 \mathrm{M}$, Glicina $0.09 \mathrm{M}$, y EDTA $0.003 \mathrm{M}$ ), $\mathrm{pH}=8.3$. A continuación se le adicionó 5 mg de SDS.

Preparación de buffer separador: Se prepara a partir de 27.2 g de Tris base y $0.6 \mathrm{ml}$ de TEMED, se lleva a volumen final de $150 \mathrm{ml}$ con agua bidestilada y se ajusta el $\mathrm{pH}$ a 8.8 con $\mathrm{HCl}$ concentrado.

Preparación de buffer stacking: Se pesan 3 g de Tris base y $0.2 \mathrm{ml}$ de TEMED, se lleva a volumen final de $50 \mathrm{ml}$ con agua bidestilada y se ajusta el $\mathrm{pH}$ a 6.8 con $\mathrm{HCl}$ concentrado.

Preparación de la muestra: a partir de las muestras procesadas tal como se describe en la sección 7.12 de este capítulo, se pesó la cantidad de materia suficiente de soja cruda, RST y RCST para obtener $150 \mu \mathrm{g}$ de proteína ( 0.4 mg de muestra). A continuación se desgrasaron todas las muestras mediante una extracción con éter de petróleo en agitación en un termoagitador marca Eppendorf durante una hora a temperatura ambiente. Los extractos etéreos se centrifugaron en una microcentrifuga marca Eppendorf modelo $5415 \mathrm{R}$ a $10000 \mathrm{xg}$ durante 10 minutos, al finalizar se descartó el sobrenadante. A los pellets obtenidos se les adicionó la solución en una relación pellet:buffer de 1:10. Una vez preparadas las dispersiones se agregó a cada una de ellas, 5 mg de DTT y se calentó a ebullición durante 5 min, para favorecer la acción del agente disociante. 
Preparación del gel de poliacrilamida al 12\%: A continuación se detallan las cantidades empleadas de cada uno de los reactivos necesarios para llevar adelante la corrida electroforética.

\begin{tabular}{lcc}
\hline & Gel de apilamiento & Gel de resolución \\
\hline $\mathrm{H}_{2} \mathrm{O}$ dd & $3.7 \mathrm{ml}$ & $1.7 \mathrm{ml}$ \\
Acrilamida + Bis & $0.4 \mathrm{ml}$ & $2.4 \mathrm{ml}$ \\
Buffer separador & - & $1.5 \mathrm{ml}$ \\
Buffer apilamiento & $0.75 \mathrm{ml}$ & - \\
TEMED & $3.4 \mu \mathrm{l}$ & $6 \mu \mathrm{l}$ \\
Persulfato & $100 \mu \mathrm{l}$ & $50 \mu \mathrm{l}$ \\
\hline
\end{tabular}

Una vez preparado el gel, se procedió al sembrado de las muestras y se dio inicio a la corrida. Todas las electroforesis se realizaron en miniplacas separadores de $1 \mathrm{~mm}$ de espesor, utilizando un equipo Mini Protean III (Bio-RAD Life Science, USA). Las corridas electroforéticas se llevaron a cabo a una corriente constante de $20 \mathrm{~mA}$.

\subsubsection{Determinación de la Actividad Antitríptica. Método de González-Carrillo (Gonzáles y Carrillo, 1987).}

Los inhibidores de proteasas conocidos como inhibidores de tripsina o factores antitrípticos son compuestos de origen proteico de bajo peso molecular capaces de asociarse con las enzimas proteolíticas y formar un complejo estable que no tiene actividad catalítica (Dergal, 1990). Este tipo de sustancias pueden reducir hasta un 50\% el valor nutritivo de la soja, por tanto resulta imprescindible eliminarlos o inactivarlos. Gonzáles y Carrillo (1987) propusieron el siguiente test como un método útil para 
determinar la actividad de estos factores en productos crudos o procesados, y evaluar la eficacia del tratamiento de inactivación aplicado.

Fundamento: Las reacciones que ocurren son, de modo simplificado, las siguientes:

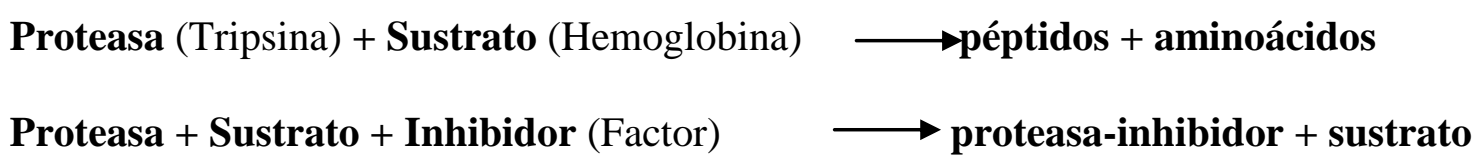

El complejo proteasa-inhibidor activo no puede producir la hidrolisis del sustrato. El reactivo de Folin reacciona químicamente con los residuos de los aminácidos tirosina, triptófano, y en menor grado, con los de cisteína e histidina de las proteínas dando un complejo de color azulado. Al adicionar TCA (Ácido tricloroacético) al producto de la reacción enzimática, precipitan los péptidos no hidrolizados (de gran tamaño) quedando en solución los péptidos menores y aminoácidos, que luego serán determinados espectrofotométricamente utilizando el reactivo de Folin. Por lo tanto, a mayor porcentaje hidrolizado (muestra sin inhibidor de la proteasa o con inhibidores inactivados), se producirá mayor coloración.

Preparación de Hemoglobina desnaturalizada: Se pesó 2 g de Hemoglobina bovina (Sigma-Aldrich) y se la disolvió en $16 \mathrm{ml}$ de $\mathrm{NaOH} 0.5$ N. Se agregó $64 \mathrm{ml}$ de agua destilada y 36 g urea en constante agitación sobre un agitador magnético Thorball. Se dejó en reposo por 1 h. Se agregó 4 g de urea y se ajustó a pH 8 con una solución de ácido fosfórico $1 \mathrm{M}$. A continuación, se agregaron 4 g más de urea y se ajustó nuevamente a $\mathrm{pH} 8$. 
Extracción de los inhibidores: Se pesó $1 \mathrm{~g}$ de muestra molida de soja cruda, soja RST y soja RCST y se mezcló con 30 ml de $\mathrm{HCl} 0.05 \mathrm{~N}$ durante 15 min. Se dejó reposar 24 h a $10^{\circ} \mathrm{C}$. A continuación, se centrifugó a $2000 \mathrm{rpm}$ durante $10 \mathrm{~min}$ en una centrifuga marca Rolco Modelo 2036. Se tomó una alícuota del sobrenadante y se ajustó a pH 8 con una solución saturada de $\mathrm{Na}_{2} \mathrm{CO}_{3}$. Finalmente se llevó a volumen final de $25 \mathrm{ml}$ en un matraz con buffer fosfato de sodio.

Determinación espectrofotométrica: Se rotularon tres tubos de ensayo de la siguiente manera, blanco, muestra y control. Se agregó a cada uno, $1 \mathrm{ml}$ de sustrato, Hemoglobina bovina desnaturalizada $(\mathrm{Hb}-\mathrm{d})$, y se incubó a $37^{\circ} \mathrm{C}$ durante $10 \mathrm{~min}$, al cabo de este tiempo se adicionaron las siguientes cantidades de reactivos:

\begin{tabular}{lll}
\hline Blanco & Muestra & Control \\
\hline Hb-d & Hb-d & Hb-d \\
$0.1 \mathrm{ml}$ buffer $\mathrm{pH} 8$ & $0.1 \mathrm{ml}$ de muestra & $0.1 \mathrm{ml}$ de buffer $\mathrm{pH} 8$ \\
$0.1 \mathrm{ml}$ enzima & $0.1 \mathrm{ml} \mathrm{de} \mathrm{enzima}$ & $0.1 \mathrm{ml}$ enzima \\
$2 \mathrm{ml} \mathrm{de} \mathrm{TCA} \mathrm{(5 \% )}$ & & \\
\hline
\end{tabular}

Los tubos muestra y control se llevaron a estufa a $37^{\circ} \mathrm{C}$ durante 20 minutos para que la digestión se lleve a cabo. Al cabo de este tiempo, la reacción se detuvo por la adición de $2 \mathrm{ml}$ de ácido tricloroacético al 5\%. Después de 10 minutos se centrifugó a 2000 rpm, se añadió $2 \mathrm{ml}$ de $\mathrm{NaOH} 1 \mathrm{~N}$, se agitó, y se agregó $0.6 \mathrm{ml}$ de reactivo de Folin. Se dejó en reposo durante $1 \mathrm{~h}$ y se leyó la absorbancia (A) a $650 \mathrm{~nm}$ en un espectrofotómetro Hitachi modelo U-1900. 
Los cálculos se realizaron de la siguiente manera:

$\boldsymbol{A}_{\text {Control }}-\boldsymbol{A}_{\text {Blanco }}=100 \%$ actividad de proteasa

$\boldsymbol{A}_{\text {Muestra }}-\boldsymbol{A}_{\text {Blanco }}=X \%$

$100 \%-X \%=\%$ Inhibición

El control presenta la mayor absorbancia debido a que no se le adiciona el extracto con el inhibidor, por tanto la enzima puede actuar adecuadamente sobre el sustrato. En el caso del blanco la absorbancia es muy baja porque al precipitar la hemoglobina con el TCA la enzima no tiene sustrato disponible para su acción. Los valores obtenidos en este caso se atribuyen a impurezas o a la presencia de cantidades muy pequeñas de aminoácidos libres.

\subsubsection{Determinación de propiedades antioxidantes.}

Para determinar la actividad antioxidante se utilizó el ensayo con el radical estable DPPH, de acuerdo al método especificado por Brand-Williams y col., (1995). Midiendo el consumo del radical libre 2,2-difenil-1-picrilhidrazil (DPPH) en un extracto etanólico de la muestra. Se prepararon extractos de poroto de soja crudo, RST y RCST. Se suspendieron aproximadamente 2 gramos de cada muestra en $10 \mathrm{ml}$ de etanol $96^{\circ}$. Se mantuvo en agitación durante 40 minutos a $4{ }^{\circ} \mathrm{C}$, luego se centrifugó 10 minutos a $10000 \mathrm{rpm} \mathrm{a} 4^{\circ} \mathrm{C}$ y se utilizó el sobrenadante para realizar el ensayo. Las extracciones se realizaron por duplicado. En las mezclas de reacción, se varió el volumen de extracto 
de 0 a $400 \mu$ l. En todos los casos se adicionó $1 \mathrm{ml}$ de solución etanólica de DPPH (40 ppm) preparada en el día y se completó con etanol hasta un volumen final de $1.5 \mathrm{ml}$. Los tubos de ensayo se dispusieron en un lugar oscuro y se dejó desarrollar la reacción durante 60 minutos. Al cabo de ese tiempo se midió la absorbancia a $517 \mathrm{~nm}$ y se calculó el porcentaje de DPPH consumido para cada volumen de extracto. El control representa el tubo solo con DPPH, sin muestra y es una medida de la absorbancia inicial.

Cálculo

$\%$ Reducción de radical DPPH $* \frac{\left(A_{\text {control }}-A_{\text {muestra }}\right)}{A_{\text {control }}} \times 100$

Luego se graficó el porcentaje de DPPH consumido en función de los mg de materia seca, para determinar el valor de la $\mathrm{EC}_{50}$ (concentración media efectiva) correspondiente a cada muestra. $\mathrm{La} \mathrm{EC}_{50}$ se definió como la concentración de muestra en $(\mathrm{mg} / \mathrm{ml})$ requerida para reducir al 50\% la concentración inicial DPPH en la mezcla de reacción. Los resultados obtenidos se expresaron como poder antioxidante (PA), que

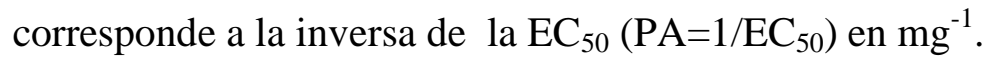

\subsubsection{Evaluación Sensorial.}

A fin de evaluar la aceptabilidad de los productos seleccionados soja RST y RCST a $140^{\circ} \mathrm{C}$ se llevó a cabo un ensayo de aceptabilidad. Se evaluaron los siguientes atributos: color, sabor, textura y aceptabilidad general. Una planilla de la siguiente forma, con una escala hedónica de 9 puntos $(1=$ me disgusta, $5=$ indiferente, $9=$ me 
gusta). El test se realizó en un ambiente tranquilo tratando en lo posible de disminuir la distracción de cada panelista. Un total de 60 evaluadores o panelistas no entrenados consumidores habituales de productos tipo snack participaron de este ensayo.

Nombre: Consumidor $\mathrm{N}^{\mathrm{o}}$ :

MUESTRA $N^{\circ}$

Utilizando la siguiente escala, por favor evalúe la aceptabilidad de cada atributo para cada muestra. Indicando con un marca vertical, sobre la línea
Disgusta mucho
Indiferente
Gusta mucho

Color

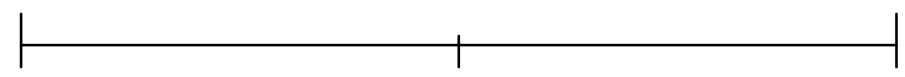

Sabor

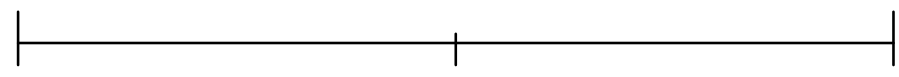

Textura

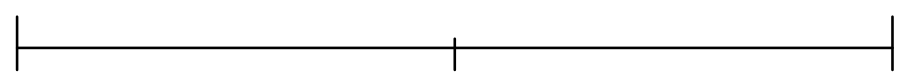

Aceptabilidad

General

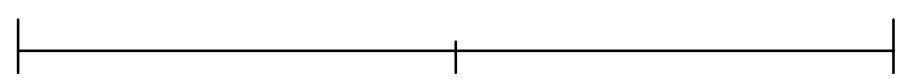

Observaciones:

Figura 7.3 Formato de planilla utilizada para llevar adelante la evaluación sensorial.

Cada muestra a degustar consistió en aproximadamente 5 gramos de porotos, la que se presentó en recipientes descartables blancos, de poca profundidad, codificadas con números de tres dígitos elegidos al azar. Las muestras se acompañaron con agua 
fresca, y se sirvieron a temperatura ambiente $\left(20^{\circ} \mathrm{C}\right)$. Se recomendó a los panelistas beber agua entre muestras a efectos de eliminar cualquier tipo de sabor residual.

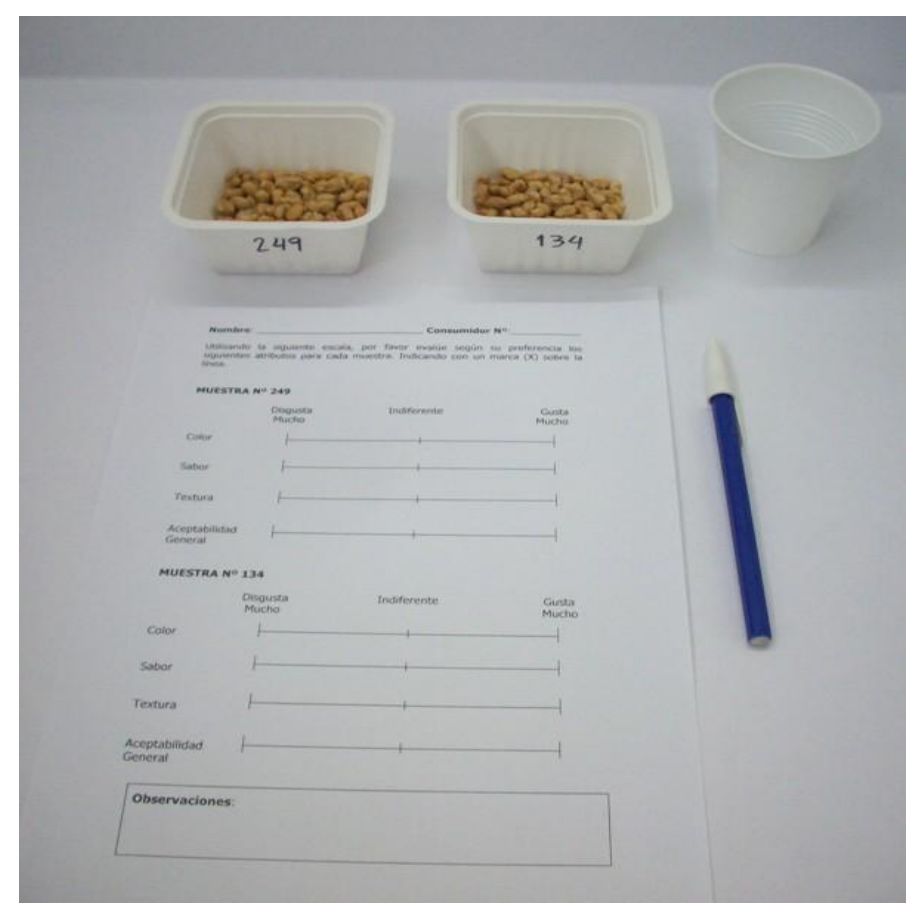

Figura 7.4 Presentación de las muestras y las planillas para la evaluación sensorial.

\subsubsection{Análisis estadístico.}

A efectos de comparar las medias de las muestras evaluadas, se realizó un análisis de varianza (ANOVA) para cada uno de los atributos evaluados, definiendo como hipótesis nula $\left(\mathrm{H}_{0}\right)$ la ausencia de diferencias sensoriales en el atributo evaluado entre ambos tratamientos (RST y RCST) y como hipótesis alternativa $\left(\mathrm{H}_{1}\right)$, la existencia de diferencias en al menos un atributo. Si el valor experimental del estadístico $\mathrm{F}$ calculado mediante el ANOVA es mayor o igual que los valores en la tabla de referencia, se debe rechazar la $\mathrm{H}_{0}$ y aceptar la hipótesis alternativa, de lo contrario se puede decir que no hay evidencia de diferencias significativas entre las muestras (Montgomery, 1991). 


\subsection{Resultados y Discusión.}

\subsubsection{Caracterización química del grano de soja crudo.}

La composición del grano de soja crudo determinado se comparó con otros datos recopilados de la bibliografía también para granos de soja crudos.

Tabla 7.1 Composición química del grano entero de soja crudo analizado. Los valores entre paréntesis corresponden a la desviación estándar calculada.

\begin{tabular}{lccc}
\hline \multicolumn{4}{c}{ Composición de soja, \% en base seca } \\
\hline Componente & Este trabajo & Erickson (1995) & Ridner y col. (2006) \\
& & & \\
\hline Proteínas & $\mathbf{3 9 . 9 ( \mathbf { 0 . 5 } )}$ & 40.3 & 39.9 \\
Lípidos & $\mathbf{2 2 . 2 ( \mathbf { 0 . 5 } )}$ & 21 & 21.8 \\
Cenizas & $\mathbf{5 . 2}(\mathbf{0 . 2 )}$ & 4.9 & 5.32 \\
Hidratos & $\mathbf{3 2 . 7 *}$ & 33.9 & 32.98 \\
\hline
\end{tabular}

\footnotetext{
*el porcentaje de carbohidratos se cálculo por diferencia.
}

de acuerdo a los datos presentados en la tabla anterior la composición del grano de soja utilizado en este trabajo presentó valores muy similares a lo informado por otros autores.

\subsubsection{Solubilidad proteica en KOH $0.2 \%$.}

La solubilidad en hidróxido de potasio está relacionada inversamente con el grado de tratamiento térmico, valores muy altos de solubilidad proteica en este test indican tratamientos térmicos insuficientes mientras que valores muy bajos indican 
tratamientos térmicos demasiado severos (Tromp y col., 1995; Caprita y col., 2010). El fundamento de este test radica en las cambios estructurales asociados a la desnaturalización de las proteínas, que favorecen la interacción con otras proteínas y la formación de agregados insolubles (Dergal, 1991, Gallardo, 2008).

Wiriyaumpaiwong y col. (2004) informan que para las industrias harineras en general, el valor de este parámetro debe hallarse entre 70 y $85 \%$. Si el valor es menor al $70 \%$, significa que el poroto de soja fue sobrecalentado, pero si los valores son superiores al 85\%, el poroto está todavía crudo. En este sentido, Caprita y col., (2010) informaron valores cercanos al $100 \%$ de solubilidad en $\mathrm{KOH}$ para harinas de soja cruda mientras que para harinas tostadas los valores disminuían hasta un 30 o $40 \%$. A continuación se presentan los resultados obtenidos en nuestro caso

Tabla 7.2 Valores de solubilidad proteica en Hidróxido de potasio $0.2 \%$ para las muestras crudas, remojadas y secadas-tostadas ( $\mathrm{RST}$ a $\left.140^{\circ} \mathrm{C}\right)$ y remojadas, cocidas y secadas-tostadas $\left(\operatorname{RCST}\right.$ a $\left.140^{\circ} \mathrm{C}\right)$. Entre paréntesis se presenta la desviación estándar correspondiente.

\begin{tabular}{l|c}
\hline Muestra & Solubilidad en $\mathrm{KOH} 0.2 \%$ \\
\hline Soja cruda & $90.4(1.8)$ \\
RST $140^{\circ} \mathrm{C}$ & $69.6(0.6)$ \\
RCST $140^{\circ} \mathrm{C}$ & $53.4(1.1)$ \\
\hline
\end{tabular}

El valor encontrado para la muestra RST se encuentra muy próximo al límite inferior establecido como satisfactorio a nivel industrial, esto implica que el producto no experimentó un tratamiento térmico demasiado severo. Con respecto al porcentaje determinado para la muestra RCST indica que existió un sobrecalentamiento, 
posiblemente por el proceso adicional de cocción que experimento el grano previo al secado-tostado en lecho fluidizado.

Los valores presentados en la Tabla 7.2 son inferiores a los valores publicados por Prachayawarakorn y col. (2006) quienes evaluaron el efecto de la temperatura sobre la solubilidad proteica en porotos de soja tratada térmicamente en lecho fluidizado. Estos autores utilizaron temperaturas de entre 100 y $160^{\circ} \mathrm{C}$ y condiciones de humedad moderada (20-30\% dec.,b.h.).

\subsubsection{Electroforesis SDS-PAGE.}

Las proteínas de reserva más importantes en la soja son las denominadas globulinas $7 \mathrm{~S}$ o $\beta$-conglicinina y la $11 \mathrm{~S}$ o glicinina. Estas proteínas poseen un alto valor nutricional y propiedades funcionales de gran importancia en la formulación de diversos alimentos. Las fracción 7S es un trímero compuesto por subunidades $\alpha^{\prime}$ (58 kDa), $\alpha$ (57 $\mathrm{kDa}$ ), y $\beta$ (42 kDa) asociadas principalmente por interacciones hidrofobicas (Puppo y col., 1995). La fracción $11 \mathrm{~S}$ se compone por 12 subunidades formadas por los polipéptidos $\mathrm{A}$ y $\mathrm{B}$, asociadas en las denominadas subunidades $\mathrm{AB}$, en la que los polipéptidos A y B se encuentran unidos por uniones disulfuro (Ortiz y Wagner, 2002).

A continuación se presentan los perfiles electroforéticos para las diferentes muestras de soja 


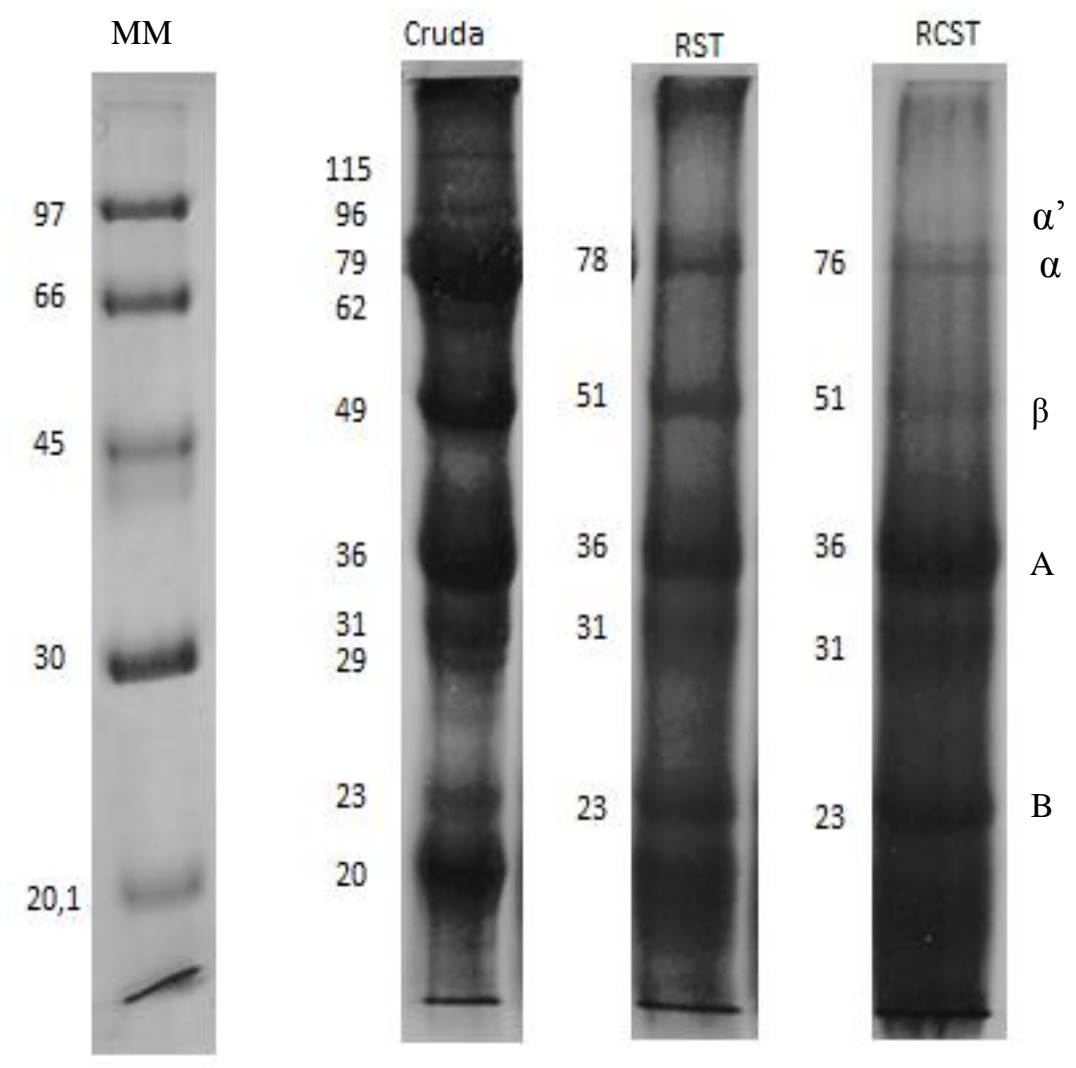

Figura 7.5 Electroforesis SDS-PAGE de proteínas de soja cruda, RST y RCST obtenidas a partir de los extractos, el agregado adicional de $0.5 \%$ de DTT y calentadas a ebullición por 5 min. Marcador de baja masa molecular (MM): fosforilasa b (94 kDa), albúmina (67 kDa), ovoalbúmina (43kDa), anhidrasa carbónica (30kDa), inhibidor de tripsina $(20.1 \mathrm{kDa})$ y $\alpha$-lactoalbúmina $(14.4 \mathrm{kDa})$.

A partir de la posición de las bandas de los patrones y de las bandas de las diferentes proteínas en estudio, se estimaron las masas moleculares de las diferentes subunidades proteicas que conforman la proteína de soja. La muestra cruda presentó dos bandas muy juntas a aproximadamente $80-79 \mathrm{kDa}$ correspondientes a las subunidades $\alpha$ ' y $\alpha$ de la fracción 7S, la fracción $\beta$-7S con valores de $51 \mathrm{kDa}$, diferentes polipéptidos A$11 \mathrm{~S}$ de 36, 31 y $29 \mathrm{kDa}$, y el polipéptido B-11S de 24 kDa. También se observaron dos 
bandas tenues a 96 y $115 \mathrm{kDa}$ y agregados solubles de alta masa molecular que no entraron al gel.

Sadeghi y col. (2006) aclaran que los valores de peso molecular determinados dependen de la heterogeneidad de la proteína, de las condiciones bajo las cuales se llevó a cabo la corrida electroforética (por ejemplo concentración del gel, grado de entrecruzamiento, etc) y de los pesos moleculares del marcador empleado.

En nuestro caso, los pesos moleculares estimados (Figura 7.5) se encuentran dentro del rango de valores informado por Puppo y col. (1995) quienes realizaron estudios en aislados proteicos de soja evaluando la influencia de diferentes condiciones de proceso sobre las propiedades funcionales de dichos aislados.

La intensidad en las bandas correspondientes a la muestra cruda mostró ser superior en comparación con las de las muestras tratadas térmicamente. Se observa que la intensidad de las bandas de 7S disminuyeron a medida que el tratamiento térmico fue más severo (Cruda $<$ RST < RCST) al mismo tiempo la intensidad de las bandas A y B$11 \mathrm{~S}$ aumentaron, principalmente para RCST, sugiriendo que un tratamiento térmico más severo produjo mayor extracción de los polipéptidos A y B, lo cual se corresponde con la ruptura de los enlaces disulfuro que los mantenían unidos a los agregados. Asimismo, la ausencia en RCST de agregados solubles de alta masa molecular, sugiere la formación de agregados insolubles como consecuencia del tratamiento térmico severo. Esto último está relacionado con lo informado en la sección anterior, donde se observó que la solubilidad proteica disminuyó conforme el tratamiento térmico fue más severo (Cruda $>$ RST $>$ RCST).

Finalmente podemos hacer referencia a la presencia del inhibidor de tripsina. Este polipéptido presente en el marcador utilizado posee un peso molecular de $20.1 \mathrm{kDa}$ si se observa la intensidad de las bandas alrededor de este valor se evidencia una 
disminución de la misma conforme avanzamos de la muestra cruda a la RCST indicando una reducción de este compuesto. No obstante, no es conveniente en este punto afirmar o no la ausencia del mismo, en la sección siguiente se utilizará una técnica específica para cuantificar la presencia de este factor antinutricional.

\subsubsection{Determinación de la actividad antitríptica.}

Estudios realizados por Kratzer y col., (1990) en ratas y pollos, mostraron que la harina de soja cruda (sin inactivar) suministrada como alimento origina la hipertrofia pancreática y una disminución en el crecimiento de ambas especies. En general, los inhibidores pueden presentar elevada resistencia a los tratamientos térmicos. Por lo tanto, a efectos de evaluar la eficiencia de las tecnologías de procesamiento, resulta importante determinar los niveles residuales de inhibidores de tripsina. A continuación en la Figura 7.6 se presenta el mecanismo de acción de los inhibidores de tripsina presentes en la soja. Estos se unen a la enzima en el intestino, disminuyendo la digestión de proteínas. Existe un mecanismo de realimentación, movilizado por la colecistoquinina $(\mathrm{CCK})$ que incrementa la secreción de pancreática de enzimas al medio, por lo que se verifica la denominada hipertrofia pancreática que si bien constituye una respuesta biológica reversible, es decir no daña de manera permanente al órgano ni su función, origina un depresión del metabolismo energético de la dieta. 


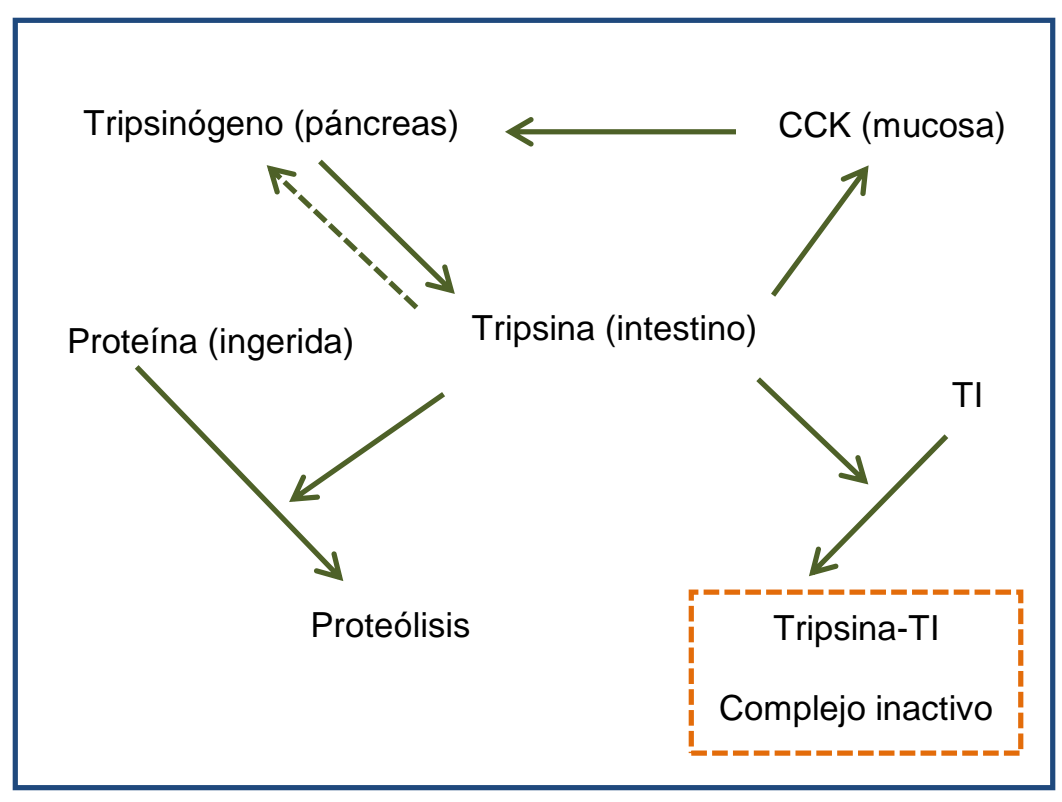

Figura 7.6 Mecanismo de acción de los inhibidores de tripsina presentes en el poroto de soja (Wagner, 2011).

Tromp y col. (1995) y Osella y col. (1997) informaron que los porcentajes de inactivación mayores al $80 \%$ son suficientes para garantizar la seguridad alimentaria de soja para el consumo humano. Por tanto, estos resultados implican porcentajes de actividad residual del factor antitríptico o tripsina, menores al $20 \%$.

El análisis realizado en esta sección implicó la determinación de la actividad residual de tripsina en muestras crudas, cocidas y en muestras remojadas y secadas tostadas y remojadas, cocidas y secadas tostadas a diferentes temperaturas, entre $100 \mathrm{y}$ $160^{\circ} \mathrm{C}$. Los resultados obtenidos se presentan a continuación en la Figura 7.7. 


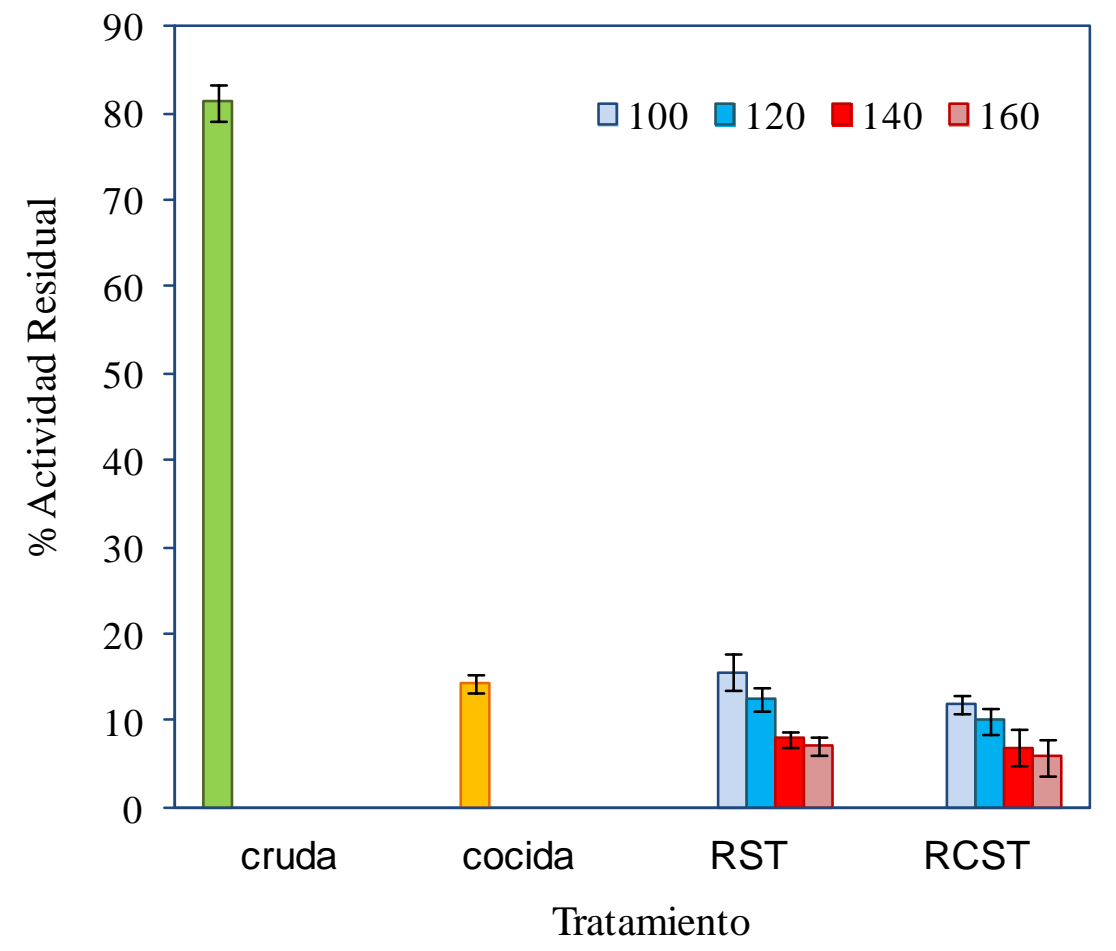

Figura 7.7 Porcentaje de actividad residual de tripsina en muestras de soja: cruda y cocida. También se presentan los valores obtenidos para las muestras RST y RCST secadas-tostadas en lecho fluidizado a temperaturas de entrada del aire de 100, 120, 140 y $160^{\circ} \mathrm{C}$. Las barras superiores indican la correspondiente desviación estándar determinada para cada grupo de valores.

En el caso de la muestra cocida, el tratamiento de cocción, valga la redundancia, (descrito en detalle en el capítulo 2, Sección 2.3.6) fue lo suficientemente intenso como para reducir la actividad del factor antitríptico hasta niveles seguros, cercanos al $14 \%$. $\mathrm{Si}$ analizamos las muestras cocidas que experimentaron posteriormente un tratamiento térmico de secado-tostado a temperaturas elevadas los valores encontrados se hallaron en el rango de 12 a $6 \%$. Con respecto a los valores correspondientes a las muestras remojadas y secadas-tostadas se encontró que ya a $100^{\circ} \mathrm{C}$, la inactivación del factor antitríptico fue suficiente, encontrandose un actividad residual del $15 \%$. Los valores 
disminuyeron conforme aumentaba la temperatura del aire de proceso de secadotostado, siendo a $140^{\circ} \mathrm{C}$ igual al $8 \%$. De acuerdo a estos resultados, el tratamiento de cocción no sería necesario en el desarrollo de un producto tipo snack como el planteado. Machado y col., (2008) destacan que la eficiencia en la eliminación de este factor depende del contenido de humedad inicial, del tipo de tratamiento térmico aplicado, y del par tiempo-temperatura empleado.

\subsubsection{Ensayo del radical DPPH.}

Los antioxidantes son compuestos cuya función primordial en nuestro organismo es contrarrestar el daño oxidativo que causan moléculas conocidas como radicales libres, entre otras. Dicho daño puede ser responsable de enfermedades de carácter degenerativo del sistema circulatorio, enfermedades cardiovasculares, envejecimiento precoz y cáncer (Romero y col., 2003; Georgetti y col., 2008).

Tal como se mencionó al principio de este capítulo, las isoflavonas son compuestos fenólicos abundantes en la familia de las leguminosas. En la soja, las representantes características de esta familia son las especies conocidas como Daidzeína y Genisteína (Kim y col., 2011). Los compuestos fenólicos actúan generalmente como capturadores y estabilizadores de radicales libres, inhibiendo de esta manera el progreso de reacciones de oxidación. Dada la importancia de estas sustancias y sus efectos benéficos para la salud, se consideró conveniente evaluar las aptitudes antioxidantes del grano de soja mediante el test del radical DPPH. Los resultados obtenidos se presentan a continuación 


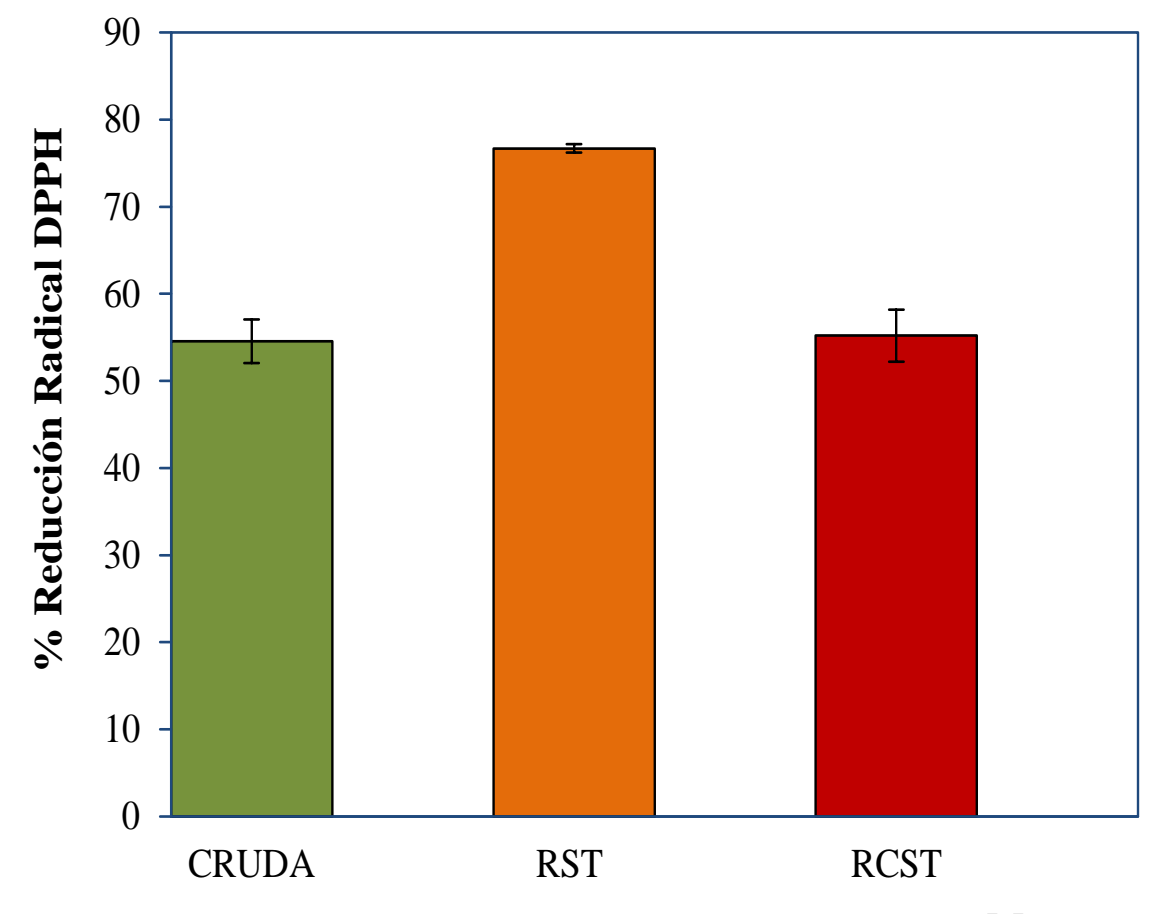

Figura 7.8 Actividad antioxidante determinada mediante el porcentaje de reducción del radical DPPH, en muestras de soja cruda, remojada y secada-tostada y remojada, cocida y secada-tostada.

El valor obtenido de este test para el poroto de soja crudo (54.4\%) fue similar a lo reportado por Kim y col. (2011), Tyug y col. (2010) y Devi y col. (2009) quienes determinaron la actividad antioxidante mediante el mismo test en extractos de soja cruda. De acuerdo a la figura anterior, la muestra RST presento una capacidad antioxidante superior a los determinados para la soja cruda y la muestra RCST, mientras que los valores entre la soja cruda y la RCST fueron similares. Un análisis estadístico realizado posteriormente mostró la existencia de diferencias significativas éntrelas tres muestras analizadas.

A continuación, se presentan en la Tabla 7.4 los valores obtenidos para la concentración media efectiva y el poder antioxidante 
Tabla 7.4 Valores de EC $_{50}$ y PA para las muestras de soja cruda, la remojada, secadatostada (RST) y la muestra remojada, cocida y secada-tostada (RCST). El valor entre paréntesis corresponde a la desviación estándar de los valores determinados.

\begin{tabular}{lcc}
\hline Muestra & $\mathrm{EC}_{50}(\mathrm{mg})$ & $\mathrm{PA}\left(\mathrm{mg}^{-1}\right)$ \\
\hline Cruda & $73.01(0.5)$ & $0.014(0.0001)$ \\
RST & $51.67(2.5)$ & $0.019(0.0009)$ \\
RCST & $71.23(2.4)$ & $0.014(0.0005)$ \\
\hline
\end{tabular}

El aumento observado entre la muestra cruda y la RST está de acuerdo con lo informado por Kim y col. (2011) quienes evaluaron la influencia de la temperatura durante el tostado en una variedad de poroto de soja negra (Glycine Max L., Merril). Estos autores atribuyeron este incremento a la solubilización de compuestos fenólicos, que se mantenían en el interior de la matriz celular, y a productos originados a partir de la reacción de Maillard. Este resultado es interesante, dado que estudios realizados en frutas y vegetales frescos encontraron que la aplicación de temperaturas por encima de $100^{\circ} \mathrm{C}$ afectaba negativamente la presencia de este tipo de sustancias (Agostini y col., 2009)

\subsubsection{Evaluación Sensorial.}

En la Figura 7.6 se presentan los valores promedios obtenidos para cada uno de los atributos sensoriales y la aceptabilidad general de los productos analizados. 


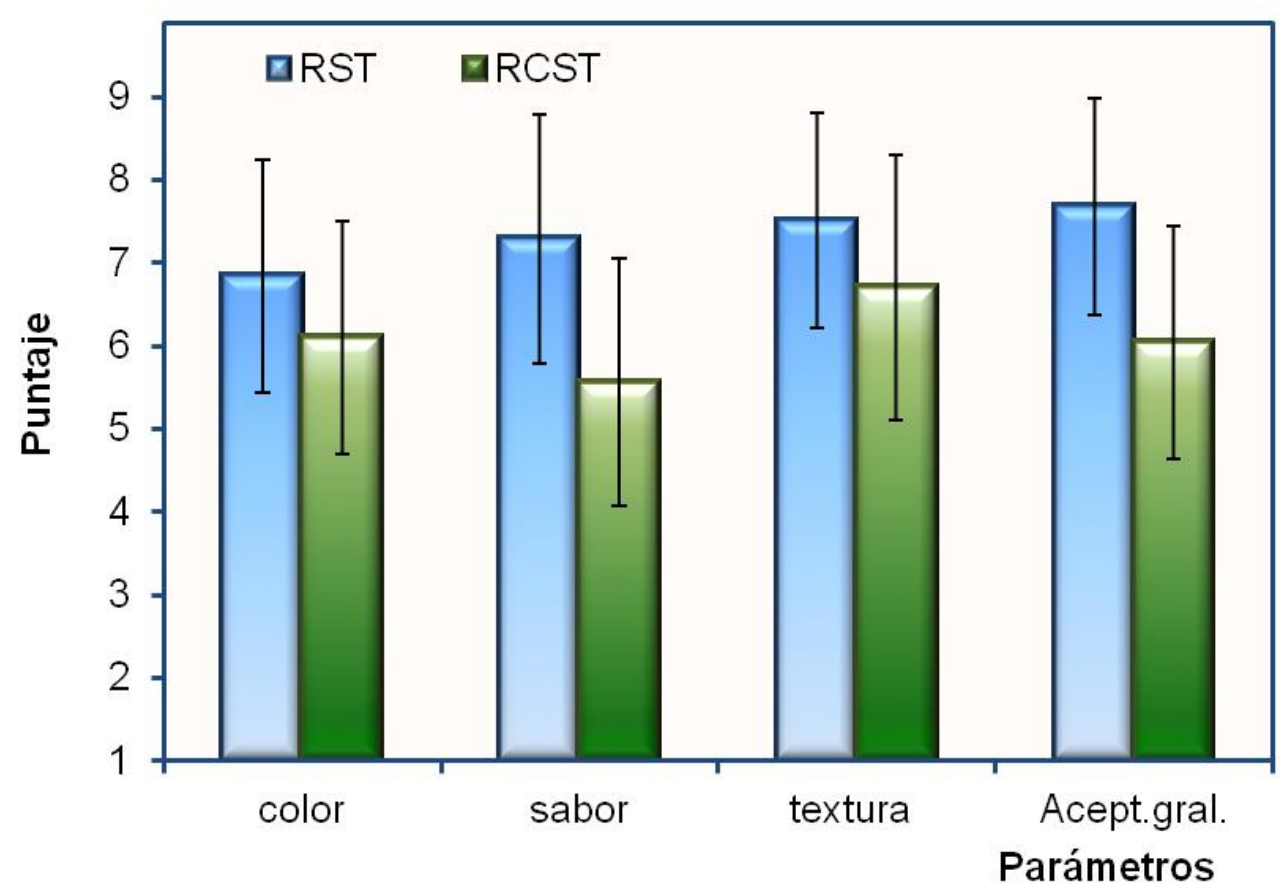

Figura7.9 Puntajes medios obtenidos para cada parámetro durante la evaluación sensorial realizada entre ambas muestras, para la escala hedónica de 9 puntos utilizada, junto a la desviación estándar correspondiente a cada valor.

Al realizar el cálculo del ANOVA, se observaron diferencias significativas para cada atributo entre las muestras evaluadas. Las puntuaciones obtenidas en ambos casos tanto para la muestra RST (codificada como 134) como para la muestra RCST (codificada como 249) fueron superiores a 5, lo que implica que ambas resultaron del agrado de los consumidores. No obstante, se observó una tendencia en los consumidores hacia una mayor aceptabilidad de la muestra RST. Si bien los productos denominados como snack por lo general suelen estar formulados con azúcar o sal, la obtención de resultados como los presentados anteriormente en productos sin el agregado de aditivo alguno como los de este trabajo (una aceptabilidad general que representa el $88 \%$ del valor máximo) resultó más que satisfactorio. 


\subsection{Conclusiones.}

De acuerdo a los valores de solubilidad proteica encontrados para las muestras analizadas, RST (69.6\%) y RCST (53.4\%), se puede concluir que la intensidad del tratamiento para la muestra cocida y secada-tostada fue mayor originado probablemente por un mayor grado de desnaturalización proteica y formación de agregados insolubles. El valor hallado para la muestra RST se halla muy próximo a los valores establecidos como aceptables, es decir puede considerarse que el grano no fue sobrecalentado.

La electroforesis SDS-PAGE realizada con las muestras crudas, RST y RCST mostró que la intensidad en las bandas correspondientes a la muestra cruda fue mayor en comparación con las de las muestras tratadas térmicamente. La intensidad de las bandas de 7S disminuyeron mientras que las bandas A y B-11S aumentaron, conforme el tratamiento térmico fue más severo $($ Cruda $<\mathrm{RST}<\mathrm{RCST})$, principalmente en la muestra RCST. Además, la ausencia en RCST de agregados solubles de alta masa molecular, sugiere la formación de agregados insolubles como consecuencia del tratamiento térmico intenso, esto concuerda con lo determinado en el test de solubilidad proteica.

La determinación de los niveles residuales de tripsina durante los distintos tratamientos térmicos demostró que en las muestras remojadas el secado-tostado a temperaturas de $100^{\circ} \mathrm{C}$ en adelante, fueron lo suficientemente intensos como para disminuir la actividad residual de este antinutriente dentro de los niveles aceptados como seguros, menores al $20 \%$. En particular, a $140^{\circ} \mathrm{C}$, la temperatura de interés en nuestro caso el valor fue de alrededor del $8 \%$. Esto principalmente es útil porque permite obviar la etapa de cocción en el desarrollo de este producto en virtud de que, 
durante el secado-tostado de las muestras remojadas se produciría una "cocción" lo que además permitiría reducir el tiempo y el costo del proceso.

Con respecto a la capacidad antioxidante, los valores para la muestra RST, fueron mayores en comparación con aquellos determinados para la muestra cruda. Si bien estos resultados coincidieron con lo informado por otros autores, aun así resultó sorprendente dado que otros estudios llevados a cabo con frutas informaron efectos negativos de la temperatura sobres este tipo de compuestos.

Finalmente, la prueba de evaluación sensorial llevada a cabo con las muestras RST y RCST, presentó resultados muy satisfactorios para ambas muestras con valores promedios muy por arriba de 5 puntos en la escala hedónica utilizada. Aunque los mayores valores fueron asignados a la muestra remojada y secada-tostada, posiblemente porque, al presentar menor densidad, que la muestra RCST, su estructura fue más porosa, proveyendo un balance entre masticabilidad y crocancia que resultó más atractivo para los consumidores. 


\section{CONCLUSIONES GENERALES}




\section{Conclusiones generales}

Los modelos desarrollados para interpretar el volumen y densidad del grano entero de soja durante el remojado, cocción y secado-tostado en lecho fluidizado mostraron que el grano se expandía durante el remojado y experimentaba reducción de su volumen y densidad conforme se deshidrataba originando productos secos, porosos y livianos. Esta modificación en su estructura afectó el comportamiento fluidodinámico del lecho de partículas. Se determinó una velocidad operativa de fluidización variable con el tiempo, que disminuía conforme el producto se deshidrataba. Por tanto, a fines de mantener un consumo adecuado de energía y evitar pérdida de material por arrastre neumático debería mantenerse un control estricto de la velocidad. El estudio de las características sorcionales del grano parcial y totalmente secado-tostado a $140^{\circ} \mathrm{C}$ indicó que el modelo más conveniente para la predicción fue el modelo de Halsey; al mismo tiempo se determinó que no existía un efecto de la temperatura sobre las isotermas, por lo que, en cálculos posteriores se consideró solo el calor de sorción del agua pura. Para realizar un análisis más realista del secado-tostado en capa delgada en lecho fluidizado se utilizaron los conocimientos de los cambios estructurales que experimentaba el grano durante el tratamiento térmico para plantear un modelo matemático que considerara la contracción volumétrica y un coeficiente de difusión variable con la humedad. Los resultados obtenidos fueron muy satisfactorios. Con base en estos modelos se plantearon los balances de materia y energía para el aire en lecho fluidizado, que se validaron con datos experimentales encontrándose una buena concordancia. Adicionalmente, dado que el aire de salida presentaba baja humedad relativa y una 
temperatura elevada, se propuso la recirculación de una fracción del aire como alternativa para mejorar la eficiencia térmica del proceso.

La evaluación de la calidad del los tratamientos RST y RCST a $140^{\circ} \mathrm{C}$ mostró que el último, que incluía una etapa de cocción en agua luego del remojado, fue más severo para las proteínas, de acuerdo a los bajos valores de solubilidad proteica determinados para esta muestra, lo cual desde el punto de vista nutricional no sería conveniente. Más aún la determinación de la inactivación de los factores antinutricionales demostró que era posible obtener valores aceptables para el consumo en las muestras remojadas y secadas-tostadas (RST). Por tanto la etapa de cocción no resultaría necesaria. Adicionalmente,la muestra RST fue la que presentó una capacidad antioxidante mayor que la de la muestra cruda. Finalmente, a partir del ensayo de evaluación sensorial se encontró que ambas muestras presentaron un alto grado de aceptabilidad general, sin embargo se observó una preferencia hacia la muestra remojada y secada-tostada.

Se propone entonces el proceso de remojado y secado-tostado a $140^{\circ} \mathrm{C}$ en lecho fluidizado como una manera apropiada para el desarrollo del snack de soja, teniendo el método de preparación promisorias perspectivas de transferencia de realizarse con una velocidad de fluidización decreciente, y con recirculación del aire de salida. 
NOTACIÓN 


\section{Notación}

$\boldsymbol{a}$ : factor promedio de contracción volumétrica, adimensional

$\boldsymbol{a}_{\mathbf{s}}$ : coeficiente promedio de hinchamiento, adimensional

$\boldsymbol{a}_{\mathrm{w}}$ : actividad de agua, adimensional

$\boldsymbol{a}_{\mathbf{v}}$ : área superficial de la partícula por unidad de volumen, $\mathrm{m}^{2} / \mathrm{m}^{3}$

$\mathbf{A}_{\mathbf{H M}}, \mathbf{R}_{\mathbf{H M}}$ : parámetros de la Ec. de Halsey modificada (4.14)

Ap: área superficial del grano a humedad W, $\mathrm{m}^{2}$

$\mathbf{C}_{\mathbf{m}}$ : concentración volumétrica efectiva obtenida a partir de $\mathrm{W}_{\mathrm{m}}$, $\mathrm{kg}$ agua $/ \mathrm{m}^{3}$ de materia seca

$\mathbf{C P}_{1}, \mathbf{C P}_{2}, \mathbf{C P}_{3}$ : parámetros de la Ec. de Chung pfost modificada (4.12)

$\mathbf{C M}_{1}, \mathbf{C M}_{2}$ : parámetros de la Ec. de Oswin modificada (4.13)

$\mathbf{C}_{\mathrm{l}}$ : concentración volumétrica de agua local, $\mathrm{kg}$ agua $/ \mathrm{m}^{3}$ de materia seca

$\mathbf{C}_{\mathbf{e}}$ : concentración volumétrica de equilibrio determinada a partir de $\mathrm{W}_{\mathrm{e}}, \mathrm{kg}$ agua $/ \mathrm{m}^{3}$ de materia seca

$\mathbf{C}_{\mathbf{p}}$ : capacidad calorífica del grano, $\mathrm{J} / \mathrm{kg}{ }^{\circ} \mathrm{C}$

$\mathbf{C}_{\mathbf{p a}}$ : capacidad calorífica del aire, $\mathrm{J} / \mathrm{kg}{ }^{\circ} \mathrm{C}$

D: diámetro interno de la cámara de secado, m

$\mathbf{D}_{\mathbf{e}}$ : diámetro equivalente del grano, $\mathrm{m}$

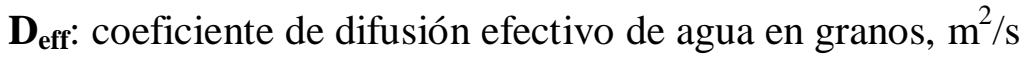

$\mathbf{D}_{\mathbf{t}}$ : coeficiente de difusión efectivo de agua en granos a la humedad $\mathrm{W}, \mathrm{m}^{2} / \mathrm{s}$

$\mathbf{D}_{\mathbf{0}}$ : coeficiente de difusión efectivo de agua en granos a la humedad $\mathrm{W}_{0}, \mathrm{~m}^{2} / \mathrm{s}$

$\mathbf{D}_{\infty}$ : factor pre-exponencial de la ecuación de Arrhenius para $\mathrm{D}_{\mathrm{eff}}, \mathrm{m}^{2} / \mathrm{s}$

D. diámetro efectivo del grano a la humedad W, m 
$\mathbf{E}_{\boldsymbol{a}}$ : energía de activación de Arrhenius para la variación de $\mathrm{D}_{\text {eff }}$ con la temperatura $\mathrm{kJ} / \mathrm{mol}$

$\mathbf{E}_{\mathbf{f}}$ : eficiencia térmica

$\mathbf{f}_{\mathbf{c}}$ : factor de Coulson, adimensional

g: aceleración de la gravedad, $\mathrm{m}^{2} / \mathrm{s}$

$\mathbf{G}_{\mathrm{a}}$ : flujo másico de aire forzado a través del lecho de granos, $\mathrm{kg} / \mathrm{m}^{2} \mathrm{~s}$

$\mathbf{h}_{\mathbf{a} 1}$ : humedad absoluta del aire a la entrada, $\mathrm{kg}$ vapor $/ \mathrm{kg}$ aire seco

$\mathbf{h}_{\mathbf{a} 2}$ : humedad absoluta del aire a la entrada, $\mathrm{kg}$ vapor $/ \mathrm{kg}$ aire seco

$\mathbf{h}_{\mathbf{r a}}$ : humedad relativa del aire decimal

$\mathbf{h}_{\mathbf{T}}$ : coeficiente de transferencia de calor efectivo aire-grano, $\mathrm{W} /{ }^{\circ} \mathrm{C} \mathrm{m}^{2}$

$\mathbf{k}_{\mathrm{P}}$ : coeficiente de transferencia de materia aire-grano, $\mathrm{kg} / \mathrm{m}^{2} \mathrm{~s} \mathrm{~Pa}$

$\mathbf{K}_{\mathrm{T}}$ : conductividad térmica efectiva, $\mathrm{J} / \mathrm{s}{ }^{\circ} \mathrm{C}$

$\mathbf{K}_{\mathbf{1}}$ : parámetro laminar de la Ecuación de Ergun (3.7)

K2: parámetro turbulento de la Ecuación de Ergun (3.7)

$\mathbf{K}_{\mathbf{v}}$ : parámetro ajustado a la Ecuación 2.16, kg/m

$\mathbf{K}_{\text {THM}}, \mathbf{N}_{\text {THM}}$ : parámetros de la Ec. de Henderson Thompson modificada (4.11)

Kр: parámetro ajustado a la Ecuación $2.17, \mathrm{~kg} / \mathrm{m}^{3}$

L.g: calor latente de vaporización del agua incorporada en el grano, J/kg

$\mathbf{L}_{\mathbf{m f}}$ : altura de lecho a velocidad de mínima fluidización, m

$\mathbf{L}_{\mathbf{w}}$ : calor latente de vaporización del agua pura, $\mathrm{J} / \mathrm{kg}$

$\mathbf{L}_{\mathbf{0}}$ : altura de lecho fijo, $\mathrm{m}$

$\mathbf{m}_{\text {wa }}$ : masa de agua absorbida en el grano durante el remojado, $\mathrm{kg}$

$\mathbf{m}_{\mathbf{d}}$ : materia seca del grano, $\mathrm{kg}$

$\mathbf{m}_{\mathbf{0}}$ : masa inicial del grano a la humedad $\mathrm{W}_{0}$, $\mathrm{kg}$

$\mathbf{m}_{\text {TP: }}$ masa total de granos empleada en la determinación picnométrica, kg 
$\mathbf{M}_{\boldsymbol{a}}$ : masa molar del aire, $\mathrm{kg} / \mathrm{kmol}$

$\mathbf{M}_{\mathbf{v}}$ : masa molar del vapor de agua $\mathrm{kg} / \mathrm{kmol}$

$\mathbf{N}_{\mathbf{T P}}$ : número total de grano en la determinación picnométrica

p: presión absoluta del aire, $\mathrm{Pa}$

pvs: presión de vapor de agua en la superficie del grano, Pa

p va: presión parcial de vapor de agua en el aire, Pa

r: coordenada del radio del grano, $\mathrm{m}$

$\mathbf{R}, \mathbf{R}_{\mathbf{0}}$ : radio externo del grano a humedad $\mathrm{W}_{0}, \mathrm{~m}$

$\mathbf{R}_{\mathbf{t}}$ : radio externo del grano a humedad $\mathrm{W}, \mathrm{m}$

R: constante de los gases Ec. (5.16), J/kmol K

S: sección transversal a la dirección del aire de la cámara de secado, m

t: tiempo, $\mathrm{s}$

$\mathbf{t}_{\mathbf{s}}$ : tiempo total de tratamiento térmico, s

$\mathbf{T}_{\mathbf{a}}, \mathbf{T}_{\mathbf{c}}$ : temperatura del aire, ${ }^{\circ} \mathrm{C}$

$\mathbf{T}_{\mathbf{a b s}}, \mathbf{T}_{\mathbf{K}}$ : temperatura absoluta del aire, $\mathrm{K}$

$\mathbf{T}_{1}$ : temperatura media en el grano, ${ }^{\circ} \mathrm{C}$

$\mathbf{X}^{2}$ : tiempo adimensional de la Ec. de difusión (5.7)

$\mathbf{V}_{\text {TP: }}$ volumen total de granos empleado en la determinación picnométrica, $\mathrm{m}^{3}$

V: volumen del grano a la humedad $\mathrm{W}, \mathrm{m}^{3}$

$\mathbf{V}_{\mathbf{m}}$ : velocidad operativa media de fluidización, Ec. (6.15), m/s

$\mathbf{V}_{\mathbf{0}}$ : volumen del grano a humedad $\mathrm{W}_{0}, \mathrm{~m}^{3}$

$\mathbf{V}_{\text {wa }}$ : volumen de agua absorbida en el grano durante el remojado, $\mathrm{m}^{3}$

$\mathbf{V}_{\text {mf: }}$ velocidad de mínima fluidización, m/s

$\mathbf{V}_{\mathbf{0}}$ : velocidad superficial de aire, $\mathrm{m} / \mathrm{s}$

$\mathbf{V}_{\mathbf{f}}$ : velocidad operativa de fluidización $1.5 \mathrm{~V}_{\mathrm{mf}}, \mathrm{m} / \mathrm{s}$ 
W: humedad media del grano en la serie infinita Ec. (5.6), decimal base seca (dec., b.s.)

$\mathbf{W}_{\mathrm{e}}$ : humedad de los granos en equilibrio con aire de $\mathrm{T}_{\mathrm{c}} \mathrm{y} \mathrm{h}_{\mathrm{r}}$, dec., b.s.

$\mathbf{W}_{\mathbf{0}}$ : humedad inicial del grano, dec., b.s.

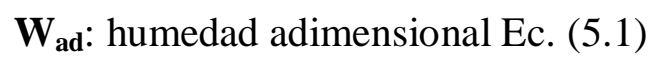

$\mathbf{W}_{\mathbf{l}}$ : humedad local intragranular, dec., b.s.

$\mathbf{W}_{\mathbf{m}}$ : humedad media del grano a partir de la integración de los valores de $\mathrm{W}_{\mathrm{l}}$, dec.,b.s.

$\mathbf{Z}_{\text {max }}$ : espesor máximo del lecho, m

\section{Reactivos químicos}

DTT: Dithiothreitol agente redox

DPPH: radical 2,2-difenil-1-picrilhidrazil

EDTA: ácido etilendiaminotetraacético

Folin: 1,2-naftoquinona-4-sulfonato de sodio

Hb-d: hemoglobina bovina desnaturalizada

HCl: ácido clorhidrico

$\mathrm{H}_{2} \mathrm{SO}_{4}$ : ácido sulfúrico

$\mathrm{H}_{3} \mathrm{BO}_{3}$ : ácido bórico

KOH: hidróxido de potasio

NaOH: hidróxido de sodio

PAGE: Poly Acrylamide Gel Electrophoresis

SDS: detergente aniónico dodecilsulfato de sodio

TEMED: tetrametiletiléndiamina

TCA: ácido tricloroacetico

$\boldsymbol{\beta}$-ME: $\beta$-mercaptoetanol 


\section{Símbolos griegos}

$\rho_{\text {so }}$ : masa seca del grano referida al volumen inicial $\mathrm{V}_{0}, \mathrm{~kg} / \mathrm{m}^{3}$

$\boldsymbol{\rho}_{\mathbf{m}}$ : densidad media del grano a una humedad $\mathrm{W}_{\mathrm{m}}, \mathrm{kg} / \mathrm{m}^{3}$

$\boldsymbol{\rho}_{\mathbf{0}}$ : densidad del grano a humedad $\mathrm{W}_{0}, \mathrm{~kg} / \mathrm{m}^{3}$

$\boldsymbol{\rho}_{\mathrm{w}}$ : densidad de agua, $\mathrm{kg} / \mathrm{m}^{3}$

$\boldsymbol{\rho}_{\mathbf{B} \mathbf{0}}$ : densidad de lecho fijo, $\mathrm{kg} / \mathrm{m}^{3}$

$\rho_{\mathbf{p}}$ : densidad del grano a la humedad $\mathrm{W}, \mathrm{kg} / \mathrm{m}^{3}$

$\boldsymbol{\rho}_{\boldsymbol{a}}:$ densidad del aire, $\mathrm{kg} / \mathrm{m}^{3}$

$\varepsilon_{0}$ : fracción de huecos en el lecho fijo de granos, adimensional

$\boldsymbol{\varepsilon}_{\mathbf{m f}}$ : porosidad de lecho a velocidad de mínima fluidización, adimensional

$\Delta \mathbf{r}$ : incremento de radio variable para la integración numérica

$\Delta \mathbf{t}$ : intervalo de tiempo para la integración numérica

$\Delta_{\mathbf{P}}$ : pérdida de carga del aire, $\mathrm{Pa}$

ø: factor de esfericidad, adimensional

$\boldsymbol{\mu}_{0}$ : viscosidad del aire, $\mathrm{kg} / \mathrm{m} \mathrm{s}$ 
BIBLIOGRAFÍA 


\section{BIBLIOGRAFÍA}

Aguilera, J.M. (2003). Drying and dried products under the microscope. Food Science and Technology International, 9(3), 137-143.

Aguilera, J.M., Chiralt, A., Fito P. (2003). Food dehydration and product structure. Trends in Food Science \& Technology, 14, 432-437.

Akpinar, E.K. (2006). Determination of suitable thin layer drying curve model for some vegetables and fruits. Journal of Food engineering, 73, 75-84.

Al-Muhtaseb, A.H., McMinn, W.A.M., Magee, T.R.A. (2002). Moisture sorption isotherms characteristics of food products: a review. Food and Bioproducts Processing, 80(2), 118-128.

AOCS Official Method Ac 2 -41. Moisture and volatile matter. Reapproved 1997. Official Methods and Recommended Practices of the AOCS. AOCS Press, United State of America.

AOAC Official Method 955.04. Kjeldahl method, boric acid modification. (1998). Official Methods of Analysis Gaitherburg, USA, AOAC International.

AOAC Official Method 963.15. Fat in cacao products. Soxhlet extraction method (1998). Official Methods of Analysis Gaitherburg, USA, AOAC International. 
AOAC Official Method 940.26. Ash of fruits and frut products. (1998). Official Methods of Analysis Gaitherburg, USA, AOAC International.

Araba, M., Dale, N.M. (1990). Evaluation of protein solubility as indicator of over processing soy-bean meal. Poultry Science, 69:76-83.

Aviara, N.A., Ajibola, O.O., Aregbesola, O.A., Adedeji, M.A. (2006). Moisture sorption isotherms of sorghum malt at 40 and $50^{\circ} \mathrm{C}$. Journal of Stored Products Research, 42, 290-301.

Baigorri, H. Pereyra, V. (2002). El INTA y el desarrollo de la soja en Argentina. Revista Agro N5, 19-21.

Bahloul, N., Boudhrioua, N., Kechaou, N. (2008). Moisture desorption-adsorption isotherms and isosteric heats of sorption of Tunisian olive leaves (Olea europaea L.). Industrial Crops and products, 28, 162-176.

Bart-Plange, A., Baryeh, E.A. (2003). The physical properties of category B cocoa beans. Journal of Food Engineering, 60: 219-227.

Baryeh, E.A. (2002). Physical properties of millet. Journal of Food Engineering, 51, 3946. 
Bartholomai, G., Tosi, E., González, R. (2001). Caraterización de compuestos nutritivos, no nutritivos y calidad proteíca. CYTED, Programa Ibero Americano de Ciencia y Tecnología para el Desarrollo. Editorial Eudeba.

Becker, H.A. (1959). A study of diffusion in solids of arbitrary shape with application to the drying of the wheat kernel. Journal of Applied Polymer Science, 1(2), 212-226.

Bhandari, B., Adhikari, B. (2009). Glass transition-based approach in drying of foods. In Advances of Food Dehydration, (Chapter 2, pp 37-62). Ratti, C., (Ed). CRC Press, Taylor and Francis Group, Boca Ratón, USA.

Bhandari, B.R., Howes, T. (1999). Implication of glass transition for the drying and stability of dried foods. Journal of food engineering, 40, 71-79.

Blahovec, J. (2004). Sorption isotherms in materials of biological origin mathematical and physical approach. Journal of Food Engineering, 65, 489-495.

Bocchetto, M. (2005). Características, transformaciones y sustentabilidad de la expansión de la soja en el MERCOSUR.

Bruce, D.M., (1985). Exposed-layer barley turing: tree models fitted to new data up to $150^{\circ} \mathrm{C}$. Journal of Agricultural Engineering Research, 32, 337-347.

Cãpritã, R., Cãpritã, A., Cretescu, I. (2010). Protein solubility as quality index for processed soybean. Animal Science and Biotechnologies, 43(1), 375-378. 
Calvelo, A. (1975). Fluidodinamica. Facultad de Ciencias Exactas. Universidad Nacional de La Plata. Curso de Reducción. Instituto Argentino de Siderurgia, Buenos Aires.

Cheftel, J.C., Cheftel, H. (1992). Introducción a la Bioquímica y Tecnología de los Alimentos. Vol. I, Ed. Acribia, Zaragoza, España.

Chau, K.V., Gaffney, J.J. (1990). A finite-difference model for heat and mass transfer in products with internal heat generation and transpiration. Journal of Food Science,55, 484.

Chen, C. (2003). Moisture sorption isotherms of pea seeds. Journal of Food Engineering, 58, 45-51.

Chen, C., Morey, R.V. (1989). Equilibrium relative humidity relationships for yellow dent corn. Transactions of the ASAE, 32(3), 999-1005.

Chen, C. (2006). Obtaining the isosteric sorption heat directly by sorption isotherm equations. Journal of Food Engineering, 74, 178-185.

Chirife, J., Buera, M.P. (1995). A critical review of some non-equilibrium situations and glass transitions on water activity values of foods in the microbiological growth range. Journal of Food Engineering, 25, 531-552. 
Codigo Alimentario Argentino. Capítulo XIX (Harinas, Concentrados, Aislados y Derivados Proteínicos) artículos 1407 hasta 1412 (Res.126,29.1.80).

Consejo nacional de coordinación de políticas sociales. (2003). Consideraciones sobre la soja en alimentación. Presidencia de la Nación Argentina.

Coulson, J.M. and Richardson, J.F. (2000). Chemical Engineering. Vol. 2, Fifth Ed. pg.200.

Crank, J. (1975). Mathematics of diffusion, Oxford University Press, Oxford.

Cuniberti, M., Rossi, R., Herrero, R., Ferrari, B. (2002). Calidad industrial de la soja en Argentina. Proceedings of Brazilian Soybean Congress, 61-70.

Delele, M.A., Tijskens, E., Atalay, Y.T., Ho, Q.T., Ramon, H., Nicolai, B.M., Verboven, P. (2008). Combined discrete element and CFD modelling of airflow through random stacking of horticultural products in vented boxes. Journal of Food Engineering, 89, 33-41.

Dergal, S.B. (1990). Química de los alimentos. Segunda Edición. Editorial Alhambra mexicana.

Deshpande, S.D., Bal, S., Ojha, T.P.(1993). Physical properties of soybean. Journal Agriculture Engineering Research, 56, 89-98. 
Devi, A.M.K., Gondi, M., Sakthivelu, G., Giridhar, G., Rajasekaran, P., Ravishankar, G.A. (2009). Functional attributes of soybean seeds and products, with reference to isoflavone content and antioxidantactivity. Food Chemistry, 114, 771-776.

Di Felice, R. Gibilaro, L.G. (2004). Wall efects for the pressure drop in fixed beds. Shorter communication. Chemical Engineering Science 59, 3037-3040.

Di Mattia, D.G., Amyotte, P.R, Hamdullahpur, F. (1996). Fluidized bed dryng of large particles. Transactions of the ASAE, 56, 89-98.

Di Scala, K., Crapiste, G. (2008). Drying kinetics and quality changes during drying of red pepper. Lebensmittel Wissenschaft und Technologie, 41, 789-795.

Doymaz, I. (2005). Drying behavior of green beans. Journal of Food Engineering, 69, 161-165.

Doymaz, I., Ísmail, O. (2011). Drying characteristics of sweet cherry. Food and Bioproducts Processing, 89, 31-38.

Ergun, S. (1952). Fluid flow through packed columns. Chemical Engineering Progress, 48, 89-94.

Erickson, D.R. (Ed). (1995). Practical Handbook of Soybean Processing and Utilization. AOCS Press, Champaing, Illinois, EEUU. 
Escardino, A. Ruiz, F., Barbero P. (1974). Circulación de aire a través de lechos formados por granos de cereales. Revista de Agroquímica y Tecnología de Alimentos, 10, 528-539.

Fennema, O.R. (2010). Food Chemistry. Third edition, CRC Press, Taylor and Fracis Group, Boca Raton, USA.

Fellows, P. (1994). Tecnología del procesado de alimentos: principios y prácticas. Editorial Acribia, Zaragoza, España.

Fito, P.M., Grau, A.M.A., Baviera, J.M.B., Sorolla, A.M.A. (2001). Introducción al secado de alimentos por aire caliente. Ed. U.P.V, Valencia, España.

Foong, C.W., Krishnainah, K., Janaun, J., Subbarao, D., Prabhakar, A. (2009). Heat and mass transfer studies of palm kernel cake (PKC) in fluidized bed fermenter. Industrial Croops and Products, 30(2), 227-234.

Formisani, B., Girimonte, R., Mancuso, L. (1998). Analysis of the fluidisation process of particle beds at high temperature. Chemical Engineering Science, 53 (5), 951-961.

Gálvez, A.V., Aravena, E.L., Mondaca, R.L. (2006). Isotermas de adsorción en harina de maíz (Zea mays L.). Revista Ciencia y Tecnología de Alimentos, Campinas, 26(4), 821-827. 
García Díaz, A.A. (2005). Cálculo del tiempo de calentamiento de granos de soya. Revista Tecnología Química. Universidad de Oriente, Santiago de Cuba, Cuba, 25(2), 59-65.

Gallardo, M. (2008). Soja, harinas de extracción para la alimentación del ganado. Informe técnico, Instituto Nacional de Tecnología Agropecuario, Rafaela.

García, F.P., Martínez, A.J.G. (2006). Evaluación de las isotermas de sorción en cereales para desayuno. Revista Mexicana Superficies y Vacío, 19 (1), 12-19.

Gastón, A.L., Abalone, R.M., Giner, S.A. (2002). Wheat drying kinetics. Diffusivities for sphere and ellipsoid by finite elements. Journal of Food Engineering, 52, 313-322.

Gely, M.C., Giner, S.A. (2000). Diffusion coefficient relationships during drying of soya bean cultivars. Biosystems Engineering, 96(2), 213-222.

Gely, M.C., Santalla, E.M. (2007). Moisture diffusivity in quinoa (Chenopodium quinoa willd.) seeds: Effect of air temperature and initial moisture content of seeds. Journal of Food Engineering, 78, 1029-1033.

Giner, S.A. (1999). Diseño de secadoras continuas de trigo. Simulación de Transferencia de Calor y Materia y de Pérdidas de Calidad. Tesis Doctoral en Ingeniería. Facultad de Ingeniería, Universidad Nacional de La Plata, Argentina. 
Giner S. A., Calvelo (1987).Modelling of wheat drying in fluidized beds. Journal of Food Science, 52(5), 1358-1363.

Giner S.A., De Michelis A. (1988). Evaluation of the thermal efficiency of wheat drying in fluidized beds: influence of air temperature and heat recovery. Journal Agriculture Engineering Research, 41, 11-23.

Giner, S.A., Gely, M.C. (2005). Sorption parameters of sunflower seeds of use in drying and storage stability studies. Byosistems Engineering, 92(2), 217-227.

Giner S.A., Mascheroni R.H. (2001). Diffusive drying kinetics in wheat, part 1: potential for a simplified analytical solution. Journal Agriculture Engineering Research, 80(4), 351-364.

Giner, S.A., Torrez Irigoyen, R.M., Cicuttín, S., Fiorentini, C. (2010). The variable nature of biot numbers in food drying. Journal of Food Engineering, 101, 214-222.

González, R., Carrillo, D. (1987). Nutrición humana. Manual de prácticas. La Habana, Cuba. Editorial Pueblo y Educación Carrillo, 34-36.

Goñi, S.M., Purlis E. (2010). Geometric modelling of heterogeneous and complex foods. Journal of Food Engineering, 97(4), 247-554.

Groenelwold, H., Tsotsas, E. (2007). Drying in fluidized beds with immersed heating elements. Chemical Engineering Science, 62, 481-502. 
Hansen, R.C., Berry, M.A., Keener, H.M., Gustafson, R.J. (1996). Current grain drying practices in Ohio. Applied Engineering in Agriculture, 12(1), 65-69.

Hsu, J.T., Satter L.D. (1995). Procedures for measuring the quality of heat-treated soybeans. Journal of Diary Science, 78, 1353-1361.

Iwe, M.O., Van Zuilichem, D.J., Ngoddy, P.O., Lammers, W. (2001). Amino acid and protein dispersibility index (PDI) of mixtures of extruded soy and sweet potato flours. Lebensmittel Wissenschaft und Technologie,34, 71-75.

Kashaninejad, M., Ahmadi, M., Daraei, A., Chabra D. (2008). Handling and frictional characteristics of soybean as a function of moisture content and variety. Power Technology, 188, 1-8.

Kim, H.G., Kim, G.W., Oh, H., Yoo, S.Y., Kim, Y.O., Oh, M.S. (2011). Influence of roasting on the antioxidant activity of small black soybean (Glycine max L.Merril). Food Science and Technology, 44, 992-998.

Kitic, D., Viollaz, P.E. (1984). Comparison of drying kinetics of soybeans in thin layer and fluidized beds. Journal of Food Technology, 19, 399-408.

Kratzer, F.H., Bersh, S., Vohra, P., Ernst, R.A. (1990). Chemical and biological evaluation of soya-bean flakes autoclaved for different durations. Animal Food Science and Technology, 31(3), 247-259. 
Kunii, D., Levenspiel, O. (1997). Circulating fluidized-bed reactors. Chemical Engineering Science, 52 (15), 2471-2482.

Lacerda, A.F., Lisboa, M.H., Barrozo, M.A.S. (2005). Heat and mass transfer in a countercurrent moving bed dryer. Applied Thermal Engineering, 25, 2641-2652.

Lewicki, P.P. (2006). Design of hot air drying for better foods review. Trends in Food Science \& Technology, 17, 153-163.

Luangmalawat, P., Prachayawarakorn, S., Nathakaranakule, A., Soponronnarit, S. (2008). Effect of temperature on drying characteristics and quality of cooked rice. Lebensmittel Wissenschaft und Technologie, 41, 716-723.

Mabellini, A., Vullioud, M.B., Marquez, C.A., De Michelis, A. (2010). Kinetic drying experimental data and mathematical model for sweet cherries (Pronus avium). Journal of Food Process Engineering, 33 (6), 1115-1128.

Machado, F.P.P, Queiróz, J.H., Oliveira, M.G.A., Piovesan, N.D., Peluzio, M.C.G., Costa, N.M.B., Moreira, M.A. (2008). Effects of heating on protein quality of soybean flour devoid of kunitz inhibitor and lectin. Food Chemistry, 107, 649-655.

Madhiyanon, T., Techaprasan, A., Soponronnarit, S. (2006). Mathematical models based o heat transfer and coupled heat and mass transfer for rapid high temperature treatment in fluidized bed: application for grain disinfestation. International Journal of Heat and Mass Transfer, 49, 2277-2290. 
Markowski, M., Bialabrzewski, I., Modrzewska, A. (2010). Kinetics of spouted-bed drying of barley diffusivities for sphere and ellipsoid. Journal of Food Engineering, 96, 380-387.

Maronga, S. (1998). On the optimization of the fluidized bed particulate coating process. Ph.D. Tesis Departament of Chemical Engineering and Technology, Royal Institute of Technology, Stockholm.

Mayor, L., Sereno, A.M. (2004). Modelling shrinkage during convective drying of food materials: a review. Journal of Food Engineering, 61, 373-386.

Menkov, N.D. (2000). Moisture sorption isotherms of chickpea seeds at several temperatures. Journal of Food Engineering, 45, 189-194.

Mensah, J.K., Nelson, G.L., Hamdy, M.Y., Richard T.G. (1985). A mathematical model for predicting soybean seedcoat cracking during drying. Transactions of the ASAE, 28(2), 580-591.

Misra, R.N., Young, J.H. (1980). Numerical solution of simultaneous moisture diffusion and shrinkage during soybean drying. Transactions of the ASAE, 1277-1282.

Mohapatra, D., Rao, P.S. (2005). A thin layer drying model of parboiled wheat. Journal of Food Engineering, 66, 513-518. 
Mohsenin, N.N. (1970). Physical properties of plant and animal materials. Gordon and Breach Science Publishers, New York.

Mohsenin, N.N. (1980). Thermal properties of food and agricultural materials. Gordon and Breach Science Publishers, New York.

Montgomery D.C. (1991). Design and analysis of experiments. Third ed., John Wiley \& Sons, Inc., New York, USA.

Moreira, R., Chenlo, F., Torres, M.D. (2009). Simplified algorithm for the prediction of water sorption isotherms of fruits, vegetables and legumes based upon chemical composition. Journal of Food Engineering, 94, 334-343.

Nellist, M.E., Bruce, D.M. (1995). Heated-air grain drying. Cap. 16, 609-659. Stored Grain Ecosystems (Jayas D.S., White, N.D.G, Muir, W.E), Marcel Dekker, Inc.

Nilton, W., Thepa, S., Janjai, S., Kasayapanand, N., Thamrongmas, C., Bala, B.K. (2011). Finite element simulation for coffee (Coffea Arabica) drying. (2012). Food and Bioproducts Processing, 90, 341-350.

Nitz, M. Taranto, O.P. (2007). Drying of beans in a pulsed fluid bed dryer. Drying kinetics, fluid-dynamic study and comparisons with conventional fluidization. Journal of Food Engineering,80, 249-256. 
Ordoñez Pereda, J.A. (1998). Tecnología de los alimentos Volúmenes I y II.. Editorial Sintesis, Madrid, España.

Ortiz, S.M.E., Wagner, J.R. (2002). Hydrolysates of native and modified soy protein isolates: structural characteristics, solubility and foaming properties. Food Research International, 35, 511-518.

Osborn, G.S., White, G.M., Sulaiman, A.H., Walton, L.R. (1989). Predicting equilibrium moisture properties of soybeans. Transactions of the ASAE, 32(6), 21092113.

Osella, C.A, Gordo, N.A, González, R.J, Tosi, E, Ré, E. (1997). Soybean Heat-treated using a Fluidized Bed., Lebensmittel Wissenschaft und Technologie 30, 676-680.

Ou, S., Kwok, K.C., Kang, Y. (2004). Changes in in-vitro digestibility and available lysine of soy protein isolate after formation of film. Journal of Food Engineering,64, 301-305.

Pabis, S., Jayas, D.S., Cenkowski, S. (1998). Grain Drying. Theory and Practice. John Wiley \& Sons, Inc., New York, USA.

Perea-Flores, M.J., Garibay-Flebes, V., Chanona-Pérez, J.J., Calderón-Domínguez, G., Méndez-Méndez, J.V., Palacios-González, E., Gutiérrez-López, G.F. (2012). Mathematical modelling of castor oil sedes (Ricinus communis) drying kinetics in fluidized bed at high temperatures. Industrial Crops and Products, 38, 64-71. 
Perez-locas, C., Yaylayan, V.A. (2010). The maillard reaction and food quality deterioration. Chemical Deterioration and Physical Instability of Food and Beverage, pp. 70-94. Woodhead Publishing Series in Food Science Tecnnology and Nutrition

Prachayawarakorn, S., Prachayawasin, P., Soponronnarit, S. (2006). Heating process of soybean using hot-air and superheated-steam fluidized-bed dryers. Lebensmittel Wissenschaft und Technologie,39, 770-778.

Puppo, M.C., Lupano, C.E., Añon, M.C. (1995). Gelation of soybean protein isolates in acidic conditions. Effect of $\mathrm{pH}$ and protein concentration. Journal Agriculture Food Chemistry, 45, 2356-2361.

Rahman, M.S. (2009). Food properties handbook. Ed. CRC Press, Taylor and Francis Group, Boca Raton, USA.

Ratti, C., Crapiste, G.H., Rotstein, E. (1989). A new water sorption expression for solid foods based on thermodynamic considerations. Journal of Food Science 54(3), 738-742.

Ratti, C. (1991). Diseño de secaderos de productos frutihorticolas. Tesis doctoral departamento de química e ingeniería química. Planta piloto de ingeniería química. Universidad Nacional del Sur, Bahía Blanca, Argentina.

Ratti, C. (1994). Shrinkage during drying of foodstuffs. Journal of Food Engineering, 23(1), 91-105. 
Ratti, C. (2009). Advances in food dehydration. CRC Press, Taylor and Francis Group, Boca Ratón, USA.

Ridner, E. (2006). Soja, propiedades y su impacto en la salud $1^{\mathrm{a}}$ ed., Buenos Aires. Sociedad Argentina de Nutrición.

Roos, Y.H. (1995). Phase Transitions in foods. Food science and technology. Chapter 5 (pp 109-154). Taylor L.S., (Ed), San Diego, Academic Press.

Senadeera, W., Young, G., Wijesinghe, B., Bhandari B. (2006). Fluidization characteristics of moist food particles. International Journal of food engineering 2(1), 113.

Sobral, P.A., Wagner, J.R. (2007). Thermal properties of soybean whey and its proteins. Functional Properties of Food Components, 57-76. Research Signpost, Kerala, India.

Soponronnarit, S., Swasdiseve, T., Wetchacama, S., Wutiwiwatchai W. (2001). Fluidised bed drying of soybeans. Journal of Stored Products Research, 30(2), 133- 151.

Souraki, B.A., Andres, A., Moula, D. (2009). Mathematical modeling of microwaveassisted inert medium fluidized bed drying of cylindrical carrot samples. Chemical Engineering and Process Intensification, 48(1), 296-305.

Srinivasakannan, C., Balasubramanian, N. (2009). An investigation on drying in fluidized beds. Advanced Powder Technology, 20, 298-302. 
Srivastava, V.K., John, J. (2002). Deep bed grain drying modeling. Energy Conversion and Management, 43, 1689-1708.

Sun, D.W., Woods, J.L. (1994). Low temperatures moisture transfer characteristics of wheat in thin layers. Transactions of the ASAE, 59, 273-283.

Syahrul, S., Hamdullahpur, F., Dincer, I. (2002). Thermal analysis in fluidized bed drying of moist particles. Applied Thermal Engineering, 22(15), 1763-1775.

Tosi, E., Masciarelli, R., Tapiz, L., Ciappini, M. (1988). Secado de granos em lecho fluidizado. Fluido-dinámica de lechos de soja, sorgo y triticale. Revista agroquímica y tecnología de alimentos, 28 (2), 221-231.

Tromp, C.T., Raghavan, G.S.V., Alikhani, Z. (1995). Nutritive quality of whole soybeans heat-treated in a continuous flow processor. Journal Agriculture Engineering Research,61, 49-56.

Torrez Irigoyen, R.M., Giner, S.A. (2011). Volume and density of whole soybean products during hot-air termal treatment in fluidised bed. Journal of Food Engineering 102, 224-232.

Van Der Poel, A.F.B., Stolp, W., Van Zuilichem, D.J. (1992). Twin-screw extrusión of two pea varieties: effects of temperatura and moisture level on anti-nutritional factors and protein dispesibility. Journal of the Science and Food Agriculture, 58, 83-87. 
Vatani, Z., Taghizadeh, M., Orouj, R. (2011). CFD Simulation of mass transfer around spherical particles in fluidized bed. International Journal of Chemical Reactor Engineering, 9, 1-18.

Vazquez, A., Calvelo, A. (1980). Gas particle heat transfer coefficient in fluidized pea beds. Journal of Food Process Engineering, 4, 53-70.

Vega-Gálvez, A., Miranda, M., Díaz, L.P., López, L., Rodriguez, K., Di Scala, K. (2001). Effective moisture diffusivity determination and mathematical modelling of the drying curves of the olive-waste cake. Bioresource Technology, 101, 7265-7270.

Vilche, C., Gely, M., Santalla E. (2003). Physical properties of quinoa seeds. Biosystems Engineering, 86(1), 59-65.

Wagner, J. (2011). Curso sobre proteínas de soja: propiedades, funcionalidad y aplicación. Programa de capacitación de la Asociación Argentina de Grasas y Aceites, Rosario, Santa Fe.

Werther, J. (1999). Measurement techniques in fluidized beds. Powder Technology 102, 15-36.

Wiriyaumpaiwong, S. Comparative study of drying and heating of soybean. (2002). A dissertation submitted in partial fulfillment of requirement for the degree of doctor of philosophy (thermal technology). School of Energy and Materials King Mongkut's University of Technology Thonburi. 
Wiriyaumpaiwong, S., Soponronnarit, S., Prachayawarakorn, S. (2004). Comparative study of heating processes for full-fat soybeans. Journal of Food Engineering, 65, 371382.

Yang, W.C. (2003). Handbook of fluidization and fluid-particle systems (Chemical Industries). Second edition, CRS Press, Taylor and Francis Group, Boca Raton, USA.

Zeng, X.S., Ruan, R.R., Fulcher R.G., Chen P. (1996). Evaluation of soybean seedcoat cracking during drying. Part I: using drying test. Drying technology, 14(7), 1575-1593.

Zomorodian, A., Kavoosi, Z., Momenzadeh, L. (2011). Determination of EMC isotherms and appropriate mathematical models for canola. Food and Bioproducts processing, 89, 407-413. 